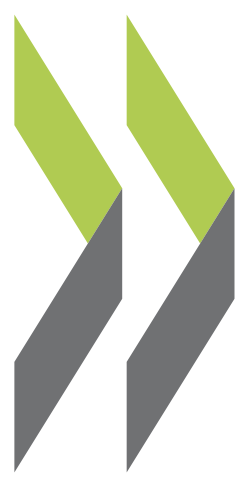

SIGMA Papers No. 12

\title{
Country Pofiles of Civil Service Training Systems
}

\section{OECD}


COUNTRY PROFILES OF CIVIL SERVICE TRAINING SYSTEMS

SIGMA PAPERS: No. 12

ORGANISATION FOR ECONOMIC CO-OPERATION AND DEVELOPMENT

Paris

54081

Document complet disponible sur OLIS dans son format d'origine

Complete document available on OLIS in its original format 


\section{THE SIGMA PROGRAMME}

SIGMA -- Support for Improvement in Governance and Management in Central and Eastern European Countries -- is a joint initiative of the OECD Centre for Co-operation with the Economies in Transition and the European Union's Phare Programme. The initiative supports public administration reform efforts in thirteen countries in transition, and is financed mostly by Phare.

The Organisation for Economic Co-operation and Development is an intergovernmental organisation of 29 democracies with advanced market economies. The Centre channels the Organisation's advice and assistance over a wide range of economic issues to reforming countries in Central and Eastern Europe and the former Soviet Union. Phare provides grant financing to support its partner countries in Central and Eastern Europe to the stage where they are ready to assume the obligations of membership of the European Union.

Phare and SIGMA serve the same countries: Albania, Bosnia-Herzegovina, Bulgaria, the Czech Republic, Estonia, the Former Yugoslav Republic of Macedonia, Hungary, Latvia, Lithuania, Poland, Romania, Slovakia and Slovenia.

Established in 1992, SIGMA works within the OECD's Public Management Service, which provides information and expert analysis on public management to policy-makers and facilitates contact and exchange of experience amongst public sector managers. SIGMA offers beneficiary countries access to a network of experienced public administrators, comparative information, and technical knowledge connected with the Public Management Service.

SIGMA aims to:

- assist beneficiary countries in their search for good governance to improve administrative efficiency and promote adherence of public sector staff to democratic values, ethics and respect of the rule of law;

- help build up indigenous capacities at the central governmental level to face the challenges of internationalisation and of European Union integration plans; and

- support initiatives of the European Union and other donors to assist beneficiary countries in public administration reform and contribute to co-ordination of donor activities.

Throughout its work, the initiative places a high priority on facilitating co-operation among governments. This practice includes providing logistical support to the formation of networks of public administration practitioners in Central and Eastern Europe, and between these practitioners and their counterparts in other democracies.

SIGMA works in five technical areas: Administrative Reform and National Strategies, Management of Policy-making, Expenditure Management, Management of the Public Service, and Administrative Oversight. In addition, an Information Services Unit disseminates published and on-line materials on public management topics.

\section{Copyright OECD, 1997}

Applications for permission to reproduce or translate all or part of this material should be made to: Head of Publications Service, OECD, 2 rue André-Pascal, 75775 Paris Cedex 16, France.

Views expressed in this publication do not represent official views of the Commission, OECD Member countries, or the central and eastern European countries participating in the Programme. 


\section{PREFACE}

This publication is the product of a project which SIGMA started in autumn 1995. The country papers were completed in late spring 1996, and since that time some countries have reviewed their training strategies. Lithuania, for example, has adopted a regulation concerning the qualification of civil servants, which includes training.

The rationale for launching this project was the recognised need for more detailed information on training systems and on the organisation of training in central and eastern European countries. This information is essential to the efforts by countries in transition, working in collaboration with the donor community, to develop demand-driven training strategies, efficient structures for civil service training, and cost-effective and sustainable training activities.

\section{FOREWORD}

Countries in transition are facing the challenge of adapting their public service to a new environment, which has emerged as a result of changes in the political and economic system, new expectations and demands of citizens, and requirements to comply with European standards.

These fundamental changes call for not only new structures and institutions for public administration but also major changes in public management, including human resources management. To meet these challenges, it is crucial for the public workforce to acquire as quickly as possible new skills and qualifications, including changes in behaviour towards the public. A wide range of initial and in-service training is offered by a variety of providers in transition countries to improve the professionalism of the civil service staff and to obtain these new skills and qualifications. As the economic situation calls for rapid changes in public administration and as resources for training are limited, it is an important issue for all countries in transition to dispose of an effective and efficient civil service training system, which will enable staff to carry out their new tasks and thus support economic development.

To assist countries in improving their training capacities and in enhancing the effectiveness and efficiency of their training, SIGMA launched this project to produce profiles of national training systems. These profiles, as a stock-taking exercise, are intended on the one hand to improve the comparative information base of central and eastern European countries and, on the other hand, to provide donors with additional information on existing training structures and systems in the respective countries.

The profiles aim to give a comprehensive overview of the training landscape of each country participating in the project. They cover organisational aspects of training, such as the number and legal status of training institutions and their funding, including non-budgetary funding and in particular through the donor community. At the same time they provide information on the status of trainers, training formats and content of training. 
A special concern of the profiles was to determine if training was basically demand- or supply-driven. They therefore examined whether methods and techniques to assess training needs and to evaluate training did in fact exist and were applied.

As most central and eastern European countries do not yet dispose of a full-fledged public service training system but are still in the process of developing one, the profiles also include any envisaged future developments.

The training profiles are introduced by a chapter pointing out crucial issues in civil service training. This overview chapter was prepared by Professor Dr. J.J. Hesse, Nuffield College, Oxford University, and European Centre for Comparative Government and Public Policy, Berlin.

This report is published on the responsibility of the Secretary-General of the OECD.

\author{
SIGMA-OECD \\ 2, rue André-Pascal \\ 75775 Paris Cedex 16, France \\ Tel (33.1) 45.24.79.00 or 45.24.13.94 \\ Fax (33.1) 45.24.13.00 \\ e-mail: sigma.contact@oecd.org \\ http://www.oecd.org/puma/sigmaweb
}




\section{EXECUTIVE SUMMARY}

The development of a professional and efficient public service depends on a number of conditions, including a basic legal framework, broad political backing and a comprehensive human resources management system within an overall reform strategy. To meet these preconditions and to implement the necessary changes, civil servants will have to acquire additional qualifications and skills. Good training schemes for public servants adapted to theses emerging needs are therefore crucial.

Public sector reform as a whole will not succeed unless it is buttressed by a policy of comprehensive and continuous public service training, which in turn will enable the public sector staff to meet the challenge of implementing reforms. The analysis of the strengths and weaknesses of the training systems presented in this publication has revealed a number of guiding principles in creating such a system.

Training efforts during the period immediately following the collapse of communist regimes were often experiments rather than systematic endeavours. The need to introduce consistency and coherence in public sector training led, in most cases, to the creation of an institutional focal point, such as a co-ordinating ministry. The next step in the development of public service training - a step still to be taken in many countries - could be the establishment of public sector training in the form of a school for administrative issues or governance in general, or the development of a "marketplace" for training. Any further development of a comprehensive and coherent State training system requires increased financial commitment to public service training.

Establishing alliances is important in training since an isolated public service will not be able to react to societal, political and economic developments. Alliance-building strategies include learning from the private sector; exploiting public-private partnerships for mutual benefit; developing professionalism in training activities; drawing on foreign expertise and involving international organisations.

Training for the public sector should be given a higher priority, and, on the international level, the aim should be to adopt the "best practice" identifiable across national borders.

This publication comprises profiles of the civil service training systems in Albania, Bulgaria, the Czech Republic, Hungary, Latvia, Lithuania, Poland, Romania, Slovakia and Slovenia. The rationale for providing country profiles was to offer an account of the existing situation in public service training with regard to both the organisational and management aspects and the training content. For easy access to comparative information, each profile is structured in the same way. After an introduction, offering some information about the training system prior to the political change, each profile contains information on the following topics: 
- Objectives of Training: are there any, and if so, what are the objectives stated by the government for providing training for public service personnel?

- Legal Framework: is there a right and an obligation of the civil servant to undertake training, and is training in some way linked to career development?

- Funding: how are budget allocations for training drawn up, and which institution holds the training budget?

- Training Institutions and Legal Status: which training institutions exist, and are they independent, public or private bodies, or are they linked to ministries or universities?

- Teaching Personnel: do the training institutions primarily make use of practitioners, and/or do they have a permanent faculty?

- Needs Assessment and Contents of Training: what methods of training needs assessment exist, and what are the subjects trained, including possible priorities?

- Target Groups: is training only targeted at the management level, or is training provided for at lower levels as well?

- Training Formats: which training formats are offered by the institution, and are there specific induction and adaptation training schemes?

- Development of Training Curricula: are there specific methods and/or techniques applied to ensure that training curricula meet the demand?

In addition, the country profiles offer information on Planned Changes and Further Developments in the national training systems.

This publication reflects the situation as of spring 1996. Later developments could unfortunately not be included; however, it is planned to provide updates through the SIGMA Internet site. The issues presented here remain relevant as guiding principles for the creation of civil service training systems. 


\section{TABLE OF CONTENTS}

THE SIGMA PROGRAMME

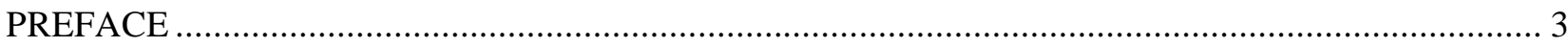

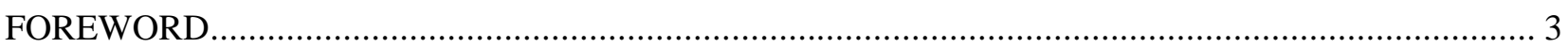

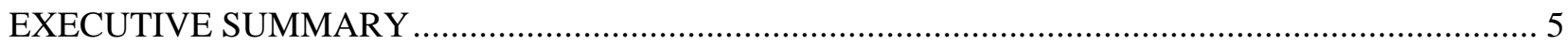

TRAINING AND PUBLIC SECTOR REFORM - THE CASE OF CENTRAL AND EASTERN

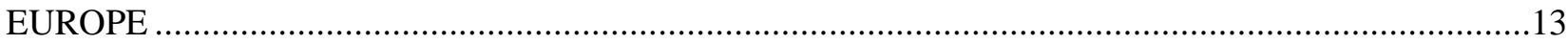

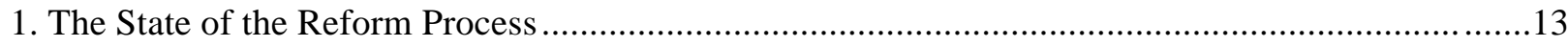

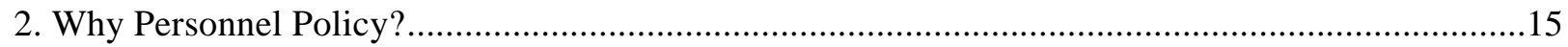

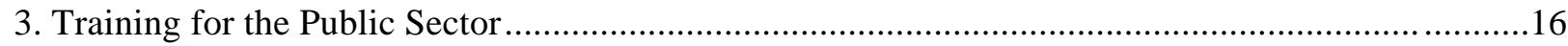

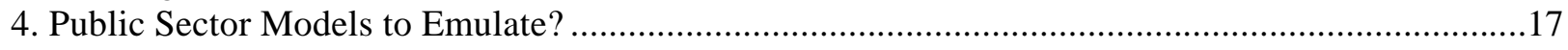

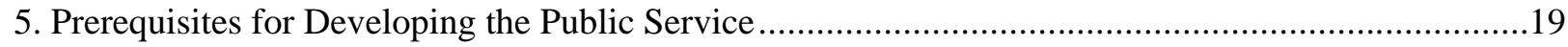

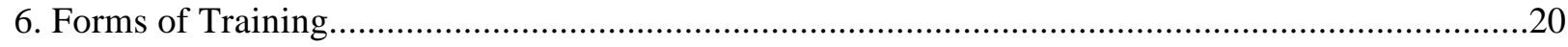

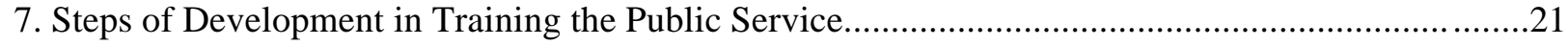

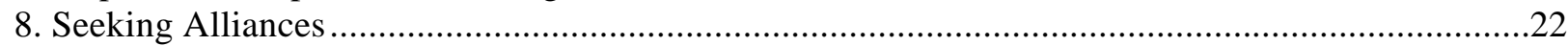

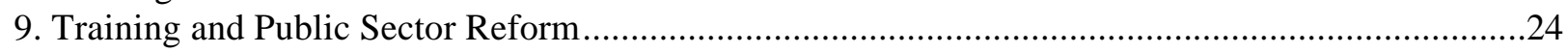

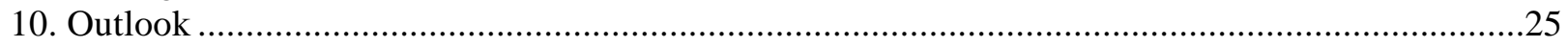

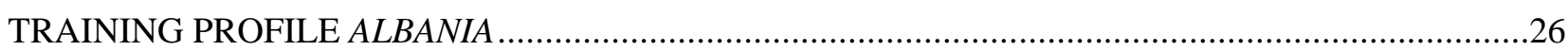

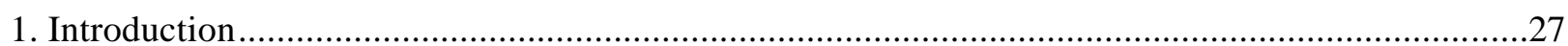

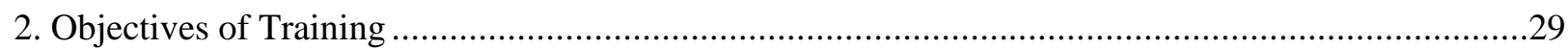

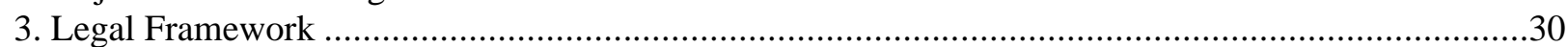

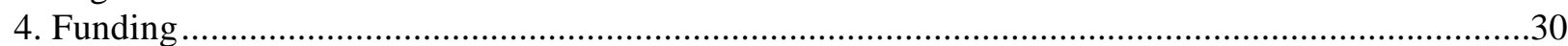

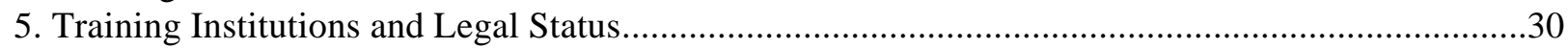

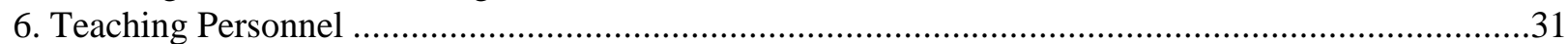

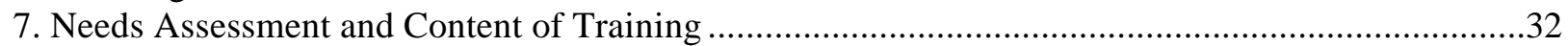

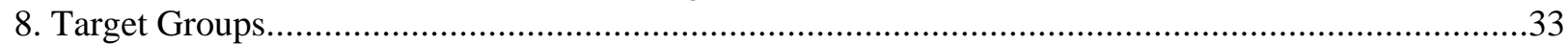

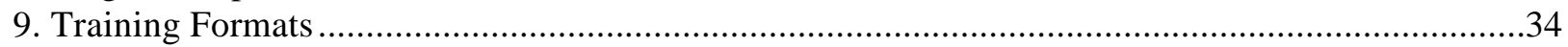

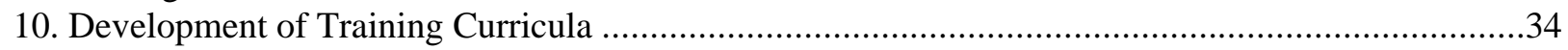

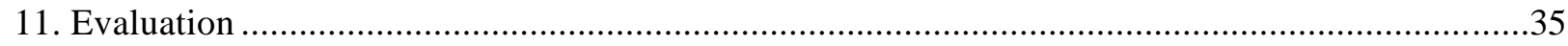

12. Planned Changes and Further Developments in the Training System ..........................................36

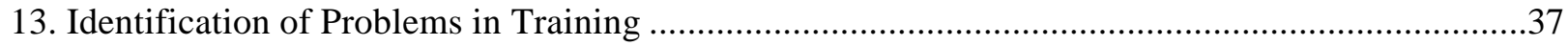

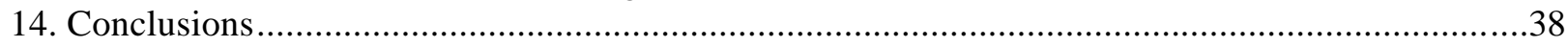

ANNEX 1. SELECTED ARTICLES FROM THE ALBANIAN CIVIL SERVICE LAW .......................39

ANNEX 2. SELECTED DEFINITIONS RELATED TO THE ALBANIAN PUBLIC ADMINISTRATION AND CIVIL SERVICE. 


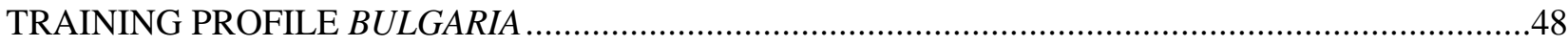

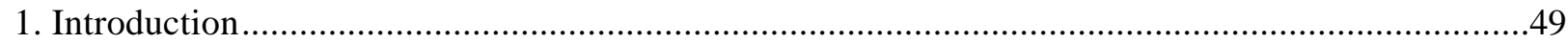

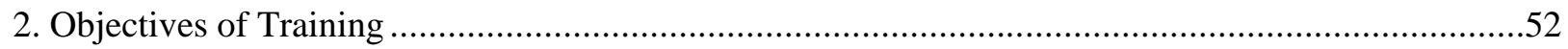

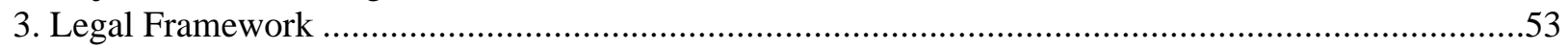

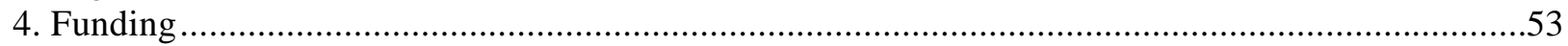

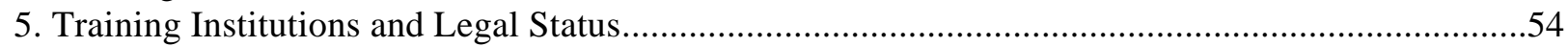

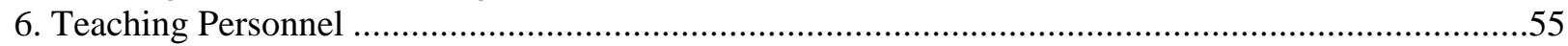

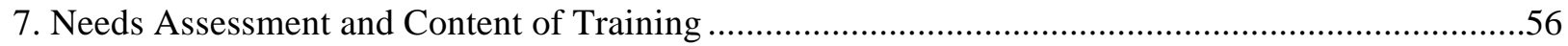

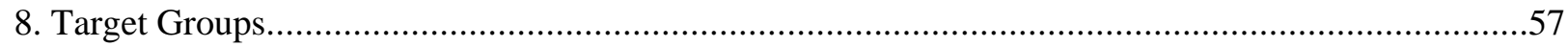

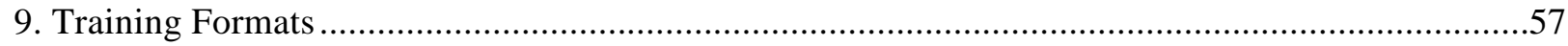

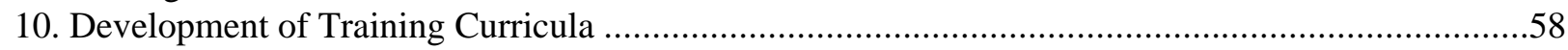

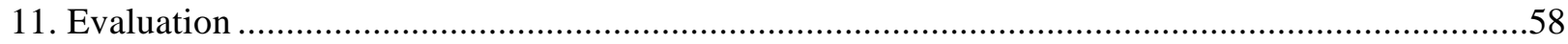

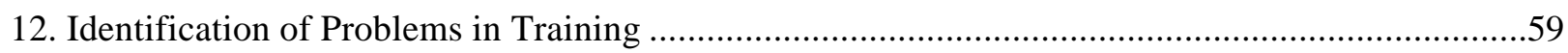

ANNEX 1. CENTRAL ADMINISTRATION TERRITORIAL DIVISION ...........................................60

ANNEX 2. CURRENT TRAINING PROGRAMMES FOR BULGARIAN CIVIL SERVANTS............61

ANNEX 3. UNIVERSITY OF NATIONAL AND WORLD ECONOMICS: INSTITUTE FOR

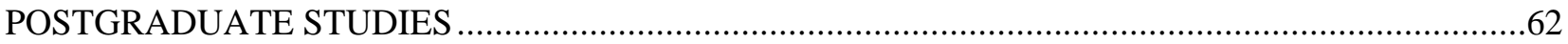

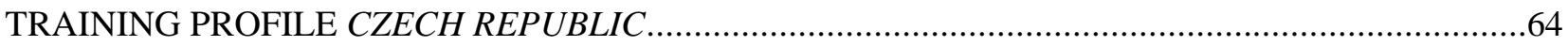

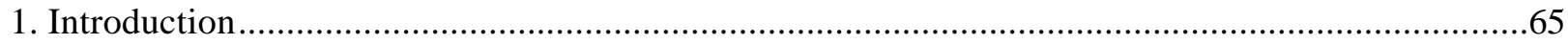

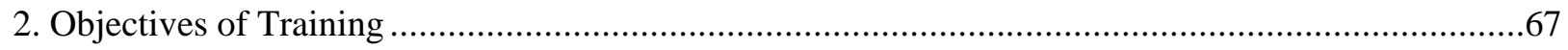

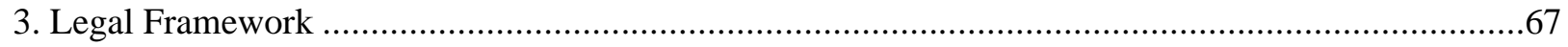

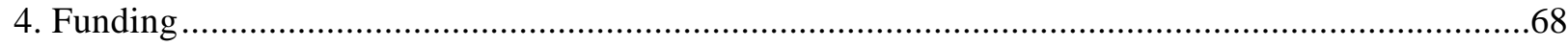

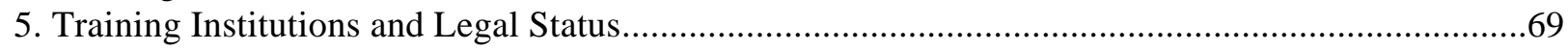

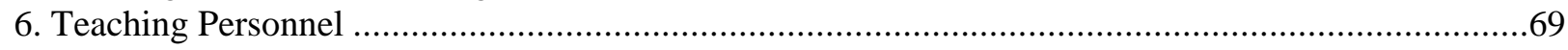

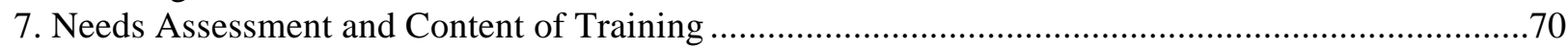

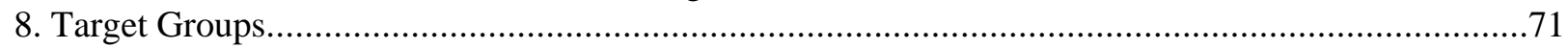

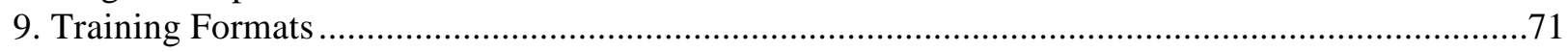

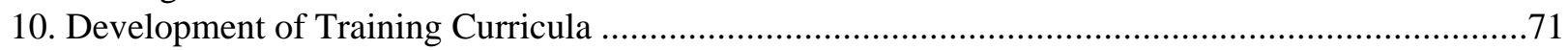

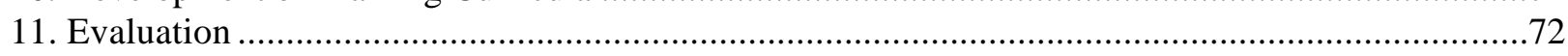

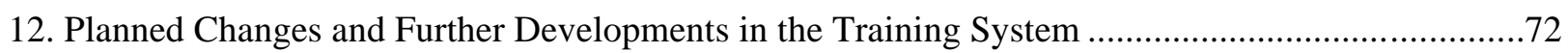

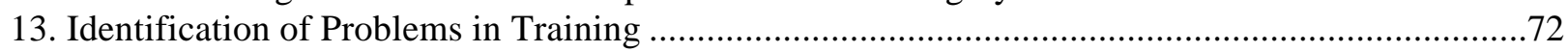

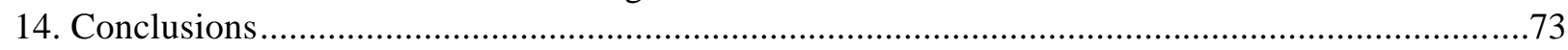

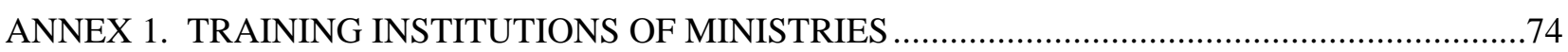

ANNEX 2. UNIVERSITIES AND OTHER INSTITUTIONS OF HIGHER EDUCATION …................80

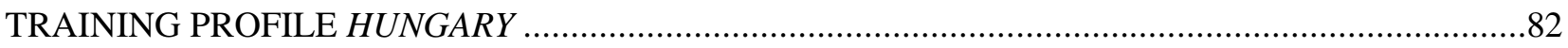

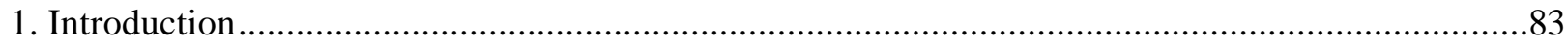

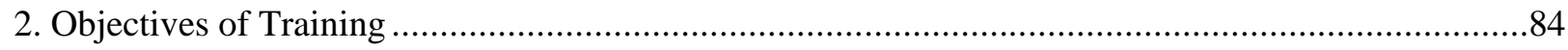

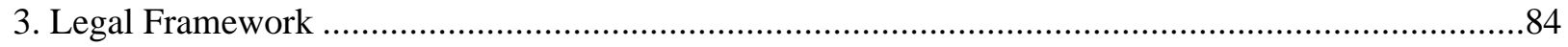

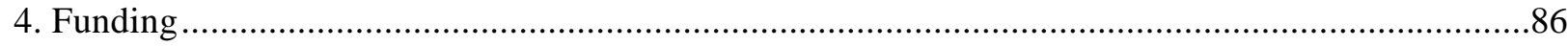

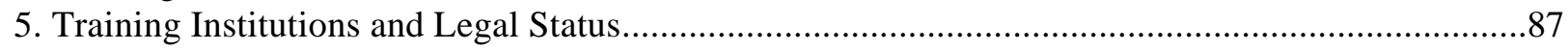

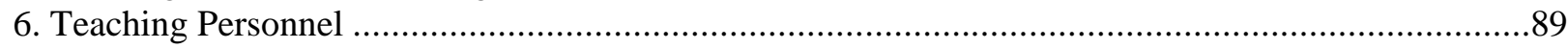




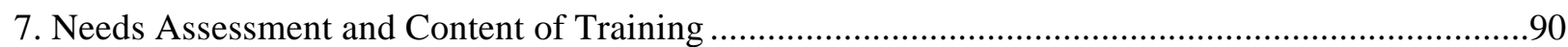

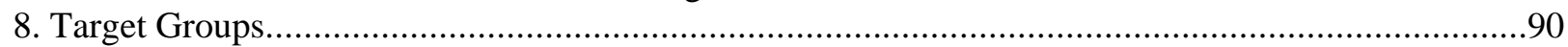

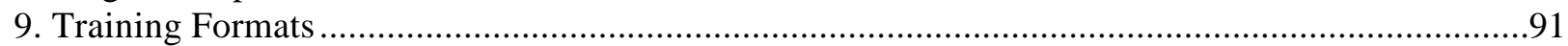

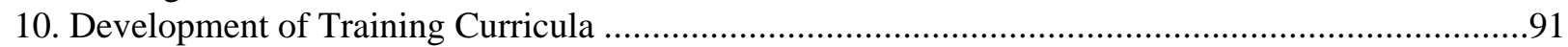

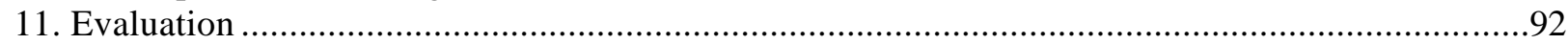

12. Planned Changes and Further Developments in the Training System ......................................93

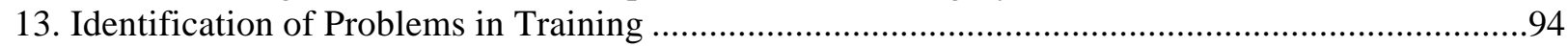

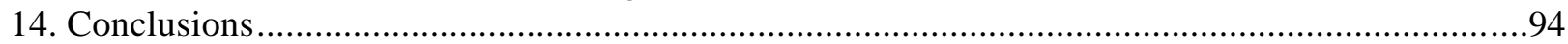

ANNEX 1. EXAMPLES OF TRAINING COURSES SUPPORTED BY INTERNATIONAL DONORS95

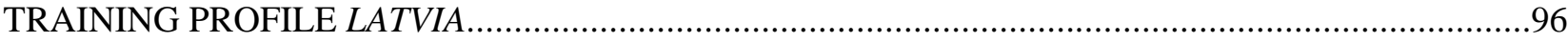

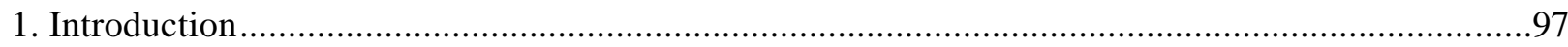

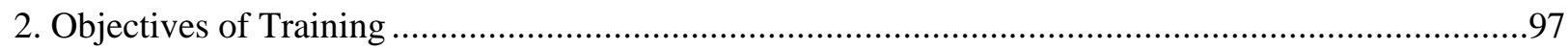

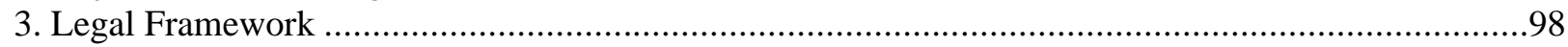

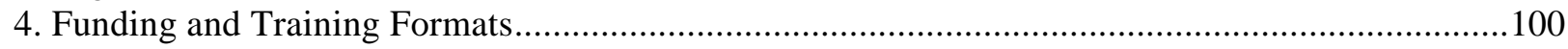

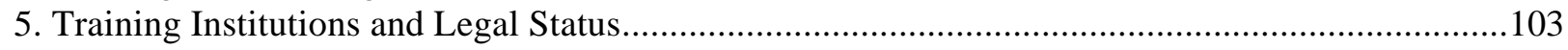

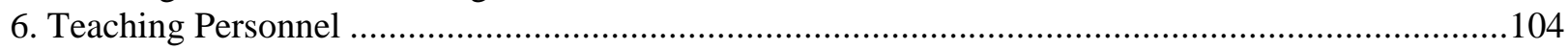

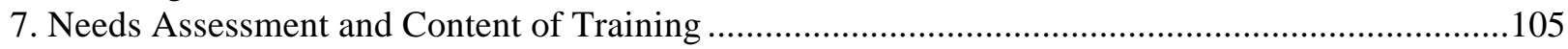

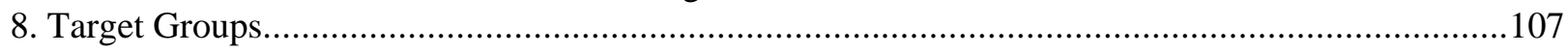

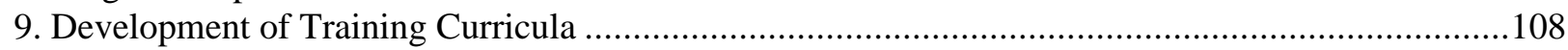

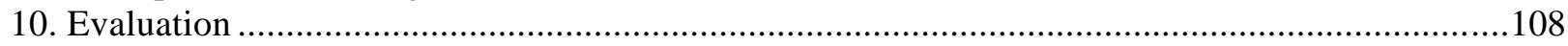

11. Planned Changes and Further Developments in the Training System ........................................109

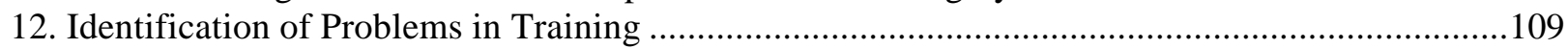

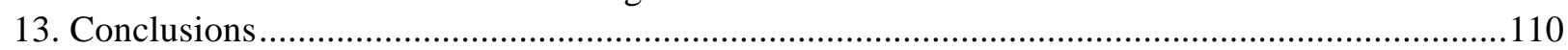

ANNEX 1. LATVIA'S MAIN SOCIAL AND ECONOMIC INDICATORS …....................................111

ANNEX 2. PROVISIONS OF THE LAW “ON CIVIL SERVICE” ................................................112

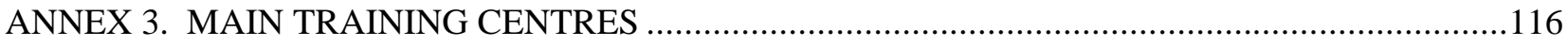

ANNEX 4. PROVISIONS OF THE LAW “ON CIVIL SERVICE” REGARDING TARGET GROUPS FOR TRAINING AND COMPOSITION OF LATVIAN CIVIL SERVICE .......................................117

ANNEX 5. CONCEPT ON INTRODUCTION OF THE CATEGORY OF PUBLIC SERVANTS INTO

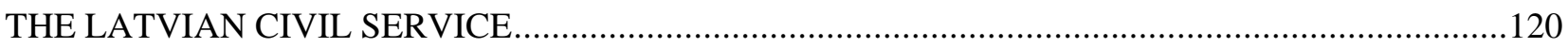

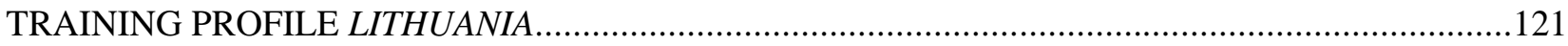

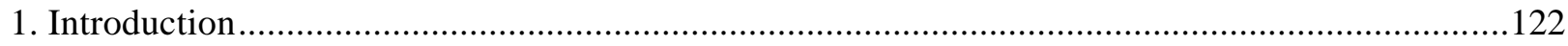

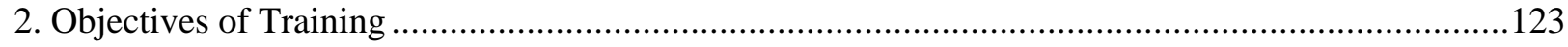

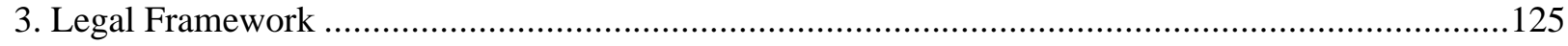

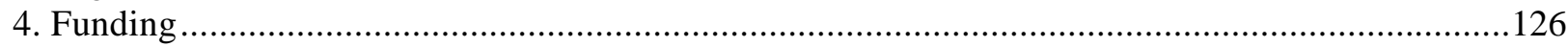

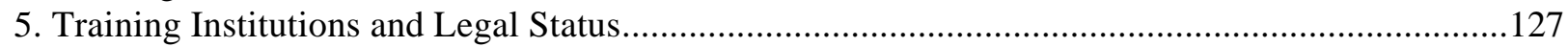

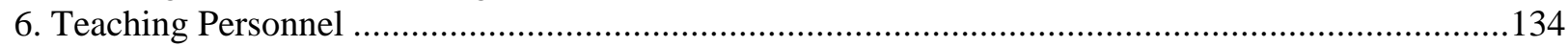

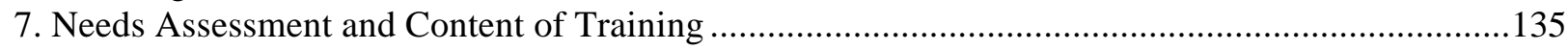

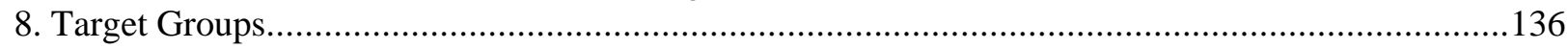

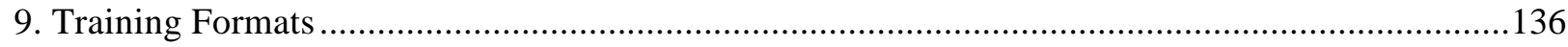

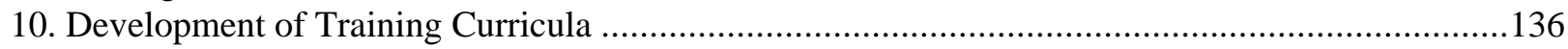

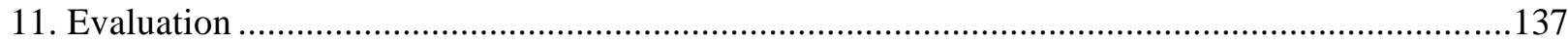


12. Planned Changes and Further Developments in the Training System

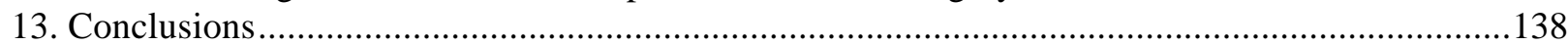

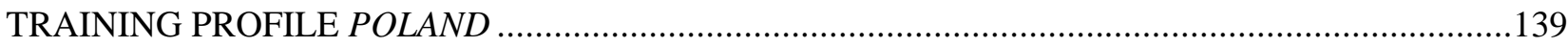

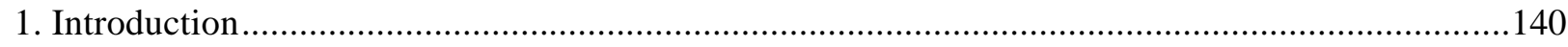

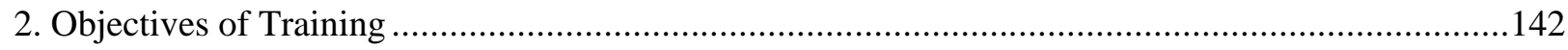

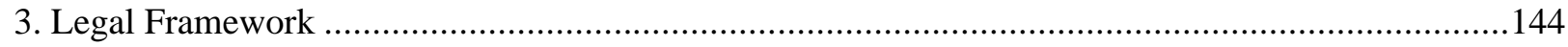

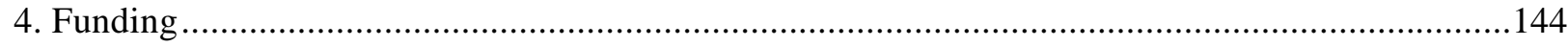

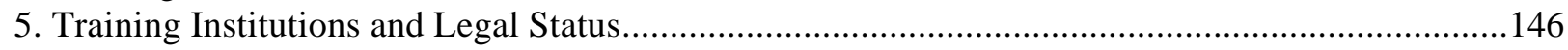

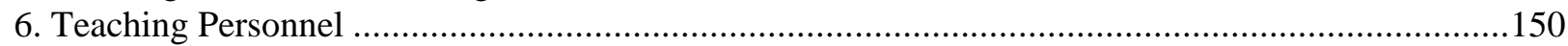

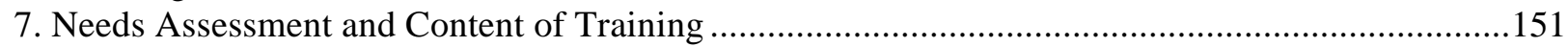

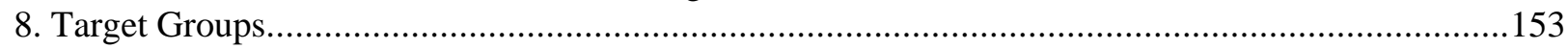

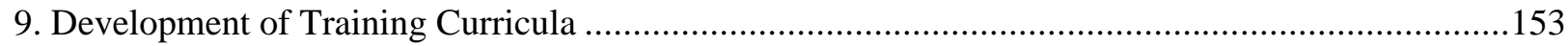

10. Planned Changes and Further Developments in the Training System .........................................155

ANNEX 1. THE SYSTEM OF TRAINING IN EUROPEAN INTEGRATION ..................................156

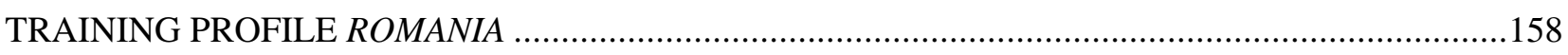

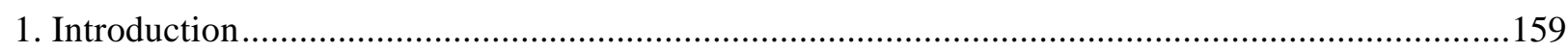

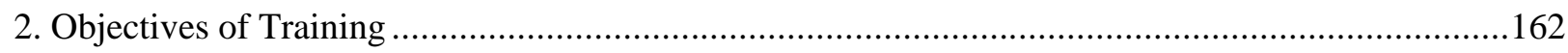

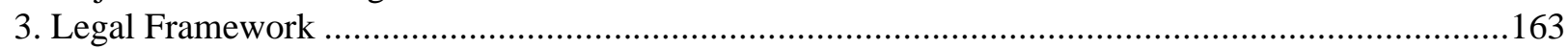

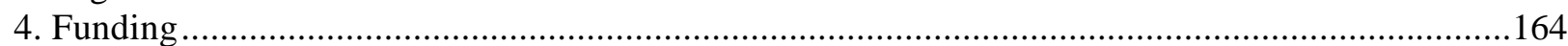

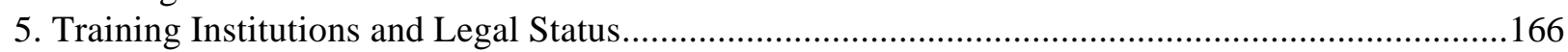

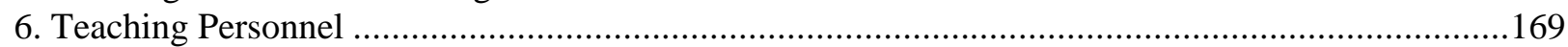

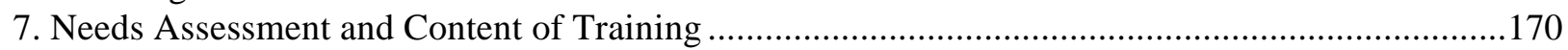

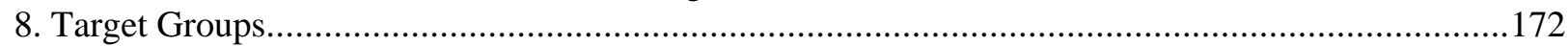

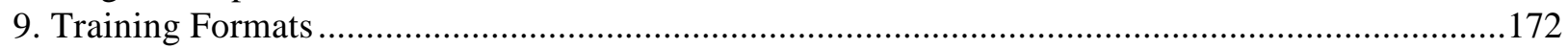

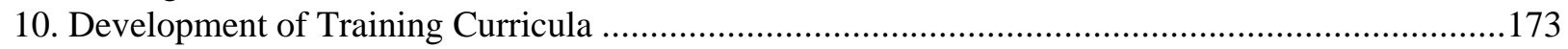

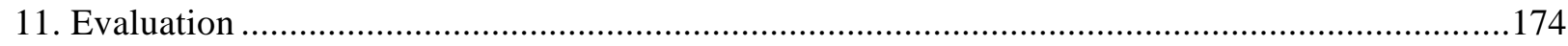

12. Planned Changes and Further Developments in the Training System ........................................175

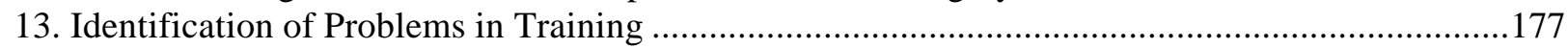

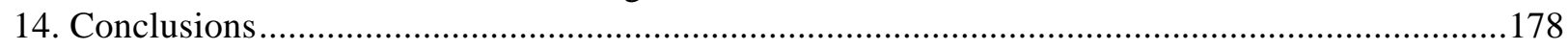

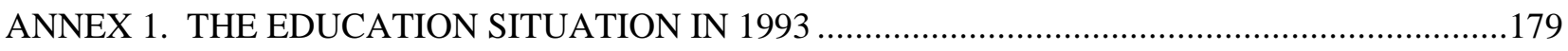

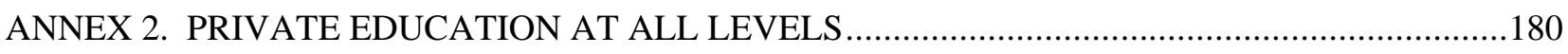

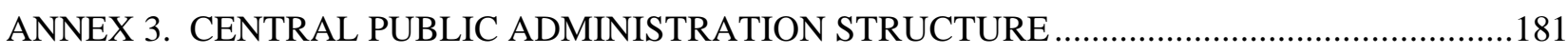

ANNEX 4. PRINCIPAL LEGAL ARTICLES CONCERNING PROFESSIONAL TRAINING FOR

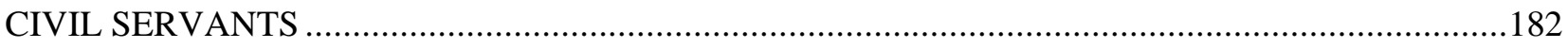

ANNEX 5. THE TRAINING SYSTEM BEFORE TRANSITION …................................................. 184

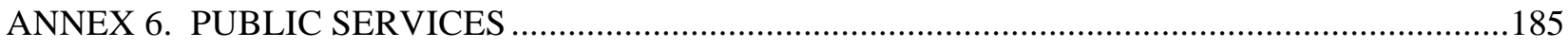

ANNEX 7. MINISTERIAL BUDGETS ALLOCATED TO PROFESSIONAL TRAINING .................187

ANNEX 8. EMPLOYMENT BY BRANCH OF THE NATIONAL ECONOMY 1993 .......................188

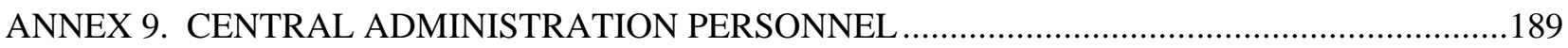


ANNEX 10. STATE OR PRIVATE HIGHER EDUCATION INSTITUTIONS USING THE WORD ADMINISTRATION IN THEIR TITLE ....

ANNEX 11. CURRENT TRAINING CENTRES FOR MINISTERIAL PERSONNEL .191

ANNEX 12. THE MOST IMPORTANT STATE OR PRIVATE TRAINING INSTITUTIONS COLLABORATING WITH INTERESTED MINISTRIES

ANNEX 13. SECONDARY EDUCATION BY TYPE 1993/1994

ANNEX 14. CURRICULA OF THE NATIONAL SCHOOL OF POLITICAL AND ADMINISTRATIVE STUDIES AND OF THE PUBLIC ADMINISTRATION TRAINING CENTRE, BUCHAREST ....

TRAINING PROFILE SLOVAK REPUBLIC. .198

1. Introduction 199

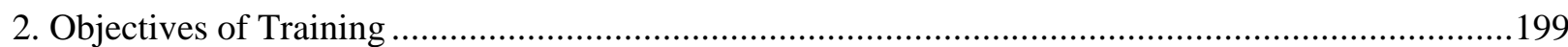

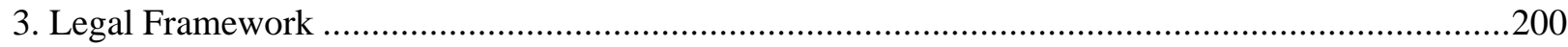

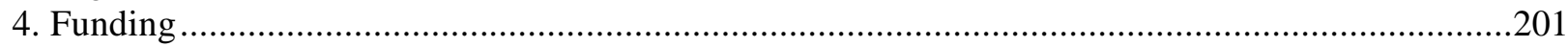

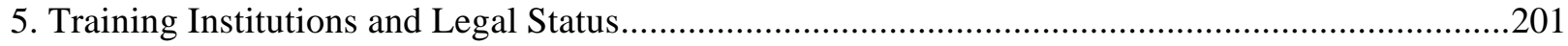

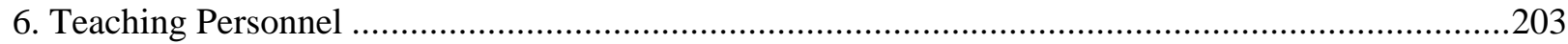

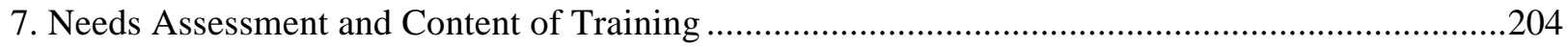

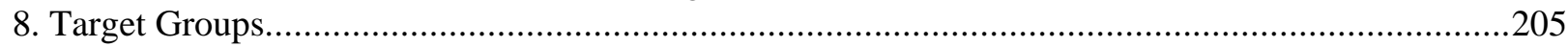

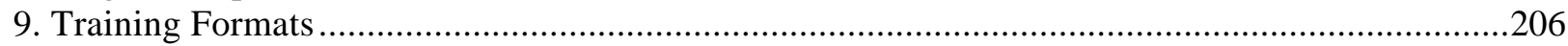

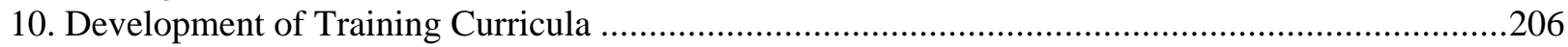

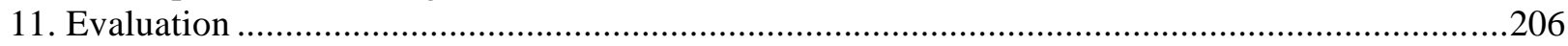

12. Planned Changes and Further Developments in the Training System ........................................207

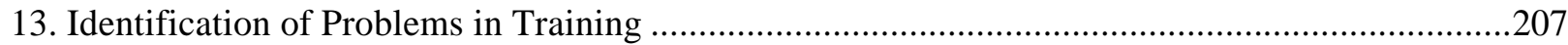

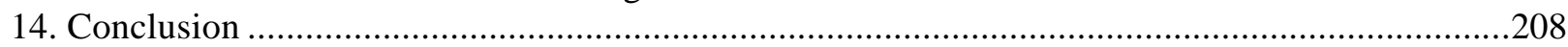

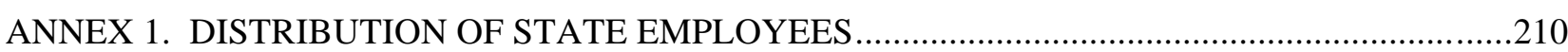

ANNEX 2. CENTRAL STATE ADMINISTRATION STRUCTURE ...............................................211

ANNEX 3. SIMPLIFIED STRUCTURE OF STATE ADMINISTRATIVE ORGANISATION .............212

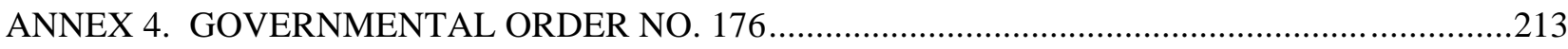

ANNEX 5. UNIVERSITIES AND PUBLIC ADMINISTRATION EDUCATION …...........................217

ANNEX 6. TRAINING ORGANISED THROUGH STATE TRAINING INSTITUTIONS ................218 


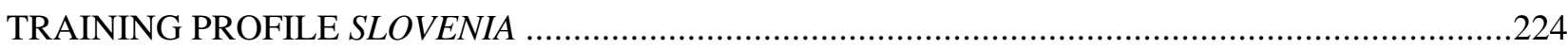

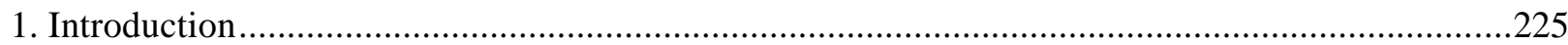

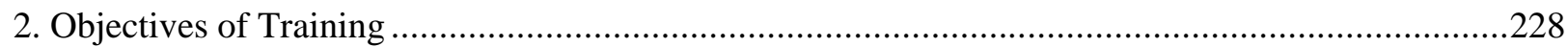

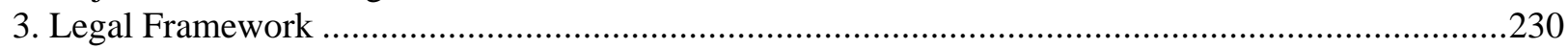

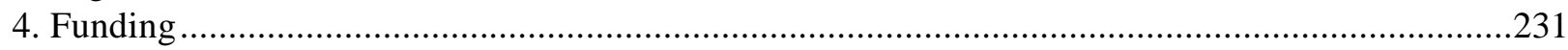

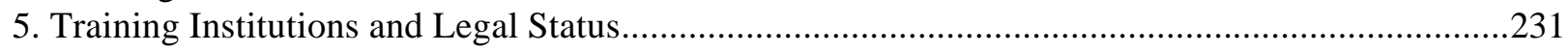

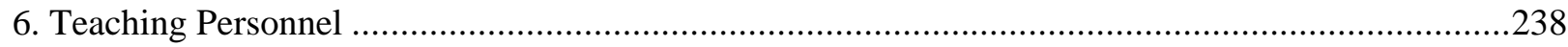

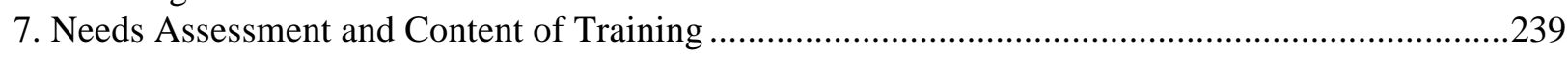

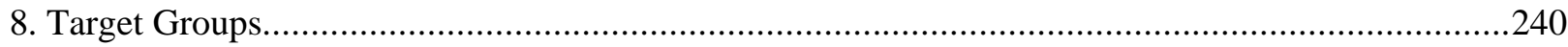

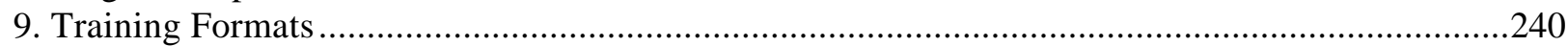

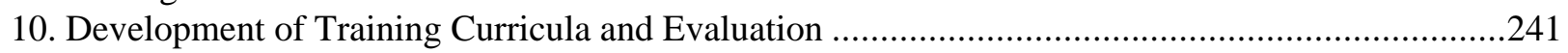

11. Planned Changes and Further Developments in the Training System ........................................242

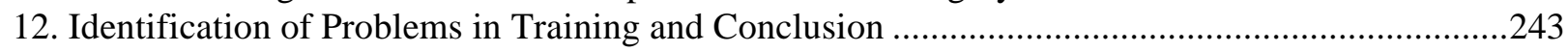

ANNEX 1. COURSE SYNOPSES: SLOVENE - SWISS MASTER PROJECT ..................................245 


\section{TRAINING AND PUBLIC SECTOR REFORM - THE CASE OF CENTRAL AND EASTERN EUROPE}

\section{The State of the Reform Process}

The attempts to improve the quality of the public service via pre-service and in-service training have to be looked at with a view to the broader objectives of public sector reform. In the case of central and eastern European countries, reformers have made considerable progress in overcoming understandable, but still damaging, anti-state attitudes by stressing the positive contribution of a modernised public sector to a functioning market economy. In such a context, the need for an inclusive approach at reform is acknowledged. This means that tasks, organisational structures, administrative procedures and issues of personnel are not to be considered in isolation. It also implies that horizontal and, in particular, vertical linkages and interdependencies between different levels of government are taken into account. Doing so, it becomes obvious that the contextual conditions under which the central and eastern European public sector operates are subject to a degree of change which has made larger scale adjustments inevitable.

Although bureaucratic organisations are, of course, capable of absorbing considerable external 'shocks' without having to resort to fundamental reforms, the unprecedented character of the central and eastern European transformation processes calls into question some of the most basic principles on which the administrative apparatus had been built. The public sector is, therefore, under tremendous pressure to adapt, being both the object and the subject of reform. As reform efforts aim at introducing stability, dependability and continuity into the administrative system, they must, at the same time, not hamper later revisions and modifications, which are bound to be required as the environment continues to be transformed. Thus, stability needs to be combined with flexibility, dependability with openness, continuity with adaptability. Under such conditions, one needs to be careful in prescribing specific institutional, procedural or personnel arrangements or even an elaborate public management approach.

Looking at the different stages of development, it might be possible, however, to identify some common trends or stages of development that are to be distinguished in the central and eastern European reform process.

During the initial phase of transformation the old legal, political, social and economic orders irrevocably broke down and new structures began to be formed. Characteristics of this transformation phase include: the emergence of multi-party systems; regular elections on the national, regional and local levels; the overhaul of public sector institutions, in some cases amounting to an attempt at recreating the entire governmental machinery; the formulation and partial implementation of what often were radical economic reform programmes; as well as thorough and in some cases heated constitutional debates. As all encompassing the developments appeared, the results were varied and often fragmentary. Volatile voting patterns, unstable coalitions and unresolved power struggles between different governmental institutions were as common as constitutional debates were inconclusive, privatisation programmes incomplete and institutional arrangements and re-arrangements short-lived. 
The initial transformation phase was followed slowly by what one could call a process of consolidation, during which increased political stability allowed for a more systematic approach to de-étatisation, privatisation and marketisation. Whilst the demarcation between the executive and the legislative as well as that between the political and administrative spheres remained somewhat fuzzy, and whilst constitutional issues remained unsolved, the programmes of economic transformation began to show first encouraging results. Less erratic voting behaviour supported the expectation of continuity which proves to be necessary to stimulate and sustain private sector investment, and that also turns out to be conducive to a more rational approach at evaluating and reforming the public sector. As 'big bang' approaches lost their appeal, designing and implementing crucial and more specific policies became the staple rule of the game.

The said stability in turn allowed for at least a medium-term approach, instead of ad hoc measures, which - combined with enhanced problem awareness - led to the third phase of modernisation. The need to overhaul institutional arrangements and to look out for 'best practice', not least triggered by the need to secure various policies, characterised this stage. Unresolved problems and newly emerging deficiencies suggested, finally, a redefinition of the public sector, its extent, role and institutional make-up. It became increasingly clear that marketisation and privatisation would in the long run only produce the hoped for results if based on a comprehensive and binding legal framework accompanied by the necessary safety provisions, checks and balances, and if supported, regulated and controlled by an efficient and reliable public sector.

Yet, the re-organisation of the machinery of central government as well as both the functional and territorial demarcation of competencies proved notoriously difficult undertakings. Added to this was a widespread problem of discontinuity in personnel, resulting on the one hand from the increased attractiveness of private sector employment, and from the practice of incoming governments to replace large fractions of the public administration leadership on the other. In some cases, the mentioned unresolved constitutional issues continued to hamper the modernisation process.

A fourth and partly overlapping phase to be distinguished in the process of reforming the public sector is that of adaptation towards the state of the art of public sector performance, as observed in Western environments, as well as towards the pressures brought about by the preparation for European Union membership. Ten of the eleven SIGMA beneficiary countries have deposited their applications for membership at the Commission and have already concluded association agreements. The remainder is also working towards membership. The administrative capacities as well as the regulatory instruments (legal approximation) needed in order to fulfil the acquis communautaire will require enormous legislative, institutional and procedural adjustments to be made by the applicant countries. Given that the extent to which these preparations have been completed will be one of the determining factors in the European Union's decision on the opening of formal negotiations - expected after the completion of the Intergovernmental Conference - this adaptation process has been given high priority in the countries concerned.

In distinguishing these phases or stages of transformation, consolidation, modernisation and adaptation, one has, of course, to be aware of their contingency when applied to eleven such widely different countries. The succession of these phases should, furthermore, not be taken to suggest a 'logic', a time continuum, let alone a uniform experience within the SIGMA beneficiary countries. Neither should different stages be distinguished merely depending on the respective developmental process; in each case they represent the outcome of different settings such as specific legacies, state traditions or indeed different administrative cultures. Instead, they may serve as broad categories wherein which all eleven countries can indeed be located. If the most advanced have gone through this typical development process, the four phases might help to identify a kind of 'state of the art' as far as the reform process and its constituent parts are concerned. This should not, however, be confused with convergence of the public 
administration systems of the eleven, let alone with global convergence. Nonetheless, given that there are a number of important similarities in the external and internal challenges facing public administration in Central and Eastern Europe - and indeed in Western environments as well - it seems more than appropriate that international organisations should be involved in supporting the reform process.

\section{Why Personnel Policy?}

Irrespective of which phase identified above is applicable, the formulation and, more crucially, the implementation of reform policies - whether active or reactive - require expertise and commitment on the part of the public service. Structural and procedural administrative reform alike, are therefore ultimately dependent on prior or simultaneous changes and innovations in the state's civil service. However, in the approach taken by most of the countries under consideration, this interdependency appears to have been neglected. So far, reform efforts have concentrated on transforming legal systems, on adapting the institutional framework to the needs and requirements of a profoundly changed environment, and on freeing former command economies of state interference and control. The development of 'human capital' in the public sector appears to have played a negligible role in this process, and it is only recently that personnel has been recognised as a crucial category and a long underestimated bottleneck to reform.

This is, of course, not to suggest that pre-1989 personnel policies have been allowed to continue. Yet, for the most part, the only policy 'successfully' implemented, has been that of removing those officials who had been compromised in discharging their responsibilities under the previous regimes. Given the historical experience of an ideologically controlled public administration, the focus on these so-called 'lustration' policies is as understandable as the near absence of more positive measures in the area of personnel policy is counterproductive today. So far, one cannot speak of a personnel policy (in the more advanced understanding of the term) in the majority of the public administration systems under consideration here.

In analysing the problems of personnel faced by the SIGMA beneficiary countries, it may be helpful to differentiate between a quantitative and a qualitative challenge. The former refers to a necessary reduction of the total number of state employees. However, contrary to what is sometimes assumed, this quantitative problem does not necessarily occur with regard to the number of employees working in core state and local administration. The bulk of state employment under the previous regimes was concentrated in what used to be called the socialised sector of the economy, including (in addition to organs of state and local government) social and political organisations, trade unions, and, most importantly, public sector enterprises. Here, the privatisation drives of recent years have significantly reduced the burden on the public purse. The inevitable social costs associated with these redundancies have varied in accordance with the general economic climate determining whether or not the private sector absorbed the labour thus freed.

The second - somewhat hidden, yet equally significant - concern is the qualitative challenge in core state and local administration. The difficulties facing personnel policies here are not just shortages in qualified staff, but also salary scales that offer few performance incentives, and a mismatch between existing and required skills. In combination with the widespread uncertainty about the legal status of civil servants, these factors give rise to the vicious circle of instability, de-qualification and de-motivation.

Instability, because of the inconsistencies in administrative performance and policy implementation which themselves result from qualification differentials and an unusually high turn-over rate of personnel - two aspects which have proven particularly detrimental in the context of reform policies requiring sustained attention. 
De-qualification, due to the obvious tendency of the private sector to attract the most highly skilled public administration employees. In many of the countries under consideration one can, in effect, detect elements of a 'negative selection' process as regards public servants.

De-motivation, in turn, refers to the effect of the above mentioned factors on those remaining in public sector employment. Adding to their disillusionment is the fact that budgetary constraints (imposed, for example, by IMF stipulations) are habitually adhered to by means of downward adjustments of the public sector pay scale. Though this latter point increasingly also applies to western systems of public administration, here public servants are somewhat protected, or at least change is cushioned by long-established checks and balances.

It is increasingly being recognised that the combined effect of these three phenomena is not restricted to the internal workings of the public service. The quality of its 'output', in form of regulatory and interventionist measures to further societal stabilisation and to manage economic transformation, is equally adversely affected. The qualitative challenge in the public sector represents, therefore, an intricate obstacle even to seemingly unrelated issues on the wider reform agenda.

\section{Training for the Public Sector}

In order to counteract the above mentioned deficiencies, a whole range of measures need to be taken, including the creation of a legal framework and the provision of financial commitments sufficient to enhance the attractiveness of public sector employment vis-à-vis the private sector. Recruitment and retention of highly qualified staff alone will not suffice to meet the challenges faced by public administrations operating in a rapidly changing environment. To ensure the necessary adaptability of the public service, the knowledge and skills of its employees will have to be constantly updated with regard to policy formulation and implementation. Of course, training is but one aspect of personnel policy, yet in periods of administrative transformation, consolidation and in particular modernisation, the centrality of its functions is obvious in a number of respects:

To create the capacity to govern. In the broadest terms, training — or indeed the lack thereof — affects a whole array of policies. It is obvious that even the most skilled politicians cannot put into reality their programmes if they are not able to rely on a well-trained and motivated administration. In the absence of the latter, political programmes remain declarations of intend which, as observed only too often, is to the detriment of public acceptance of the political system as a whole.

To ensure the success of reform policies. It is commonly accepted that market reforms are doomed to fail, if they are not underpinned by the necessary legal provisions and the institutional prerequisites required for their implementation. It is here that the quality of public sector personnel is of crucial importance as well. Put simply, if there are no public servants sufficiently trained to design, implement and monitor a regulatory framework - including draft law-making - privatisation and marketisation policies will lead not only to sub-optimal results in terms of economic development, but the social costs associated with converting a socialist planned economy to a market economy will almost certainly be higher than necessary. Neither will the state apparatus be in a position to control the negative effects of rapid transformation by pursuing supplementary policies, including, inter alia, welfare provisions, environmental protection, the enforcement of anti-trust legislation and the prevention of corruption.

To induce stability, predictability and adaptability. Only a well trained public service will guarantee the uniform application of administrative rules and regulations over both time and space, which in turn represents an important determinant not only of public confidence in the political system, but also of 
business expectations conducive to investment decisions. Of at least equal importance in a rapidly changing environment is, as mentioned above, the degree of adaptability of public administration. Here too, well trained personnel is indispensable. It is only seemingly trivial to record the fact that necessary adaptations will take place only if there is someone supplying 'adaptation services', not to speak of innovative ideas and draft laws.

To guarantee continuity. The frequent reference to the need for the public service to show continuity in the institutional setting and the regulatory framework as a prerequisite for societal development, has to be extended to cover personnel too. Only if this latter factor is as stable over time as the first two, will policy formulation and implementation serve as a sound basis for the development of legitimacy and acceptance of the system as a whole. A permanently rotating and fluctuating civil service will only produce policies which are potentially counterproductive in this respect.

To save the 'bonum commune'. In more general terms, a well trained and motivated public service also serves to mitigate the disruptive effects of an all too expansionist and selfish form of free market behaviour. Even successful market economies have had to acknowledge that it is impossible to sustain themselves without the securing of core public tasks and the protection of common values. Reinventing the public domain is as important as privatisation and marketisation, for the latter will only succeed if endorsed by society at large.

In all, personnel policies in general and training the public service in particular may be regarded as a crucial 'background variable' in the processes of reform which the SIGMA beneficiary countries are currently undergoing.

\section{Public Sector Models to Emulate?}

In order to secure the advantages outlined above, personnel policy and in particular training efforts have to be formulated in accordance with an overall approach to the public sector at large. Given that the organisational principles as well as the procedural practice of 'democratic centralism' had been almost comprehensively rejected in 1989/90, it should not come as a surprise that the governments of central and eastern European countries began to look to Western environments in search for a civil service model appropriate to their own.

The first of these models may be termed the élite approach, the prime example of which is found in the organisation of the French public sector and the personnel policies associated therewith. The unitary character of the French system favours the state-centred approach represented by the École Nationale d'Administration. Hence, the training efforts (and the resources devoted to this purpose) are concentrated on cultivating a small but highly skilled administrative leadership, not least with the aim of securing a high rate of intra-administrative mobility and an inclusive approach to state administration. The attraction of the élite approach as a model for central and eastern European public administrations lies in that it is both inexpensive and manageable, and, furthermore, that foreign aid - in form of resources and expertise - can be concentrated rather than dispersed.

However, the key problem associated with the élite model, which is increasingly being recognised even in Western environments, is that of 'too many chiefs, not enough Indians'. As has been noted above, consistent, comprehensive and diligent implementation is at least as important to the success of reform as is competent policy formulation. Concentrating on a training of élites will undoubtedly prove particularly problematic in countries in which the general education system - at school and university level - cannot as yet be expected to produce the necessary number of 'Indians'. Furthermore, the placing and distribution 
of élites will not succeed without enormous disruptions of established routines. Hence, a balance may be more appropriate for public sector activities.

A second model potentially to be followed is, of course, the Anglo-Saxon variant. The introduction of business approaches in public administration, as advocated by New Public Management concepts, includes, not surprisingly, a training dimension. The skills required may allow for significant synergetic effects to arise between public and private sector training activities. Hence, the institutions of government and administration may be able to draw on a much wider pool of potential employees, given that entry into the public service seems no longer conditional upon specific administrative expertise. However, it is questionable whether New Public Management systems can be made applicable to a continental European tradition in which either the preconditions may not be in place or where they may be rejected due to their inherent logic. Particularly problematic in the transformation context will be the all too limited ability of New Public Management systems in cushioning the impact of unrestrained free market behaviour. At best, a drive towards improved management methods may be appropriate, while it appears impossible to simply adopt Anglo-Saxon administrative cultures.

The third model to be considered can be termed the Germanic approach. It may be said that its rather legalistic basis - given the similarities of administrative structures — is the most appropriate to central and eastern European public administration (in the sense of a 'most similar case' orientation). As far as training for the public sector is concerned, the model relies on a predominantly legally trained élite, supplemented by comprehensively trained - pre-service and in-service - middle and lower echelons of public servants. The transparent pay scale, rigid career path and tenure found in the Germanic system facilitates recruitment and retention as well as alleviating the danger of skill drainage. However, apart from the near prohibitive costs of introducing such a system, a decision on the adoption of this approach should take into account that there is a growing realisation even in Germany that the legalistic approach has proven partly dysfunctional and hence requires changes in a number of areas. It might, therefore, not serve as a blueprint for the development of the public sector in the countries of Central and Eastern Europe.

The problems associated with each of the three models are aggravated in so far as they are 'sold' by foreign consultancies and advisors. Depending on the administrative culture in which these consultancies originate, they offer 'off-the-shelf products', which are often long past their sell-by date and which rarely fit the given needs. This should, of course, not be taken to mean that the strengths and weaknesses of the respective models should be ignored in the process of public sector reform in Central and Eastern Europe. Yet, given that they represent such widely different contexts and are themselves under discussion, the countries concerned ought to engage in a demand and supply analysis on the basis of their own national conditions, needs, traditions, administrative cultures and legacies.

The fact that the countries of Central and Eastern Europe would be ill-advised to adopt uncustomised Western models should, however, be viewed as an extraordinary chance for the public administrations concerned. A chance for renewal because, at present, the public sector is under critical review world-wide. Having the opportunity to 'start nearly from scratch', these fledgling democracies may develop a new kind of public service with a new ethical background. Not being tied up in the web of powerful interest groups and institutional constraints to the same extent as many a Western system, they may be more successful in aiming at the creation not of an all encompassing but a core public service to put into effect the most necessary regulatory and interventionist policies. 


\section{Prerequisites for Developing the Public Service}

The creation of an efficient and successful public service is conditional upon a number of contextual conditions, which, if ignored, may well cause appropriate individual reform measures to remain wholly ineffectual.

The most basic, yet undoubtedly most consequential, among these can be termed legal minima. Without a legal framework, provided for example with a comprehensive civil service law, it will be impossible to attract an élite into the public service. Confidence - particularly important as a determinant in individual career choices during transformation and modernisation processes - will only be ensured if employment duties as well as rights are guaranteed and made enforceable. A degree of flexibility which may have been appropriate during the earliest stages of reforming the machinery of government now hinders the development of the reliability and expertise required by modernisation and adaptation.

In addition to confidence based on legal minima, there has to be broad political backing for public sector reform, as well as political will to see this effort through to its successful conclusion. Official and public acknowledgement of the importance of a solid, efficient and accountable public service to secure democratic government is essential not only in creating legitimacy, but therewith also in enhancing the social prestige of public sector employment. Once again, the historical experience of a discredited state apparatus suggests that an extra effort has to be made in this regard in order to attract qualified personnel into the public service.

Motivation and long-term commitment of individuals to working in the public sector have to be ensured with the establishment of a career system. Only detailed job descriptions, instituted qualification requirements, and promotion prospects made calculable by equality of treatment and performance appraisals will allow for the degree of career planning necessary to enhance the attractiveness of continued civil service employment. A transparent pay structure and the possibility of performance related bonus-awards complete the list of incentives, the combination of which will significantly contribute to achieving the desired quality and continuity in the civil service. It is in this context that lessons can be drawn from Western models, albeit by negation rather than imitation. A successful implementation of a career system thus defined may well make the fledgling democracies leaders rather than followers in international comparison.

A fourth and somewhat broader precondition for creating an efficient and successful public service is the incorporation of individual reform initiatives within an overall reform strategy. Of course, it may not be possible - perhaps not even advisable in view of on-going change and adaptation - to aim at a 'once-and-for-all' definition of the size, shape, tasks and organisational make-up of the public sector. Yet, rather than accepting disarray and flux as 'inevitable' companions of transformation processes, some effort will have to be made to broadly define long-term objectives, so as to allow for individual reform measures to be formulated and implemented as part of an incremental and evolutionary, yet coherent, process.

The preconditions outlined above are of particular relevance to training as an element of public sector reform. Rather than formulating and implementing training in form of ad hoc and isolated events, training measures need to be incorporated within civil service legislation, both as a right and a duty; their financing secured on a permanent basis; their attestations linked to recruitment, promotion and ultimately pay structure; and their content attuned to the overall objectives of public sector reform. It is with regard to establishing these linkages, that some effort is still required in many a central and eastern European public administration. Only then will the effects of training not evaporate but be allowed to fulfil the functions outlined in section 3 . 


\section{Forms of Training}

As the country reports have demonstrated, the discussion about forms of training centres on pre-service and in-service training, while also taking into account the state of secondary and tertiary education.

Secondary and tertiary education. Determining factors for the overall quality of the pool of potential public sector employees are, of course, the school and university systems in the countries under consideration. Though these are largely outside the immediate control of public sector training proper, it has proven beneficial to lend political support to the inclusion of administrative (public sector) themes in high-school curricula as well as to aid the establishment of relevant university courses and faculties. As the reports amply document, there are promising attempts to build upon in future, though it remains to be seen whether declarations of intent are indeed followed by a continuous political and financial commitment to broadening the recruitment base in this way.

Pre-service training. Prior to recruitment and placement, all candidates for civil service employment need to be provided with initial or pre-service training, preparing them for an entry examination. The latter should be competitive and should (for all but the most technically specialised parts of the public service) take the form of a general aptitude test. To invest into specialised training at the pre-service stage instead, will most certainly lead to qualification differentials which, in turn, will act to reduce mobility at a later stage. Hence, pre-service training should be aimed at testable skills for which common standards can be applied. These include oral and written communication, organisational and team-work performance, languages, computer literacy and social behaviour - elements which are arguably at least as important for a successful civil service as familiarity with specific legislation. Given the more general nature of pre-service training advocated here, the appropriate training format will most likely be a comprehensive, yet concise, full-time introductory course. A degree of standardisation is still to be introduced in many a training system in Central and Eastern Europe.

In-service training. Continuous training of civil servants serves two distinct purposes. On the one hand, the progress of individual employees has to be ensured and assessed before decisions on promotion are to be taken. The value of such training and subsequent assessment over and above the preparation of the individual for the duties of a new position have been emphasised already. On the other hand, and of equal importance, is the in-service training of civil servants remaining in their given position. The on-going modernisation and adaptation processes require a constant up-dating of knowledge and skills within public administration.

Given the variety of specific knowledge to be imparted to trainees of both categories, no single training format should be favoured. A whole range of activities may usefully be pursued, including long-term and short-term courses, information days, workshops, study tours, visits, on-the-job training, funded educational leave, individual programmes, exchange programmes, internships and consultancies coupled with training. Care should, however, be taken in selecting the format best suited to achieving the objectives of each training measure. Hence, study tours and visits of foreign experts conducting one-off seminars may be useful in fostering international co-operation only if the need for, the subject of and the organisational mechanisms for co-operation are clearly and narrowly defined. Otherwise, academic and professional 'tourism' in both directions may be the only 'benefit'. Familiarisation with new pieces of legislation may well be possible during an information day, yet the adaptation of legal and procedural bases necessary for future accession to the European Union will certainly require a longer-term commitment of trainers and trainees. Secondment is, at present, a much under-utilised form of training for promotion.

Admonitions of this latter kind should not be taken as undue criticism of training systems in transition. The degree of confusion to be observed with regard to the training formats chosen is often a direct result of funding 
difficulties and institutional overlap, and is therefore not directly related to the training programme in question. It is for these and other reasons to be elaborated in more detail below, that it may be advisable to institutionalise a co-ordination mechanism for both pre-service and in-service training. A national school for public administration may, in this context, be charged not only with the necessary standardisation of pre-service training and examination, but also with the co-ordination of in-service training activities both internally and externally funded. One desirable result of linking training programmes by means of a single institution would be the development of an esprit de corps potentially uniting rank and file civil servants, as well as furthering the cohesion of the public service across the horizontal and vertical demarcation of competencies.

\section{Steps of Development in Training the Public Service}

Somewhat analogous to the phases of public sector reform at large, the approach to training public servants in central and eastern European countries has undergone a number of changes since 1989. Though in most cases an unfinished process, it is possible to locate each of the training systems under consideration somewhere within the following - by no means mutually exclusive - categories.

Training efforts during the period immediately following the collapse of communist regimes are to be characterised as experiments rather than as systematic or as based on needs and demands. Given that public sector training had been either wholly party-based or at least ideologically dominated, the training system was discredited in the eyes of civil servants and the public alike. In combination with the scaling-down of public sector activities, institutional flux, political instability and 'lustration', these circumstances prevented the immediate replacement of existing training routines with a comprehensive new policy. In any case, it should not surprise that training for and within the public sector was not given top-priority in the aftermath of the political upheavals. Training programmes, which took place nonetheless, were predominantly short-term and often inconsequential.

While the first step in the development of public sector training was, therefore, somewhat of an 'external shock', the second can be said to have been 'demand-led' in so far as pressing needs began to draw a more concentrated and sustained response. The legal, organisational and procedural changes enacted during the transformation and consolidation phases of public sector reform gave rise to a need for suitably qualified public servants. However, while there was certainly more continuity, the training policies pursued lacked structured aims and objectives and represented ad hoc reactions. Characteristic of this stage was an almost frantic process of institution-building, leading to a multitude of public as well as private training centres competing for scarce resources with uncoordinated, frequently over-lapping programmes.

The resulting need to introduce some consistency and coherence in public sector training led, in most cases, to the creation of an institutional 'focal point', either in form of a co-ordinating ministry (mostly that of internal affairs) or state offices specifically created for this purpose. Though not with immediate effect on the structure and content of the training system, these first careful steps towards institutionalisation allowed (or will allow in future) for a more evolutionary approach by focusing crucial elements such as funding, organisational prerequisites, teaching personnel and content. Ad hoc reactions to pressing needs may therewith be replaced by planned change.

A fourth step (still to be taken by many of the countries under consideration) involves a broad institutionalisation of public sector training in form of a school for administrative issues (or governance in general). Such schools may not only offer programmes which lead up to official entry or promotion examinations, but may also co-ordinate the training curricula of other institutions and decide on the accreditation of degrees, diplomas and certificates offered by the latter. One of the prerequisites for this co-ordinating function is, of course, the establishment of a system of checks and balances to avoid a 
combination of demand and supply roles, which may allow national schools manipulating standards to favour their own training programmes over those of other suppliers. The schools for administrative studies may additionally be charged with organising the co-operation with foreign donors and international organisations, as well as with conducting more thorough and continuing needs assessments than practised at present. However, a note of caution appears appropriate in this context. The institutionalisation of public sector training in this form carries with it the danger of routinisation and over-bureaucratisation - as can be observed in the case of even the most prominent German and French examples of such schools. The latter may already have lost in significance for their respective administrative systems, given their over-institutionalised, inflexible, over-rigid nature as well as their lack of accountability. Here again, the evolving training systems in central and eastern European countries could aim to become front-runners, rather than imitating seemingly proven examples.

To move from any of these stages to the next is associated with an increasing financial commitment to training the public service. Irrespective of the value which may be placed on training in the wider context of public sector reform - and the importance of the former to the overall success of the latter has been emphasised here - , the costs associated with the logic of development advocated are all too often viewed as prohibitive. And indeed, resources are a category not to be ignored, yet at the same time it is not a decisive one. What is important is to at least set in motion the evolutionary process towards a comprehensive and coherent training system. Of course, this also requires some increase in budgetary allocations, but they can be dealt with in a flexible manner, while being supplemented by continuing foreign assistance. In the medium term, needs assessments, co-ordination and accreditation may be expected to eliminate duplication of training, hence reducing the financial burden as compared to the present situation.

\section{8. $\quad$ Seeking Alliances}

Though the main focus of the efforts to develop the public sector training system is, of course, put on its funding, organisational structure and teaching capacity, there is a widespread realisation that this process will not be successful without embedding the training system in a broader (institutional) environment, both nationally and internationally. Training is an area in which it is particularly important to seek and foster alliances; otherwise, an isolated public service will not be able to react to, absorb and in some cases counteract societal, political and economic developments. In the main, such alliance-building may involve the following strategies:

Learning from the private sector. This, by now almost axiomatic, strategy is followed in most of the countries under consideration. Its attractions are obvious given the enormous lead private sector training has over comparable public sector activities. The initial policy priority being placed on privatisation and marketisation, along with substantial foreign assistance devoted to training in this field, have indeed made the private sector and its training institutions the front-runners. However, this situation has somewhat changed and it can no longer be said that the public sector has to aim merely at catching up. Though public sector training institutions will, for the foreseeable future, remain recipients rather than promoters of new ideas, in some areas their relationship to the private sector can already be one of exchange. The public sector may usefully adopt new management techniques from the private sector, while the latter has an immediate interest in learning, for example, about framework legislation for business enterprises. In this sense, a 'give-and-take' can be allowed to enter into the relationship between private and public sector.

Developing and exploiting public-private partnerships for mutual benefit. The above point does not only apply to 'institutional learning' but may also include the synergetic effects promised by exchanges of teaching personnel as well as trainees between the public and private sector. The more is known within the 
private sector about the workings of public administration and vice versa, the less charged and conflict-laden will be the often difficult interaction between the two spheres.

Developing professionalism in training activities. An attempt has to be made to replace the present ad hoc approach to the recruitment of trainers with the creation of a more professional body of teaching personnel. Professionalism should, however, not be taken to mean an increase in the number of full-time trainers. Instead, trainers should never be solely trainers, but should be able to transmit to trainees the expertise gained through permanent employment elsewhere. In this context, it is not only the private sector that can be 'exploited', potential trainers should also be identified within the academic sphere; the expertise of associations should be utilised as well. An adequate pay structure and selection procedure ought to be implemented to ensure that teaching the public service is not regarded as the domain of a 'spent' élite, but that it is in the general interest of all societal and political groups.

Drawing on foreign expertise. Again, this is a widely used source of teaching personnel and one which is frequently motivated by the external funding associated therewith. However, the 'market' for educational and consultancy services has in the past been misused, in so far as 'foreign experts' have been allowed to sell 'off-the-shelf' solutions which were often not applicable, at times even counterproductive, in the given national environment. Furthermore, the experts themselves often lacked public administration experience; instead, their recommendations were based on textbook formulae acquired during an all too recent university education. In all, foreign expertise has to be viewed with some suspicion, and at the very least, there has to be an evaluation or quality control procedure before too much confidence is placed in such training programmes.

Involving international organisations. The substantial involvement of international organisations, both financially and in substance, is an important element in the evolution of public service training systems in Central and Eastern Europe. The said organisations are, of course, aware of the problems mentioned, but in the absence of an overall approach they rarely have a choice but to accept the piecemeal, ad hoc approach, which still characterises most of the systems under consideration. Under these circumstances they may, however, be advised to redirect their attempts at improving training to focusing on crucial bottlenecks of the reform process. Given their experience and 'distance', international organisations may indeed be the only 'disinterested' candidates for assuming this responsibility. One bottleneck potentially to be addressed by international organisations is the much needed introduction of a policy of educating teaching personnel to ensure up-to-date quality.

However, trainers should never be trainers alone, but should simultaneously play an active role in public administration and private business so as to constantly renew their body of experience. Another problem area in which international organisations could play a useful role is that of needs assessment. The above mentioned factors of frantic institution-building, duplication of training, diversity of formats, questionable consultancy involvement and the multiplicity of private sector training institutions are at least partly the result of a near total neglect of this crucial element in the development of an efficient and cost-effective training system. Though it should not come as a surprise that early attempts to create a training system focused on the 'supply side' with the building up of training capacity, the time has come for the central and eastern European administrations to pay increased attention on the 'demand side' in order to sustain the reform process. 


\section{Training and Public Sector Reform}

Though the interdependence between training and public sector reform is often acknowledged in passing, it has never been thoroughly investigated. The empirical evidence now gathered by these SIGMA initiated training profiles allows for at least an attempt at analysis of this relationship in the context of the new democracies of Central and Eastern Europe. In addition to the many country-specific challenges, achievements, obstacles and problem areas identified therein, the contributions pave the way for broader conclusions to be drawn. In sum, these amount to the seemingly mundane, yet politically compelling perception that public sector reform as a whole will not succeed unless it is buttressed by a policy of comprehensive and continuous public service training, which in turn is not to be isolated and has to be linked to its legal, institutional and procedural bases.

Referring to the above mentioned functions of training for the public service, the following observations might apply.

The training of public servants - pre-service and in-service, continuous and promotion-oriented - is an important and for a crucial time period nearly overlooked means to secure the motivation for and the continuity in employment as inevitable prerequisites to stabilising the public sector. The value of a predictable, reliable and accountable public administration for the development of a democratic political, social and economic system should not be underestimated.

More specifically, further attempts at training public officials will play a crucial part in securing basic public services. Nearly all reports from the SIGMA beneficiary countries document that the attempts at improving training have significantly increased the efficiency in delivering basic public services on which the general public and the private sector rely. In doing so, training can be expected to enhance both the legitimacy of public activity and the overall performance of public institutions.

Training is, furthermore, to be perceived as a means to allow for an improved interchange between the private and the public sectors. By providing a platform for the exchange of know-how and for the articulation of public and private interests, training could contribute to the transparency and the responsiveness of both spheres. To expect more rational policy-making and an improved implementation of crucial policies to result from this interchange does not appear unreasonable.

In addition to the stabilising, efficiency-increasing and communication-securing functions of training, its perhaps most important contribution lies in enabling the political sphere to put programmes into practice. As the results of ongoing implementation research have amply documented, interventionist as well as regulatory and moderative policies will not work without being communicated via the public personnel. Underestimating the human factor in implementing policies has already been a grave mistake in many a Western environment; it should not be repeated within the context of the central and eastern European countries.

Making these functions explicit, exposes as fallacious and counter-productive the much hailed 'steering not rowing' model of some all-too-fashionable publications and various other 'new management' initiatives. There is no doubt that within the still highly turbulent environments of Central and Eastern Europe it needs rowing as well as steering to keep the boat afloat, as even the most attentive steering is conditional upon the day-to-day success of those implementing public policy. It is, therefore, not the recommendations of 'management gurus' that are to be followed, but the realisation of a broadly based, multi-levelled, comprehensive and continuous training system that helps in safeguarding and improving administrative performance. The analysis of the strengths and weaknesses of the present training systems 
in SIGMA beneficiary countries - and indeed elsewhere - has revealed a number of guiding principles to be observed in creating such a system:

On the national level, training for and within the public sector ought to be given a higher priority and improved public acknowledgement than so far detected. Respective policies are to concentrate not only on further attempts at pre-service and in-service training, but also at forming a focal point for administrative issues, at which the undeniable advantages of an increased training and its positive repercussions for public sector reform at large are communicated within the public sector and towards a wider audience.

On the international level, the aim should be to pinpoint and adopt the 'best practice' identifiable across national borders. Given the eleven country-specific reports in this volume, it has become only too obvious that no single model fits the given needs within the individual countries. The unquestioned and unmodified embracement of entire public sector approaches is, therefore, certainly not to be recommended, as the variety of national settings and given traditions will not allow an implementation as expected.

To give training more prominence within the different attempts at improving public sector performance, it seems to be necessary to involve the national élites (political, academic, administrative and business) to a much greater extent than is presently the case. This applies equally to the process of setting up training institutions, formulating curricula, producing teaching material and training the trainers.

As regards 'foreign expertise', a more solid needs assessment seems to be appropriate. It has become only too obvious that purely supply-led forms of training, designed and executed by foreign experts, did not meet the given situation. Inducing self-sufficiency might, therefore, be an objective to aim at. In doing so, the experiences made within the private sector should not be overlooked, as they have not only identified a number of crucial problems to be dealt with, but also given rise to the hope that there is much more to public-private partnership than the mostly theoretical recommendations expect.

\section{Outlook}

In all, there are growing signs that functional considerations, focusing on administrative performance and the implementation of the various policies adopted, are gaining ground in the countries which have formed the scope of this analysis. This concerns the need to secure was has already been achieved, to complete the ongoing public sector reform process, and to pursue selective corrections were initial transformation processes resulted in dysfunctional arrangements. The emphasis is, therefore, on complementing structural reforms at the governmental level with processes of internal differentiation, to take into account the demands of horizontal and vertical intergovernmental co-operation and co-ordination, and pragmatically to re-orient reform efforts towards crucial bottlenecks, even if that includes adapting over-ambitious reform attempts to the given needs and capacities. Training has developed into a crucial category in this respect, it not only enhances the quality of the 'human factor' in the reform process, but also secures the implementation of other reform steps taken. It therefore deserves a much greater attention than it has received so far. 


\title{
TRAINING PROFILE
}

\author{
ALBANIA
}

(As of April 1996) 


\section{Introduction}

Albania has a surface area of $28748 \mathrm{~km}^{2}$ and is mostly a mountainous country. The population of Albania numbers about 3.5 million people, 55-60 per cent of whom live in the countryside and the rest in the cities. On the western side, Albania is bordered by the Adriatic Sea, in the north by the former Yugoslavia, in the east by the Former Yugoslav Republic of Macedonia and in the south by Greece.

The number of people working in the Albanian public service is about 158000 , out of whom 3900 work in the ministerial system.

These numbers have decreased continuously since 1992, and the Prime Ministers' office and the Government have strong control over the numbers.

Albania is a parliamentary republic. The law on "major constitutional provisions", which was enacted on 29 April 1991 and amended several times in 1992 and 1993, is the present constitutional base until the adoption of the new constitution.

The President of the republic is the head of state. He represents all the people and is elected by Parliament. The President nominates the Prime Minister, and upon the proposal of the Prime Minister he appoints or discharges, by decree, ministers or other members of the government.

The Albanian legal system is a continental one and is presently undergoing reform.

The Parliament of Albania is the highest body of state power and the only legislative body in Albania. Amongst other duties, Parliament approves the composition of the Government and its programme by majority vote. It also has the right to pass a vote of no confidence in the Council of Ministers or any of the Council's member bodies.

The executive authority has different levels:

- The supreme body of the executive authority is the Council of Ministers which is a collective body. It meets, in principle, every week to make decisions and to discuss new legislation.

- Three inter-ministerial committees function as consultative bodies of the Council of Ministers.

- Thirteen line ministries and some other central bodies and agencies operate.

- Central government is represented at the local level by the prefects in 12 prefectures. Each prefecture has three or four districts under its jurisdiction.

Local government is composed of the following levels: communes (315); municipalities (45); and districts (36).

\section{Overview of Training}

In the previous system, there were no training institutions or schools for public administration. Some seminars and courses were organised, however, but they were highly politicised and of poor quality.

Hence, when the new government was formed, it had to establish everything from scratch. The first step taken was the establishment of the Institute of Management and Public Administration (IMPA). This 
institute is now developing, but not as fast as required, considering that it is the only institute in place to answer to the needs of the entire public administration. The government aims to build up a higher training capacity in this institute and after that, if necessary, to open schools of public administration.

\section{Background of the Civil Service Law}

On the subject of training, the new Civil Service Law provides the following:

- Civil servants have the right to receive, at the expense of the state, necessary training for their career development, and they have the right to receive study leave (Article 33, paragraph 3).

- Decrees of the Council of Ministers will determine the civil servants training system and its connection to promotion and career development. The decrees will also lay out training conditions and criteria for entering the training system. The Council of Ministers plans and organises the training and makes sure that it includes the entire civil service.

- The Council of Ministers undertakes necessary measures to finance coverage of training costs (Article 39).

In order to implement what is mentioned above, the Public Administration Department is working to formulate a master plan or a strategy for training of civil servants, with IMPA as an important partner. In order to achieve these training goals, foreign assistance is needed..

The Public Administration Programme in Albania (PAPA) is designed to do the following:

i) provide technical assistance to strengthen local government's public management and administration;

ii) improve the structure and process of economic development, strategic planning and implementation; and

iii) deliver training for local government officials and staff on how to improve their capacity to transfer the processes they have developed during the course of the technical assistance programme.

In addition, training will involve local Albanian institutions in order to institutionalise the process. The three objectives are as follows:

\section{1) Public administration and management}

The public administration and management aspect will focus on high priority issues in the fields of financial and operational management, as deemed appropriate, and as agreed upon by consultants and by those receiving assistance in selected pilot cities. Potential issues include: operating and capital budgeting, activity-based costing, treasury and cash management, organising for results, customer service, advisory boards, citizen committees, and public infrastructure management.

\section{2) Economic development}

The economic development aspect will focus on the development and transfer of processes that can be used to establish economic baselines to support the identification of economic development strategies and action plans. The processes will maximise input from business, industrial and commercial sectors, as well 
as from government and community sectors. The objective is to improve and increase business attraction, creation and expansion.

\section{3) Institution building and information dissemination}

Appropriate training topics will be developed during delivery of public administration and management, and technical economic development assistance. The consultant specialists providing technical assistance will develop self-study and informational material for use during training and for subsequent dissemination to local government throughout Albania. This material will address training processes, as well as local government-related issues. Albanian training institutions and non-governmental organisations (NGOs) will be invited to participate in the training processes and workshops as part of the institution building process.

\section{Objectives of Training}

Training is deemed a crucial aspect of public administration. For the moment, the main purposes of training are the following:

- To provide assistance for restructuring and increasing the efficiency of public administration, on the basis of a comparative analysis of the structures of public administration in different western and eastern European countries, understanding the relation between the mission of those structures, their size and shape, as well as their cost.

- To increase the awareness of civil servants of the need to differentiate between political roles, managerial roles and executive roles, and to improve understanding of these. Such awareness has to be combined with the realisation of the fact that responsibility has to be delegated, thus reflecting one of the pivotal functions of management.

- To improve the skills of civil servants for effective decision-making. This means that people get training not only about management but also about technical matters in their respective fields.

- To develop ethical guidelines for civil servants which aim at fighting corruption and increasing and improving the image of public administration and civil servants.

No additional objectives are formally stated in supporting pieces of legislation apart from the objectives stated by the Public Administration Department in its programme for training, which are more or less those mentioned above. These objectives are set together with the IMPA. They are short- and long-term objectives because training is a never-ending process. Training is underway now, and more training will be needed in the future.

A specific long-term goal is the establishment of an elite group of managers and administrators, formed by selecting young and bright people and training them in postgraduate programmes abroad in prestigious schools. Following graduation, these people enter a fast-track training and career development process.

These objectives do not derive from constitutional debate. They derive from the immediate needs that have emerged during the transformation phase and from foreseen needs. At the beginning of changes, the Albanian Government, like those of other eastern European countries, pursued administrative reform following certain models. 
Lessons learned from earlier mistakes had to do with mis-co-ordination of training and non-identification of needs and priorities. The Albanian government is now trying to build up a system of needs and priorities identification and co-ordination of the use of training resources.

\section{Legal Framework}

The Albanian Constitution does not touch upon the issue of training of Albanian civil servants and neither did the debate about drafting of a new constitution. A new Civil Service Law recently passed by Parliament, however, provides for training issues (see Introduction).

Though the new Civil Service Law has already been approved by Parliament, no regulatory framework for training issues exists. This is going to be developed in detail by the Public Administration Department, the inter-ministerial task force and IMPA.

The labour code recently approved by Parliament applies to the civil service as well. The difference is that the Civil Service Law covers the higher level of the civil service, whereas the labour code applies to all others in the public service.

Up to now, civil servants were under no obligation to get involved in the training process. But the new Civil Service Law and the regulations for its implementation will put forth obligations regarding training, as well as providing a link between of training and career development and promotion.

\section{4. $\quad$ Funding}

Funding for training has been coming from various external donors. Albania never had domestic funds dedicated to training in the budgets of ministries and other central government institutions. Hence, the issue of the ratio between self-financed and outside funding does not arise. The origin of training funds has been from multilateral organisations and bilateral co-operation (e.g. EC, its Phare Programme, WB, IMF, UNDP, Italy, Germany, other European countries, USAID, USIS , different foundations, etc.).

No specific or aggregate data exists on the amounts of money provided by different donors or the total amount of money given for training so far.

As mentioned previously, the only training institution for public administration in Albania is the Institute of Management and Public Administration (IMPA). This institution is a project funded entirely by UNDP. The project runs from 1993 to 1996 and has an overall budget of US\$898 418. During 1995, US\$238 107 were allocated to this project; for 1996, the allocation is US\$412 000. The institute administers this budget, and the civil servants who participate in its training sessions do not contribute to the cost of their training.

\section{Training Institutions and Legal Status}

Training institutions in general are not in abundance in Albania. The only two training centres that are not part of government agencies are the Training Centre of Bankers and IMPA.

Both centres aim to deliver pre-service and in-service training. There is no overlap in the training activities of the two institutions. The Training Centre of Bankers provides training relative to the different activities 
of a bank. Given the lack of information in Albania concerning an appropriate banking system, there is a huge demand for training.

IMPA aims to assist government and businesses in efficient management thinking and entrepreneurial behaviour through its training, consultancy and action research programmes. In harmony with its goals, IMPA offers a range of services to suit particular needs and bring lasting benefits.

IMPA's training covers the fields of business management, public administration and NGO management.

The training institutions have a certain degree of autonomy. They independently prepare field surveys, determine market demand, locate their customers and formulate appropriate activities.

IMPA has a Board of Directors which is chaired by the Deputy Prime Minister and financed by UNDP and the Albanian government. Nevertheless, UNDP and the Albanian Government only control IMPA's activity through the Board of Directors.

The Institute cannot be considered subordinate to any ministry or agency, and there is no case of ministries or agencies influencing staffing and curriculum development of training institutions. A statute defines the rights and obligations of the training institutions in accordance with Albanian law.

Competition is not very keen as there are only two institutions with specific mandates and no private sector training institutes.

Though the units listed below cannot be regarded as training centres in their own right, there are also several units in different ministries, such as the Ministry of Finance, Ministry of Health, Ministry of Construction and Tourism, Committee for Environment Protection, etc., which provide training for specific subjects. Generally, they are organised like programme and project units and financially supported by IDA, EBRD, EC, UNDP. There are also some trainers who come from different technical assistance programmes, but it is impossible to know their exact numbers, which in any case fluctuate.

\section{Teaching Personnel}

In IMPA, there is a permanent staff of eight professional trainers, including economists and engineers with academic and non-academic backgrounds. IMPA's part-time teaching staff are very diverse in their backgrounds. They include foreign, as well as local experts, representatives from the public and the private sector, practitioners, academics, etc.

The qualifications required for full-time staff are as follows:

- Professional integrity;

- Professional competence;

- Ability to deliver;

- Ability to mobilise further resources;

- Appropriate reputation or image;

- Creativity and innovation;

- Assignment design (quality, imagination, participatory approach, efficiency).

Qualifications required for part-time teaching staff are more focused on their particular experiences and successes in practice. Management and business trainers or consultants have varied qualifications. 
However, the characteristics mentioned above - technical competence, consulting know-how, professional integrity — are the core qualifications for professional trainers.

Briefly, the qualifications for full-time and part-time staff are can be divided into "hard" and "soft" skills. Of course, to obtain and evaluate a trainer, other and more obvious criteria of technical competence are also used, such as:

- education, degrees, diplomas and further training and development;

- length and type of his or her experience in management or consulting;

- references provided by different institutions for which he or she has done comparable work;

- membership and work done in a professional association or institute (which may have provided the consultant, trainer with a diploma as a "certified consultant or trainer");

- books, articles, research, papers and other technical documents published by the consultant (trainer).

IMPA's teaching personnel works on the basis of contracts signed between the director of the institute (representing IMPA) and the permanent trainer. Part-time foreign consultants have contracts with consulting firms or institutions that have taken them to Albania. Part-time Albanian consultants involved in training are usually civil servants, and they do not work under any contract for the training activity because they carry it out during their regular working hours.

The level of remuneration of teaching staff at IMPA is not very motivating, and some improvements are deemed necessary in order to attract high quality trainers.

The training of current trainers is not sufficient either. Yet, to keep up with the rapid transformation process, professional trainers of public administration need continuous updating of their knowledge in specialised institutions abroad.

There are also some plans to train the people within public administration who are going to deal with the training process. They will deal with the identification of training needs, formulate training programmes, locate resources and monitor the training process. Nevertheless, priority is being given to the development of the skills of existing trainers in IMPA and increasing the number of trainers in this institute. Another aim is the development of the training capabilities of the experts actually working in the ministries, so that they may provide training as part-time trainers, if needed.

\section{Needs Assessment and Content of Training}

The attempts at training the civil servants in Albania are based on needs assessment. This is realised through questionnaires and evaluation forms as well as through direct contacts with directors of personnel in several ministries and governmental organisations.

IMPA and the Public Administration Department work together in co-operation with the inter-ministerial task force to identify needs. Apart from those mentioned above, the training needs identified relate to the following areas:

- diagnosing and solving problems;

- improving the flow of information;

- developing and implementing new methods and systems;

- planning and implementing organisational change;

- training and developing management and staff; 
- establishing new contacts and links;

- obtaining an impartial expert opinion;

- reshaping the organisational structure (job division);

- increasing the efficiency of work of civil servants; and

- preparing requirements for meaningful job profiles.

These recommendations do not at the moment lead to changes in the curriculum or training content since curricula are not well-defined yet. Indeed, curricula are being drawn up at the moment. To support the objectives mentioned above, foreign expertise, western models and outside funding is being used.

In addition to the specific training needs of individual civil servants and organisations, the issue of preparing for European membership is recognised as an over-riding objective. Albania has already started to put into place laws and procedures and build up structures based on European models and in co-operation with the European organisations. The need for training in matters of European integration is evident.

In training provided up to now, civil servants were not required to take any kind of examination and were therefore not granted any degree. So far, there have been no entry requirements for pre-service training programmes and no success rate of qualifying tests for entry into the public service but the new Civil Service Law is taking care of these problems. The sub-legal acts for the implementation of this Law are going to provide for the format of examinations and their link to entry into the civil service and career development.

The sub-legal acts will also put forth criteria for entry requirements for pre-service training programmes and for success rates of qualifying for entry into the public service. (See Annex 1 for some of the articles of the Civil Service Law.)

\section{Target Groups}

The main target groups for training in Albania have both group-related and problem-specific training needs. Participants in training are drawn from different levels. From the political level, they include vice members and members of cabinets of the ministers; from the top- and middle-management levels, they comprise directors in different ministries and institutions and from the lower managerial level, they include experts in the ministries and local government bodies.

The training offered to the various groups is, of course, different and designed in accordance with the experience level of participants and with the problems associated with their everyday activity. Yet, there are still some problems associated with the application of these criteria. At times, the training does not fit the participants' levels nor their everyday activities. A high priority is placed on rectifying such problems in order to make better use of training resources.

The following table shows which training subjects for training are offered to which groups of civil service staff: 


\begin{tabular}{|c|c|c|c|}
\hline \multirow[b]{2}{*}{ Subject of Training } & \multicolumn{3}{|c|}{ Civil Service Group } \\
\hline & Top Civil Service & $\begin{array}{c}\text { Middle } \\
\text { Management }\end{array}$ & $\begin{array}{c}\text { Lower } \\
\text { Management }\end{array}$ \\
\hline $\begin{array}{l}\text { Improving Efficiency in } \\
\text { Public Administration }\end{array}$ & $\mathrm{X}$ & $\mathrm{X}$ & \\
\hline Public Management & & $\mathrm{X}$ & $X$ \\
\hline Management for Objectives & $\mathrm{X}$ & $\mathrm{X}$ & \\
\hline Work Study & & $\mathrm{X}$ & $\mathrm{X}$ \\
\hline Accounting and Controlling & & $\mathrm{X}$ & $X$ \\
\hline Project Management & & $\mathrm{X}$ & $\mathrm{X}$ \\
\hline Marketing Management & & & $\mathrm{X}$ \\
\hline Chaos Management & & & $\mathrm{X}$ \\
\hline Windows New Technology & & & $\mathrm{X}$ \\
\hline Financial Markets & & $\mathrm{X}$ & $\mathrm{X}$ \\
\hline
\end{tabular}

\section{Training Formats}

The types of training offered to target groups mainly include short-term training information days, workshops and on-the-job training, as well as consultancies coupled with training. The Public Administration Department has organised study tours and visits in seven western European countries for a group of fifty people who constitute the inter-ministerial task force for public administration reform. The members of this task force are vice ministers (political level), directors of personnel in the ministries (top-managerial level), and information technology (IT) specialists (technical level).

The practice of carrying out study tours and visits was not new in Albania. Overall these tours have helped a great deal to expand people's knowledge and their comparative outlook, but this depends on how the study tours and visits are organised. Indeed, they can either be a sheer waste of money or an extremely fruitful investment, as the study tours of the task force proved to be.

IMPA has offered a variety of courses to the public, including civil servants. These courses had the formats listed below:

- short-term training (like work/study in-service training);

- information days (introducing Windows NT and its potential applications);

- exchange programmes and internships (joint programme of the Municipality of Tirana and IMPA together with the Salford Municipality and Salford College).

IMPA has not yet offered training specifically for obtaining promotions, but participation in its courses may increase the chances of getting promoted.

\section{Development of Training Curricula}

Training for the public sector in Albania has not been based on planned curricula. This will soon change, however, following a strategy of public administration reform. This strategy has already identified public sector needs and is seeking higher qualification of civil servants in order to improve performance in public administration. 
The pressing demands which are taken into account besides those mentioned above are:

- efficient planning control;

- setting objectives;

- organising;

- budgets and finances;

- personnel policies and administration;

- office methods and procedures;

- policy development; and

- dialoguing with public.

Albania emerged from the communist era with no experience in the field of public sector training. Now, and in co-operation with the Department of Economic Development and Aid Co-ordination and the task force, the Public Administration Department aims to play the role of the co-ordinator in the training process.

IMPA is seen as the main domestic partner in fulfilling the training needs of public administration.

Effective co-operation is being sought with the public and private sector and with academic advisers. In developing its curricula (especially in fields such as selection and training of local civil servants, efficiency within the public sector, public management, quality and service, personnel development, communication, etc.), IMPA has collaborated with managers from the public as well as private sector, including: deputy ministers from different Albanian ministries; ministers' advisers and academic advisers from the Faculty of Economics at the University of Tirana; foreign academic advisers from Salford College, Manchester University, Deakin University (Australia), Nebraska University, the Southern Illinois University College of Business, WIFI (Austrian Chamber of Commerce) and several other universities and specialised institutions.

The curricula reflect the changing environment of the public sector, focusing on public administration reform currently taking place in Albania. Several seminars have been developed on selection and training of local civil servants because of local public administration structures installed recently, such as new municipal councils, departments and new district authorities. Other curricula are developed on public management, public accounting and control due to rising demand from the new staff in local state administration.

\section{Evaluation}

As far as the evaluation of the training process is concerned, a fully developed system cannot be said to be in place, though some efforts are being made in this direction. IMPA itself continually evaluates its training programmes in order to keep up-to-date and to change them according to needs. On the other hand, a lot of training programmes developed by foreign experts and funded by foreign donors are not evaluated. At times it is difficult to ascertain whether the training results justify the expenses incurred.

In cases where the effects of training are evaluated, this evaluation includes investigations on the performance of the participants, on if and how they manage their daily work differently and whether output improvements can be detected. From time to time, the evaluation procedure also includes an investigation into whether training had any effect on the promotion of participants, though there is, as yet, no regulation formally linking promotion and training. 
IMPA, whose policy has always been the matching of demand and supply, is one of the most important evaluators of training. IMPA staff are regularly involved in the evaluation process, but participants and ministries also help very much through their opinions, ideas, and proposals.

\section{Planned Changes and Further Developments in the Training System}

As stated above, the aim is to develop a master plan for training. This plan will be based on job descriptions and on the evaluation of the people performing those jobs. Thus, by involving the candidates for training, their specific needs will be identified as a matter of course. Considering that this activity will include the entire public administration and especially that part of the public administration covered by the Civil Service Law (See Annex 2 for definitions related to the Civil Service Law), it is obviously an immense task. The intention of the Public Administration Department is to start with the creation of units which will deal with training and training needs identification. The mission of these units and the job description of the people working in these units will be clearly specified. Thereafter, the training of the people working in these units will be the main focus.

Ministerial personnel and organisation directorates are already in place, and their staff will be the first target group for training. They will help with the training of the people working in same positions in the institutions and other bodies under the Ministries.

The same kind of training is going to be extended to the people working in local government bodies. The Public Administration Department thereby seeks in a first stage to establish people in all sectors of public administration who know how to identify training needs, find training resources, organise training, and relate training to entry into public administration, to career development and to pay structure. The second phase will be concentrated on training experts in a wide variety of subjects. In this process, the Public Administration Department will be assisted by the group mentioned above and by the inter-ministerial task force.

In addition to the points raised above, the training plans include:

1) Training ministries' heads of departments and other managers from local administration in fields, such as human resource management, setting objectives, budget and expenditure control, procedure structuring, time management, and ethics.

2) Training junior supervisors and main specialists in managing subordinates, new office methods and procedures, administrative skills, drafting, budgets and finances.

3) Exposing top managers from the public sector to dialogues with senior civil servants and academics from abroad, concentrating on foreign systems likely to influence the Albanian administrative reform.

Government and ministries are becoming increasingly aware of the importance that training has for the successful implementation of their policies. Political parties, with some exceptions, show a certain reluctance to contemplate such issues. By contrast, managers from private business have shown interest in getting acquainted with public law and new procedures of public administration. Valuable lessons for the public sector can indeed also be drawn from the private sector. The most important ones include these suggestions:

- The organisation of the public sector should resemble efficient ,up-to-date private business organisation and try to define the ways public servants get motivated for their work. 
- The simplicity of structures in the private sector should be followed.

Privatisation and contracting out of public service training is seen as a possible strategy for the future. Private institutions might then get paid to train civil servants, or private consulting firms might deal with training in public administration.

\section{Identification of Problems in Training}

The first problem lies in the training needs analysis which still to be conducted. Of course, such needs are related to the organisational structures of the institutions, the mission of these structures, the job description of personnel working in these structures and their present qualifications.

The second problem is to formulate and implement training programmes with short-, medium- and long-term goals.

The third problem is to find the training resources, both in terms of finances and qualified trainers.

The fourth problem is to strengthen domestic training capacity which is much less expensive than the training offered by foreign consultants.

The fifth problem is to monitor the ongoing process of training and the results they yield.

In solving these problems, the Public Administration Department depends, of course, on the support of the Albanian people and its institutions; but of equal importance is the continuing support of donors and international organisations and programmes, such as Phare, SIGMA, etc. 


\section{Conclusions}

Annex 3 presents the work programme of the Department of Public Administration. This programme covers the whole public administration and is drafted with the participation of the Prime Minister and through consultation with members of the inter-ministerial task force. The public administration reform programme supported by Phare is going to be based on this programme. The analysis of the training situation in public administration has revealed the need to focus attention on the development of training for the public sector - this being an inseparable component of all the objectives stated in the programme of work. It means:

- identifying the training needs for the implementation of each part of the programme;

- strengthening internal training capacities by assisting as much as possible and by working very closely together;

- finding international donors who can provide financial support and expertise in training areas.

Of benefit would also be a pool of highly experienced specialists, preferably practitioners, who might contribute to finding solutions for the various problems addressed by the programme. It would be desirable for these specialists to come from both foreign countries and Albania. The Public Administration Department can take over the responsibility for finding Albanian specialists, but would need and appreciate the help of foreign institutions in selecting the international specialists and arranging the funds to bring them to Albania when they are needed.

Finally, as stated above, the possible development of private training institutions should be encouraged. This will bring competition that will contribute to the improvement of the quality of training 


\section{ANNEX 1. SELECTED ARTICLES FROM THE ALBANIAN CIVIL SERVICE LAW ${ }^{1}$}

\section{Article 19. Nomination of civil service employees.}

The nomination of civil servants to the civil service is done through a selection process which is based on examinations and sometimes, more simply, without examinations. Nomination to the civil service is done in conformity with the regulations defined in this Law by the Civil Service Commission who work closely with the nomination/appointment councils.

\section{Article 20. Civil Service Commission.}

Selection of the candidates who will be nominated to the civil service in the capacity of civil servants, as well as the guarantee of protection of their rights as Civil Servants, a process which follows the criteria defined in this Law and the requirements of the specific assignments, is the responsibility of the Civil Service Commission....

Article 21. Delegation of competences.

....The Commission may set up subcommittees in the ministries, prefectures and organs of local government. These subcommittees perform tasks which are competences of the commission and which are delegated by it....

....The subcommittees are not permanent organs. They are dismissed immediately after they have performed the assignments delegated from above and their members are entitled to an award as defined by the Council of Ministers for the period of their membership in these subcommittees.

\section{Article 23. Selection through competitions.}

The competitions for selecting the candidates who will enter the civil service are organised by the Civil Service Commission. The competitions are organised for selecting and nominating candidates to vacant positions, as well as for nominating people to special positions in the Civil Service....

....The Civil Service Commission, after each examination, compiles a list with the names of the candidates who scored best in the competition, ranking them according to their final results....

....The procedures for selecting candidates, for organising the competition and defining their contents, as well as the formulation and the contents of the public announcement are defined by a decision of the Council of the Ministers....

1. Articles taken from "About the Civil Service in the Republic of Albania," Law No. 8095, 21 March 1996, proclaimed by the Decree of the President of the Republic No. 1455, 5 April 1996. 


\section{Article 25. The integration of existing employees in the Civil Service.}

Existing employees in the civil service, who are working in positions covered by this Law for a period of not less than a year before this Law becomes effective, benefit from the civil servant status when, at their own request, they receive a qualification certificate issued by the Civil Service Commission: The request should be accompanied by:

1) A presentation of the tasks and competences of the position in which the employee has worked, issued by the nominating council.

2) A presentation of the qualifications, work experience and personal traits of the employee which will support his request.

3) An evaluation report by the nominating council in connection with the performance of the employee.

The commission issues the certificate to the employee when the qualifications and work experience qualify the employee to work as a civil servant at the proper level and when the nominating council certifies that the employee has satisfactorily performed his duties.

When the Civil Service Commission is of the opinion that the employee does not have the necessary qualifications to become a civil servant, then he notifies the employee and the nominating Council of this decision.

When the Civil Service Commission thinks that the employee does not have the necessary qualifications to become a civil servant at the moment but can be qualified within a reasonable period (no longer than two years) by successfully satisfying the following conditions:

- earning special qualifications;

- successfully accomplishing specialisation and training courses;

- fulfilling one or more special tasks assigned to him or her;

....then, the employee and the nominating council are notified of this and the decision is annulled until the time when this period terminates....

....Existing civil servants who work in positions covered by this Law for a period of less than a year before this Law becomes effective, benefit from civil servant status when they are subjected to an examination organised by the Civil Service Commission in close co-operation with the nominating councils. If these employees do not fulfil the examination requirements, they do not benefit civil servant status and are a) dismissed from work; and b) demoted to a lower level in accordance with the scores of the examination, a demotion defined by the nominating council. When there are no vacant positions at the appropriate level, they are put on a waiting list.

\section{Article 26. Qualifications.}

Entry into the civil service and the career path process are accomplished according to the qualifications of the employees. The Council of Ministers defines the conditions and the requirements for the general qualification for civil servants who will work at different levels of the civil service, as well as the requirements for special qualifications for special assignments. 


\section{Article 33. Special rights.}

The civil servant enjoys the following special rights:

.... 3. The right to receive necessary training at state expense - which is considered as part of the career development process - as well as the right to receive leave for study reasons....

\section{Article 39. Training.}

The system of training for civil servants, its link with the career development process and promotion, training conditions and the criteria for entry into the civil service are determined by the Council of the Ministers. The Council of Ministers takes measures that training be planned, organised systematically and that it covers the entire civil service. The Council of Ministers takes measures to cover the financial costs of training. 


\section{ANNEX 2. SELECTED DEFINITIONS RELATED TO THE ALBANIAN PUBLIC ADMINISTRATION AND CIVIL SERVICE}

1) The Albanian civil service encompasses the entire Albanian public administration with the exception of elected officials, police forces, defence system members and all other military force personnel who are all subject to special laws.

2) All the 100 per cent budgetary institutions are considered part of the Albanian public administration.

3) The Albanian civil service has three levels:

- The politically-nominated (political functions) who are treated in the first part of this Law;

- The high-level civil servants (top state functionaries) who are treated in the second part of the Law and who enjoy a special status. (This category of employees is further subdivided into top-level leading position employees, medium-level leading position employees, low-level leading position employees and specialists;

- Other civil service employees are covered by the labour code. These employees represent the majority of the Albanian civil service. 


\section{ANNEX 3. 1996 WORKING PLAN FOR THE PUBLIC ADMINISTRATION DEPARTMENT}

The focus of the department is the improvement of the public administration from the functional and structural point of view, in order for this administration to offer the public quick, qualified and low-cost services. Thus, the department aims to:

- improve the administrative structure;

- define to the best of its capabilities the missions, including also individual ones;

- define the qualifications required from a public servant before he or she is hired in the public administration;

- anticipate the right number of necessary services and employees;

- promote training courses for employees and assist them in their careers;

- provide appropriate working conditions and equipment, such as computers;

- compile the necessary legislation for all the above points.

To reach these objectives, the Public Administration Department will be working on the following:

1) Continuous review and analysis of ministry structures and the other central institutions, involving institutions of local government assisted by the State's Secretariat on Local Government

Under this activity, a periodic government newsletter will compile information on organisational and functional structures and detailed missions of the main institutions of central government. The same will be done for different levels of local government institutions. The latter will require close collaboration with the State's Secretariat on Local Government.

The government handbook and other local government information leaflets will not only reflect information on the services they provide and the way they function, but will also provide the necessary information for any step to be taken on structural and organisational reforms.

This objective will be pursued with the collaboration of the task force on administrative reform, consisting of deputy ministers, personnel managers and computer experts from all the ministries. This task force has been operating for a period of one year.

\section{2) Preparation of legislation on the institutional structure}

This legislation will reflect the law through which the ministries and central institutions are created. It will involve the necessary elements that are to be mentioned in the law or verdict through which a ministry or central institution is created. Which elements constitute the ministry and institution profile and how they describe their missions and specific areas, as well as the main elements of their organisational and functional structures. 
Sub-legal acts will be drafted on:

- the procedure of hiring a public servant and useful examinations;

- the creation of the hiring institutions and the way they function;

- career development for public servants and disciplinary procedures;

- the procedures for performance evaluation;

- the number and distribution of public service positions, ranks and stations; conditions guaranteed to employees after their withdrawal from their position; remuneration levels and privileges linked to these levels.

A detailed procedure will be defined as to: 1) who will carry out control systems and how civil service costs will be controlled in regard to wages, bonuses, pensions, labour expenditures, etc.; 2) who will define and control the number of the public servants in the entire civil service as well as in individual ministries and agencies; and who will adapt the number of the employees to the state budget capacity.

Sub-legal acts will be designed concerning the testing or probationary period of new employees and their transfer conditions within the ministry and institutions. This topic takes into account the proper distribution of employees in the state administration, and the filling of vacant positions, as well as the distribution of employees from those places where there are more human resources than actually needed.

Further sub-legal acts will be formulated which relate to the retirement of employees who hold the status of the public servant. These sub-legal acts will be concerned with retirement or withdrawal from the public service in cases of sickness, incompetence, or other issues, such as negative conduct or resignation.

Additional sub-legal acts will be designed related to the duties, rights, and discipline of employees.

4) Compilation of sub-legal acts related to the implementation of the law on the status of politically-appointed individuals

This law will focus on positions starting at the rank of the deputy minister and continuing up to the top of the hierarchy including ministers, the Prime Minister and the President, as well as politically-appointed individuals, such as cabinet members.

For the implementation of this law, sub-legal acts will be compiled on:

- rewards and other advantages these officials will enjoy during the period they hold the specified position, and then after they leave.

- ethical issues that these officials will face during the period they exercise their functions, and then after they leave.

\section{5) Development of personnel management policy}

This will include the development of the necessary legal personnel and the guidelines for the management of the human resources. 
The Governmental ethics code will be completed, with all the elements and the rules for its implementation.

The creation of implementing institutions of this code and the presentation to the public of the governmental ethics policy is envisaged.

Training is required for the realisation of this duty.

\section{7) Development of the public administration library}

The Public Administration Department considers the enrichment and development of this library, and its transformation into a very important centre of necessary information on public administration, including the legislation of different countries, the models of different countries, various handbooks, etc., a very important element for the training of employees and a very important information resource.

8) Development of the concept and strategy for the orientation of the public administration public services

Now is the time for the activity of our administrative body to become orientated to the public. Therefore, we think that we should start immediately, by introducing this concept to employees and by creating structures for to support public service. This item will be placed under the framework of the orientation strategy of the public administration services related to the public.

Formulation of this strategy will commence, including the definition and realisation of the first steps towards its implementation.

9) Development of professional level staff, work strategy, ways of working and the organisational as well as the functional structure of the Public Administration Department, involving also staff professional training

In the framework of the Public Administration Department, consideration is given to the creation of a Wage department, a Directorate on Personnel Management and Organisation, a Directorate of Information Service, a Legislation Directorate and a small supporting sector, consisting of a translation-secretary for the department, the director's secretary and the library documentalist. Intensive work is being undertaken towards the distribution of the missions at the directorate level and at the individual employee level, as well as towards training the department's staff.

\section{0) Improvement of the information network and better organisation of the information}

This is a process that will be developed through the means of technology (computers). It will be implemented in regard to the computerisation of the Management Personnel Team, the Wage system, and Legislation data, thus, facilitating law codification. It will be also include the computerisation of data, statistical data, as well as databases. Naturally, data must be available before computer processing of them can take place.

After these databases are computerised, we will proceed with the creation of local area networks in the ministry, thus, creating great opportunities for information distribution. It is anticipated that installing of local E-mail programmes, which will allow for the establishment of a future connection between the 
ministries and the Internet, will definitely introduce great advantages in communication between ministries, the ministry and public, and communication with other countries.

\section{1) Improvement of working conditions and environment}

At present, employees often work in uncomfortable offices that lack some of the basic equipment. This reduces efficiency at work because it causes a huge amount of time to be spent on "nothing" and it also decreases motivation. In many of our institutions, there is a great need for basic items.

Therefore, we will work on equipping offices in order to create the necessary working conditions. We have already tried to create a better environment with low expenses, and the effect has been obvious: people have worked with much greater motivation and efficiency. Obviously, to make this possible, we will need funding.

\section{2) Strengthening harmonious relations between the activities of the local administration and} the central administration

Local government is a very important part of public administration. Therefore, in the process of administrative reform, we will pay special attention to improving the local administration from the structural point of view and at the professional level. Co-operation is being offered to equip the local administration with the necessary material base.

The completion of the legal framework on local government activity and the harmonisation of this legislation with the legislative framework of central government, will be of great importance for the improvement of local government activity and public administration in general.

Thus, we are of the opinion that there should be more frequent collaboration with the State's Secretariat on Local Government in order to achieve the goal of having a efficient public administration in all possible areas.

\section{3) Training courses}

All the activities mentioned above are envisaged as being accompanied by intensive and co-ordinated training courses. Procedures for needs identification should be created simultaneously.

We think needs identification should be created in the Personnel Directorate, including the management levels. A detailed plan will be designed on the general training of the public administration in close collaboration with the ministries and central institutions, the Secretariat of State on Local Government and the Institute of Management and Public Administration (IMPA).

In order to implement this plan, we are thinking of assigning an important role to the IMPA. In this way, we not only fulfil our training needs at relatively low cost, but will also contribute to developing the training capacities at IMPA, which for the moment is the only Albanian training institution for public administration.

The training experience of the Public Administration Department has shown that one of the most effective ways of training are work and research trips to various European countries, aimed at gathering information directly from the compilers and the executors of laws, structures, procedures and services that we ourselves are trying to create or improve. 
From the comparison allowed by these visits, as well as through the exchange of experience and specific literature with the countries that are being visited, many important suggestions are made towards solving the problems that present themselves during the administrative reform process. For these reasons, this training element should be developed further, especially now that we are faced with the problem of European integration and the issues of contact intensification with the public administrations of the other European countries.

\section{4) Consolidation of the task force on administrative reform, expansion of its working area, and intensification of the collaboration with this task force}

Presently, this task force consists of three categories of officers from all the ministries, the State's Secretariat on the local government and the Prime Minister's Office. The categories of the officials that are part of this group are: deputy ministers representing political standing, personnel and organisation directories representing officials from the management level, and computer experts representing the official technical level. Thus, including Public Administration Department staff, about 50 officials make up this task force. Apart from the task force, the Public Administration Department collaborates with a group of experts from various institutions, such as INIMA, QIDTSH, the Committee of Science and Technology, Telecom, the National Institute of Statistics, the University, National Commercial Bank, etc. that comprise the task force on information consultancy. These two task forces were created upon the initiative of the Public Administration Department and with the support of the Prime Minister. They both represent a very important contributing potential in the description and implementation of the programme of the Public Administration Department. Our present experience with the two task forces above has been very positive and fruitful. Therefore, we are thinking of intensifying our connections and collaboration, as well as enlarging these task forces to include the attorneys of the above institutions.

The department wishes to create special training conditions for the task force on administrative reform so that it may become a strong pillar in this process. 


\section{TRAINING PROFILE}

BULGARIA

(As of April 1996) 


\section{Introduction}

Bulgaria is situated in south-eastern Europe where it occupies the north-eastern part of the Balkan peninsula. The country owes a lot to its favourable geographical situation at the cross-roads of Western and Central Europe with the Near and Far East. Its territory is approximately $111000 \mathrm{~km}^{2}$, and the population in 1995 was 8500 000. The capital is Sofia (1 200000 inhabitants) and the main cities are Plovdiv, Varna, Rousse, and Bourgas.

Bulgaria is a parliamentary republic and a unitary state with local self-government. The new Constitution adopted in 1991 confirmed the separation of powers and replaced the principle of unity of powers that was linked with the domination of the communist party over the past 45 years. The Head of State is the President of the Republic elected in free elections for a five-year term.

\section{Bulgarian State Administration}

The government of the Republic of Bulgaria (the Cabinet) is composed of the Prime Minister and sixteen ministers. The Prime Minister heads, co-ordinates and bears responsibility for the overall policy of the government and is elected by Parliament. He or she presides over meetings of the Council of Ministers.

The Council of Ministers is the central executive body in Bulgaria. It consists of the Prime Minister, deputy prime ministers and ministers. From an administrative point of view, the most important figure in the Council of Ministers is the Secretary General. The Council of Ministers develops and implements the state's domestic and foreign policy. It ensures public order and national security and exercises overall guidance of state administration.

The administrative function is carried out by sixteen ministries. Traditionally, ministers are assisted by deputies, general secretaries and heads of the cabinet.

The structure of the central state administration comprises some other bodies created in response to the new requirements of the transition period. These are usually committees, commissions, agencies or departments. They report directly to the Council of Ministers.

In 1991 the Local Self-Government and Local Administration Act decreased central representation at local levels. According to the administrative territorial division of the country there are two levels of central administration - regional and district. The region is an administrative territorial unit responsible for implementing regional policy, exercising state administration at the local level, and harmonising national and local interests. Regions are governed by a Regional Governor assisted by a regional administration. The district is the basic administrative territorial unit in the country. It is governed by a mayor and a locally elected council and administration. The self-government administration is located at the level of municipalities which are the smallest territorial administrative units. Today Bulgaria has nine regions (oblasty), 279 districts (obshtiny), and 4032 municipalities (kmetstva) (See Annex 1, Table 2). Numbers of personnel employed in the state and local administration, distributed in the nine regions, including the judicial authority, are shown in Annex 1, Table 1 (data provided by the National Statistical Institute). 
The general structure of the Bulgarian state administration is as follows:

$\underline{\text { Council of Ministers }}$

Ministries, Committees, Agencies

Agencies to the line ministries

Regional branches of the agencies and other deconcentrated

structures of the line ministries on regional, sub-regional and local levels

\section{Administrative Reform}

The transition period started in November 1989, and since then, there have been five different governments. The present government was elected in January 1995.

The process of transition from centralised planning to a market economy and from a totalitarian to a democratic state caused these dramatic changes in the state administration:

- Some ministries and other central institutions, such as central planning and control bodies were liquidated.

- Some ministries were first closed and later re-established, such as the Ministry for Foreign Trade.

- More than 80 per cent of the managing personnel employed in the central administration bodies was replaced.

- The Bulgarian National Bank, the National Statistical Institute and some other central institutions became independent, and now they operate on the basis of special legislation.

- A new constitution was adopted, as well as new legislative acts which were designed to create the legal infrastructure for a market economy and a democratic society.

- New administrative structures appeared on the basis of the new ministries' functions - for example, the National Employment Office which is designed to deal with unemployment and has branches on the regional and local levels.

At the same time many negative tendencies intensified:

- The instability of public administration, arising from discontinuity of government, should have been reduced by the creation of a non-political, loyal and efficient administration. Unfortunately, there is no law concerning civil servants in Bulgaria and their status. The latter is regulated by the Labour Code of which a particular article (the Kapudaliev article) caused a lot of political changes and was eliminated only in $1996^{2}$.

- Constant changes even with regard to new legislative acts increased the administrative red tape.

- Public trust in central institutions fell drastically.

- Communication among ministries was very poor and became even worse due to the coalition type of governments and the lack of a professional corps of senior civil servants.

- The quality of services to the public decreased due to worsening discipline and the constant changes in format and content of services.

- There was practically no systematic training of civil servants.

2. Article Kapudaliev (Article 328a in the Labour Code) stated that the labour contract of a person in a leading position could be terminated in respect of the company's interest. It was abrogated in 1996; Official Gazette 2nd issue 1996. 
As a result of the chaotic way of accomplishing reforms in state administration, its size grew constantly during the period 1990-95 (19 per cent increase), as seen below.

\section{Number of Personnel in the Central and Local Administration}

\begin{tabular}{|c|c|c|}
\hline Year & Total Staff & Management Staff \\
\hline $\mathbf{1 9 9 0}$ & 49364 & 12472 \\
\hline $\mathbf{1 9 9 1}$ & 45192 & 10493 \\
\hline $\mathbf{1 9 9 2}$ & 46257 & 8646 \\
\hline $\mathbf{1 9 9 3}$ & 55030 & 8563 \\
\hline $\mathbf{1 9 9 4}$ & 58422 & 9087 \\
\hline
\end{tabular}

It is obvious that a new approach to administrative reform is needed and that it has to be based on a common strategy for all state administrative bodies and formulated in accordance with the process of European integration.

A strategy for administrative reform under the title "The New Administration" was initiated in September 1995 and adopted in March 1996 by the Government Committee for European Integration.

It is hoped that the reform of the existing administration will resolve, first and foremost, some fundamental issues to ensure attainment of the new quality of the administrative system. Of the many existing problems and issues, the following have been identified as the main targets to be tackled in the course of the reform:

1) Decentralisation of administration, mastering of new functions and increasing the effectiveness of the state administration in the implementation of government policies stemming from democratic legislation;

2) Personnel development within the state administration, development of professional non-political career civil servants in the context of clear incentives and procedures of selection, recruitment, promotion, social security and retirement benefits;

3) Orientation of the state administration towards the standards of service provision to individuals and corporations which are common within the European Union.

\section{The Training System Before 1989}

The old training system for civil servants was highly centralised but fortunately separated from ideological education and training. A professional training system for managers of public enterprises, ministerial officials and heads of regional and local authorities was established at the end of the 1960s with the creation of the Centre for Management Development by the Ministry of Labour under the UNDP project, executed by ILO with branches in Varna and Plovdiv. In 1970, an Academy for Social Sciences and Management was established on the basis of that entity with branches in nearly all of the 28 regions existing at that time. Management training for both economic and administrative managers was organised by the Institute for Social Management (ISM), later the Institute for Management and Administration (IMA). In 1980, a system for permanent and on-going training of civil servants from ministries, regional authorities and public enterprises was created through Act No. 42 of the Council of Ministers. The methodological supervision was carried out by ISM (now IMA). Institutes and training centres of 
ministries and districts were involved in this training system. Special branches for post-graduate in-service training were established at some universities.

\section{The Training System After 1989}

The old system was totally dismantled in 1990. In 1992, the central institute IMA was transformed into a Centre for Administration. This centre was closed at the end of 1994.

Since the beginning of 1996, a new system of Centres for Civil Servants Training (CCST) has been in the process of development. It will aim to organise training on the basis of a system of training the trainers. This system will use all the advantages of the available centralised training potential and will be orientated towards the goals of administrative reform and European integration.

Such training potential is found in:

- Universities. During the 1995-1996 academic year, there were 24 universities. Fourteen of these have faculties of law; some of them include programmes in public administration. Only two have departments of public administration (See Annex 2, Table 1).

- Colleges. There are 15. Five colleges are specialised in management and administration.

- Private companies. Many provide consulting and training in management and administration, accounting and finance. Now more than 150 companies that organise courses for the unemployed are registered at the National Office for Employment (NOE). These companies also offer courses for public institutions.

All this training potential is used in a chaotic way and cannot satisfy the urgent needs for civil servants training.

\section{The Civil Servants Continuous Training System}

On the basis of the strategy for administrative reform in Bulgaria which was accepted by the Governmental Committee for European Integration, a new system for civil servants training is planned. A special act of the government concerning the new training system is in preparation. It will create a Permanent Civil Servants Training System (PCSTS) for which major principles will be included in the Civil Service Law, itself now the subject of public discussion. The system will be in operation in 1997 with the adoption of the new budget and the new Phare Programme for administrative reform.

It is envisaged that training of civil servants will become the responsibility of general secretaries of the ministries. Under the new Civil Service Law, this position will be the highest of the non-political administrative staff. For operational and controlling purposes, a National Civil Servants Training Centre (NCSTC) has to be created at the Council of Ministers. Centres for Training of Civil Servants (CTCS) will be created at line ministries. Other central administrative institutions' staff will be trained in the centre of the Ministry of Labour or at NCSTC.

\section{Objectives of Training}

The main goals of the training system that existed to the end of 1995 were:

- To train existing as well as newly recruited personnel about new legislation implementation and institutional functions. 
- To provide basic knowledge of information technologies.

- To provide the opportunity for foreign language training.

Only a few seminars, organised mostly by foreign organisations, aimed at further goals than those mentioned above.

The main goals of the new permanent civil servants training system created in the effort towards administrative reform are:

- Creation of professional knowledge and skills for performance of civil servants' activities within a democratic society and a market economy.

- Developing capacities for policy formulation and evaluation and for loyalty to the government in policy implementation.

- Improving client-oriented public services, following standards for quality services.

- Introducing management knowledge and skills for the innovation process, using information technologies and market-oriented methods.

- Preparing for European integration, by enhancing the understanding of the European Union's administrative system and by developing skills of international communication, including overcoming the language barrier.

\section{Legal Framework}

With the revocation of Act No. 42 (1980) in 1990, the legal background for training civil servants no longer existed.

The new legal framework is based on the Civil Servants Act and the Government Act for the Civil Servants Training System which will be in operation in 1997.

\section{4. $\quad$ Funding}

During the last five years, training was funded mostly by foreign resources offered by:

- The Phare Programme;

- The Know How Fund;

- Other funds of foreign foundations;

- Bilateral agreements with European countries;

- SIGMA activities, etc.

Estimations based on individual reports for seminars, study tours and short-term courses organised by some ministries show that during the past three years the annual amount of money used directly for training purposes is less than US\$100 000. In 1997, more than US\$500 000 is expected from the Phare Programme for training.

Up to now, state budgetary funds have been primarily used for computer literacy and foreign language courses. The new budget envisages allocation of special funds training centres' activities.

The system of training the unemployed, based on a special non-budgetary fund for social support, is the only one at present which has clear rules for the use of fund resources, but the resources are used mainly to prepare people for private sector activities. 


\section{Training Institutions and Legal Status}

Ministries and other central government bodies have no specialised centres for training of civil servants at the moment. The existing training facilities are used for other purposes or for seminars usually organised by foreign institutions.

The main providers of training are the universities. Recently, a new law for higher education was adopted and will be implemented at the beginning of the new academic year 1996/97. The new law is harmonised with European educational standards and the Bachelor and Master degrees are already accepted in our universities. Non-governmental universities and colleges are legalised. A universal procedure for accreditation of universities is approved. All universities can develop specialities within their own judgement but also in compliance with the state nomenclature of specialities. Public administration programmes appear on the new list of specialities in the universities in Sofia, Varna, Blagoevgrad and Sliven (See Annex 2, Tables 1 and 2). Most universities are not state universities. This paradox shows the very difficult adaptation process of state universities to the new situation. Private colleges in Varna, Sofia, Blagoevgrad and Sliven also have programmes of public administration.

Activities of all these academic institutions in the field of short-term training in public administration are very limited due to the lack of an organised system for ministries' staff training. Some of the universities create institutes for postgraduate studies oriented to medium-term courses from one to 18 months. They grant qualification or requalification certificates (18 month courses), and some of the courses are oriented to specific groups of civil servants, such as accountants, social workers, etc. The most active is the Institute for Postgraduate Studies at the University of National and World Economics, Sofia (See Annex 3).

There is no communication between ministries and these kinds of training institutions. At the Ministry of Interior, there is a special school which combines specialised long-term education up to four years with short-term courses. This educational programme leads to a university-type diploma or to specific short-term certificates. All curricula of the school must be approved by the Ministry of Education. The education and resulting qualification is paid for by the Ministry of Interior.

A similar system for medical doctors and teachers exists at the Ministry of Health and the Ministry of Education, Science and Technology where institutes for development of doctors and teachers, respectively, provide the qualification necessary for promotion or for acceptance into new specialities. Courses for managers in the fields of healthcare and education are very rarely organised and mostly on the initiative of foreign consultancy teams.

Some ministries organise courses for their own staff, inviting lecturers from institutes in their own system or from independent consultants. A rare example of that type of course is the strategic management course for senior civil servants organised by the Ministry of Education, Science and Technology, designed for all administrative personnel involved in management at the central body of the ministry (See Annex 3).

Private consulting firms are the most active in the organisation of short-term qualification courses. They do not organise long-term courses because of the financial risk involved and because of the need for university-type licensing when courses run for longer than one year. Private colleges offer an intermediate form of that kind of education and training and are usually organised jointly by a private firm and a university-type of institution.

Licensing for private consulting firms is needed for their participation at tenders for courses organised by labour offices under the supervision of the National Agency for Employment. These courses are part of the 
system of orientation and preparation of temporarily unemployed people while they are seeking new employment. The most popular courses are in management, accounting, computer literacy and small-scale businesses. Some of these courses are adequate for civil servants and are offered to ministries' staff. The fact that licensing is not needed in these cases is regarded as an advantage.

New centres for civil servants training are to be established this year. These centres will have the following organisational priorities:

- Training civil servants on issues of administrative reform and European integration;

- Comprehensive training of new entrants; and

- Training executives for autonomous public service outlets.

The main functions of the National Civil Servants Training Centre will be:

- To study training needs in accordance with the trends in administrative reform and European integration;

- To develop programmes and training materials for short- and long-term training courses;

- To organise special post-graduate studies for civil servants in Bulgaria and abroad;

- To organise competitive tenders for basic training of civil servants to be provided by independent universities and colleges;

- To train trainers for all programmes;

- To organise the training of on-the-job training instructors;

- To offer short courses and seminars to top state officials on current issues of administrative reform and European integration.

The legal framework of permanent training of civil servants has to be ensured not only by the forthcoming governmental act but, in the first place, by the Civil Service Law which is due to be adopted before the end of 1996. It will ensure rights and obligations for training of civil servants and will link training and promotion.

The delay in the creation of the new training system is due mostly to funding problems which may be solved with the new budget. Special funds will be allocated in all ministries for permanent civil servants training. Nevertheless, foreign donors will be the main sources of finance.

The development of the training institutions will be stimulated on the basis of free and open competition between universities, state and private institutions and consulting companies. A system of competitive tender analogous to the one which is in operation for training the unemployed will be applied.

\section{Teaching Personnel}

Up to now, there has been no systematic training of trainers in Bulgaria. The qualification of trainers is their own responsibility.

There are two groups of trainers:

- Officially accepted professional lecturers with title of Professor or Associate Professor (the latter title is given by a special Central Accreditation Commission);

- Consultants and other non-professional lecturers. 
The distinction above is essential when the honorarium for lectures is contractually fixed. Practitioners mostly civil servants with university degrees - are often invited as lecturers and, in many cases, they are highly valued.

Preliminary training of trainers even for specific courses is not provided for by any particular organisation. At the same time, a special license for some specific courses, such as those in the privatisation field (evaluation, accounting, etc.) is required.

In practice, all institutions that organise courses are involved primarily in the planning of courses. Monitoring is the task of the training team. Evaluation of the quality of training is done by using the questionnaire technique. This is the case even for postgraduate university activities.

The focus of the Permanent Civil Servants Training System (PCSTS) will be needs assessment, development of curricula, planning of training activities and training of trainers. A licensing system for trainers will be applied and related to the training of trainers activities.

The first priority of PCSTS is training in European unification. Special curricula for different courses providing general information on the European Union, negotiation skills and language education will be developed for mass training of administrative staff in European matters.

All training formats will be used to fulfil training needs.

\section{Needs Assessment and Content of Training}

There is no system of training needs assessment. The evaluation of needs is based on general recommendations made by the heads of administrative units and on proposals of training institutions and foreign consultants.

In the case of seminars organised by foreign donors, the procedure usually includes preliminary discussions with the head of a particular administrative unit to select the most appropriate lectures from a list of topics offered by the donor institution.

At the Ministry of Foreign Affairs, it is a common practice to train the personnel abroad in programmes funded by foreign organisations.

In general, it is accepted that computer literacy and foreign language courses are the most needed in ministries, hence they are offered most frequently.

Up to now, curricula of the universities' and colleges' programmes are developed mostly as an eclectic combination of foreign programmes. An example of such a programme is that offered by the University in Sliven (See Annex 2, Table 2).

There is no understanding of the need for the development of a specific curriculum for administrative positions for which more economic, engineering or legal knowledge and training are required.

The new system for continuous training of civil servants creates three types of curricula:

- Pre-service training aimed at meeting the criteria used in the selection process for specific jobs;

- In-service training for better performance and innovation;

- EU integration training, including negotiation skills. 
The last of these may be open to the public in order to promote a favourable public opinion and faster adaptation to the new European environment. This training activity needs very good organisation and substantial funds.

\section{8. $\quad$ Target Groups}

The lack of planning in civil service training creates two target groups by default:

- Voluntary participation in courses organised by administrative units for their own staff. This is the case with all internal courses for language and computer training.

- For courses co-organised with foreign sponsors, participation is based on an evaluation of the post filled by the employee and its relevance to the problems discussed. In practice, this is the case with all courses organised by foreigners.

Targeted training is being established with the implementation of the new Civil Service Law and the System for Continuous Education and Training of Civil Servants (SCETCS).

Here, the main target groups are:

- Candidates for civil service positions;

- Administrative personnel of state ministries and agencies;

- Managers of different administrative units;

- Members of different social groups who need better understanding of the new role of the government in a democratic society and market economy.

Various approaches and training formats will be applied for these target groups to meet real educational and training needs.

\section{Training Formats}

Initial training is offered only to employees working in the new financial control and tax collecting administration. These are short-term courses for the presentation of the new legislation adopted in 1995. Similar courses will be organised for staff of the newly created National Auditing Chamber.

Workshops, study tours/visits are the most frequently offered forms of training organised by foreign donors. Long-term individual programmes and paid sabbatical leaves no longer exist in public administration. Consultation combined with training is the most common practice, proposed especially by foreign consultants through various Phare Programmes.

The new system proposes different forms of education and training not only for the preparation of administrative personnel but also for the provision of a social environment which ensures modern state functioning.

Below is a list of the types of courses offered under each category:

\section{General Education}

- Primary and secondary school educational courses giving information on the state, its functions, and the public services provided to citizens and firms; 
- College and university programmes on public administration;

- Open education which includes public seminars and lectures, radio universities, television programmes, and so on, dedicated to the general public and aimed at enhancing awareness of the functions of the modern democratic state in a socially-oriented market environment.

Pre-service Training

- Specialised courses for candidates for employment in the civil service;

- Pre-exam general courses for applicants for civil service positions to create an equal opportunity for all candidates.

In-service Training

- New job training by specialised trainers for newcomers in civil service;

- Qualification courses for better performance, for the implementation of new techniques and for higher position in the hierarchy;

- Re-qualification courses for new job opportunities within the civil service corps;

- Specialised management training for managers in different positions, concurrent with the introduction of new management techniques in public administration.

\section{Training for European Integration}

- General knowledge courses on European institutions and regulations;

- Negotiation skills training;

- Visits abroad to learn from foreign experiences.

\section{Development of Training Curricula}

Training curricula validation is based on different systems depending on the training institution and the way courses are organised. For the educational system of colleges and universities, specialised councils of faculties and colleges are adopting curricula for all disciplines, including postgraduate courses for acting civil servants. Training courses organised by the Council of Ministers and ministries - even when conducted by outside university lecturers, consultants, etc. - are adopted by the respective collective body after evaluation by specialised expert councils. Independent private firms organise their own courses without curricula being formally adopted by specialised councils.

\section{Evaluation}

Evaluation of training activities without the existence of a system of training can be based only on the participants' opinions. This is the case for all seminars organised with national and foreign funding.

The evaluation is based on more or less standard questionnaires that are distributed during the last seminar session. The information is used to inform organisers about which training team is most welcomed. In the situation where there is no regular training, this information is practically useless.

A new accreditation commission for colleges and universities was established by the Law for Higher Education. It will evaluate the quality of educational processes at colleges and universities, including education in public administration. 
No special system of evaluation of in-service training activities is envisaged by the new Permanent Civil Servants Training System.

\section{Identification of Problems in Training}

The main problems in training for public administration stem from the lack of understanding of the new role of the government in a democratic society and a socially-oriented market economy. There is not as yet much public appreciation of a professional career-oriented public administration. In the highly-politicised social environment, the creation of a professional administration with permanent professional training is a very difficult task. It is also very important to introduce an adequate training system in order to enable state administration to provide:

- transparency - by using modern information technology which enables immediate access to any level within the hierarchical structure and makes possible obtaining information about legal obligations and real activities;

- accountability - by organising a control system as a combination of proper management control, internal control, and external control performed by the National Audit Office, and by reporting results to Parliament and to the public;

- standards for public services which will be a criterion for public evaluation of quality;

- policy making procedures - by involving appropriate administrative structural units to create a clear responsibility for policy formulation and policy implementation within the administrative bodies.

Only fundamental changes concerning the functions and organisation of public administration can make training effective and efficient, as well as properly designed and organised. 


\section{ANNEX 1. CENTRAL ADMINISTRATION TERRITORIAL DIVISION}

Table 1. Average Number of Employees in the Public Administration (1990 to 1995)

\begin{tabular}{|c|c|c|c|c|c|c|}
\hline Region & 1990 & 1991 & 1992 & 1993 & 1994 & $\begin{array}{c}1995 \\
\text { near 31 December }\end{array}$ \\
\hline Sofia City & 12880 & 11564 & 14194 & 13650 & 15215 & 14521 \\
\hline Central State Administration & 10219 & 9127 & 12109 & 11542 & 13074 & 12470 \\
\hline Local Administration & 2661 & 2437 & 2085 & 2108 & 2141 & 2051 \\
\hline Bourgas & 4030 & 3974 & 3492 & 4671 & 4875 & 5425 \\
\hline Central State Administration & 1346 & 1658 & 1430 & 2543 & 2687 & 3053 \\
\hline Local Administration & 2684 & 2316 & 2062 & 2128 & 2188 & 2372 \\
\hline Varna & 4299 & 4086 & 3802 & 4973 & 5282 & 5868 \\
\hline Central State Administration & 1370 & 1574 & 1585 & 2693 & 3000 & 3239 \\
\hline Local Administration & 2929 & 2512 & 2217 & 2280 & 2282 & 2629 \\
\hline Lovetch & 5294 & 5441 & 4800 & 6431 & 6609 & 6833 \\
\hline Central State Administration & 1741 & 2261 & 1972 & 3525 & 3681 & 3666 \\
\hline Local Administration & 3553 & 3180 & 2828 & 2906 & 2928 & 3167 \\
\hline Montana & 3544 & 3789 & 3215 & 4331 & 4516 & 4954 \\
\hline Central State Administration & 1111 & 1551 & 1238 & 2266 & 2421 & 2608 \\
\hline Local Administration & 2433 & 2238 & 1977 & 2065 & 2104 & 2346 \\
\hline Plovdiv & 5300 & 4987 & 4356 & 5966 & 6100 & 6876 \\
\hline Central State Administration & 1505 & 1830 & 1520 & 3051 & 3072 & 3395 \\
\hline Local Administration & 3795 & 3157 & 2836 & 2915 & 3028 & 3481 \\
\hline Rousse & 4066 & 3869 & 3673 & 4247 & 4363 & 4773 \\
\hline Central State Administration & 1277 & 1355 & 1536 & 2030 & 2090 & 2239 \\
\hline Local Administration & 2789 & 2514 & 2137 & 2217 & 2273 & 2534 \\
\hline Sofia Region & 5287 & 4731 & 4705 & 5733 & 5834 & 7432 \\
\hline Central State Administration & 1466 & 1470 & 1626 & 2440 & 2531 & 3578 \\
\hline Local Administration & 3821 & 3261 & 3079 & 3293 & 3303 & 3854 \\
\hline Haskovo & 4664 & 4572 & 4009 & 5028 & 5628 & 6071 \\
\hline Central State Administration & 1318 & 1601 & 1458 & 2390 & 2720 & 3016 \\
\hline Local Administration & 3346 & 2971 & 2551 & 2638 & 2908 & 3055 \\
\hline TOTAL & 49364 & 47013 & 46246 & 55030 & 58422 & 62753 \\
\hline Central State Administration & 21353 & 22427 & 24474 & 32480 & 35267 & 37264 \\
\hline Local Administration & 28011 & 24586 & 21772 & 22550 & 23155 & 25489 \\
\hline
\end{tabular}

Table 2. Districts and Municipalities

\begin{tabular}{|l|c|c|}
\hline \multicolumn{1}{|c|}{ Regions } & No. of Districts & No. of Municipalities \\
\hline Sofia City & 25 & 54 \\
\hline Bourgas & 21 & 440 \\
\hline Varna & 30 & 478 \\
\hline Lovetch & 32 & 450 \\
\hline Montana & 33 & 396 \\
\hline Plovdiv & 34 & 441 \\
\hline Rousse & 27 & 436 \\
\hline Sofia Region & 50 & 685 \\
\hline Haskovo & 27 & 652 \\
\hline TOTAL & $\mathbf{2 7 9}$ & $\mathbf{4 0 3 2}$ \\
\hline
\end{tabular}


ANNEX 2. CURRENT TRAINING PROGRAMMES FOR BULGARIAN CIVIL SERVANTS

Table 1. Graduate Programmes

\begin{tabular}{|c|c|c|}
\hline University & $\begin{array}{c}\text { Current } \\
\text { Enrolment }\end{array}$ & Number of Graduates \\
\hline $\begin{array}{l}\text { New Bulgarian University, Sofia } \\
\text { Department for Public Administration }\end{array}$ & 8 & $\begin{array}{l}3 \text { graduates per year; } \\
3 \text { graduates total. }\end{array}$ \\
\hline $\begin{array}{l}\text { University of National and World Economics, Sofia } \\
\text { Institute for Postgraduate Studies } \\
\text { Programme for State Administration and International Law }\end{array}$ & 178 & $\begin{array}{l}\text { First class of } 100 \text { will graduate in } \\
\text { February } 1997 .\end{array}$ \\
\hline $\begin{array}{l}\text { University of National and World Economics } \\
\text { Institute for Postgraduate Studies } \\
\text { Programme for Administration and Personnel Management }\end{array}$ & 500 & 100 graduates annually. \\
\hline $\begin{array}{l}\text { Sliven Branch of Varna Technical University } \\
\text { Department for Public Administration }\end{array}$ & 20 & $\begin{array}{l}\text { No graduates yet; first class will } \\
\text { graduate in } 1997 .\end{array}$ \\
\hline $\begin{array}{l}\text { Varna Free University } \\
\text { Faculty for Administration, Political Science, and International Relations } \\
\text { Programme for Administration }\end{array}$ & 800 & $\begin{array}{l}\text { First class ( } 52 \text { students) will } \\
\text { graduate in June } 1996 .\end{array}$ \\
\hline
\end{tabular}

Table 2. Undergraduate and Two-Year College Programmes

\begin{tabular}{|c|c|c|}
\hline University & $\begin{array}{c}\text { Current } \\
\text { Enrolment }\end{array}$ & Number of Graduates \\
\hline $\begin{array}{l}\text { New Bulgarian University } \\
\text { Department of Public Administration } \\
\text { Four-year bachelor programme started in } 1994\end{array}$ & 142 & 50 per year; no graduates as of yet. \\
\hline $\begin{array}{l}\text { Slavianski University } \\
\text { Department of Management } \\
\text { Programme for Administrative Management } \\
\text { Four-year bachelor programme started in } 1995\end{array}$ & 30 & No graduates as of yet. \\
\hline $\begin{array}{l}\text { Blagoevgrad University } \\
\text { Legal Faculty } \\
\text { Programme for Public and Business Administration }\end{array}$ & 216 full-time students & No graduates yet. \\
\hline Four-year bachelor programme of Public Administration started in 1993 & 502 part-time students & No graduates yet. \\
\hline $\begin{array}{l}\text { Sliven Branch of Varna Technical University } \\
\text { Programme for Public Administration } \\
\text { Four-year bachelor programme started in } 1993\end{array}$ & 430 & No graduates yet. \\
\hline $\begin{array}{l}\text { Varna College for Public and Business Administration } \\
\text { Programme for Public Administration } \\
\text { Two-year programme started in } 1991\end{array}$ & $\begin{array}{l}180 \text { full-time } \\
200 \text { part-time }\end{array}$ & 120 graduates per year. \\
\hline
\end{tabular}




\section{ANNEX 3. UNIVERSITY OF NATIONAL AND WORLD ECONOMICS: INSTITUTE FOR POSTGRADUATE STUDIES}

1. PROGRAMME FOR STATE ADMINISTRATION AND INTERNATIONAL LAW

\section{Module I:}

1. Market economics

2. World economics and international economic relations

3. Constitutional law

4. Administrative law

5. Business management

\section{Module II:}

1. Marketing

2. Business book-keeping

3. Financial law

4. Labour law

5. International economic policy

\section{Module III:}

1. Bulgaria and European co-operation

2. International relations and international organisations

3. International monetary-financial relations and techniques for international payments

4. External economic operations

5. Civil and trade law

\section{Module IV:}

1. Tender organisation for investment projects

2. International law

3. International arbitration

4. Diplomatic protocol

5. Public relations and advertisement 
2.

(Four-month course)

\section{Module I:}

\section{Elaboration of Management Strategies}

Lectures and discussions on:

- Modern knowledge of management. Necessity for a strategic approach to the civil servants activities. International experience in the field of civil servants training;

- Formulation of strategy and decision making.

\section{Module II:}

\section{The Process Of Decision-Making}

Lectures and discussions on:

- Specificity of the decision as a management tool. Characteristics of the decision and its implications in the field of the education. Quantitative and qualitative aspects of the decision;

- Case-studies;

- Analysis of the stages toward a decision. Mistakes occurring in the decision-making process. Decisions and improvement of the management system.

\section{Module III:}

\section{Personnel Management}

Lectures and discussions on:

- Human resources management - scope and goals. Effectiveness of the human potential;

- Motivation and stimulation;

- Selection, recruitment, training, performance appraisal, payment and development of personnel.

\section{Module IV}

\section{Job Organisation}

Lectures and discussions on:

- Characteristics of the senior civil servant's job. Time management. Effective organisation of working with documents;

- Working with subordinates. Delegation of rights and responsibilities. Communication. 
TRAINING PROFILE

CZECH REPUBLIC

(As of April 1996) 


\section{Introduction}

The Czech Republic originated as a sovereign state on 1 January 1993, after the Czech and Slovak Federal Republic ceased to exist and split into two independent states, the Czech Republic and the Slovak Republic.

On the same date, the Constitution of the Czech Republic entered into force which characterises the Czech Republic as a sovereign, unitary and democratic state, based on the rule of law and on respect for the rights and freedoms of human beings. State power is exercised by means of the respective bodies of the legislative, executive and judicial powers. The legislative power belongs to Parliament consisting of two chamber: the Chamber of Deputies (200 deputies elected for four years) and the Senate (81 senators elected for six years). The first Senate election will take place in November 1996. The President of the Republic, elected by Parliament for five years, is the Head of State. The supreme body of executive power is the Government which is accountable to Parliament. Judicial power is exercised by independent courts, comprising the Constitutional Court, the Supreme Court, superior, regional and district courts. The judicial system is complemented with the Supreme Administrative Court which, however, has not yet been established.

The territory of the Czech Republic covers $78864 \mathrm{~km}^{2}$; and its population numbers 10336000 . The majority of people are Czech, Moravian or Silesian; there are no minorities of significant numbers, as a result of which the state can be considered homogeneous with reference to nationalities.

The system of public administration includes central and territorial state administration. The following figures will give an idea about the size of the system: (i) 16 ministries and seven other central governance bodies employ 8451 people; (ii) the deconcentrated organs of state administration within the given ministries and other central governance bodies, such as financial offices, labour offices, school offices, veterinary offices, etc., operating in districts and regions as special competence bodies, employ 114798 people; iii) and the district offices as state administrative bodies of general competence employ 15859 people. These figures pertain to 1995 and total 139108 employees.

The figures above do not include the staff of various budget-financed organisations operating within the framework of the ministries, but not carrying out state administration activities. Their staff includes teachers, doctors and other services of other than state administration character.

The employment figures for public administration should also include, however, the employees of local authorities exercising, as appointed officials, both state administration and activities of self-government character, i.e. those which are within the self-governing responsibilities of elected municipal councils. The total number of these employees is difficult to ascertain, as the number of employees is within the competence of every municipality, and no central state administration authority keeps any records thereof. The number of employees of communal and municipal councils, which totals approximately 42000 , can be extracted from statistical data.

These few explanatory notes are given as an indication of the size of the staff which the training system described below should serve. The training system does not cover the entire public sector; it is concerned with public administration stricto sensu. Only these boundaries make it possible to give somewhat credible figures, even though there is no co-ordination centre which could provide accurate data. 


\section{The Public Administration Training System Before Transition}

When referring to the period before November 1989, it is preferable to use the term state administration rather than public administration, as there was no territorial self-government in the democratic meaning of the term. Although elected organs (the so-called national committees) existed on local, district and regional levels, they were elected bodies of the Soviet type, controlled from a single political centre. All activities were exercised as state administration activities. Moreover, there was no independent Czech Republic at that time. There was the Czechoslovak Socialist Republic, and only since 1968 a federal state comprising two Republics.

In 1976, a staff training system was introduced in the federal state administration, called "Comprehensive System of Education and Further Training of State Administration Employees", experimentally verified in 23 selected state administration organs and in two regional national committees in the following two years. After the evaluation of this experimental phase, the system was gradually extended to the majority of ministries and further central state administration agencies of the Federation, to both national Republics and to all regional national committees.

The co-ordination, methodological and consulting centre for the preparation and implementation of the system was the Institute of State Administration which performed this function until 1989. It drafted methodological instructions for education and training system implementation, prepared model materials for the adaptation of new employees to state administration and tested job qualifications at the end of the adaptation process. For officials without previous practice in state administration and for officials after the appointment to the first executive post, the adaptation process lasted six months for new employees with medium-level education and one year for new employees with high-level education. At the conclusion of the adaptation process, the employee underwent an interview (the so-called qualification verification) at the respective central state administration authority. This interview had no legal links, however, with the official's salary or his or her promotion.

The system of staff training proceeded in accordance with training plans prepared at that time by the cadre and personnel departments in co-operation with the divisions of education. The training plans were based on individual plans of preparation and further development of every individual employee and comprised, consequently, the available forms of professional, and, in particular, political training.

The Institute of State Administration as the co-ordination centre for the training of central state administration employees also prepared model projects of further training formats and even implemented some of them. The training formats included:

- training courses and seminars for new state administration employees;

- training courses to prepare employees for managerial posts;

- updating (or continuing education) seminars;

- four-semester correspondence courses to prepare young talented employees for managerial functions in state administration;

- specialised training courses and seminars for the employees of personnel departments and for employees responsible for education; and

- training courses and seminars for the employees of legislation departments.

Most training courses lasted one week; the seminars, three to five days. Professional training of employees in the framework of individual sectors was conducted by the ministries or other central state administration agencies themselves, mostly in training institutions of their own. 


\section{Objectives of Training}

The objectives of public service staff training are not officially defined. As there is still no specific legislation for civil servants, there is no legal basis for any institution to deal with this problem generally, i.e. for all public administration employees or their individual groups (executive officers, administrative officers, clerks, etc.). There is no such institution in the public administration system of the Czech Republic.

Training after 1990 has been performed unsystematically on an ad hoc basis, when the need arose. Because public administration reform began with the reform of territorial self-government and territorial state administration (i.e. the establishment of self-governing communes and of district offices), the first co-ordinated training efforts were aimed at that level (already in place when the federal state existed). As early as 1991, the Ministry of Interior of the Czech Republic issued an order on the specific professional qualifications of district and communal office staff and its verification (see "Legal Framework" section below). The Local Government Institute of the Ministry of Interior is the organisational centre not only for examinations, but also for the preceding training.

A similar system on central state administration level is absent. The training of ministries' and other central state administration agencies' employees is not co-ordinated and proceeds linearly in the framework of individual sectors. Since 1990 such training has focused particularly on the implementation of new laws. The substantial reconstruction of the legal system, which has taken place in the Czech Republic since 1989 necessitated the training of literally thousands of officers (accurate data is not available).

Further training concerns information technology. All public administration offices were provided with computers and complementary equipment. This new technology brought about a revolution in paperwork, accountancy, personnel services, etc., and necessitated the training of thousands of clerks. This training continues with the arrival of new software and further procedures.

The on-line connection with various European structures and their management centres also necessitates continuous staff training. Various foreign language courses, particularly English, and also - though to a lesser extent - French and German (possibly other languages according to individual needs), are also offered .

At present the training of the staff of ministries and other central state administration agencies in European matters is under preparation. The project of this first horizontally co-ordinated training programme developed by the Institute of Legislation and Public Administration of the Czech Republic (OLPA) will be reviewed not by the present, but by the next government (after parliamentary elections of 31 May 1 June 1996). It can only be hoped that it will be followed by other projects of general training of all civil servants.

\section{Legal Framework}

The 1992 Programme Declaration of the Government emphasised the need to improve the quality of state administration, its professionalism and its technical and information facilities, as well as to restore its public prestige. Towards this end, the Government has undertaken rapid preparation of a draft civil servants law. Furthermore, the Constitution of the Czech Republic provides (Article 79, paragraph 2) that legal relations of civil servants in the ministries and other administrative authorities shall be provided by law. The draft law has been prepared (by the Ministry of Labour and Social Affairs and the OLPA), but 
has not yet been reviewed by the Government and will not be reviewed by it in the present period in office.

Consequently, civil servants are governed by the uniform Labour Code which specifies further duties (i.e. duties over and above the basic duties of employees in general) of state administration offices' and other precisely-defined authorities' employees, but does not contain any provisions concerning the education and training of civil servants. The Labour Code contains only certain provisions concerning working concessions and material assurance of employees participating in training courses or external studies and certain duties of these employees.

Special training legislation concerns only the employees of district offices, i.e. district-level state administration authorities of general competence, and communal offices, i.e. the employees of communal self-government, if they exercise so-called "transferred state administration." On the basis of the 1990 District Office Act, as amended, the Ministry of Interior issued an order on special professional qualification of the employees of district and communal offices and its verification (Order No. 260/1991 $\mathrm{CoL}$ as amended by the Order No. 535/1992 CoL). The order accurately specifies the groups of employees of district offices and communal offices in transferred state administration competence who require special professional qualification for the exercise of their activities, the content of this qualification, the method of its verification, its organisational assurance and the forms of its further improvement. The content of professional qualification is extensive indeed, and covers the exercise of state administration in all sectors.

As mentioned above, the central institution for the organisation of the examinations as well as the preceding training of the employees concerned is the Local Government Institute of the Ministry of Interior. The employees specified in the Order cannot perform their work without a professional qualification certificate. Moreover, the Institute organises supplementary "updating" training courses for those who have been issued this certificate. The respective district or communal office may request its employee to undergo another verification, if the legislation in the respective field of state administration has undergone substantial changes.

\section{4. $\quad$ Funding}

The budgets of most ministries and other central state administration agencies contain items of planned employee training expenses. These funds are budgeted as two items. The first item covers the expenses connected with the training institute for employees of the individual ministry or other central state administration authority and possibly the expenses related to the operation of training centres, if there are any. The second item may comprise the expenses of the employees' training, if the central authority or agency has no training institution of its own and uses contracting-out. The funding is centralised; the budget items for training of individual ministries are fixed by the Finance Ministry.

Training institutions are either fully or partly budget-financed. In the former case the corresponding state administration authority provides them annually with their own budget within the framework of the respective budget item. In the latter case, the state administration authority provides them with a certain annual contribution to their expenses. The data on the percentage of training expenses in the total budget expenses is not available. However, they are certainly not identical for all state administration authorities.

Participants in training courses usually do not contribute to the cost of their training.

It is impossible to give any exact data on foreign assistance in the sphere of public service training because there is no co-ordinated record thereof. The situation is not better as regards the Phare Programme either. 
There are at least two reasons for this: first, the split of the Federation into two parts; and second, the planning system whereby training of public servants may be included mainly under GTAF programme. Under GTAF I (1991-1995) the total allocated sum was 12763415 ECU from which 1403407 ECU was committed to local government training (both officials and elected). Under GTAF II (1992-1995) the total allocated sum is $16092034 \mathrm{ECU}$, of which $799719 \mathrm{ECU}$ is committed to public service training. For GTAF III - European Agreement 1994-1996, the total sum is 4790000 ECU out of which 500000 ECU are committed to training in European matters. The recently started GTAF IV programme (1995-1996) has a total sum of $9000000 \mathrm{ECU}$, out of which $450000 \mathrm{ECU}$ are allocated for and $36700 \mathrm{ECU}$ committed to training.

\section{Training Institutions and Legal Status}

Some ministries still have training institutions of their own. These institutions had been established before 1989 and have been largely used for training purposes. In summer and winter seasons, they are also used for the recreation of the staff of the ministries. These training institutions are subject to public law and are financed through a special item of the state budget in the framework of the respective ministry, if they are fully budget-financed (See previous section on "Funding"). If they are only partly budget-financed, they obtain only a contribution to their expenses from the state budget and organise fund-raising operations of their own to cover the rest of their expenses (See Annex 1). In the ministries, they are usually managed by personnel or educational departments, if such departments exist in the organisational structure of the individual ministries (in some cases, they form part of personnel departments).

There is no specific public administration post-graduate school. Some universities, however, have established faculties concerned with public administration, or some faculties have established departments or institutes concerned with public administration (See Annex 2).

Since 1990 dozens, perhaps hundreds of various training institutions have been established, mostly under private law. There are no accurate records about them. If they want to issue state-recognised educational certificates, they must be accredited by the Ministry of Education. Such institutions, however, are oriented primarily towards the private business sector, and they mainly provide enterprise management training. They also train the employees of banks and other public law institutions which are not considered in this report.

The National Training Fund, established in 1994, does not provide training for public service staff.

\section{Teaching Personnel}

The trainers are both full-time and part-time employees. They do not have the status of civil servants, as this status has not yet been codified in the Czech Republic (See section 3 "Legal Framework"). The majority of trainers are working in educational and training institutions as external staff on a contractual basis. Pedagogical workers employed in these institutions form the minority. The number of external experts includes both academics and practitioners, mostly from the ministries and other public administration authorities, but also private consultants. The institutions also use the services of private training firms, though to a limited extent. There is no accurate aggregate data for the whole Czech Republic, but some specific information is given in Annex 1. The remuneration of public sector teaching staff compares unfavourably with the salaries in private sector. The qualification of teaching staff is on the whole satisfactory. There is, nevertheless, a problem found in the shortage of qualified external trainers, particularly of practitioners from the ministries, as they have practically no time to spare for 
external teaching. If they do have some spare time, they prefer working for private firms, where their remuneration is much higher.

There is no difference in remuneration of civil servants and other external staff working as trainers in ministerial educational and training institutions. All external trainers are paid. The majority of the institutions listed in Annex 1 replied that they pay external trainers 110-180 CzK (net) for one hour. Only the institutions of the Ministry of Finance pay a higher amount: 200-500 CzK/hour (gross).

There is no legal obstacle for civil servants to lecture (in both public service training institutions and private institutions); however, the fact that everybody must be present in the office during normal working hours means that he/she must ask for approval, if this activity is being performed not on weekends but on weekdays, as is normally the case. In practice, there are differences according to the situation in individual ministries or other state administration authorities. Where there is lack of staff, approval is not given. The applicant can then ask for one day (or half a day) paid leave or for an unpaid day off.

In the Decree of the Federal Ministry of Finance No. 18/1991 CoL, "On other activities in common interest", there is a stipulation on the scope of working paid leave. This may be granted to employees (including civil servants) for lecturing, training and examining for a maximum of 12 working days per year, unless serious operational reasons on the side of the organisation do not permit it.

To sum up, it is not very motivating for civil servants to deliver lectures in public service training institutions in comparison to lecturing in private institutions where the fees are on contract basis and where they are usually several times higher $(4000-5000 \mathrm{CzK} / 2$ hour lecture). Yet, the problem is not only remuneration of civil servants lecturing but the possibility of performing this activity during normal working time.

\section{Needs Assessment and Content of Training}

After 1990, the country received numerous foreign offers of assistance to public administration and its reform, comprising, naturally, consulting and training assistance. Every firm or educational institution proposed what they currently provided. Most of them offered training of state administration managers. Many of these offers were accepted; however, there are no records. General data is unavailable and can therefore not be evaluated.

OLPA commissioned a study of training needs assessment to be conducted by the European Institute of Public Administration (EIPA) in Maastricht which submitted a Report on the Identification of Training Needs in the Czech Public Service to the OLPA in November 1994.

The report was based on a relatively broad questionnaire survey of all ministries and on controlled interviews with senior officials of selected ministries. The authors summed up some previously known facts, such as the absence of a co-ordinated training system. Of particular interest was the fact that the respondents regarded the study of languages and information technology (working with computers) as clear training priorities. Yet, this assessment completely ignored the qualification necessary for the performance of the activity and the fact that the recommended skills can be used everywhere, including the private sector. It has happened that public administration employees, having acquired sufficient knowledge of information technology and having improved their knowledge of languages at the public expense, have left the public administration for jobs in the private sector. 
In its conclusions, the report recommends the development of a training system and appropriate training tools, on the one hand, and the elaboration of further specific studies, particularly the Forward Management of Posts and Human Resources (FMPHR), on the other hand. The political decision concerning the crucial civil service problem, i.e. the adoption of a civil servants act which would also provide the principles of civil servants education both before entering service (including the duty to pass entry examinations) and in the course of the service, was not made, so these recommendations were not developed. The report was made available to all ministries with the intention that their personnel departments or their educational divisions should make the most of the recommendations in their respective sectors.

\section{Target Groups}

Training courses are organised for the target groups listed in Annexes 1 and 2. Targeted training forms the basis of both training institutions of individual ministries and post-graduate study organised by various universities for targeted groups of officials. In this respect, the term "target" is interpreted in two ways : on the one hand concerning the object of training, such as a new taxation system, new legislation, etc., and on the other hand concerning the individual staff grades: senior managers, administrative officials, secretaries, etc.

Politicians also form a target group but only at the local level (mayors of municipalities). Politicians at the central level are not considered candidates for training.

\section{Training Formats}

Annex 1 shows that various formats are in use (long-term, short-term, seminars, workshops, and study tours, particularly in case of training provided by foreign institutions). However, there are no accurate records which would allow for a summary in this report. Yet, it is possible to say that pre-service training is entirely exceptional, and where such training is provided, it is of short duration. Training for promotion is the exception rather than the rule. The largest proportion of training provided is in-service training.

\section{Development of Training Curricula}

Training for the public sector is based on curricula, particularly if offered by schools, certain training institutions of ministries (such as the Postgraduate Medical School) or universities or other higher learning schools.

Very often, however, the training follows an ad hoc identification of needs, particularly in the case of the implementation of new legislation.

The drafting of curricula differs: sometimes it comes under the responsibility of the training institution itself, sometimes it is up to the individual ministry; in some cases the curricula are drafted in co-operation between training institution and ministry, in other cases the ministry (a department of it) approves the draft curriculum. The drafting of curricula for special professional qualifications (See Annex 1 - Ministry of Interior: Local Administration Institute) is in the hands of individual ministries but drawn up in co-operation with the Training Institute for Local Administration. Other curricula are drafted by the Institute in co-operation with individual ministries and other central state administration authorities, universities, district offices, mayors and secretaries of municipal authorities. 


\section{Evaluation}

It is common for participants to evaluate their course after completion. Conclusions from such evaluations should be drawn by the organiser. The extent to which this is really done is difficult to estimate. The activities of training institutions operating in the framework of individual ministries are subject to control and evaluation of the respective departments of the ministries. Nothing is known about the evaluation of training courses contracted-out to training firms. Maybe the "invisible hand of the market" makes itself felt here.

Recognising private training institutions is the responsibility of the Ministry of Education, Youth and Physical Training. There are some 1200 training institutions at present. Only a small percentage of these (an accurate number is not known) is concerned with training for public administration Out of the

1200 , only some 800 have been accredited. Only those training institutions which have been accredited by the ministry may issue their students certificates which are nationally recognised. The Ministry of Education, Youth and Physical Training has pointed out that the monitoring of these training institutions is irregular, as the ministry has no staff to perform this task. Monitoring is performed only on an ad hoc basis, particularly if initiated by a complaint. The training institutions conduct their own evaluations.

\section{Planned Changes and Further Developments in the Training System}

No co-ordinated scheme of training system exists. Neither is there a single ministry or other central state administration authority in charge of public service training. These problems are covered by the draft civil service law which, unfortunately, was not discussed in Government session and, consequently, not passed to Parliament. Some planned changes of the training systems of individual ministries are included in Annex 1.

\section{Identification of Problems in Training}

Problems in public service training arise from the insufficiently identified status of the public service itself, due to the absence of a civil service law. Furthermore, there is no central training institution (Public Administration University), which could provide general (national) monitoring of training needs and organise the training accordingly. Neither is there an organ in central public administration with horizontal competence in training matters. In short, there is no concerted effort. More surprising is the recent finding that the absolute majority of ministries is satisfied with the present system and does not consider the establishment of a Public Administration University a necessity. The situation may have two explanations: either the ministries are satisfied with the horizontally deconcentrated system in which every ministry independently plans and organises the training of their employees, or the answers to the questions were given by the heads of other than the appropriate department, a case which cannot be excluded. So far, the government has not reviewed the problem of the absence of a centrally co-ordinated training system.

The only attempt at centrally organised training for officials of all ministries and other central state administration bodies was made by the OLPA which organised three one-day seminars in 1994 for the directors of personnel departments and other senior officials of ministries. Here, experts from the United Kingdom, the Federal Republic of Germany and France lectured on the systems of public service training in their countries. At present, these seminars are being followed-up with two training projects, both concerned with management problems in government. The first project is funded by the Phare Programme, and the competition of tender was gained by a consortium comprising the Civil Service 
College, United Kingdom, and the firms of ROI and DHV from the Netherlands. The trainees are senior officials responsible for training in the individual ministries. The course consists of four 5-day modules comprising:

1. training needs analysis, training planning, budgeting;

2. training methodologies, group dynamics, programme design;

3. quality care, evaluation, transfer, follow-up dossiers;

4. training strategies, buying in training, marketing of training, trainers as advisors and consultants; and a final five-days study visit to the United Kingdom and the Netherlands.

The second project is also primarily targeted at the directors of personnel departments and divisions of education, but permits the participation of other senior officials. The goal is to support and assist in the process of modernising the Czech civil service in order to develop a professional and well-managed civil service, suitable for a market economy and a democracy. This project is the result of bilateral co-operation with the British Know-How Fund. The project, implemented by the Civil Service College, United Kingdom, comprises three one-week courses (each with different participants, the target being the training of a total of 60-80 officials). It envisages the evaluation of the project jointly with OLPA at the end of 1996 and subsequent assistance in building up training capacities and management training programmes in the Czech civil service.

\section{Conclusions}

The main conclusion of this report is that there is no uniform co-ordinated training system nor the organisational structure necessary for its implementation.

With reference to content, this system should comprise both pre-service training and qualification prerequisites for recruitment, including examinations for individual staff categories as well as continuous education for officials.

With reference to organisation, attention must be afforded particularly to the structure of the bodies responsible for the whole training system within public service. It is possible to select a highly concentrated or deconcentrated system. In either case, there should be one central authority in charge of recording and monitoring.

Last but not least, it is necessary to provide for the training facilities proper for which there is a variety of possibilities. The drafting of such a system and its subsequent implementation, however, necessitate a political decision which is still to be taken.

Foreign assistance in public service training has been granted since 1990 through the Phare Programme and also through bilateral agreements. The types of assistance are diverse; however, there are no central records or evaluation of this assistance. 


\section{ANNEX 1. TRAINING INSTITUTIONS OF MINISTRIES}

\section{Ministry of Finance}

There are four training centres within the framework of the Ministry of Finance. All of them are fully financed through the state budget by the Ministry of Finance. One centre, established in 1985, is used for the training of ministerial staff only. A further two, established in 1990, also cater for the staff of the territorial financial offices (totalling approximately 13500 , without differentiating between civil servants and other employees). The number of employees of the individual centres are different; the majority consists of service staff, with teaching personnel forming a minority. In addition to the teaching staff of the centre and/or the officials of the Ministry of Finance, the training is carried out by external trainers. The centre that was established in 1985 resumed its operation in 1995 and provides one- to three-week training courses. So far, 300 employees of the ministry have passed through it. The other centres provide one-week (sometimes longer) training courses with an annual attendance of some 5000 employees.

The last type of training concerns customs administration which forms part of the Ministry of Finance sector. The teaching staff of this centre is made up of its own trainers; the employment of external teaching staff being the exception. The training courses last one day, one week, or sometimes longer. On average, these courses are attended annually by about 4000 customs officials.

The present training system is considered satisfactory. Neither privatisation nor contracting-out is being considered.

\section{Ministry of Industry and Trade}

Within the framework of the ministry there is the Foreign Trade Institute, established in the 1960s as a training and educational institution of the former Ministry of Foreign Trade. It has 24 employees, comprising 17 professionals and a service staff of seven. Its operation and the salaries and wages of its employees are fully covered by the state budget.

The Institute provides language courses, professional courses and seminars. Language courses include 2-3 years study in the form of 4-6 lessons a week. At the end, the students obtain a certificate. Annual attendance is 600 participants. The training is provided by nine language teachers (employees of the Institute) and 12 contractual external staff.

Professional training courses and seminars generally last 1-3 days; one week in exceptional cases. The training is provided mainly by external lecturers, such as employees of banks, state administration authorities, university professors as well as people in private practice. Most teachers are contractually hired.

In 1996, the Institute will discontinue its operations as an institution of the Ministry of Industry and Trade and will be privatised to the highest bidder. 


\section{Ministry of Interior}

The Local Administration Institute has been in existence as a state budget-financed organisation with its own legal status since 1 January 1968. It is under methodological supervision of the Civil Administration Sector of the Ministry of Interior, and under the economic control of the Financial Department of the Ministry. Since 1 January 1995, the Director of the Institute is directly reports to the Chief Director of the first Department of the Civil Administration Sector of the Ministry of Interior.

The annual budget of the Institute is determined by the Ministry of Interior. In 1995 it amounted to 19.8 million CzK. In 1995 the staff of the Institute numbered 76 people, 12 of whom were teaching staff, 24 administrative workers and 40 service staff assuring the operation of the training centre. The Institute is located in Prague, but all training takes place in the training centre outside Prague which has a capacity of 200.

The Institute provides training for the employees of district offices and the employees of municipal offices exercising transferred state administration on the basis of the Order No 260/1991 CoL of the Ministry of Interior, as amended, on special professional qualification of the staff of district offices and communal offices and its verification. The examination for this professional qualification which covers a wide range of administrative law regulations is preceded by 2-3 week training courses which represent 70 per cent of the training capacity of the Institute. The aforementioned Order also authorises the Institute to organise special professional qualification examinations.

The Institute conducts its training and examinations with the help of a wide body of external lecturers whom it employs on (private law) contracts. These lecturers are drawn from ministries and other central state agencies, courts, banks, universities, non-state organisations and private enterprises. The cost of this external staff amount to some 18.5 per cent of the total volume of wage and salary funds of the Institute.

In 1995 the training courses for special professional qualifications were attended by 2398 people and training in other forms of education by 2852 people. Other forms of education include 1-5 day short-term "updating" seminars, 2.5-5 day mono-thematic programmes, and five day or longer multi-thematic programmes for:

- heads of district offices;

- newly elected mayors of communes;

- secretaries of communal and municipal offices; and

- new senior officials of district offices.

One-week seminars for the presidents of district offices and other senior officials of district offices are organised twice a year.

The present system is considered satisfactory. No change is envisaged.

\section{Ministry of Justice}

The Institute for Further Education of the Ministry of Justice was established on 1 January 1989, as a fully budget-financed organisation with its own statutes and organisational rules. The Director of the Institute is directly accountable to the Director of personnel department of the Ministry of Justice.

The annual budget of the Institute is provided by the Ministry of Justice. In 1995, it amounted to 7.6 million CzK. The Institute has a permanent staff of 12 employees, four of whom are teaching staff, 
seven administrative and one service worker. Apart from its own teaching staff the Institute contractually hires about 50 lecturers, recruited mostly from the Supreme Court, superior courts, Ministry of Justice and the Faculty of Law, Charles University, Prague. The cost of external lecturers amounts to some 19 per cent of the total volume of the budgeted wage and salary funds of the Institute. Since 1995, the Institute also co-operates with the TIS managerial agency in the field of training administrators of assets in bankruptcy. The Institute has no training centre of its own. The training courses take place on its own premises, the premises of the Ministry of Justice and/or the recreation centres of various institutions.

In 1995, the Institute trained 2750 people. Training is oriented towards judges and state attorneys, judicial staff (court secretaries, heads of court administrations, economists, probation officers, bailiffs), and towards the preparation and examination of judicial candidates. One-week courses prevail; about one quarter of the seminars last for only one day. The Institute also offers language courses for central level officials, organises typing competitions and participates in the operation of the School of Justice for higher court officials. No change of training activities in the future is envisaged.

The School of Justice for higher court officials in Kromeriz was established on 1 January 1995, and started its training activities in September 1995. Its director is appointed by the Minister of Justice. For every school year the director recruits the necessary teaching staff among those working in the sector of justice, possibly other law specialists outside the sector. The study formats include:

- ordinary three-year study, comprising theoretical education and practical training;

- special one and a half year study for the Faculty of Law graduates, comprising practical training only.

Both forms conclude with a final examination.

The school year is divided into educational periods and practical training periods. The educational periods extend from 1 September to 30 November and from 1 February to 31 March. The practical training periods last from 1 December to 31 January and from 1 April to 30 June. The principal training formats are lectures, seminars, exercises and their combinations, and consultations.

\section{Ministry of Labour and Social Affairs}

Within the framework of the Ministry of Labour and Social Affairs are (i) the Institute of Labour Safety Training; and (ii) training centres of labour offices.

(i) The Institute of Labour Safety Training was established in 1973. Until the end of 1991 it had the status of an independent fully budget-financed organisation. Since 1992, it has only been partly budget-financed. In March 1994, responsibility for the Institute passed from the Czech Labour Safety Office to the Ministry of Labour and Social Affairs. The state budget contribution covers 47 per cent of the total expenses of the Institute (which total 3.9 million $\mathrm{CzK}$ ). The Institute provides education and training in the field of labour safety and health protection at work for:

- the officials of the sector (particularly the inspectors of state technical supervision);

- professional and lay public (particularly the labour safety technicians and executives of various institutions and firms).

Such training is also offered by other training institutions, thereby creating a competitive environment.

The Institute has 15 employees, seven of whom are professionals and eight who are service staff. The professionals act as teachers, but not on a full-time basis. For training purposes, the Institute uses an 
additional 45 external lecturers, including officials of the Czech Labour Safety Office, universities, enterprises and private practice. The cost of external staff in 1995 amounted to $193000 \mathrm{CzK}$.

Training courses last from one to several days. An example of a specific training course consists of a two-year course on labour safety and health protection at work, organised for medium-grade school graduates. The course has 405 lessons. On average, the training courses are taken by 1500 people annually.

No change to the existing system is envisaged in the future.

(ii) In the sector of the Ministry of Labour and Social Affairs there are 76 labour offices. Three labour offices were provided with training centres after 1990. Their operating costs are not monitored centrally but are included in the costs of the respective labour offices, forming part of the state budget. These three training centres have nine employees. No centre has accommodation facilities.

The training activities usually last 3-5 days; the topical subject seminars 1-2 days. Some training courses are contracted-out on the basis of tenders from private firms.

In the framework of labour offices, 110 internal lecturers have been trained who work in the labour offices and may conduct training activities up to 12 days per year. External trainers are used exceptionally and on contractual basis, as a rule.

The present system is satisfactory. More extensive contracting-out is envisaged, however.

\section{Ministry of Public Health}

The Ministry of Public Health has two training institutions, one located in Prague and established in 1953; the other in Brno, established on 1 January 1992. The founder of both institutions is the Ministry of Public Health. Both institutions are partly financed from the state budget.

The Postgraduate Medical School (PMS) in Prague has 83 specialised departments and units with a total of almost two hundred full-time and part-time teachers (including 31 university professors and 50 associate professors). The PMS is the only government organisation licensed to issue certificates to new specialists. External teaching staff represents about 15 per cent of the total.

The educational activities of the PMS include short or longer seminars, workshops and individual vocational training organised prior to specialisation examinations or certification. The greatest part of these activities is offered as programmes of continuing medical education (CME). Specialisation training, specialisation examinations and continuing educational activities are also offered to foreign participants, especially from developing countries. In 1995 the PMS provided 1547 educational activities to some 18700 participants.

The participants in educational activities are housed in a special hotel with a lecture hall for up to 120 persons and eight lecture rooms. Educational programmes (in English) provided by satellite transmission (EUROTRANSMED) are available. The building includes a modern library connected to Internet. The PMS actively co-operates within the international network of scientific and educational institutions.

The objective of the Institute for Further Education of Health Service Staff in Brno is the improvement of the professional and ethical standard of health service staff (not only doctors). The Institute is responsible for the organisation of training and retraining courses of the system of continuous medical education 
(CME). It primarily serves the employees of the ministry, but also provides training courses in the field of health service for the employees of the Ministries of Defence, Justice, Labour and Social Affairs, Transport and others, if required. The Institute has 228 employees, 97 of whom are concerned with pedagogical and educational activities. The major part of the staff are technical, economic and administrative employees including service staff.

The Institute has its own premises with ten classrooms, further seminar and examination rooms and an assembly hall with 80 seats. The premises include accommodation facilities with 260 beds, a dining room and further facilities.

Three-quarters of training activities are provided by the Institute's own staff. The remainder is covered by external experts drawn from the ranks of top-level specialists from universities and private practice as well as specialists from the ministries and other state administration authorities and agencies.

The education provided by the Institute is of two types: specialised external study, and one- to two-week ad hoc training courses. On average the number of trainees amounts to 11000 every year.

The present system is satisfactory. No changes are envisaged.

\section{Ministry of Transport}

The Central Transport Institute was established as a training institution by order of the Minister of Transport. Three quarters of its expenses are covered by a contribution from the state budget; the remainder has to be covered by paid activities.

The Institute organises training courses for the employees of its own sector as well as for other institutions. It has its own building which provides accommodation as well as catering for the trainees. It has 41 employees, only one of whom is an educational specialist. The remainder are technical, economic and administrative employees and service staff. The training is conducted by external staff, either by individuals (on contract) or by specialised training organisations (contracting-out). The Institute regularly co-operates with a number of private firms operating in the field of education and training.

The study is organised in the format of one-day, one-week and longer training courses which take place on the premises of the Institute and on other leased premises.

The government resolution of June 1995 decided on the privatisation of the Institute which will be carried out in the course of 1996. 


\section{Foundation "Fund of Assistance to Local Government in the Czech Republic"}

The Foundation was established in August 1991 and is financed from domestic resources - subsidies from the Czech Republic - on the one hand, and from foreign resources - grants from the Phare Programme and the British Know How Fund - on the other. The activities of the Foundation are targeted at local government authorities. The prevailing formats include one-day seminars and lectures for the staff of communal and municipal offices and elected functionaries of local councils. The activities of the Foundation partly overlap with those of the Local Government Institute of the Ministry of Interior.

The Foundation and its secretariat are located in Prague. The Foundation has 31 employees, four of whom are administrative workers and four editors located in Prague. Twenty-three education organisers and managers work in the 12 regional centres of the Foundation all over the Czech Republic. The Foundation has contacts with some 400 external lecturers and experts.

In 1995, the Foundation organised 459 one-day seminars with the participation of some 17000 people. In the future the Foundation intends to develop its activities in accordance with the demand of its clients and to reduce its dependence on the government subsidy. 


\section{ANNEX 2. UNIVERSITIES AND OTHER INSTITUTIONS OF HIGHER EDUCATION}

People entering public service are either university graduates (civil servants) or medium-grade school graduates (administrative employees, clerks) or have lower-grade education that does not conclude with a final examination (industrial workers, young technicians). Entry tests are required only to a minimum extent and concern mostly the lower grades.

University graduates in public service have graduated largely from the faculties of law or from economic universities. Many of them, however, have graduated from the faculties of natural sciences and pedagogical faculties as well as technical universities. There is no public administration university which would provide general public administration education. Given the absence of such a school, the core of state administration officials (civil servants) consists of graduates of the faculties of law and economic universities.

The Faculty of Law, Charles University, Prague, organises post-graduate courses or other formats of training in the framework of continuous education for civil servants. At present, there are two formats of post-graduate studies available for the graduates of law faculties working in public administration:

Public law I, II, III courses, comprising:

- Public law I - constitutional, international and European law;

- Public law II - constitutional, administrative and financial law, environmental law and social security law;

- Public law III - constitutional law, penal law, criminal investigation practice and criminology.

These courses are attended by some 100 post-graduate students at present.

Courses for the public with or without a legal background, organised on commercial basis, comprising:

- Legislation techniques — three bisemestral courses for 100 students;

- Environment - bisemestral courses for 37 students from district offices;

- Social policy and personnel management - two four-semester courses for 100 students;

- Legal relations to real property - for cadastral office employees (since 1996 also for private parties), altogether 78 students;

- Building law - bisemestral course for 33 students from building authorities;

- European law - bisemestral course for 33 students from building authorities;

- European law - bisemestral course for 57 civil servants;

- Essentials of law for public administration - 20 students from mining offices;

- Essentials of legal system for the Ministry of Defence - 35 students. 
The Faculty of Law reacts to demand, the courses are prepared on an ad hoc basis by the faculty's individual departments. Training courses for sworn court interpreters in English and German are under preparation.

In 1993 the Economic University, Prague, opened a bachelor level study of "Public Administration and regional Economy" and the engineer (Masters) level study of "Regionalistics and Public Administration". Both are focused on territorial state administration and territorial self-government. Tuition is provided mostly by internal teaching staff; however, external experts are also used, particularly from the scientific institutes of the Academy of Sciences of the Czech Republic and top-level specialists from central state administration authorities.

At the beginning of the 1990s, two faculties of economy and administration were established, one at the Masaryk University, Brno, the other at the University of Technology in Pardubice.

The Faculty of Economy and Administration of the Masaryk University in Brno provides education in public economy, regional development and administration, inter alia, at both bachelor's and master's level. However, the percentage of students admitted to these specialisations (in the 1994/1995 school year) amounted only to 16 per cent of the total number of students. The majority studies economic courses with the prospect of working outside public administration, particularly in public businesses and banks. The bachelor level study of the course "Regional Development and Administration" is taken externally by 25 employees of state administration institutions, mostly district offices or other offices on district level.

The Faculty of Economy and Administration of the University of Technology in Pardubice provides only a three-year bachelor level course. The faculty concentrates on economy and management, with some attention being given to computer application and to the study of languages.

At the West Bohemian University the study of "Public Administration" originated particularly in co-operation with American Universities. Most teaching is provided by external teachers, most of them from the United States, lecturing in English. The school is oriented towards future self-government officials.

The Institute of Regional Management in Jindrichuv Hradec forms part of the Pedagogical Faculty of the South Bohemian University. It provides three-year (internal and external) bachelor grade study in the specialisations of "Management of Public Services" and "Management of Transport". Study is mostly economically-oriented. The graduates should find employment both in the private sector and in public administration. Internal teachers prevail, but 30 per cent are external teaching staff, primarily specialists from economic practice. The Institute also organises short-term and long-term retraining and complementary training courses on such subjects as: "Topical Problems of State Administration", "Administrative Law and Communal Enterprises", etc.

All regional universities and institutes co-operate with foreign universities or other foreign schools - with the assistance of which most of them have been set up. Their main problem remains the shortage of internal teaching staff of a sufficiently high professional standard.

This survey is not complete, but covers the most important higher education schools. 


\section{TRAINING PROFILE}

HUNGARY

(As of April 1996) 


\section{Introduction}

The main statistical figures for Hungary (1996) are:

- 10.2 million inhabitants;

- the territory $93000 \mathrm{~km}^{2}$;

- around 100000 civil servants work in central and local public administration; and

- about 650000 public servants work in schools, universities, hospitals.

\section{Background}

Changes in the Hungarian political system commenced in 1989 with the reform of state administration organisation. The system of public administration was transformed first, including internal structure, functions and organisational system of government. Ministries were reorganised and, finally, the overall system of local administration was adapted. In addition to organisational changes, the policy style of public administration has also been transformed. The erstwhile centralised system of intervention, which had concentrated on every aspect of needs satisfaction, has been replaced by a public administration which practices control and legal supervision, plans processes and ensures conditions for development. Finally, policies concerning public administration personnel have been changed. The Civil Service Act of 1992 is of particular importance in this respect, since it established a civil service career system which is similar to those in most countries of the developed market economies.

Public administration reform can altogether be considered as a process which has improved the democratic operation and openness of public administration, the respect for human rights and the relationship between citizens and public administration. Among the steps taken to these ends, the following are to be mentioned: the widening of possibilities for the judicial review of administrative decisions, and the authorisation of administrative courts and the establishment of the ombudsmen to counteract unlawful activities of public administration.

Compared to the pre-1989 period, however, efficiency, effectiveness and promptness of public administration have not improved significantly. More and more experts believe that political transition has even reduced the efficiency of public administration. Public administration has become disorganised and the co-ordinating activities of government have decreased significantly. The Prime Minister has to quarrel several times with his own ministers in order to implement government decisions. Public administration has been fragmented into sectors; the flow of information is incidental; and officials' discipline has weakened. A traditional characteristic of Hungarian public administration - namely that it concentrates on the preparation of decisions and hardly functions when it comes to carrying out and controlling these - has become even more pronounced.

Yet, more harmful consequences can be observed with regard to the personnel of public administration. The number of employees in public administration has increased from 65000 in 1989 to $95-100000$ in 1995, a development which threatens the balance of state finances. Reasons for the enormous increase of 50 per cent in a period of five years are found in the decentralisation of responsibilities, the multiplication of administrative organisations, local self-governments and the lack of a human resources policy in public administration. The Civil Service Act (Act No. XXIII of 1992) mentioned above can be considered a turning point with regard to the latter problem. No improvement, however, can be found in the system of training and education. The framework developed in the decades before 1989 was destroyed without creating new types of training and education. This will be discussed in more detail below. The steps taken 
were incidental and often a consequence of accepting international support without a policy aiming at a carefully developed and integrated system.

Before 1989, a system of training and education had been operating in Hungary, albeit with low efficiency. The system did indeed pay attention to the differences in the levels of public administration. Separate sub-systems were therefore operating for civil servants working in the central or local administration. Civil servants employed by ministries and subordinated territorial administrative (deconcentrated) organisations received training in institutions located in each department. Civil servants of local administration were trained by training institutions in each county. The pre-1989 training system also paid attention to the different needs of leaders and subordinates. An independent organisation, the National Institution for Training Leaders, dealt with the training of administrative leaders.

The system reached the end of operating ability, however, in the 1980s. The lack of a single centre for public administration policy constituted the main reason for its demise. Neither the government nor a specific ministry was authorised to revise the training system and provide general direction. A non-transparent system of parallel training therefore developed. Further decreases in efficiency were caused by the fact that in addition to the training centres of the state, many differentiated training institutions were created and operated by the communist party, the communist youth organisation and by trade unions. This led the training system into a state of anarchy, in which it was no rare occurrence that the same people were invited to several training courses in one year - some organised by the state, others by the party and the trade union. Hence, they spent most of their working time at different training courses. The outdated topics of these training courses, however, were problematic. The courses were dominated by political topics, pushing professional issues into the background.

\section{Objectives of Training}

Governmental concepts, legal regulations, parliamentary and party documents concerning the training of civil servants reveal that a consistent, integrated and homogeneous policy does not yet exist. Only fragments of ideas can be identified, of which this report will discuss those included in legal measures.

The government decrees on basic and professional administrative examinations mention widening, deepening and renewing knowledge as objectives for training. There is no mention of the kind of knowledge which should be the subject of this process. Such objectives can, however, be deduced from preparatory materials: firstly, information on the system of democratic institutions established since 1990; secondly, specific professional knowledge; and thirdly, general administrative management skills.

The Civil Service Act mentioned above also classifies training formats by means of differentiation between professional and career-related training. Professional training is obligatory for civil servants; career-related training is facultative and optional. According to the Act, administrative organisations should support the training of civil servants.

Summarising training objectives, it can be said that they are mainly aimed at promotion, and that they are to be achieved through existing training formats.

\section{Legal Framework}

Following a long preparation period, Parliament adopted the Civil Service Act in 1992. Preparation activities had started as early as 1988 , before the transition. After a two-year long parliamentary debate and several amendments, the original concept was adopted with few internal contradictions. The Act 
regulates the most important principles of the status of civil servants, such as selection, pre-requisites of employment, formalities of nomination, phases and pre-requisites of promotion, principles of salaries, salary tables, definition of rights and duties of civil servants and principles of responsibilities, including disciplinary measures and damages. The Act regulates the cases of removal and some items of training and retraining mentioned above.

The Act represents a recognition of the fact that civil service employment is somewhat unique and, hence, that its contractual base has to be different from the general rules of the Labour Code. The new Civil Service Act establishes career-based promotion, separates politics and civil service and, specifically, excludes civil servants from playing an active role in politics. Another intention of the Act is to develop a new system of employment and promotion, which ensures that such decisions are based on merit and skill only. For selection and employment, a high school degree is required; the condition for top positions and employment in central organisations is a university degree. With regard to training, it is paragraph 33 of the Act which is of prime importance: "civil servants are entitled to take part in training courses which are necessary for them to be promoted, and organisations are required to help them participate".

According to the Act, there is, as mentioned above, a strong correlation between training and career, promotion and salary.

As for salary, there are separate salary tables for civil servants with a university degree and for those with high school degree. Candidates for employment are required to attend a training course preparing for a basic administrative examination [regulated by Government decree No. 51/1993 (III.31)] and to pass that examination. This format of education serves the goal that civil servants gain general knowledge of the structure of the state organisation, democratic requirements, bases of the legal system, as well as the professional knowledge required for handling the issues. This examination is an entry pass to civil service, but it also ensures that civil servants with similar basic knowledge are mobile and can easily be moved between different sectors and areas of the civil service.

Another training format required by the Act is related to career development. This is the so-called professional administrative examination [regulated by Government decree No 46/1995 (IV.24)], which should be passed during the 4th-6th year of employment (differences are dependent on the degree level of the civil servant - high school or university). The aim of the professional administrative examination is to test how wide and deep the knowledge of the civil servant is in his or her area of expertise. This examination does not concentrate on general professional knowledge, but on the sector closest to the everyday activity of the candidate. While the basic administrative examination requires theoretical knowledge, the professional administrative examination tests the operational skills based on theoretical knowledge. The examination is related to career development, as it should be passed in order to reach middle phases of the career. While the basic administrative examination is a pre-requisite of being employed and should therefore be passed during the first one or two years of employment (also differing according to the degree level of the civil servant), the professional administrative examination is a pre-requisite of progressing to a higher level of a civil service career.

Another aspect to be mentioned is that the Act entitles organisations to require civil servants to take part in training courses or to pass examinations as pre-requisites for each promotion. When demanding such specific requirements, the administrative organisation should fully ensure the conditions necessary for meeting these. 


\section{4. $\quad$ Funding}

The distinction mentioned above between professional and career-related training constitutes the basis of the Hungarian training system. A basic principle is that professional training should be fully funded by the administrative organisation. Taking part in professional training is an obligation: it is included in the job description; it is held during working hours and all costs must therefore be covered by the administrative organisation. By contrast, career-related training is optional and not held during working hours (civil servants should cover therefore the costs).

Naturally, there are several exceptions to these principles. Different types of obligatory training are co-financed by the civil servant, such as language courses taken by civil servants working in special areas such as international affairs, police and customs. In these functions, the ability to speak foreign languages is required for high quality completion of the tasks. On the other hand, language skills are not only job requirements, they also improve the general education level of the participant. The knowledge thus gained can also easily be used and "sold" outside the civil service as well. As a result, in the case of language courses, the civil servant is required to contribute, generally with a symbolically low amount of money; however, cases of 50-50 co-financing are known as well. In other areas of career-related training, the administrative organisation also contributes to the costs. This applies to both further education organised by universities and other institutions of the country's education system (e.g. earning a degree), and other facultative courses which widen or supplement existing knowledge. The amount of the contribution varies between full and partial financing, including the contribution of a symbolic sum only. Since there is no general rule regarding such contributions, they depend on the instructions of the head of the given organisation, the financial state of the organisation, the length of employment of the candidate and the necessity of the knowledge for the organisation.

The level of government spending on training civil servants is difficult, if not impossible, to ascertain, given that the relevant figures are not separated in the state budget. Instead, such expenditure is hidden in different budgetary items, which can be used according to the discretion of the head of the organisation and do not necessarily have to be devoted to training. According to experts, the level of spending of training is estimated to be around $0.2-0.3$ per cent of total spending of the organisations, which is far below actual needs and international trends.

Given that government expenditure on training is difficult to specify, the proportions that are domestically financed and internationally supported can hardly be assessed either. The amount of international training expenditure has increased remarkably; support provided by different funds increased continuously between 1989 and 1993 (See Annex 1). Complete figures, however, cannot be given, since these resources are rather fragmented, target-oriented and administered by the providing country. No national registers are kept. The number of countries which contribute to the financing of training programmes - organising programmes themselves or supporting Hungarian initiatives - is estimated at around twelve. International organisations also play an active role in supporting training activities - especially the European Union and OECD, providing support through Phare, SIGMA and several other programmes and projects.

Each ministry spends a stipulated amount for training purposes from their annual budget, yet the amount itself is not recorded separately among the different items. The ratio of training expenses to total spending depends on the individual cases and on the decision of the minister or those who advise him or her. Another fact which makes the collection of expenditure data for training even more difficult is that from the beginning of this year, so-called further education institutions which were located at the ministries were discontinued or contracted out as part of privatisation efforts. 


\section{Training Institutions and Legal Status}

The network of training institutions catering for civil servants is rather differentiated in Hungary. These institutions can be classified according to their location within the different levels of public administration: organisations which operate subordinated to ministries; others which are part of the organisation of ministries; and institutions which are maintained and directed by local self-governments. Another classification is according to revenue: organisations fully funded from the state budget; those which are self-maintained and practically operate in the private sector; and institutions which receive state donations in addition to their own revenues. Institutions can be classified as Hungarian, in the sense that these institutions are financed from the state budget, unlike others which are supported by international foundations. Finally organisations can be distinguished according to being operated within institutions of the education system or being operate (or indeed directed) by ministries or local self-governments.

Among the training institutions operated within or directed by central and local administrative organisations, first mention should be given to the institutions subordinated to central organisations. Until the end of 1995, each central administrative organisation maintained its own institution for further education, which meant more than 30 institutions nation-wide. Two or even three training institutions were found in ministries dealing with complex questions. As mentioned above, these institutions ceased operating as institutions subordinated to central organisations were privatised and carried on operating in different formats - mainly as limited companies and partnerships - according to the Company Act from 1 January 1996. Only one institution, the Hungarian Institute of Public Administration, remained under the authority of the Prime Minister's Office and, concerning training, the Ministry of Interior. This institute plays an active role in two areas. First, it organises the basic administrative examination which was mentioned above, including preparing and editing the subject of training courses and textbooks and preparing lecturers. The second activity of the institute is related to the professional administrative examination. While basic administrative examinations have already established and more than 40000 civil servants have passed them (since the exam is designed for the greater portion of civil servants), the activities concerning professional administrative examinations have only reached the preparatory level, i.e. developing subject areas and preparing textbooks.

Until 1989, so-called county institutions for further education were operating in each county (which is the highest level in the structure of territorial public administration). These institutions were authorised to organise obligatory examinations, professional and other training courses. Each county maintained highly-developed institutions. Students were provided with accommodation, food and up-to-date education. From 1990 onwards, the formerly homogeneous local administration was split. On the one hand, local self-governments were established, and deconcentrated administrative organisations subordinated to different central organisations were formed on the other. In addition to these organisations, the institutional network of the so-called regional commissioners of the republic was of outstanding importance. After the establishment of local self-governments, the two organisational types have started to compete for these county training institutions. This competition led administrative organisations into uncertainty, with political quarrels replacing professional activities. Neither has the Ministry of the Interior found a solution to the problem of (re-)locating such organisations. As a result, 10 out of the former 20 county education and training centres were simply closed. Although the remaining 10 could still satisfy local education and training needs, the problem is that their location and supervision remains uncertain. Several are directed by county self-governments; others are operating in subordination to the county administrative offices (which replaced the former offices of the commissioners of the republic in 1994).

The network of training institutions of central and local organisations reveals an even bleaker picture than five to six years ago, since their former institutional bases have disappeared (with the exception of the Hungarian Institute of Public Administration and four regional training institutions). A respectable number 
of institutions is still to be found among the organisations of local administration. However, these institutions are of mixed character, the given operational framework also differs from county to county.

International foundations, most of which are from Germany, are different from former Hungarian institutions operated by central or local organisations, since these foundations generally do not maintain their own institutional network. Foundations supporting training co-operate with existing institutions, using the infrastructure of the latter. The foundations formulate programmes and organise lecturers. Training programmes organised by different foundations are usually irregular, depending on the heads of the foundation and on the available financial resources. At present, these courses are of a supplementary nature, their mass approach has been abandoned. During the first years of the transition (1990-91), international foundations tended to organise training programmes with huge numbers of participants, mainly in co-operation with Hungarian organisations of state administration. An example can be found in the training of newly elected mayors in 1990, which was provided by several German foundations.

A large proportion of the money provided by international foundations is spent on training and retraining courses run by the said international organisations. The most important among these are: training on human resources management; training on the latest techniques of improving financial management; and training aimed at the implementation of business management tools.

Another type of training institution focuses on gradual further education. The School of Public Administration should be mentioned in this context. The School is outstanding among Hungarian institutions in respect of its history, the number of trained civil servants and the complexity of the training. The School was founded in 1977 with the expressed goal of educating administrative leaders on the legal, economic and organisational aspects of public administration. The School started operating in three sections. Firstly, there is the regular day-school, in which students who are not yet employed in public administration are trained for the service. A high school degree is required for this three-year basic programme which ends with a final examination. Most of the students completing this programme become chief administrators at local organisations - positions which require generalist knowledge. In addition to this programme, active civil servants can take part in evening and correspondence courses to be trained and earn a university degree. This programme is open to those working in public administration and who therefore have some practical experience. The students have so-called training contracts with the sending organisation, and they are granted leave for the training hours as well as being given a few days off as "a study holiday" to secure that they have enough time to prepare for examinations. Altogether, the School's programmes are attended by 2200 students; 600 of them at regular day-school, 450 in the evening programme and the remainder as students by correspondence.

In addition to this educational activity, the School also runs substantial retraining programmes, training thousands of civil servants annually. Among these programmes, general training courses, special training courses concentrating on special fields and courses ordered by different ministries or administrative sectors should be mentioned.

The School is unique among training institutions for maintaining its own pool of lecturers, employing more than 100. Other institutions, especially those belonging to ministerial and local administrative organisations employ only very few teachers. As institutions, they mainly organise and do not provide training courses; therefore, they do not maintain their own pool of trainers.

In the context of training the public service, university faculties of law should also be mentioned, despite the fact that they are, of course, primarily concerned with the education of lawyers. Graduates of these faculties are highly appreciated in public administration, however. Faculties of law can therefore be 
considered background institutions for educating civil servants. There are five faculties of law in Hungary, with around 500 to 600 students each.

The Budapest University of Economic Sciences should be mentioned as another important training institution, turning out a small number of highly qualified students. The Department of Public Service educates 25 to 30 students annually, all of whom possess a thorough knowledge of economics and management to be applied in the civil service as well.

Finally, there is a small number of private companies offering administrative training. In the beginning of the 1990s, these companies seemed to be competitive compared to the public sector. However, after a short time, it became clear that the administrative sector does not provide the necessary turnover of students. Most of these private institutions have by now abandoned their attempt at training the public sector, as a result of the lack of interest which led to low numbers of participants whose combined fees were not enough to cover the costs. Another reason for the failure of private organisations can be found in the fact that these companies were not directed by the most experienced trainers, but by former civil servants who had often left the service because of a lack of professional skills or other technical factors. However, private companies providing training services in competition to public sector training institutions are desirable. At the moment, there is no measurable competition, especially because rates are impossible to compare. There are only about three small private companies in Hungary which deal with organising training programmes for the public sector. These companies operate under private law, while state institutions which are supported from the state budget are regulated by public law.

\section{Teaching Personnel}

Only the further education institutions mentioned above and the Hungarian Institute of Public Administration maintain their own training staff. All other training institutions under central or local direction employ training organisers only, not professionals who actually provide training. These organisers work as civil servants. The staff of the few private companies dealing with public service training also concentrate on organising rather than actually providing training. Hence, in determining the total number of trainers, only those employed by universities and by the Hungarian Institute of Public Administration can be taken into account. The School of Public Administration mentioned above employs most of the trainers, 100 of them work at the School itself and some 30 part-time employees are seconded to ministries or local organisations. At the faculties of law, five to 15 experts deal with educating administrative knowledge with between two to three part-time experts actually practising it. At the Budapest University of Economic Sciences, six to eight full-time and the same number of part-time trainers can be found. In the Hungarian Institute of Public Administration, eight full-time experts deal with training. Additionally, active civil servants have a significant role in the training of all types.

Trainers at further education institutions should meet the following criteria to be employed: They need to possess an academic degree, speak at least one foreign language, have experience in professional public life and have published learned articles or books. Part-time trainers are not required to meet these standards. In this case, experience and professional appreciation are of decisive importance.

As mentioned above, training courses organised by central and local organisations are aimed at active civil servants. As a consequence, the training programmes largely concentrate on practical knowledge; academics are therefore rarely invited to give lectures at these courses.

The professional knowledge of trainers at further education institutions is generally considered satisfactory. Most of the trainers speak foreign languages, are familiar with the administrative experiences 
of other countries and have taken part in courses of different lengths at European universities. Further requirements should not necessarily be placed on their employment, since their academic activities are highly appreciated. However, their knowledge should regularly be updated, for example through international study tours.

Remuneration of trainers is extremely low, given that the civil service pay scale stipulates salaries far below those common in the private sector. This is particularly the case for teachers. Among them, university teachers salaries are perhaps the poorest, if compared to the private sector. They commonly receive less than one-fourth of the amount paid to experts with similar knowledge in the private sector.

\section{Needs Assessment and Content of Training}

Different factors influence the assessment of training needs, which vary according to the characteristics of the respective training organisations.

The training curricula of universities have been developed as a result of long professional debates and are continuously being improved as practical experiences are collected. At all other institutions, needs assessment is incidental, often depending on new tasks for public administration. According to new legal measures, orders, tasks, or new ways of completing existing tasks, training curricula are modified to meet new demands. Training curricula can also be determined by training routines developed over several years or even decades.

International experts sometimes come to Hungary with detailed plans, since they are to carry out a training programme as part of a defined aid project. The problem is that most of these programmes are not based on actual needs, but on the ready-made concepts of foreign experts. Such programmes are therefore of uncertain value; some satisfy Hungarian training needs, some others are on unnecessary topics. Civil servants do not therefore get the expected results while attending. Because of this, Hungary made significant steps to develop tailor-made training programs.

Training courses do not necessarily end with final examinations, as is the case for most short and professional courses. Courses which are classified as career-related, or those which are organised by universities, end with examinations; so do preparation courses for basic and professional administrative examinations.

The pre-requisites for attending training courses differ according to the type of organising institution. Universities can be attended only after passing entrance examinations, since the number of applicants is well above the limited places. Those who perform best at oral and written examinations are selected to attend. For other training formats, especially professional courses, there are no pre-requisites in order to take part in the courses.

\section{8. $\quad$ Target Groups}

According to experts, priority should be given to provide training for top-level civil servants - a view shared by government. Until the problem of training top leaders is solved, training programmes for lower-level civil servants cannot be developed. The first category of 600 to 800 likely candidates for top-level training can be found in the ministries and at other offices of the government. The success of public administration reform, of reconstruction and of international integration largely depends on them. Furthermore, decisions of this group strongly affect the status of public administration in society. An institution that aims to solve this problem is to be set up in the near future. It is planned to deal with 
improving language skills of top-level civil servants and to provide training on creating legal measures, since this is the level where most of the decisions of this kind are made. Another important goal is to gain deeper knowledge on budgetary and financial issues, since the ability to find additional resources for their organisation has become an important aspect in evaluating the success of administrative leaders. Finally, information on European issues should also be provided for top-level civil servants, especially in the following two fields: organisations and legal measures of the European Union, and benefits and disadvantages to be expected to emerge from European integration.

\section{Training Formats}

Long-term training courses organised by universities run from three to five years. Training programmes of less than two years' duration are commonly classified as short-term. One- or two-year long training courses organised by universities and ending with a final examination are included in this group, as are postgraduate courses for active civil servants on environmental protection, economics, information technology, human resource management and social issues organised by the School of Public Administration. Another format are the one- or two-week long courses organised by international organisations, which concentrate on one specific topic. There are also some one- or two-day long training programmes - a format mainly used for refreshing knowledge in different fields. Private training institutions almost exclusively organise one-day programmes.

Study tours should also be mentioned as a training format. Such tours were organised for great numbers of civil servants after 1990 in order to allow them to familiarise themselves with international experiences in their field. This possibility is open primarily to top-level civil servants, such as state secretaries, deputy secretaries, director generals and mayors. However, in many cases, lower-level civil servants also took part in international programmes. The number and length of these tours vary, and without a complete register, it is not possible to determine the number of participants at these programmes. The number of civil servants who took part in international study tours during the last five years is estimated at more than 5000 .

\section{Development of Training Curricula}

As mentioned above, training curricula for joint programmes (such as through university programmes) in certain fields are well-established; they have both conceptual components and are tested in practice. Short-term courses are ad hoc in character, reflecting actual needs. International experiences - study tours or Hungarian visits by international experts - also affect the development of the curricula of these programmes. Programmes provided in the last few years differ significantly from earlier ones, in so far as they pay more attention to the efficiency of public administration. This is also a sign of strengthening American influence; subjects concentrating on legal issues have been replaced by those concerned with efficiency, cost-saving methods and related topics.

Naturally, changes in the environment of public administration are also reflected in the development of training curricula. The best example of this is the relation between civil service and the possibility of joining the European Union. In Hungary, the general expectation is that the country will soon join the European Union; the civil service is hence preparing for integration, and training courses for top-level administrative leaders have started. These courses provide information on the institutions and the operation of the European Union, on advantages and disadvantages expected to emerge for Hungary from integration and on factors resulting in feelings of certainty or uncertainty. 
The classification of Hungarian training organisations above has revealed that the greatest differences exist between institutions within and those outside the further education system. Concerning the development of training curricula, this difference is even more pronounced. Naturally, university curricula are well-established, debated and accepted, and they commonly reflect long-term needs. There are several obstacles to change, since all developments cannot be fit into the existing order. Other institutions are not tied to their curricula to the same extent and can therefore react to $a d$ hoc needs; there are only general rules with which their curricula have to comply, such as a definition of the area of training, such as trade administration or internal affairs. Ad hoc needs require ad hoc programmes.

The development of training curricula is also affected by practical experience, which confirms that professional knowledge should be refreshed from time to time, even if no major changes can be observed in a given field.

Hungarian public administration is fragmented, connections between sectors and levels are loose and infrequent. This is true for the training system as well. Different institutions rarely exchange experiences. The lack of a centre of human resource management contributes to the fragmentation problem, even more spectacularly than in other countries. However, it cannot be said that no interaction or co-operation exists between different training institutions. Surprisingly, the strongest connections have developed between training formats organised by domestic and international central organisations, which is a result of the fact that international aid programmes were completed with the co-operation of organisations under ministerial direction. Mutually positive effects of co-operation are evident in this field.

Environmental changes probably have the strongest effect on the development of training curricula, which means that changes in social, economic and cultural life influence training programmes most directly. The reforms of the financial and budgetary system, state finances, banking system and internal changes in the organisational system of public administration are all aspects which induced modifications in training curricula.

\section{Evaluation}

There are two approaches to evaluating training programmes. Firstly, the performance of participants may be evaluated, as is obviously the case with courses ending with an examination. The most important training programmes do conclude in this way, specifically each programme provided by further education institutions and courses for basic and professional administrative examination. During these courses, performance of the participants is evaluated both continuously and at the end of the course. Other training formats conclude with various evaluations, without being integrated into an organised, homogeneous system. In the second approach to evaluation, participants themselves evaluate the quality of the course. This type of evaluation is quite popular in Hungary: participants anonymously answer questions concerning the quality of the course, the performance of trainers and the success of the course. These answers are usually taken into account when developing the curricula of future courses, inviting trainers and so on.

There is no organised and institutionalised connection between performance at training courses and promotion. Positions are at times filled with applicants with the worst training results. This shows that the training certificate itself is of decisive importance, instead of the quality of training.

There is no regulation for selecting training institutions. Only further education institutions must meet several criteria laid down in the Further Education Act. The same requirements are to be fulfilled by all institutions; an accrediting committee examines financial and human conditions of training. Other training 
formats can be offered without any kind of official recognition. The lack of regulations has a disadvantageous effect on the quality of training institutions. It should be stressed once again that private organisations do not provide training by themselves and do not employ their own teaching staff. These organisations often try to sell training programmes very similar to those of public sector institutions, yet their courses are five to six times more expensive. They are therefore not competitive.

\section{Planned Changes and Further Developments in the Training System}

At present, there are several options for change being considered by government officials of which the most important are the following:

As for institutions of further education, it is planned to recognise the School of Public Administration as a university, which would increase the length of education to five years from the current three.

As mentioned above, a system of institutions for training top-level administrative leaders is planned.

Another central institution planned would combine several existing educational and governmental institutions, such as the School of Public Administration, the faculty of law at Eötvös Loránd University of Sciences, the public service department at the Budapest University of Economic Sciences, and the Hungarian Institute of Public Administration.

With regard to training and retraining, the performance of the private sector is nothing better than that of the public sector; private education systems are also disintegrated. There is no homogeneous training profiles in the private sector. In this respect, the two sectors are rather similar. However, there is little chance for educational experiences to be transferable between the two sectors, since private sector training institutions employ a completely different group of trainers who provide entirely different training on business-management focusing on altogether different aspects. These circumstances have changed somewhat, as trainers started to cross the boundaries between sectors, necessarily affecting training subjects and methods.

The Hungarian government is of the opinion that institutions directed, funded and controlled by the state should play a decisive role in training civil servants, and that privatisation can only be supplementary in this area. The reason for this approach is not some aversion to privatisation, but the fact that private sector organisations are primarily profit-oriented and cease to function if turnover is not satisfactory. Training civil servants appears to provide little opportunity for profit-making, since the resources of administrative organisations are limited. Experience shows that re-opening a formerly well-established system of institutions costs a lot less than setting up a new one. Reforms are needed, but these reforms should not concentrate on privatising and decreasing the ratio of state ownership in this area, but on changing training profiles, increasing quality and inviting better trainers. 


\section{Identification of Problems in Training}

The most urgent problems to be solved are the development of a new and coherent policy and the appointment of officials responsible for the process. Neither the state of human resources management nor that of training can be considered satisfactory. As has been shown, training is fragmented between several organisations. It reflects ad hoc needs; the courses organised are based on outdated traditions and international intentions without a clear policy or people in charge. Policies for public service training should be formulated as fast as possible. The government has ordered the development of a concept for public administration reform, which includes the reform of the straining system; some preparatory material has been compiled already.

The Civil Service Act stresses the importance of training. An important question regarding the evaluation of civil servants, which is required for each step of promotion, is whether he or she has attended the required courses, earned the required degrees, has the knowledge required by the Act and has passed the required examinations, such as the basic and professional administrative examinations and any other examinations demanded by the head of the employing organisation.

\section{Conclusions}

The connection between training of civil servants and the performance of public administration is very strong. Public administration performance in Hungary was at its poorest in the early 1950s, when the educational level of civil servants was even lower than the national average. On the contrary, improvements in training civil servants were shown to have a direct effect on improving performance. Performance of the civil service has been decreasing for a few years, as a result of a draining effect of the private sector. During political transition, civil servants felt threatened, since various political forces promised a spring-cleaning, in which they would be removed as servants of the former regime. Thousands of civil servants left the sector, especially the highly skilled for they had a favourable competitive position in the labour market. Civil servants today are not as skilled, still in unstable positions and badly paid - a situation which cannot be changed merely by improving training.

Viewed from this aspect, privatisation cannot be the final and definitive solution, as was discussed above. Anyway, possibilities for privatisation are limited, as a consequence of the profit-orientated nature of enterprises. It should be stressed that up to now the quality of private courses has been rather low and participation fees have been disproportionate to knowledge provided. The future lies - similarly to the European experience - in the contributions of better-organised state public institutions. The government is seeking solutions of this kind. 


\section{ANNEX 1. EXAMPLES OF TRAINING COURSES SUPPORTED BY INTERNATIONAL DONORS}

Training courses on financial and personnel management have been carried out on the subject of "Human resources management", which is part of the "Training of civil servants" project. These courses, held in four different places (Mihályi, Nyíregyháza, Noszvaj, Balatonföldvár), were attended by 160 civil servants.

In addition to this training programme, a further one, entitled "Training of top-level civil servants" is being organised, which will be attended by 80 people. Preparation was completed by the end of last year, and the course is going to be carried out during the first half of this year.

English language courses (attended by 120 civil servants) started in the beginning of 1995, and have been followed by English, German and French language courses for some 600 participants. Preparation for 1996's language courses, which are organically connected to the previous year's ones, were finished in December 1995.

Within the "Public administration development" programme, 120 civil servants have been trained. Participants will take part in training courses or in the modernisation of public administration as trainers or "multipliers".

In 1996 a special training programme began for civil servants working with EU affairs. This Euro-GTAF programme helps prepare 46 top-level and 103 middle-level civil servants, as well as 123 subject experts, for EU accession.

\begin{tabular}{|l|c|}
\hline \multicolumn{2}{|c|}{ Phare Assistance for Training in Hungary (1994-1995) } \\
\hline \multicolumn{1}{|c|}{ Training } & Amount in ECU \\
\hline 1. Human resources management by IIAP & 1048825 \\
\hline 2. Public administration development by GTZ & 499975 \\
\hline 3. Training of top level civil servants & 120000 \\
\hline 4. Minority training & 35000 \\
\hline 5. Language courses & 232113 \\
\hline 6. Euro training & 900000 \\
\hline Total Amount & $\mathbf{2 8 3 5 9 1 3}$ \\
\hline
\end{tabular}




\section{TRAINING PROFILE}

LATVIA

(As of April 1996) 


\section{Introduction}

The independent Republic of Latvia was re-established as a result of disintegration of the USSR. The August 1991 revolution in the USSR led to the breakdown of the Soviet political and administrative system in Latvia. Components of this system, including administrative training, had been identical to those of the rest of the USSR before transition (See, for example, Lithuania's Training Profile).

The Republic of Latvia is one of three Baltic states. It covers $64.6 \mathrm{~km}^{2}$ and its population is estimated at 2.53 million (end of 1994). The GDP is US\$2.72 billion (1993) and the state budget comprises around two-fifths of total GDP. The capital of Latvia is Riga, a city of 840000 inhabitants. The representation of nationalities in the country's population is the result of the former Soviet migration policy. In Latvia (figures for Riga in brackets), 54.2 per cent (38.1 per cent) of the population is Latvian, 33.1 per cent (47.4 per cent) is Russian and 12.7 per cent ( 14.5 per cent) is made up of other nationalities. Additional social and economic indicators are provided in Annex 1.

Administrative reform commenced through the initiative of the party which headed the majority coalition in Parliament (Saeima) from Autumn 1993 to Autumn 1995. The Civil Service Law was adopted in April 1994, and three institutions were established to carry out the reform: the temporary Ministry of State Reforms (MSR), established in 1993 and in dissolved July 1995, was the central body responsible for development and implementation of the reform; the State Civil Service Administration (SCSA) is responsible for the development and implementation of general regulations on the organisation of the civil service; and the Latvian School of Public Administration (LSPA) is responsible for the development of the curriculum, the co-ordination of in-service training of civil servant candidates (See section below entitled "Legal Framework") in all Latvian civil service institutions. The LSPA also organises and conducts civil service qualification examinations (See "Legal Framework").

The new system's aim is to adapt the Latvian civil service to the new Western-orientated political trends of the country. The LSPA is a newly established institution that organises raising the qualification level in the civil service. The LSPA does not deliver training through its own staff. It draws up contracts with outside training centres for the delivery of in-service training to develop skills necessary for civil servants (See "Objectives of Training" and "Content of Training" sections below). In carrying out its tasks, the LSPA is limited only by generally defined provisions of the law entitled "On Civil Service" (See sections on "Target Groups" and "Legal Framework") which states the school's responsibilities as mentioned above. The LSPA also organises separate advanced level training courses for top managers (See section on "Teaching Personnel").

\section{Objectives of Training}

In January 1995, the MSR put forward a working paper entitled "The Latvian Public Administration Reform Programme." This document defines objectives, contents and means of carrying out the reform in a rather broad policy. It indicates that the civil service is to be built on the following principles: trust, universal application, career and professional development, care and code of ethics. It also lists the main instruments of public administration. In this context, it states that it is necessary:

"to establish the SCSA, which promotes the principle of a career within the civil service and selects the candidates for the civil service; and to establish the LSPA, which will provide the necessary training to ensure the universal applicability of civil servants, and the development of professional qualifications." 
Subsequently, the working paper spells out the career principle in some detail: "In building the civil service on the principle of career, the state expresses trust in its civil servants that they will constantly raise their qualification level to grow with the system. The state also allocates the financial means for professional development of civil servants, being aware that the civil service is an active competitor in the labour market."

The above policy statements are reflected in the LSPA's training activities. Its curriculum consists largely of general public administration subjects which develop skills related to the principle of universal applicability (See section entitled "Content of training").

The LSPA identifies top management positions and organises training (by providing logistical support to foreign companies or trainers) according to its separate curriculum for top management civil servants. These courses are of advanced training level, and along with the common objectives of in-service training, they aim at developing corporate culture and transparency of communication among top managers.

The working paper focuses on general principles of reform of the system of governance in Latvia. The specific content of civil service reform has been provided more explicitly in the Civil Service Law, which will be examined in the following sections. The objective of internationalisation of civil service operations and capabilities is reflected in the Law's Article 37 (See section on "Legal Framework") which encourages civil servants' learning of foreign languages by providing a 10 per cent salary increase per language mastered.

These training objectives derive from both societal pressure and demand and from the international community in the context of European integration policy.

During this early stage of reform, the need for training is increasingly being recognised, thus creating job opportunities for well-qualified staff. Attracting such staff is somewhat hindered by a centralised and regulated approach to reforms, especially with regard to remuneration policy. Market demands are rather high (e.g. at least 5 to 10 years of work experience in top management positions, supplemented with good professional training or education abroad followed by practical application of this training), and this stimulates competition. The demand for international co-operation is being recognised clearly in all levels of public administration.

\section{Legal Framework}

The following legal acts are relevant to the civil service:

- law "On Civil Service";

- law "On Disciplinary Procedures for Civil Servants";

- law "On Conflict of Interest";

- Code of Ethics;

- law "On Administrative Process".

The law "On Civil Service" provides the framework for the civil service and establishes the background for civil service training. Much of this country training profile focuses on this law, which is divided into

3. Likums "Par valsts civildienestu"; Law adopted 21 April 1994, published in the Latvian newspaper Latvijas vestnesis (Latvian Courier), No. 52 of 1994, and No. 82 of 1995 (amendments). 
five chapters. A detailed analysis of its provisions is given in Annex 2. The SCSA's English translation of the law "On Civil Service" is used here as the basis of references.

According to the law "On Civil Service", the process of becoming a civil servant comprises two steps. To enter the civil service system, the first step is a test as part of a competitive selection procedure. This test is organised by the SCSA which awards those who pass it with the status of "civil servant candidate". The second step (after a given probationary period) is to pass a qualification examination (Article 5, 15, 57) organised by the LSPA. After passing this examination, the candidate is awarded civil servant status. In the meantime, civil servant candidates are offered training by the LSPA on the basis of its curriculum (See "Needs Assessment and Content of Training" section).

The legal framework for training is set in Article 5, which allows for a broad interpretation of the scope, obligations and responsibilities of the LSPA:

\section{Article 5. The LSPA}

"The Cabinet shall establish the LSPA and approve its Statute, as well as appoint and dismiss its Director. The main responsibilities of the LSPA shall be the following:

1) development of training courses for qualification examinations and for qualification-raising; elaboration of the contents and the procedures of qualification examinations;

2) conduct qualification examinations of the state civil service.

Requirements for applicants for separate public civil service qualification categories in regards to their general, special and professional training, as well as the procedure for testing the abilities of the applicants, their knowledge about the specifics of civil service and their ability to meet the requirements for the respective positions, or the procedure for taking the qualification examinations of civil servants, shall be set by Cabinet regulations, unless provided differently by this law and special laws."

The first point above leaves curriculum development, course design and the elaboration of the procedures up to the LSPA. The law does not stipulate that the courses are mandatory for civil servant candidates to take the qualification examination. The procedural part is not precisely defined, leaving open, for example, the question as to who will invite to attend and then conduct the qualification examination and issue certificates of the civil servants. These topics should be covered by Cabinet regulations.

The last part of Article 5 referring to requirements tends to relate the training programme to the civil servant's qualification category (See Article 52 in Annex 2) which is to be issued after the qualification examination. The present task of the LSPA and the SCSA is to define what kind of knowledge or abilities should be tested in the qualification examination, and if the result of the examination will affect the qualification category.

Subsequent articles of the Civil Service Law above are related to training, examination, legal status and promotion of civil servants (and civil service candidates).

Article 15. Status of the civil servant candidate

"A person can obtain civil servant status only after passing the qualification examination for the civil servant candidate [this procedure is herein after referred to as the attestation] and having performed the responsibilities of a civil servant as a civil servant candidate for not less than three, but no more than five years, and having passed the qualification examination. 
All requirements, restrictions and rights, provided by this law and other normative acts shall be applicable to a civil servant candidate, unless provided differently by law.

A person's tenure as a civil servant candidate shall be included in the total tenure of a civil servant in the public civil service."

The first part of Article 15 states that civil servant candidates have a maximum of five years for training and passing qualification examinations in order to become civil servants. The LSPA uses the first phrase as a guideline for preparing terms for the qualification examinations and for assessing the quantity of the civil servant candidates prepared for passing the qualification examinations.

Chapter Three of the Civil Service Law is devoted to the responsibilities and restrictions of civil servants. The following provision forms the basis for in-service training activities.

Article 22. Obligation to raise the qualification level

"The civil servant (candidate) has the obligation to learn continuously and to improve his or her professional skills.

The managers of civil service institutions have to ensure the possibility for civil servants (candidates) to raise their qualification level not less than 45 days in the period of three years, preserving their salaries and covering the tuition costs, if the qualification-raising takes place in Latvia."

This Article serves as the background for in-service training of civil servant candidates. Trainees are usually granted one or two weeks of study leave per year. The second part of the article implies a de-centralised approach to the financing of training. So far, however, all of the funds allocated to the LSPA for in-service training have been from the state budget; the school has not charged ministries and other public administration institutions for its services.

\section{4. $\quad$ Funding and Training Formats}

This paper focuses mainly on civil service training associated with civil service reform, covering the period from the end of 1994 to the beginning of 1996. Since 1991, government-funded training and international assistance for reform constituted only a small part of total training received by different parts of the civil service. Until 1994, no special funding for training was allocated from the state budget; and self-financed (Latvian government) training activities, which are mentioned below, refer to the period 1994-1996.

Overall figures on technical assistance for Latvia provide some insight into the ratio between self-financed training and outside or external funding. 


\begin{tabular}{|l|l|r|r|}
\hline Period & \multicolumn{1}{|c|}{ Donor } & $\begin{array}{c}\text { Technical } \\
\text { Assistance (in } \\
\text { millions ECU) }\end{array}$ & $\begin{array}{c}\text { For Training } \\
\text { (in millions ECU) }\end{array}$ \\
\hline $1991-4$ & Denmark & 12.54 & \\
\hline $1991-4$ & Finland & 3.79 & \\
\hline $1991-4$ & Germany & 8.77 & \\
\hline $1991-4$ & Sweden & 14.13 & \\
\hline $1991-4$ & Other EU countries & 6.48 & \\
\hline $1991-4$ & Other G24 countries, mainly USA & 64.70 & \\
\hline $1991-4$ & EC-Phare, total & 32.50 & \\
\hline 1995 & EC-Phare, total & approx. 55 & \\
\hline $1994-5$ & EC-Phare, Public Administration Reform Programme & $4^{4}$ & approx. 1 \\
\hline $1994-5$ & Latvian government & & $0.85^{5}$ \\
\hline
\end{tabular}

The assistance of multilateral donors other than EC-Phare (international financial institutions, such as the World Bank, the International Monetary Fund [IMF] and others; international organisations like the United Nations Development Programme [UNDP] and OECD; foundations like the Soros Foundation; and others) is not included in the above list, though these contributions are significant. For instance, recipients of the assistance of international financial institutions usually include state-owned banks, and therefore such assistance extends far beyond the legal framework of the civil service.

When estimating the amount spent exclusively on training, one should take into account that technical assistance projects usually contain training as one integrated component, along with other measures associated with training. A very rough estimate of the training component in such projects is 20 per cent. Therewith, it is possible to calculate the amount of funds spent for training from the above data on technical assistance. Generally speaking, between 1991 and 1995, the financial volume of assistance projects in the institutional, human resources, social, private and infrastructure sectors have run into millions of ECU; practically all of these sectors have thereby received training for improvement of the managerial capability of their staff.

Funds for in-service training are allocated from the state budget. The funds necessary for training development of the LSPA are set in the management contract of the LSPA concluded with the MSR for 1995. Other civil service institutions do not have special budgets for training (though some of them which have independent financial capabilities and operations can organise training courses independently, for example, the State Revenue Service). The model of centralised distribution of funds for training (See

4. This is an on-going project which provides assistance at the central government level to the SCSA, LSPA, LGTC and other institutions (See section entitled "Training Institutions and Legal Status") directly involved in the civil service reform.

5. This figure pertains to centrally allocated state budget funding; and the amount represents 0.1 per cent of total government spending in 1995; conversion rate ECU to Latvian Lats 0.69 (March 1996). 
Article 22 of the Civil Service Law in the "Legal Framework" section above) was chosen by the government. Major outside funding has been received from the EC-Phare public administration reform Programme in the form of advisory and training assistance, as well as office equipment supplies. This assistance was given to MSR, SCSA, LSPA, the Local Government and Latvian University State training centres (See "Training Institutions and Legal Status" section).

Civil service institutions receive various bilateral training assistance from Western countries channelled through the LSPA's logistical support. Major donor countries are Denmark, Ireland, the Netherlands, Sweden and United States (primarily management training methodology), Canada (primarily economics), France (primarily language training and training for top-level civil servants in EU Integration matters).

Trainees do not have to pay for the LSPA nor other institutions' training courses. For instance, civil servants usually attend the language training courses in the Public Language Training Centre only if the training costs are covered by a civil service institution.

In practice, the LSPA concludes contracts with training centres about the delivery of a block of subjects. This division of subjects into blocks is for organisational purposes, so that groups of trainees can have a full week of training. Financial characteristics of the contracting procedure are listed below. The training costs in US dollars is an approximation on the basis of the Latvian currency Lats (Ls). The costs are representative of the contracts between the LSPA and the training centres.

\begin{tabular}{|c|l|l|c|c|c|}
\hline Block No. & \multicolumn{1}{|c|}{ Block Name } & Subjects & $\begin{array}{c}\text { No. of } \\
\text { Units }\end{array}$ & $\begin{array}{c}\text { Max.Fee Per } \\
\text { Person/Day (US\$) }\end{array}$ & $\begin{array}{c}\text { Max.Fee Per } \\
\text { Person (US\$) }\end{array}$ \\
\hline 1 & Economics & Economics & 5 & 11 & 55 \\
\hline 2 & Management and Daily & Management & 5 & 11 & 55 \\
& Working Methods & & & 11 & 38.5 \\
\hline 3 & Law and & Law & 3.5 & 11 & 51 \\
\hline 4 & History & History & 1.5 & 17 & 38 \\
\hline
\end{tabular}

The LSPA arranges groups of trainees, normally around 20 to 25 people. They have one-week study leave attending the subject(s) of one of four blocks.

Advanced training is being organised for top-level civil servants. This category cover positions from State secretaries to the directors of departments in ministries and State agencies (approximately 200 people). Although the training curriculum is the same, special attention is being paid to the quality of training, i.e. Western consulting companies are being invited to deliver courses, the methodology of training may be different and advanced (interactive, cases studies, etc.). Greater emphasis is put on management courses and less on technical ones. Thus, management courses have been delivered by the Swedish consulting company OMNIA (financed by BITS, Sweden), and a course in economics has been given by the Danish and Irish Schools of Public Administration, in the framework of the EC-Phare Programme of assistance to public administration reform.

Summing up the training activities mentioned, the following table presents their overall volume in terms of quantity of civil service candidates trained during the period under consideration (LSPA training data, covering 1 January 1995 to 1 December 1995). 


\begin{tabular}{|c|l|c|}
\hline Subject Block No. & \multicolumn{1}{|c|}{ Training Subjects } & Quantity of Trainees \\
\hline 1 & Economics & 1985 \\
\hline 2 & Management and Daily Working Methods & 3495 \\
\hline 3 & Law and History & 539 \\
\hline 4 & Ethics, Psychology and Computers & 3066 \\
\hline \multicolumn{2}{|c|}{ Total number of trainees } \\
\hline
\end{tabular}

According to the LSPA, the total planned state budget funding for training was about Ls 586000 (approximately US\$ 1106 000) in 1995. Up to 1 December 1995, the majority of these funds was spent on the training of civil servant candidates and on the preparation of learning materials.

According to the law, training of civil servant candidates is a priority. However, substantial changes in the law entitled "On Civil Service" are envisaged, restricting the civil service mainly to the management group, which may reduce the number of civil servants to only about 3500 persons. Consequently the composition of the target group for training could be dramatically changed.

One of the most important activities of the LSPA associated with training is the conduct of qualification examinations for the status of civil servants. These are expected to begin in 1997 with the examination of 200 top-level civil servant candidates.

\section{Training Institutions and Legal Status}

All training according to the common curriculum (See "Needs Assessment and Content of Training" section below) is provided by 23 training centres situated in Riga and other Latvian cities. LSPA management is dealing with the co-ordination of the process, and its staff (16 people) is permanently occupied with the corresponding logistical arrangements and other activities facilitating training. These include, among other things, writing and publishing training materials. Annex 3 provides a list of the 13 largest training centres.

There is some difficulty in finding common criteria for characterising training centres which are rather different in nature, size and profile. On the one hand, there are training centres which have been organised in state universities, such as the Jelgava Academy of Agriculture, Riga Technical University (RTU), Latvian University (LU) State Training Centre (STC) and others. On the other hand, there are newly established training centres, such as the Local Government Training Centre (LGTC) owned by the Latvian Union of Self-Governments, and new training, consulting and education companies, such as Computerland Riga, the "Turiba" training centre owned by the Latvian consumer society of the same name, the Latvian Bank College and the Latvian International Business Economics College. The LGTC and the STC are recognised as well-qualified training centres; and they have received considerable assistance from the EC-Phare Programme.

All of the training centres are independent legal entities. Their names usually derive from those of their owners (e.g. RTU, "Turiba", LGTC, Computerland), and they are subordinated to their owners in accordance with regular company legislation. None of the training centres receives support from the state budget; and all of them have been established as a result of an assessment of training needs. Thus, training centres in universities and that of the Union of Self-Governments have emerged as the result of foreseeable 
demand from the civil service. The "Turiba" training centre deals mainly with training for their own staff, and it is only able to offer training of civil servants as a secondary activity. Banking and economics colleges are orientated towards private banking and other sectors beyond the civil service.

Well-established training centres usually have their own training activities, mainly in the private sector, municipalities, etc. They could not "survive" solely on training civil servants. Training centres compete on the basis of their reputation, their status with regard to the possibility of receiving international assistance and their ability to deliver state programmes. The "market" of public service training is well divided up among training centres; they usually establish direct contact with potential "clients" in civil service institutions. The disbursement of funds for training by the LSPA and the issuing of contracts to deliver training on behalf of the LSPA is not prescribed by any procurement procedure; therefore contracts are awarded to training centres depending on an ex ante assessment by the LSPA of their capacity to deliver and, as regards recurrent contracts, as well as on the participants' evaluation (See also "Evaluation of Training Activities" section).

Another feature is the limited specialisation of the training centres, which tend to cover the entire LSPA curriculum in their programmes. This is especially true for the regional training centres which have to train civil servant candidates from the corresponding region. However, it may be argued that some specialisation of training centres in Riga would add considerably to the quality of subjects delivered.

Subjects are not covered in equal measure. For instance, the subject of law has been delivered only to a limited extent. The Department of Law of the LU is somewhat unique in this context. Its on-going experience with students facilitates the design and delivery of a similar course for the civil service. Yet, civil servants often consider the subject of law as a difficult one; hence, they do not choose this subject in their initial phase of training.

\section{Teaching Personnel}

The subjects are delivered in the training centres by trainers licensed by the LSPA. Before licensing, the LSPA involves potential trainers in curriculum development, training-the-trainers and other activities. During these activities, trainers have to demonstrate their commitment and skills in training. After licensing, a list of certified trainers is drawn up, and training centres choose their training staff from this list.

There are around 200 trainers, none of whom are full-time staff or employed on the basis of a permanent contract. Almost all of them have a background of university teaching, and many deliver courses in universities along with other jobs (e.g. in civil service, private business, and training). Most of the trainers come from the LU and the RTU, or from universities in Jelgava, Daugavpils, Liepaja, Rezekne and Ventspils. The main challenge is to introduce new interactive methods into their work, instead of simply carrying out lectures.

An effort is being made to introduce interactive methods, exercises and group assignments into training methodology. Trainers have been trained to deliver courses to civil servant candidates, which are oriented towards the qualification examinations.

The quantity and composition of the LSPA trainers employed by training centres on a contractual basis is constantly changing. Trainers conclude fixed-term contracts with training centres, usually for the duration of the contract between the training centre and the LSPA. Remuneration is therefore determined by the training centres. The rate of remuneration ( 3 to $5 \mathrm{Ls} /$ hour) is higher than that for university teaching 
(approximately 1 to $3 \mathrm{Ls} /$ hour). However, the remuneration for those trainers providing private sector training in special fields, such as finance and economics, can be considerably higher.

Within the framework of the EC-Phare assistance Programme, potential trainers have themselves been trained in groups of 20 in subjects of management, psychology and ethics, and market economy. In addition, the Danish School of Public Administration has contributed to this activity in the framework of this bilateral programme.

To sum up, potential trainers in the LSPA system are being trained by Latvian trainers, who possess recognised authority and experience of university teaching in corresponding subjects, and by Western trainers through assistance programmes.

\section{Needs Assessment and Content of Training}

The LSPA training programme is based on a common curriculum, which means that the course syllabus used for training civil servant candidates in different training centres is uniform. Each training centre that secures the contract on training civil servant candidates with the LSPA is obliged to deliver the course according to this contract, using trainers prepared for instruction and certified by the LSPA. The following subjects are being taught:

\section{Market Economics}

This course (40 instruction hours or five days) is designed as an introduction to the basic concepts of the subject. Microeconomics (14 hours): market, price, competition, market of production resources, fundamentals of entrepreneurship. Macroeconomics ( 8 hours): main economic indicators, money, banking system, credit, macroeconomic equilibrium and stability. Impact of the state on market economy (6 hours): Keynesianism and monetarism, state budget and tax system. International economic relations (6 hours): analysis and forecast of economic situations (6 hours).

\section{Management}

(24 instruction hours or three days). Planning, problem solving, decision making (2 hours); strategic planning and management (4 hours); organisation theory and structure (4 hours); motivation and communication (4 hours); personnel management (4 hours); management of change ( 2 hours).

\section{Daily Working Methods}

(14 hours or two days). This course in its current version focuses on procedures of work with documentation, correspondence and information processing.

\section{Law and Fundamentals of the Governance of the State}

(30 hours). This course introduces the basic principles and structure of the subject of law. It focuses on legislation regarding the system of governance, and from this point of view it introduces the legal status and the role of the civil service. The following fundamental areas of law are also included: the Constitution (Satversme); administrative legislation, process and responsibility; environmental protection; labour; criminal justice; municipalities. 


\section{Latvian History}

(10 hours). This course focuses on the history of the Latvian state in the 20th century. The course is divided into the following themes:

1) Development of the idea of the independent state of Latvia (1903-1917);

2) Establishment of the independent and democratic state of Latvia (1918-1920);

3) Latvia in the system of international relations (1920-1940);

4) Fundamentals of the Latvian political system, its developments and results (1920-1940);

5) Latvian national economy: the model of development (1920-1940);

6) Latvian culture (1920-1940);

7) Latvia under the USSR (1940-1941);

8) Latvia under the Nazi regime (1941-1945);

9) Latvia under the USSR again (1945-1986);

10) Awakening $^{6}$ (Atmoda) in Latvia. The re-establishment of the independence of Latvia.

\section{Human Relations; Psychology and Ethics}

(24 hours or 3 days). This course is designed for the application of these concepts in the civil service, i.e. "the civil servant from the point of view of psychology and ethics, the portrait of the civil servant". Its main themes are as follows: orientation of values; types and means of communication; mutual perception and interaction; psychology of groups; conflicts and conflict-resolution; personality; moral and mental values; professional ethics of the civil servant.

\section{Computers}

(16 hours or 2 days). This course introduces the basic principles of working with personal computers (IBM-PC compatible computers are the most widespread in Latvia). The course introduces the components of the computer and peripheral devices, some basic DOS applications and mainly Microsoft Windows applications, focusing on text editor. The course content may vary from the very basic level to the advanced level, depending on the audience; advanced course may also include spreadsheets, etc.

The teaching materials for the courses listed above have been compiled mainly by the LSPA trainers. In the cases of Market Economy and Management, teaching materials have also been prepared by donors providing assistance for the training of top managers (See "Training Formats and Funding" section). These have been translated into the Latvian language.

For training to proceed in accordance with existing policies of civil service reform, the LSPA will have to continue training activities for civil servant candidates as described in the previous sections until the year 2000. However, as already mentioned above, if the Cabinet of Ministers approves the law "On Civil Service," this time frame will change considerably.

6. The Awakening (Atmoda) is the common Latvian expression which characterises popular political activities in Latvia that started as a result of the Perestroika policy in the former USSR. These activities resulted in the re-establishment of the Republic of Latvia over the period 1991-1993. 
Due to the long-term commitment to train all civil service candidates following the curriculum above, and in the face of considerable budget constraints, immediate needs for in-service training, which appeared during 1995, could only partly be met by the School. Despite these difficulties, the School designed two new courses, namely on management consulting and audit and on human resources management, during the period of November 1995 to May 1996 to meet immediate demands. Aware of insufficient national training capacities in these areas, the School has invited international partners from Sweden and Britain to carry out training.

Needs assessment was carried out by the EC-Phare public administration reform Programme in order to facilitate the re-orientation of the LSPA towards the needs of the civil service "market". Based on these assessments, the LSPA has launched a training program on European issues. The training needs analysis was based on interviews with the representatives of civil service institutions responsible for training. Some items from this analysis are summarised in the following paragraphs.

Almost all institutions included in the study (comprising the majority of the ministries and the State Revenue Service) have recognised the need for training in European Union matters. Some of them (such as the Ministries of Welfare and Finance) have anticipated their future activities associated with the implementation of the White Paper. In these cases, the respective institutions tended to express their needs rather specifically.

The following common training needs, covering a wide range of subjects, have been cited:

- EU institutions;

- EU decision-making procedures;

- sources of EU law;

- EU policies;

- EU member states and EU information sources; and

- negotiation skills.

Other common needs include training for managers and human resource officers, daily working methods and language training (English, German and French in descending order of importance). The need for training top managers was particularly acute in general subjects of public administration. Training in management, and the related issue of daily working methods, has been identified by interviewees as a current need of middle management in ministries (at the level of decision preparation).

\section{8. $\quad$ Target Groups}

Chapters I and II of the law "On Civil Service" as well as its transition regulations define the Latvian civil service and provide the order of involvement of the Latvian state and municipal institutions, and define persons employed in these institutions within the system of civil service. Provisions of the law are described in detail in the section "Legal Framework". Detailed analysis of the provisions of the law regarding target groups is given in Annex 4.

The target group for training is a pool of civil servant candidates employed in civil service institutions, who shall be trained for passing the qualification examinations for the status of civil servant. 
Article 3 states that the Cabinet has the right to determine civil service positions to be filled with persons employed on the basis of the labour code 7 . Usually these are so-called "political positions": advisers and assistants to ministers or the prime minister, as well as other people working in close contact with political leadership. They are hired for the term of office of the corresponding superior. Technical and other support staff can also be employed on the basis of the labour code.

The law "On Civil Service" states that civil service positions are those which involve the preparation and/or the taking of decisions. This formulation implies that the civil servant carries considerable responsibility, and hence, should have certain qualifications. This category of position is sometimes referred to as "top management service". However, the attestation has resulted in 11830 civil servant candidates (official data of the SCSA as of March 1996). This number does not correspond to the number of decision-makers and persons carrying responsibility for the preparation of decisions in the civil service. Some positions which should more properly be described as typically "clerical" have entered the system established by the law "On Civil Service". In order to avoid confusion, the Latvian government has recently (March 1996) put forward a concept of a three-level civil service, dividing managerial and decision-making functions from other operations. For details, please see Annex 5.

\section{Development of Training Curricula}

According to the LSPA, the training curriculum was formulated by working groups consisting of potential LSPA trainers and experts. They have designed the present model using corresponding experiences from European countries and United States, adjusting the training programme to Latvian specificities.

After formulation, the training curricula have been adopted by the LSPA. The training curricula have not been changed considerably during the delivery of courses. The LSPA is being assisted by experts of EC-Phare and others in the development of the curricula according to actual needs. This assistance is also associated with on-going bilateral co-operation programmes.

\section{Evaluation}

Although the need to evaluate training programmes is being recognised, no significant effort has been made so far to conduct a substantial ex post evaluation of courses. Again, since the bulk of present training activities in the civil service is initial training, targeted to civil service candidates and therefore not directly demand-driven, there is no obvious necessity for estimation of the rational outcome. Hence, some of the efforts to evaluate courses, described below, carry little information on value-for-money.

The results of evaluation efforts of courses are usually rather positive. Immediately after the courses, participants are given evaluation questionnaires on both course content and methodology. Questionnaires are collected and analysed by the LSPA staff. The LSPA management is hesitant about straight interpretation of these results because participants usually attend such courses for the first time and do not have a reference for comparison. The evaluation of the quality of delivery, contents of the programme,

7. The general labour code is the basis for labour legislation in Latvia and more than 30 articles from the code apply to the civil service as well. The law entitled "On Civil Service" puts additional restrictions on employees; and sometimes they prefer to be employed under the general labour code rather than the law "On Civil Service". In the case of political positions, this preference is due to the multiple-jobs opportunity and wide freedom to act. 
training intensity, quality of the trainers and practical applicability of the courses tends to show very positive results with around 60 to 98 per cent of respondents ticking the highest quality category offered.

The evaluation of the training-the-trainers course run by the EC-Phare public administration reform Programme is similar to the LSPA course evaluations above. In their comments on the questionnaires, potential trainers have indicated that these courses are useful for their further work (80 to 90 per cent). Among the most useful issues, "teaching methodology" was mentioned most frequently.

As mentioned above, training institutions must fulfil the following criteria in order to qualify for the delivery of courses to the civil service:

- they shall follow the common curriculum, adopted by the LSPA;

- they shall employ trainers, certified by the LSPA;

- they shall deliver the courses within appropriate quality standards.

Although the last requirement is somewhat uncertain due to the absence of formal criteria, it has been used by the LSPA along with course evaluation questionnaires. Indeed, representatives from the LSPA are paying visits to training centres during the courses without prior notice to check the actual performance. There are some more informal means for evaluation, such as the collection of informal responses.

\section{Planned Changes and Further Developments in the Training System}

Training issues in the civil service cannot be separated from the development of the legal and regulatory framework of the civil service in general. Currently, new and substantial changes regarding the law "On Civil Service" are under way. For details, please see Annex 5.

Apart from possible new approaches, the LSPA is planning to continue with the existing training approach until the completion of training for all civil servant candidates. Thus, possible future programmes are divided into short- and long-term components: the short term component (1994-January 1997) is in keeping with existing programmes and parallel development of advanced programmes; the long-term component (1996-2000) aims at sustainable development and the delivery of advanced courses according to current and changing needs.

According to the LSPA, it will continue to be Latvia's central civil service training agency. The main focus of the School will be on European integration matters and advanced courses (demand-driven career development programmes) for the civil service's top managements.

\section{Identification of Problems in Training}

One of the problems identified in training is that the allocation of state budget funding does not seem flexible enough to satisfy the actual needs of civil servants and institutions. Centralisation may present somewhat of a problem in this context, as does insufficient attention to newly emerging demands due to budget constraints. More flexibility may also be appropriate with regard to the courses delivered by training institutions. The most needed courses are more likely to be ad hoc, urgent and specific. Such conditions have an impact on the standards of training institutions, regarding their qualification and managerial capability.

The LSPA's current status may correspond too much to a kind of agency for the administration of training. Maybe it should make an effort to develop into a school of public administration. Specifically, it will have 
to continue to develop its own staff to design and carry out training courses and to develop a central training capacity in human resources management in co-operation with the SCSA.

\section{Conclusions}

Civil service reform in Latvia commenced in 1993 with a set of crucial decisions, taken by Parliament (the Seima). The law "On Civil Service" was adopted, a separate article was included in the state budget for the reform and new institutions were established to carry out the reform in accordance with politically determined provisions. These efforts show the political will of the government and the legislature to develop an efficient and professional civil service, capable of handling the challenging and controversial tasks of transition from a producing to a regulating government. Nevertheless, there is still a lack of awareness on the part of some politicians about the tasks of the civil service, in particular its task to guarantee the implementation of policies outlined by the country's political elite, and the fact that a professional civil service is needed to promote sound economic development.

Training in the civil service directly improves the performance of the public sector. Foreign assistance plays the crucial role in this process (See figures in the section on funding). The challenge for Latvian political and administrative leadership is to ensure that the technical assistance resources provided by the international community are used in the most efficient way. Present training activities in the public sector extend far beyond the legal framework of the civil service. Therefore, another challenge for Latvian public administration is to keep up with the development of the public (and private) sector, facilitating the acquisition and application of new skills, methods and knowledge. 


\section{ANNEX 1. LATVIA'S MAIN SOCIAL AND ECONOMIC INDICATORS}

The following basic data, drawn from an official source (Main Statistical Indicators 1995; Latvia and Riga. Latvian Statistics, Riga, 1995. ISBN 9984-9038-4-2) provides a general picture of the country.

Territory: $64600 \mathrm{~km}^{2}$

Population (end of 1994)

$\begin{array}{lr}\text { in Latvia: } & 2530000 \\ \text { in Riga: } & 840000 \\ \text { in Daugavpils: } & 120000 \\ \text { in Liepâja: } & 100000 \\ \text { in Jelgava: } & 71000 \\ \text { in Júrmala: } & 59000 \\ \text { in Ventspils: } & 47000 \\ \text { in Rèzekne: } & 42000\end{array}$

National composition in per cent (at beginning of 1994)

in Latvia: Latvians 54.2; Russians 33.1; others 12.7;

in Riga: Latvians 38.1; Russians 47.4; others 14.5.

\section{Employment (1994)}

Total in the national economy: 1205 000; including:

state enterprises, institutions and organisations: 504000

agricultural enterprises: $\quad 64000$

other enterprises: $\quad 368000$

private enterprises like farms and individual jobs: 269000

retired:

663000 (in Riga, 215 800)

unemployed:

83900 (in Riga, 12 455)

\section{National economy}

GDP (in 1993): 1467 million Ls (around US\$2 716 million).

State budget (in 1994):

revenue 561.3 million Ls (around US\$1 038 million)

expenditure 599.2 million Ls (around US\$1 109 million)

\section{Foreign trade (1994)}

Total exports (FOB; million Ls) 571.1 (around US\$1 057 million);

Structure (in \%): CIS 42.7; EU and EFTA 41.3; others 16;

Main partner countries (million Ls): Russia 156; Germany 58; Great-Britain 54; Sweden 38; Ukraine 33;

Lithuania 31; Belorus 24.

Total imports (FOB; million Ls) 700.1 (around US\$1 296 million);

Structure (in \%): CIS 30.4; EU and EFTA 41.6; others 28;

Main partner countries (million Ls): Russia 164; Germany 94; Finland 59; Sweden 45; Lithuania 41;

Estonia 24; Belorus 21; Ukraine 21. 


\section{ANNEX 2. PROVISIONS OF THE LAW “ON CIVIL SERVICE”"}

Chapter 1, Article 1 defines the scope of operations of this law. It regulates the civil service relations of the state and municipal civil servants and civil servant candidates. Relations which are not regulated by this law shall be regulated by other laws. This law also regulates service relations of civil servants (and civil service candidates) in those civil service institutions, which are subject to special laws, as far as regulations are not provided by these special laws.

This provision is rather important in case of the Ministry of Interior which has a separate legal framework of operations. Practically, the system of this Ministry has a military organisational structure, and which retains some features from the former militia heritage. Introduction of the civil service in this Ministry is problematic due to a substantially different approach to the provisions on retirement, remuneration, promotions and other items. However, the necessity for the introduction of an adequately adapted system of civil service in the Ministry of Interior is clearly recognised by all involved parties. As mentioned above, the terms of the introduction of the civil service system in this case have been extended up to the end of 1996. Problems of this kind also exist with involvement of the municipalities in the civil service system.

Chapter 2 of the law deals with appointments to civil service positions. Thus (as laid out in Article 7), for 12-8 qualification category (the lower) positions open tenders shall be organised; and open or internal (only civil servants or candidates) tenders shall be organised for 7-1 category (the higher) positions. The announcements shall be published in the official newspaper. Persons who apply for the positions of the managers and deputy managers of the civil service institutions (as laid out in Article 8) shall apply to the SCSA. Persons who apply for the corresponding positions in municipal civil service institutions shall apply to the municipality. Other applicants apply directly to the manager of the corresponding civil service institution. All applicants shall submit the following documentation:

- curriculum vitae, information about previous work, documentation certifying education;

- document which certifies the applicant's appropriate state of health;

- statement by the applicant of compliance with the conditions of the Article 6 (See Annex 4);

- certificate on passing the Latvian language test at the highest (3rd) level of proficiency, if the applicant is not a graduate of the Latvian language school.

8. Likums "Par valsts civildienestu"; Law adopted 21 April 1994, published in the Latvian newspaper Latvijas vestnesis (Latvian Courier) No. 52 of 1994, and No. 82 of 1995 (amendments). 
The SCSA shall set the date of attestation (Article 9) for the candidate no later than two months after the registration and verification of all necessary documentation. If the candidate passes the attestation, the SCSA shall issue the certificate of the civil servant candidate (Article 10) which is valid for 6 months. This certificate gives rights to the candidate to apply for the position in the civil service. The candidate is appointed to the civil service position by the manager of the corresponding civil service institution (Article 11). In the resolution on appointment to the position (Article 12) the following significant points shall be indicated:

- name of the state civil service institution, date;

- position title;

- qualification category set by the SCSA and the monthly salary;

- terms of appointment (fixed time, or not-fixed time).

The position description shall be included in the above resolution as the annex.

The regulations "On Position Descriptions in the Civil Service" of the Cabinet were endorsed on 17 January 1995 and supplemented with the SCSA methodology on elaboration of the position descriptions. Position descriptions are being introduced in civil service institutions, and methodology is being improved in the process of practical applications and parallel development of related issues of position evaluation and qualification categories.

Article 13 provides the preferences for holding civil service positions. Preferences are given to those civil servants who:

- have been deployed from the civil service under circumstances which are beyond their control (See conditions under Article 48); or those who shall retain their positions after the expiry of the mandate of the elected representative (See conditions under Article 49);

- have desirable characteristics, such as a good service record, knowledge of at least two foreign languages, computer skills, special administrative education, or a Ph.D. degree in the relevant area of science, awarded or recognised in Latvia.

The second part of Article 15 (See section on "Legal Framework" beginning with the phrase "All requirements....") provides that all conditions of the law shall apply equally to civil servants and civil servant candidates (including allowances and benefits mentioned in Article 32 on accommodation, Article 34 in the case of birth of a child and child-care, and Article 50 in the case of injury or death), except remuneration and certain other allowances and benefits (See Article 31).

Chapter 3 of the law "On Civil Service" is devoted to the responsibilities and restrictions for civil servants. 
The following are some of the other significant restrictions disallowing certain activities:

- (Article 23) to participate in entrepreneurial activities, except cases when he or she is authorised to represent state's interests in the management and revision structures of enterprises;

- (Article 24) to perform other jobs without the permission of the manager of the civil service institution; the time limit for such jobs shall not exceed two-fifths of the regular working hours in the civil service (40 hours/week);

- (Article 25) to serve as a lay-judge in courts; act as a third party in cases, where the other party is the civil service institution, where he or she is employed;

- (Article 26) to take on elected positions in political organisations;

- (Article 27) to strike;

- (Article 28) to express the official position of the civil service institution to the mass media without the authorisation of the manager of the civil service institution.

Chapter 4 of the law "On Civil Service" is devoted to the rights, compensations and guarantees of civil servants. The following provision of the law is one of the basic stimuli for the civil servant candidates to obtain the status of civil servants.

Article 31. Remuneration. The monthly salary and tenure steps of a civil servant shall be set by the Cabinet in accordance with the qualification category range envisioned for civil service positions.

A civil servant candidate shall receive 80 per cent of the monthly salary of the civil servant's salary; and 40 per cent of all allowances and benefits provided for civil servants by this law.

Provisions of Chapter 4 are important for understanding the actual and potential motivation for civil servants. Some of the provisions are directly linked with training and education, and therefore it is worth describing this Chapter in some detail. The following are some of significant rights:

- (Article 30) to a permanent civil service, independently of the changes in the political and/or administrative leadership; the order of deployment (Article 48) in the cases of staff reductions and liquidation of the civil service institutions shall be set by the SCSA, retaining the former monthly salary for a period up to three months;

- (Articles 32-41) to get residence, vacation, transfer and special (in the case of accidents, death of members of the family, birth of the child, child-care) benefits, family allowance, yearly and other bonuses and rewards;

- (Article 37) to receive an allowance amounting to $\mathbf{1 0}$ per cent of his or her monthly salary for proficiency in the third and every additional foreign language, if the necessity for that particular language knowledge, and required level of language proficiency is certified by a certificate issued by the SCSA;

- (Article 40) to perform successfully in studies in the education establishment, which are necessary for the execution of the duties in the civil service; to receive compensation covering half of the 
annual tuition fee; and (Article 43) to have study leave of $\mathbf{2 0}$ days for taking the final examination, while retaining monthly salary;

- (Article 42) to have annual leave (four weeks), while retaining monthly salary;

- (Article 44) to have unpaid leave up to two months upon authorisation from the manager of the civil service institution. The unpaid leave up to two months shall be allocated for the civil servant in the case of his or her nomination as a candidate for the parliament or municipal elections. In the case of a civil servant being elected (Article 49), the SCSA guarantees him or her the same or equivalent position after one term of his or her mandate of an elected representative;

- (Article 45) to undergo medical examination and to have medical care, and mandatory social insurance, according to the special law(s) and regulations of the Cabinet;

- (Article 46) to have a pension in accordance with the law on state pensions;

- (Article 47) to apply for a vacant civil service position which corresponds to his or her qualification category, after being out of civil service up to threes years. If the period of leave is from $\mathbf{3}$ to $\mathbf{5}$ years, he or she shall pass the qualification examination in the LSPA.

Some of these rights have been referred to as potential, as they are not implemented in practice. Their implementation often is associated with development of the new procedures (e.g. Article 37) according to priorities and significant financial resources and organisational undertakings (e.g. Article 45). In some cases guarantees are defined uncertainly (e.g. Articles 30, 48). The quality of the law and regulatory system of the civil service is being permanently improved by the initiative of the SCSA on the basis of the work experience.

Chapter 5 of the law deals with the order of service within the civil service. Among other provisions there are some articles which deal with qualification categories and promotions. These issues should be connected with the training and qualification raising issues. However, the concept of qualification categories is not yet elaborated and, therefore, existing provisions do link promotion with qualification raising explicitly, but the meaning (definition) of the qualification category is still unclear.

Thus, Article 52 states that all civil service positions are divided into 12 qualification categories; and the civil servant can receive 15 tenure ranks (one step in two years). Article 57 provides that the civil servant can be promoted to a position requiring the higher qualification category only after passing the qualification examination and receiving the corresponding qualification category. Therefore, one might suggest that the qualification category is a quality of the person, rather than of the position. The methodology of determination of qualification categories will be one of main concerns of the SCSA during 1996.

Data about the civil servants, including training courses attended and education, shall be collected in individual service records (Article 63). 


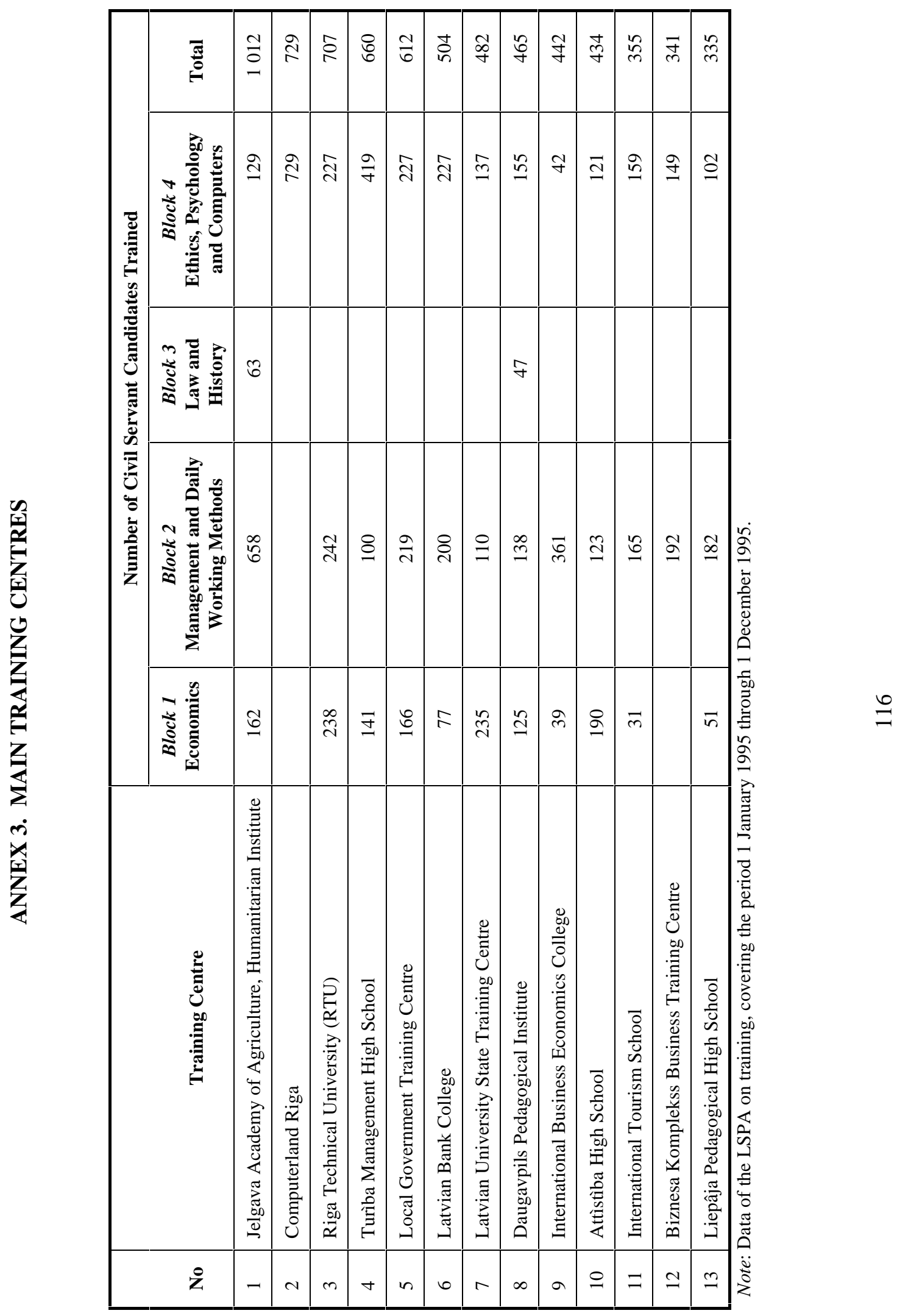




\section{ANNEX 4. PROVISIONS OF THE LAW “ON CIVIL SERVICE” REGARDING TARGET GROUPS FOR TRAINING AND COMPOSITION OF LATVIAN CIVIL SERVICE ${ }^{9}$}

According to Article 1, the following civil service institutions exist in Latvia: State Chancellery, all state and municipal institutions, courts, prosecutor's and state audit offices, as well as all other institutions established by the Constitution (Satversme), the law, the resolutions of the Cabinet or municipalities; which execute state or municipal functions.

According to Article 2 the civil servant is a person who has passed the qualification examination for the status of the civil servant, and has been appointed to the civil service position. The civil servant candidate is a person who has passed the attestation, and has been appointed to the civil service position until passing the qualification examination for the status of the civil servant.

Article 3. Civil service positions are the following:

1. manager of a civil service institution;

2. deputy manager of a civil service institution;

3. a line manager to whom other civil servants are subordinated;

4. positions which in accordance with the laws, regulations of the Cabinet or resolutions of the self-governments have to prepare or make decisions, which are mandatory for a definite number of persons.

This article also defines the positions which are not civil service positions: President of the State, Members of the Saeima, Ministers, Parliamentary Secretaries, members of the elected municipal councils, Chairman of the Supreme Court, his deputies, judges, Prosecutor General, his deputies and other prosecutors, State Auditor General, members of the State Audit Council and members of Revision Councils.

9. Likums "Par valsts civildienestu"; Law adopted 21 April 1994, published in the Latvian newspaper Latvijas vestnesis (Latvian Courier) No. 52 of 1994, and No. 82 of 1995 (amendments). 
Article 6 provides mandatory requirements for candidates for civil service positions (having the status of the civil servant or civil servant candidate as a prerequisite). They are the following:

- citizenship of the Republic of Latvia;

- at least general secondary school education;

- knowledge of the Latvian language and at least one foreign language;

- at least 18 years old and under the legal retirement age (60 years for men and 55 years for women, and particular exemptions are allowed);

- no criminal record, except exonerated persons;

- not incapacitated;

- not having or not having had relations with foreign security or intelligence agencies, nor with these agencies of the former USSR;

- not members, or have not been members of the organisations banned in Latvia;

- not otherwise restricted by the laws from holding the positions of the civil servants.

Transition Regulations of the law provide that the attestation shall be carried out by the attestation commissions (bodies which take actual decisions about candidates) in accordance with the procedures set by the Cabinet. The SCSA has the duties of the organiser and co-ordinator of the process; and it deals with corresponding records and issues the certificates. Practically, the SCSA identifies the civil service institutions which have to enter the reform in accordance with the current schedule of attestation, provided by the Transition Regulations:

- 2nd round (until 31 December 1995): Naturalisation Office and State Land Service;

- 2nd round (until 1 April 1996): Department of Citizenship and Immigration of the Ministry of Interior;

- 2nd round (until 31 December 1996): central staff of the Ministry of Interior;

- 3rd round (until 31 December 1996): state and municipal institutions supervised and subordinated to the Ministry of Interior. 
The following are the official data of the SCSA about the number and distribution of civil servant candidates in the civil service institutions (as of May 1995).

\begin{tabular}{|c|c|}
\hline Ministry & $\begin{array}{c}\text { Number of Civil Servant } \\
\text { Candidates }\end{array}$ \\
\hline $\begin{array}{l}\text { Defence: } \\
\quad \text { including State Service offices }\end{array}$ & $\begin{array}{l}349 \\
248\end{array}$ \\
\hline $\begin{array}{l}\text { Foreign Affairs: } \\
\quad \text { including central staff } \\
\quad \text { including Embassies, Consulates }\end{array}$ & $\begin{array}{r}260 \\
163 \\
97\end{array}$ \\
\hline $\begin{array}{l}\text { Economy: } \\
\text { including system of Statistics Committee }\end{array}$ & $\begin{array}{l}522 \\
373\end{array}$ \\
\hline $\begin{array}{l}\text { Finance: } \\
\quad \text { including State Revenue Service }\end{array}$ & $\begin{array}{l}3211 \\
2841\end{array}$ \\
\hline Interior & 10 \\
\hline Education and Science & 254 \\
\hline Culture & 120 \\
\hline $\begin{array}{l}\text { Welfare: } \\
\quad \text { including State Social Insurance Foundation }\end{array}$ & $\begin{array}{r}1163 \\
768\end{array}$ \\
\hline Transport & 246 \\
\hline $\begin{array}{l}\text { Justice: } \\
\quad \text { including Archives } \\
\text { including State Land Service }\end{array}$ & $\begin{array}{l}603 \\
229 \\
218\end{array}$ \\
\hline State Reforms (dissolved July 1995) & 88 \\
\hline $\begin{array}{l}\text { Environment Protection and Regional Development: } \\
\text { including regional committees }\end{array}$ & $\begin{array}{l}405 \\
219\end{array}$ \\
\hline Agriculture & 1128 \\
\hline $\begin{array}{l}\text { Other institutions: } \\
\text { Prosecutory } \\
\text { State Chancellery } \\
\text { State Audit Office }\end{array}$ & $\begin{array}{r}1 \\
112 \\
88\end{array}$ \\
\hline Total: & 8549 \\
\hline
\end{tabular}




\section{ANNEX 5. CONCEPT ON INTRODUCTION OF THE CATEGORY OF PUBLIC SERVANTS INTO THE LATVIAN CIVIL SERVICE}

This concept was adopted by Latvian government in March 1996; and since it is associated with substantial changes in the law "On Civil Service", corresponding amendments to the legislation should be prepared up to May 1996.

The pre-amble of this concept points out two main reasons that have lead to the proposed approach: 1) many persons holding technical or clerical positions have entered the civil service, 2) lack of resources for training of top management civil service.

The following provisions of the law "On Civil Service" would have to be changed or added:

- Point 4 of Article 3 (See Annex 4): “...positions which in accordance with the laws, regulations of the Cabinet or resolutions of the self-governments have to make decisions of importance in the state level, which are mandatory for a definite number of persons. The rest of the positions are public service positions";

- Persons having at least five years of exposure in the state civil service can be appointed in the civil service positions; civil servants have to pass the qualification examination; and they will have all restrictions and social benefits provided by the law "On Civil Service";

- Persons possessing the necessary characteristics (Article 6, See Annex 4), and having passed the attestation, can be appointed to public service positions; public servants will have all social benefits and part of the restrictions provided by the law "On Civil Service";

- Civil servants shall have the "highest education" (university or advanced vocational) and special knowledge in state governance in accordance with the curriculum of the LSPA;

- State civil service (civil and public servants) will be divided into three levels: A - civil servants; B public servants in the central government institutions; C - public servants in municipalities.

According to the existing draft concept the total number of civil service positions will be 3308 . This estimate is calculated from current total of 11830 civil servant candidates, holding positions in the civil service, as of March 1996. 


\section{TRAINING PROFILE}

\section{LITHUANIA}

(As of April 1996) 


\section{Introduction}

The democratic Republic of Lithuania was re-established on 11 March 1990, by the Act on Re-establishment of Independence. The Fundamental law (Constitution was adopted by referendum on 25 October 1992. It defines the main principles and functions of the country's economic and political system, as well as the main institutions of state power which is exercised by the Seimas (Parliament), the President of the Republic, the Government and the Courts.

Lithuania is the largest of the three Baltic countries, twice the size of Belgium and slightly smaller than Ireland:

- territory: $65200 \mathrm{~km}^{2}$;

- population (1994): 3738800 (similar to Ireland, Albania, Norway or New Zealand);

- composition of the population: 80\% Lithuanian, 13\% Polish, 7\% other, Vilnius the Capital, 584400 (1994).

\section{The Public Administration Training System Before Transition}

Lithuania was a dependent part of the Soviet Union between 1940 and 1990. Prior to its declaration of independence from Moscow and its subsequent international recognition in 1991, training in the administration was conducted in the Soviet style. Individuals were trained to take instructions from Communist Party committees. Under this centralised system, Kremlin authorities took responsibility for all major decisions; the country had little need for public administration structures geared towards developing and implementing its own policies. Administrators within sectional departments were responsible for implementing instructions from the centre. Individual initiative on the part of civil servants had to fit in with the general party line.

The concept of a public service serving the specific needs of the country was left largely under-developed. However, the Soviet regime was very much concerned that the main executors of Moscow commands be sufficiently educated and correctly trained and training was designed to teach individuals what, when and how to implement Party decisions. There were few theoretical arguments about how things were done. Training was ideological and politically oriented, dispensed in lectures and allowing very little for dialogue, interactive participation or hands-on application.

Starting in 1945, there were three levels of civil service training institutions in Soviet Lithuania: regional (till 1948), republic and union (USSR). Regional training was formally organised by the government of Soviet Lithuania although in practice it was directed by the Lithuanian Communist Party regional committees. Training of civil servants at the level of the republic was officially organised by the Lithuanian Communist Party's central committee. The High Party School was created in Vilnius for civil servants with secondary school education; for civil servants with less education went to the Soviet-party workers' school. All training for top and mid-level management in the ministries and state departments was conducted, until 1987, by the Soviet Union Communist Party Central Committee in Moscow. The whole Soviet Union was divided into zones and Lithuania was part of the north-west zone where the main Communist Party training institution was the Leningrad High Party School. Bi-annual training (for a period up to two months) was obligatory for all deputy ministers, department chiefs of ministries, state departments and agencies, as well as for the top managers from cities and regional public administrations. Ministers and their reserve were trained at the Moscow High Party School and the higher ranked Academy of Social Sciences at the Central Committee of Communist Party of the Soviet Union". Some of the high 
ranking ministerial staff and managers of the largest state plants and enterprises were trained at the Academy of National Economy of USSR.

Most of the training for Lithuania's mid-level managers was conducted at the Soviet Workers' Development Courses at the Council of Ministers of Soviet Lithuania. After 1973, various institutional training centres and institutes at particular ministries started to work. At the same time, on Moscow's order, the courses were closed and the Lithuanian Government established the Transbranch National Economy Managers and Specialists Development Institute instead. Some time later, the institute changed its name to National Economy Specialists Development Institute and after 1990 it became the Academy of Lithuania. Similar institutes were set up in all Soviet Republics. The academy taught courses primarily in general management, economy and legislation. There were six faculties and 18 departments by the end of its existence. The academy had about 100 full time trainers including 6 professors, and more than 20 associate professors. About 1000 lecturers collaborated on a contractual basis. Judges, arbitrators and other lawyers were considered civil servants at the time so this institution provided training for them as well.

Closely related to the academy were the Teachers Training Institute, the Culture Workers Training Institute and the Agriculture Workers Training Institute. Their curricula had to be approved by a special department of the Ministry of High and Middle-Special Education of the Soviet Union and in the central committee of the Communist Party. Only after 1989 and during Perestroika did Moscow stop its intervention in the civil service training process.

\section{Objectives of Training}

With independence, Lithuania once again needed the structures and methods appropriate for all levels of effective government in an independent, democratic and market-oriented country. A new relationship had to be found between Parliament and the government, and between the government and its executive functionaries. An efficient and clear division of responsibilities for formulating and implementing the policies of an independent country was also needed.

Lithuania has embarked upon a difficult programme of economic and social reform. The privatisation process has been largely completed. Inflation has decreased enormously and the collection of company taxes has steadily improved during the last year. Reorganisation also included the structural reform of local and regional governments (a reform of territorial division), equalisation between the municipalities (savivaldybës) and regions (apskritys) and reforms of budgeting and accounting procedures.

The transition process itself, including the modernisation of the public administration, is changing the vision of the state. One of the greatest challenges for the government of Lithuania is to promote the development of an efficient and cost-effective government machinery appropriate to its multiparty democracy and market economy through gradual reforms of the institutional structures, of working procedures, and of personnel policies in both central and local governments.

Naturally, there are some obstacles and risks for the public administration reform process. Lack of administrative continuity (changing senior civil servants according to political trends, changes of ministers or parliamentary or city council majority, etc.) is one of the main problems facing the public administration. To some extent, this creates a situation in which reforms cannot continue beyond the next elections to the central or local governing bodies (the Seimas, municipal councils) for want of budget. The 
Law on Officials was an attempt to protect professional civil servants from such political changes of winds.

The central governing institutions are working hard on preparing the implementation of the EU regulations according to the demands of the White Paper of June 1995. Some problems arise because government structures have remained largely unchanged since independence. There has been little reassessment of how to improve communication among ministries, between ministries and their staff, and between ministries, the public, and the Seimas. The need to organise the implementation of all functions of an independent state such as national defence or foreign relations, for example, has led state administration institutions to grow.

Today almost all political forces agree that the growth of state governing bodies must be contained. In 1991, for example, there were 16 ministries, by 1996 this number had risen to 19. It is important to emphasise the distinction between the state and local government entities. A state parliament still seeks to establish a regional level of self government. Having so many national state governing institutions reflects, to some extent, the problem of the division of functions among ministries and the need to improve the quality of their service. Almost all political forces in the country have put forward proposals for restructuring the ministries in terms of both the number and division of responsibilities. But the weakness of most of these proposals is that they are often not based on serious objective studies on the efficiency of current institutions or on evaluations of the social and economic consequences of change. Some practical steps were taken not long ago and. several state institutions were reformed. For example, the Ministry of Foreign Economic Relations has been abolished and its responsibilities transferred to the Ministries of Foreign Affairs and Finance. Several new institutions including the Ministry of Public Administration Reforms and Local Authorities (PARLA) were established.

The permanent structural reforms of governmental institutions and the continuous transfer of functions among them makes it more difficult to organise training for officials, and especially for assessing and planning training needs and activities. A more exact and stable division of ministerial functions and roles should make it easier to improve co-ordination in the public administration reform processes.

As strange as it may sound, there has been a long debate about how many civil servants there actually are in Lithuania. Different interpretations of civil servant lead to differing figures depending on the source of information. For example, the Lithuanian daily Lietuvos Aidas (29 November 1995) reported that trade unions counted about 300000 civil servants. The Union of Liberals political party estimated that 23000 persons are involved in government. The PARLA argues that approximately 13400 employees are working in state administrative institutions and about 7700 more work in local government institutions. All are considered part of public administration. These figures above do not include the staffs of state-owned or partly state-owned industries, nor do they include the military, police personnel and teachers. In November 1995, the state statistics department calculated that 16700 employees work in ministries and municipalities. In January 1996, this figure was revised to 16000 . Concerning the educational background of the above mentioned officials, the state statistics department claim that 77 per cent have graduated from university or high school (university degree or diploma), 9 per cent have graduated from higher special schools (non-university degree or diploma).

In order to put an end to this discussion, the government of Lithuania issued a decree obliging PARLA to establish a special data bank on civil servants. The collection of all necessary data about civil servants, including their qualifications, should be finished at the end of 1996.

The need for reorienting public servants to serve the people and to work under democratic control in the independent state with its own domestic and foreign policy - determined objectives for training civil 
servants. Of course many new employees need to become involved in public service activities because new institutions are being established. The frequent public service personnel changes and the lack of professionalism are the most visible reasons for civil service training institutions to be active. But modernising the behaviour and mentality of the Lithuanian civil service remains an imperative.

\section{Legal Framework}

Article 5 of the Constitution of Lithuania obliges all state governing institutions to serve the people and declares the right of the people to control the work of their servants. The most important and general rules and regulations for civil servants are dispersed in labour law and the civil, administrative and criminal codes.

There is no officially approved general definition of an appropriate civil service. Only recently, PARLA organised the drafting of such a document. The first version was presented to local experts for evaluation at the end of autumn 1995. The discussion of public administration development should now be broadened to allow for a cross evaluation by different interested groups in order to build a broad consensus in the near future.

\section{STATE INSTITUTIONS RESPONSIBLE FOR CIVIL SERVICE POLICY}

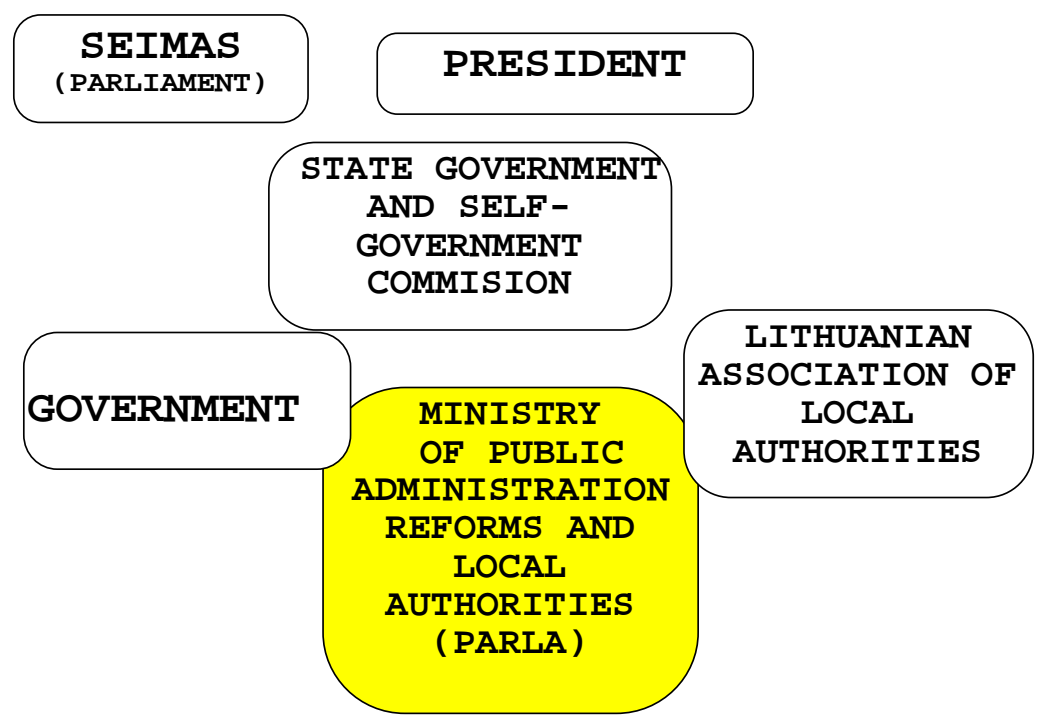

In the absence of a comprehensive concept, the civil service is partly regulated by the Law on Officials. This law contains some regulations on traditional civil service subjects such as conflict of interests, right of contradiction etc. The law is comparatively short - only 30 articles. Most of these are addressed to special governmental decrees like the government decree on basic qualification requirements for B category professional officials.

The Law on Officials partly clarifies the distinction between the terms civil servant or public servant; state and municipal official; state and local politician. It is agreed that all employees receiving their salaries from a state or municipal budget, and who are in effect paid by the taxpayer, are civil servants. Some of these; including the workers of governing bodies at both central and local levels, are considered state or local officials. All employees of state institutions elected by citizens, and members of the government, are considered politicians. 
The Lithuanian Law on Officials refers only to the rather narrow but most influential part of the civil service - decision makers in Parliament, the President, government chancelleries, ministries and their subordinate agencies, central state departments and staff of the local self government institutions. The remainder of the civil service is regulated by special laws such as the Law on Police, Law on Education, Law on Ombudsmen, etc. Almost all of these laws include particular articles about in-service training.

The President, Parliament and the government had agreed that the development of the civil service legal system should proceed step by step. As it is obviously impossible to cover all civil service problems in a single law, special laws could be issued to cover separate civil servants' categories, which would resolve the issue partially. For the future, a plan exists to merge these separate laws into a single Code of Civil Service. Since it is the most general of the existing laws, the Law on Officials could become the basis for this code.

The Law on Officials states that recruitment to the Lithuanian civil service will be based on competitive examinations. Article 14 of the law, requiring civil servants to "ensure job quality" and to "upgrade qualifications," obliges public officials to attend training. Article 15 of the same law specifies that public officials have the right to receive advanced professional training in accordance with the qualifications requirement, paid for by the institution, while retaining basic salary during 15 to 30 days within a two year period. The same article also envisages the possibility of attending training programmes abroad. However, special conditions must be met. It would appear, therefore, that training must become obligatory for at least part of the civil service.

The implementation of the Law on Officials has had a good start. The PARLA has drafted and the government has approved a large body of supplementary documents to enforce this law. The most important of these include regulations on public appointments (applications, competition, basic qualifications), on officials' rights (dismissal, appeal) and on job descriptions. An integrated archive and database on civil servants (register) are in their first stage of development. The Law on Remuneration of Civil Servants has already been presented to Seimas for formal approval.

The Law on Officials still needs a number of directives on implementation, especially concerning promotion and performance evaluation, rights, duties and responsibilities of civil servants. A working group at PARLA is drafting a general personnel training policy.

\section{4. $\quad$ Funding}

No centralised state fund exists for training civil servants. Each ministry, department or municipality must find the money for training their staff in their institution's budget. There are no rules or traditions (except in the Ministries of Education and Science, Defence, Interior and Finance) on how much money to allocate for staff training. In 1993, the government recommended that all state and municipal institutions allocate a training budget amounting to 3 per cent of the salary budget of the institution. So far, the financial resources for training are neither stable nor certain. The PARLA draft decree is still not approved by government. The ministries responsible for teachers, police officers, fire-fighters, customs officials and medical staff are providing more funds for in-service training than others.

Some state officials and clients of training institutions have not yet understood that training is not free of charge. The money issue may explain the relatively low awareness of the need for training civil servants in some ministries. 
From a funding perspective, civil service training institutions can be classified as either partly or completely self-financed institutions or mostly or entirely state financed. Self-financed institutions usually charge the trainees' institutions or the trainees themselves for training. Training institutions financed from the budget provide training free of charge. The training organiser therefore covers all expenses.

If institutional training centres are not joint venture or non-profit organisations, they are rather restricted by special government decrees targeting state budget financed institutions. The difficulty is that they cannot independently determine the remuneration levels of their trainers. This is an obstacle in competing for high quality trainers in the labour market. Self-financing institutions are much more flexible and independent in their methods of selecting and employing trainers.

Some trainers in self-financing training institutions have long-term contracts (mostly for repeat courses). In this case, they are better paid than others. For example, the best trainers of the Public Administration Training Centre (PATC) are in great demand by private institutions, universities and training centres. Depending on their qualifications and the market situation of training services, PATC trainers will earn from 20 to 40 Litas (taxes included) per hour of training (4 Litas = US\$1). Compared to universities, where the trainers are usually paid between 8 to 15 Litas per hour of instruction, this is high. But compared to private consultant firms, where trainers are paid between 50 to 200 Litas per hour, lecturing to civil servants no longer appears as attractive as training business employees. Hence, even non-profit making training institutions need financial support from the state. A good example is the state support for PATC activities.

\section{Parliamentary Allocations to PATC Activities for Fiscal Year}

1993

1994

102000 Litas
1995

130000 Litas
1996

148000 Litas

In 1995, PATC had an annual budget of 270000 Litas. In order to cover all their expenses, non-profit or joint-stock company (JSC) training institutions charge for their products and services. Course fees can range from 50 to 120 for one-day courses, and from 120 to 300 Litas for two to five-day courses. Course fees are determined mainly on the basis of how expensive the trainer is, whether or not the course is modified, and on the ability of the participant's organisation to pay the fees.

\section{Training Institutions and Legal Status}

A debate about the need for a civil service training system began in mid-1992. In December 1993, this subject was discussed at a conference held by the Public Administration Training Centre. Government officials and academics had a first opportunity in independent Lithuania to discuss matters of civil service training and training institutions development. The June 1994 conference hosted by the US-Baltic Foundation provided the next opportunity followed, in February 1995, by a third national conference. This conference was hosted by EC-Phare to review the projects it had supported.

In December 1995, PATC designed a questionnaire, subsequently circulated among the state administrative institutions, designed to obtain additional information on training organisations and institutions that consider themselves civil servants training institutions. PATC have received the feedback from almost all of those contacted. Unfortunately, most had no interest in disclosing complete information about their financial resources and training capacities. The institutions, the principal players in the civil service training field, are listed below (see Table). 
Several types of institutions offer training for civil servants: private consultant firms, state-owned institutions and autonomous institutions (non-profit, JSC or having academic autonomy). Vilnius and Klaipeda Universities, Vilnius and Kaunas Universities of Technology, Kaunas Vytautas Magnum University all have departments or divisions specialised in training in management and public administration for their students as well as for active civil servants. A Master programme in public administration has been established at Kaunas University of Technology. The Vilnius Institute of Foreign Relations at Vilnius University is expanding its regular public administration study programme. Some training for municipal staff is being offered by the foundation Self-government and Democracy, in Vilnius, and by the Centre of Self-Government Studies in Kaunas. Foreign donor institutions and programmes like Phare, SIGMA, UNDP and others occasionally organise training events for Lithuanian civil servants. Most local civil service training institutions are comparatively new.

Parallel to the Public Administration Training Centre (PATC), the Lithuanian administration witnessed the creation of a multitude of ministerial training centres, whose functions are directly related to the operations of the ministries to which they are attached. Almost all ministries have their own specific training centres and some even have a system of training centres. For example, the Ministry of Finance has established a centre for the training of its fiscal personnel (see Table below) which also provides training in personnel related issues and in overall management principles. At the same time, the Ministry of Social Security and Labour has established a training centre to provide in-service training for managing social work and training its 3000 social workers. It also provides training on such issues as general management, human resources principles and practices, etc.

All the ministerial (institutional) training centres offer management and human resources management training programmes in addition to those offered by the PATC. Hence, with some overlap between ministerial training institutions and divisions which offer training like that of PATS, the training services market appears oversupplied. In practice, however, civil servants lack in-service training possibilities. Problems with co-ordination and information between among ministries and between them and other state institutions are the principle cause of duplicate training efforts and the gaps in training content.

Some informal co-ordination on personnel policy issues is taking place among the heads of the personnel departments or divisions within the ministries and subordinate institutions. This "club" held regular meetings at the Public Administration Training Centre and discussed personnel management and staff training. Those meetings provided the opportunity for representatives from PARLA and PATC to have feedback on their activities and solutions. With the creation of a civil service division within the PARLA, this institution increasingly supervises the co-ordination of civil service training activities.

There is at present no formally adopted national structure of institutions for training the civil service. In 1992-95, a great variety of training centres existed within public administration. The most complex training situation is found in the ministries. Most ministerial training institutions are specialised and serve only their founders' needs. They are financially dependent on the ministry to which they belong, but in staffing and curriculum they are more or less autonomous. The Police and Military Academies also function as research centres and consultants for their ministries. The Ministry of Education and Science usually plays the formal role of one of the founders of academies, because the graduates of such institutions receive university degrees. So this ministry supervises students' enrolment and awarding diplomas. All institutional training centres are subject to public law and their financial activities are strictly regulated by different laws. Staff salaries vary only slightly from one institution to the next. Trainers in the Police or the Military Academy have some privileges (in the sense of salaries and other social security conditions) in comparison with the other training institutions. 


\section{Ministerial Training Institutions}

The Ministry of Interior has a separate system of training institutions specialised exclusively in training police officers. The personnel unit of the ministry works very closely with the management of those institutions.

\begin{tabular}{|l|l|l|c|c|}
\hline $\begin{array}{c}\text { Name of Training } \\
\text { Institution }\end{array}$ & $\begin{array}{c}\text { Ministry to Which } \\
\text { it Belongs }\end{array}$ & Staff & $\begin{array}{c}\text { Number of } \\
\text { Trainees Per Year }\end{array}$ & Financing \\
\hline $\begin{array}{l}\text { Police Academy of } \\
\text { Lithuania }\end{array}$ & $\begin{array}{c}\text { Education and } \\
\text { Science, Interior }\end{array}$ & $\begin{array}{c}380 \text { full-time } \\
50 \text { part-time } \\
34 \text { contractual }\end{array}$ & no information & $\begin{array}{c}100 \% \text { state } \\
\text { budget }\end{array}$ \\
\hline Kaunas police school & Interior & 52 full-time & $\begin{array}{c}290 \text { short and } \\
\text { long-term courses }\end{array}$ & $\begin{array}{c}100 \% \text { state } \\
\text { budget }\end{array}$ \\
\hline $\begin{array}{l}\text { Klaipëda police } \\
\text { school }\end{array}$ & Interior & 28 full-time & $\begin{array}{c}226 \text { short and } \\
\text { long-term courses }\end{array}$ & $\begin{array}{c}100 \% \text { state } \\
\text { budget }\end{array}$ \\
\hline Vilnius police school & Interior & 55 full-time & $\begin{array}{c}557 \text { short and } \\
\text { long-term courses }\end{array}$ & $\begin{array}{c}100 \% \text { state } \\
\text { budget }\end{array}$ \\
\hline
\end{tabular}

The Ministry of Education and Science also has its own system of training institutions. Furthermore, together with the American Professional Partnership for Lithuanian Education and the Canadian Baltic Educator Partnership Project, this ministry is organising the broad training of teachers and managers of educational institutions in the municipalities. As in other institutional training centres, the founder is appointing a director and adopting statutes. The recruitment of the rest of the staff is the responsibility of the director. This ministry does not normally intervene in defining the curriculum. At the end of each fiscal year, the qualifications division at the ministry announces a call for tender for the best teacher training project, or contracts a particular institution to conduct a very specialised course. Most Lithuanian teachers are trained in the Lithuanian In-Service Teacher Training Institute which, in 1995, had 108 full-time and 46 part-time employees and organised 12766 lectures. The institute is financed from a state budget. Educators can also get training at the following:

- Vilnius Pedagogical University qualification development centre;

- Diauliai Pedagogical Institute qualification development centre;

- Klaipeda University Pedagogical faculty qualification development centre;

- Kaunas University of Technology Diauliai faculty professional development centre;

- Kaunas Vytautas Magnum University Pedagogical Centre;

- Centre for Continuing Education at Vilnius Technical University;

- Marijampole District teacher education centre;

- Ukmergë regional teacher education centre;

- Kedainiai teachers education centre

- Kaunas City teacher culture and education centre.

- Jurbarkas City teacher education centre;

- Kaunas regional education centre;

- Panevezys teacher education centre;

- Anyksciai City A.Vienuolis secondary school teacher education centre;

- Lithuanian distance education centre;

- Music education centre; 
- Lithuanian Language Training Centre.

\section{Specialised Ministerial Divisions}

In some ministries, specialised staff training is conducted by special departments or divisions:

\begin{tabular}{|c|c|c|c|c|}
\hline $\begin{array}{l}\text { State Construction } \\
\text { Inspectorate }\end{array}$ & $\begin{array}{l}\text { Construction and } \\
\text { Urban Development }\end{array}$ & 9 full-time & 185 seminars & $\begin{array}{c}100 \% \text { state } \\
\text { budget }\end{array}$ \\
\hline Economic Department & $\begin{array}{l}\text { Construction and } \\
\text { Urban Development }\end{array}$ & 11 full-time & $\begin{array}{l}\text { no information } \\
\text { lectures }\end{array}$ & $\begin{array}{c}100 \% \text { state } \\
\text { budget }\end{array}$ \\
\hline Housing Department & $\begin{array}{l}\text { Construction and } \\
\text { Urban Development }\end{array}$ & 11 full-time & 9 workshops & state budget \\
\hline $\begin{array}{l}\text { Consultative Information } \\
\text { and Research Centre on } \\
\text { Energy Conservation }\end{array}$ & Energetic & $\begin{array}{l}4 \text { full-time, } \\
4 \text { part-time }\end{array}$ & no information & $\begin{array}{l}\text { partly state } \\
\text { budget }\end{array}$ \\
\hline $\begin{array}{l}\text { Health Care Reform } \\
\text { Management Bureau }\end{array}$ & Health Care & $\begin{array}{l}12 \text { full-time, } 5 \\
\text { contractual }\end{array}$ & $\begin{array}{l}\text { no information } \\
\text { seminars, lectures, } \\
\text { conferences }\end{array}$ & $\begin{array}{l}\text { foreign aid } \\
\text { state budget }\end{array}$ \\
\hline Personnel Unit & $\begin{array}{l}\text { Environmental } \\
\text { Protection }\end{array}$ & 3 full-time & $\begin{array}{l}\text { no information } \\
\text { consultations }\end{array}$ & $\begin{array}{c}100 \% \text { state } \\
\text { budget }\end{array}$ \\
\hline Personnel Division & Foreign Affairs & 3 full-time & $\begin{array}{l}\text { no information } \\
\text { consultations }\end{array}$ & $\begin{array}{c}100 \% \text { state } \\
\text { budget }\end{array}$ \\
\hline
\end{tabular}

Some ministries have special training centres for particular target groups:

\begin{tabular}{|l|l|l|l|l|}
\hline $\begin{array}{l}\text { Lithuania Airlines } \\
\text { Training Centre }\end{array}$ & $\begin{array}{l}\text { Transport, } \\
\text { Department of civil } \\
\text { aviation }\end{array}$ & $\begin{array}{l}14 \text { full-time, } \\
25 \text { contractual }\end{array}$ & $\begin{array}{l}800 \text { mostly } \\
\text { lectures, } \\
\text { workshops }\end{array}$ & $\begin{array}{c}\text { mostly state } \\
\text { budget }\end{array}$ \\
\hline $\begin{array}{l}\text { Lithuanian Railways } \\
\text { Vocational training } \\
\text { courses }\end{array}$ & Transport & 5 full-time & 71000 seminars & $\begin{array}{c}100 \% \text { self } \\
\text { financed }\end{array}$ \\
\hline $\begin{array}{l}\text { Vilnius centre for } \\
\text { training of taxation } \\
\text { inspectors }\end{array}$ & Finance & no information & no information & $\begin{array}{c}100 \% \text { state } \\
\text { budget }\end{array}$ \\
\hline $\begin{array}{l}\text { Vilnius centre for } \\
\text { training of customs } \\
\text { officers }\end{array}$ & Finance & no information & no information & $\begin{array}{c}100 \% \text { state } \\
\text { budget }\end{array}$ \\
\hline $\begin{array}{l}\text { Lithuanian cultural } \\
\text { workers training centre }\end{array}$ & Culture & 37 full-time & $\begin{array}{l}985 \text { lectures, } \\
\text { workshops }\end{array}$ & $\begin{array}{c}100 \% \text { state } \\
\text { budget }\end{array}$ \\
\hline $\begin{array}{l}\text { Sports information and } \\
\text { advanced training centre }\end{array}$ & $\begin{array}{l}\text { Sports Department } \\
\text { at the Government }\end{array}$ & 10 full-time & $\begin{array}{l}165 \text { seminars, } \\
\text { workshops }\end{array}$ & $\begin{array}{c}\text { mostly state } \\
\text { budget }\end{array}$ \\
\hline
\end{tabular}


The Ministry of Social Welfare and Labour has a very complicated structure of training institutions. Its Vilnius Social Workers Training Centre offers all possible subjects (upon request). Lecturers are mostly specialists from the ministry. If there is a need, the centre hires trainers on short term contracts from other training institutions. There are five regional labour market authorities like Điauliai, where some civil servants are being trained.

\begin{tabular}{|l|l|c|c|c|}
\hline $\begin{array}{l}\text { Diauliai Labour market } \\
\text { training authority }\end{array}$ & $\begin{array}{l}\text { Social Welfare } \\
\text { and Labour }\end{array}$ & 10 full-time & no information & $\begin{array}{c}\text { state employment } \\
\text { fund }\end{array}$ \\
\hline
\end{tabular}

\section{Joint Stock Companies}

There is no complete record of ministerially-owned joint stock companies that organise training for ministerial staff. These institutions are subject to private law and compete fiercely with private consultant firms and non-profit organisations.

\begin{tabular}{|l|c|c|c|c|}
\hline $\begin{array}{l}\text { Joint Stock Company } \\
\text { Computer services centre }\end{array}$ & Economic & no information & no information & $\begin{array}{c}\text { mostly self } \\
\text { financed }\end{array}$ \\
\hline $\begin{array}{l}\text { Joint Stock Company } \\
\text { Teaching Centre for } \\
\text { Economics }\end{array}$ & Economic & 8 full-time & $\begin{array}{c}\text { no information, } \\
\text { seminars, } \\
\text { consultations }\end{array}$ & $\begin{array}{c}100 \% \text { self } \\
\text { financed }\end{array}$ \\
\hline
\end{tabular}

\section{Academies, Universities and Other Institutes}

Civil servants are also being trained in universities, institutes and academies. Except for the Military Academy, this allows founders of these institutions to earn some additional money or to promote the institution's interests. Nevertheless, those institutions provide good quality training in such specialised fields as information technology. They do not usually compete in the training services market.

\begin{tabular}{|l|l|c|c|c|}
\hline $\begin{array}{l}\text { Lithuanian Military } \\
\text { Academy }\end{array}$ & $\begin{array}{l}\text { Education and } \\
\text { Science, Defence }\end{array}$ & no information & no information & no information \\
\hline $\begin{array}{l}\text { State Institute of } \\
\text { information technology }\end{array}$ & $\begin{array}{l}\text { Education and } \\
\text { Science; } \\
\text { Communications } \\
\text { and Informaticn }\end{array}$ & 67 full-time & no information & $\begin{array}{c}\text { partly state } \\
\text { budget }\end{array}$ \\
\hline $\begin{array}{l}\text { Institute of Economics and } \\
\text { Privatisation }\end{array}$ & Economy & 23 full-time, \\
1 part-time & $\begin{array}{c}380 \text { seminars, } \\
\text { conferences }\end{array}$ & $\begin{array}{c}\text { mostly state } \\
\text { budget }\end{array}$ \\
\hline $\begin{array}{l}\text { Centre for Continuing } \\
\text { Education }\end{array}$ & $\begin{array}{l}\text { Vilnius Technical } \\
\text { University }\end{array}$ & $\begin{array}{c}18 \text { full-time, } \\
8 \text { contractual }\end{array}$ & $\begin{array}{c}\text { seminars, } \\
\text { lectures }\end{array}$ & $\begin{array}{c}100 \% \text { self } \\
\text { financed }\end{array}$ \\
\hline Profession Training Centre & Vilnius University & $\begin{array}{c}8 \text { full-time, } \\
90 \text { contractual }\end{array}$ & $\begin{array}{c}700 \text { long-term } \\
\text { courses }\end{array}$ & $\begin{array}{c}100 \% \text { self } \\
\text { financed }\end{array}$ \\
\hline $\begin{array}{l}\text { Centre for professional } \\
\text { Development }\end{array}$ & $\begin{array}{l}\text { Kaunas University } \\
\text { of Technology }\end{array}$ & $\begin{array}{c}18 \text { full-time, } \\
2 \text { part-time }\end{array}$ & $\begin{array}{c}\text { no information } \\
\text { mostly self } \\
\text { financed }\end{array}$ \\
\hline
\end{tabular}

Two universities offer their students a special public administration course and hold conferences and seminars for current civil servants a few times yearly. 


\begin{tabular}{|l|l|c|c|c|}
\hline $\begin{array}{l}\text { Institute of Foreign } \\
\text { Relations and Political } \\
\text { Science }\end{array}$ & $\begin{array}{l}\text { Vilnius } \\
\text { University }\end{array}$ & $\begin{array}{c}\text { no } \\
\text { information }\end{array}$ & no information & no information \\
\hline $\begin{array}{l}\text { Public Administration } \\
\begin{array}{l}\text { Department Administration } \\
\text { Faculty of }\end{array}\end{array}$ & $\begin{array}{l}\text { Kaunas } \\
\text { University of } \\
\text { Technology }\end{array}$ & $\begin{array}{c}8 \text { full-time, } \\
9 \text { part-time, } \\
2 \text { contractors }\end{array}$ & $\begin{array}{c}200 \text { lectures, } \\
\text { seminars, } \\
\text { conferences }\end{array}$ & $\begin{array}{c}100 \% \text { state } \\
\text { budget }\end{array}$ \\
\hline
\end{tabular}

\section{Specialised Institutions}

All three institutions listed below are non-profit organisations that work under market conditions. The municipal training centre deals with top and mid-level managerial staff in municipalities. At times, this centre also offers training for local politicians. The Language Training Centre has its subsidiary in Ignalina. A particular division of the centre serves only the members of Seimas (parliament) exclusively. The PATC and Municipal Training Centres do not compete with one another because PATC is not concerned with training politicians. Both institutions occasionally encounter competitors from the private sector. Self-Government Study Centre in Klaipeda is strongest in training municipal civil servants.

\begin{tabular}{|l|l|l|l|l|}
\hline $\begin{array}{l}\text { Public Administration } \\
\text { Training Centre }\end{array}$ & Government & $\begin{array}{l}9 \text { full-time, } \\
45 \text { contractual }\end{array}$ & $\begin{array}{l}1800 \text { short-term } \\
\text { seminars, } \\
\text { workshops, } \\
\text { conferences }\end{array}$ & $\begin{array}{l}\text { mostly self financed, } \\
30 \% \text { state budget }\end{array}$ \\
\hline $\begin{array}{l}\text { Municipal Training } \\
\text { Centre }\end{array}$ & $\begin{array}{l}\text { Kaunas } \\
\text { University of } \\
\text { Technology }\end{array}$ & $\begin{array}{l}1 \text { full-time, } \\
1 \text { part-time, } \\
13 \text { contractual }\end{array}$ & $\begin{array}{l}441 \text { seminars, } \\
\text { conferences, } \\
\text { consultations }\end{array}$ & $\begin{array}{l}\text { municipal budget, } \\
\text { foreign aid, self } \\
\text { financing }\end{array}$ \\
\hline $\begin{array}{l}\text { Public Service } \\
\text { Language Centre }\end{array}$ & $\begin{array}{l}\text { Education and } \\
\text { Science, } \\
\text { British Council, } \\
\text { UK Embassy }\end{array}$ & $\begin{array}{l}6 \text { full-time, } \\
5 \text { part-time, } \\
2 \text { contractual }\end{array}$ & $\begin{array}{l}479 \text { long-term } \\
\text { courses }\end{array}$ & $\begin{array}{l}\text { more than 50\% self } \\
\text { financed, rest }- \text { state } \\
\text { budget and foreign } \\
\text { aid }\end{array}$ \\
\hline
\end{tabular}

Many private organisations - more than 569, according to the Lithuanian Information Institute catalogue - and various foundations and associations occasionally organise training for civil servants. On the whole, they do so on a commercial basis. The most successful are PC distribution firms like ALNA or Baltic-Amadeus which, together with a few other firms, have completely occupied the computer training market. As this training is expensive, some ministries are trying to use cheaper training in specialised classrooms at universities or are setting up their own classrooms for computer training, as did the Ministry of Economics. A description of activities of the other private firms dispensing civil service training is difficult but they are nonetheless important players in this field.

\section{The Public Administration Training Centre}

The creation of the Public Administration Training Centre (PATC) on 16 June 1993 was an attempt to establish the basis for a formal structure for training civil servants. Its role was defined as follows: design and implementation of original training programmes; selection and training of civil servant trainers; use of foreign assistance for civil service training; monitoring the activities of other civil servant training institutions if they depended on state or municipal funding. The PATC was established as a non-profit organisation, partly self-financed through its own activities and partly from the state budget. It was set up with the initial support of the Dutch Government and the UNDP. 


\section{Ministry of Public Administration Reforms}

and Local Authorities (PARLA)

Public Administration Training Centre

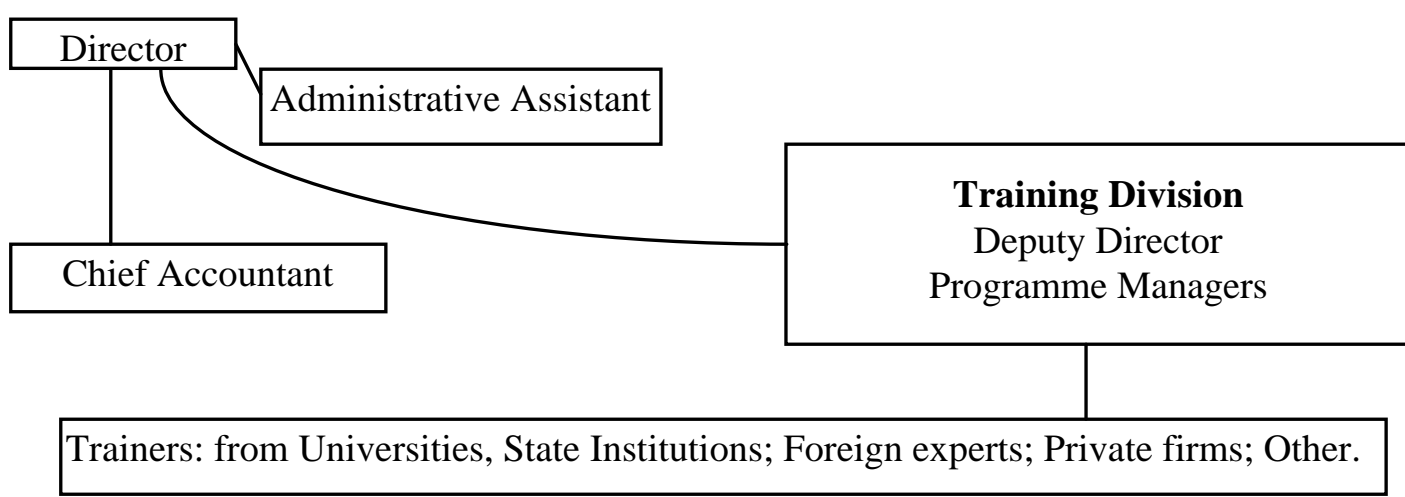

PATC bylaws were approved by the Ministry of Economics on 1 December 1993. At that time, the PATC reported directly to government. As of 13 September 1994 with the creation of the PARLA, PATC was put within the regulatory sphere of the ministry by governmental decree.

A major mission of the centre is to provide public administration training both at the central and at the local level. However, to date, PATC has mainly provided training for local government staff and to a lesser extent for central government employees. At the end of 1995, the PARLA established the non-profit Dainava Civil Service Training and Rehabilitation Centre, located 120 kilometres away from the state capital. The concept of Dainava lies in providing longer term training for central and local government managers. Dainava is expected to provide the full range of services to its clients before the end of 1996.

According to its founding resolution, PATC aims primarily to design and execute training programmes for civil servants, support the state institutions in personnel development by providing appropriate training possibilities, train civil service trainers, provide methodological assistance for other civil service training institutions, consult the Ministry of Public Administration Reforms and Local Authorities and other state and municipal institutions on civil servant qualifications appraisal, provide methodological support on setting up a system of qualification requirements for civil servants, establish a resource base for relevant educational and training materials for civil servants, and to develop the professional attitude of civil servants.

PATC has a total full-time staff of nine, including the Director, the Deputy Director and three specialised programme managers for training ministerial staff, municipal staff, and European Integration matters. They are responsible for organising seminars, conferences and other training activities. One of them also acts as public relations officer. In 1995, the PATC served 1796 clients.

The division of labour between PATC and the ministerial training centres is that the ministerial centres mostly attend to training related to the mission of the ministry, while the PATC concentrates on general management and administrative training. 


\section{Location and relationship of Civil Service Training Institutions}

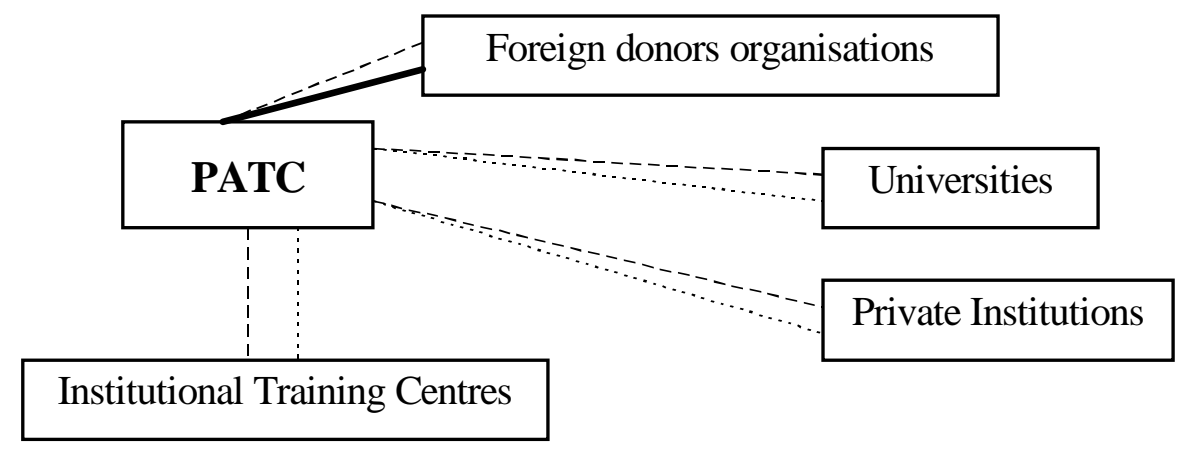

Co-ordination of activities:

Occasional collaboration:

Exchange of information:

In addition to modernising the civil service through decentralisation and privatisation, general management methods must evolve from the correct application of rules towards an increased focus on objectives and results. PATC is now working on the development and implementation of a core curriculum of supervisory and management orientation courses coupled with a curriculum of orientation courses on human resources management. These courses target the top-level civil service of state administration, local government and public corporations. Given the overall environment, for example the absence of a national training strategy etc., the PATC is the recognised training centre within the civil service.

Nearly 10 foreign donor organisations and a number of EU countries' institutions conduct training or provide training assistance to public administration. PARLA, as the government representative, as well as the Phare and UNDP branches in Vilnius play a key role in co-ordinating foreign assistance in this field.

Some foreign foundations and organisations occasionally provide training for Lithuanian civil servants on their own, without regularly co-ordinating their efforts with other donor organisations or governmental bodies: the Canadian Executive service organisation, the Konrad Adenauer and Friedrich Naumann Foundations, the Open Society Fund (Lithuania), the US Baltic Foundation: Other foreign agencies like USIA, USAID, the British Council or embassies in Vilnius also provide training. However, information about such civil service training activities is sparse.

\section{Teaching Personnel}

Competition between training institutions, their different funding arrangements and the lack of well-qualified trainers, makes it almost impossible to find out the exact number of trainers for the public service. The answer can be found partly in the tables. It is common practice in Lithuania for trainers to work in more than one training institution as either part-time or contractual employees.

The background of trainers can be illustrated using the PATC example. There is a list of approximately 45 trainers, most of whom are from Vilnius University, the Pedagogical University, the Police Academy, or are specialists in a variety of government ministries or private consultants. They have all participated in complete or partial training-the-trainer courses aimed at improving their abilities to deliver practical 
performance oriented training. Twenty PATC trainers have taken a special training course designed and run by a Dutch expert, 15 have been trained by British experts. Such training has been provided respectively by the Dutch government and by the EC LODE programme of support for public administration reform in Lithuania.

The possibility of employing trainers on a contract basis gives self-financed centres some flexibility in terms of getting the experts when they are needed. Most civil service training institutions (except Academies and Universities) have no full-time trainers. At most, a highly valued trainer collaborates with the PATC on a long-term contract that determines the availability of the particular trainer if need arises, and specifies a timetable for training activities. All other trainers working on short-term contracts signed for each training. The contracts defines fees, the timetable for accomplishing a given task, and other conditions.

It has proven difficult for training institutions to secure well-qualified specialists-practitioners as trainers. Usually, those who can run the most important training activities are most needed and busy at their regular job. Nevertheless, ministerial officials are often welcome in PATC as they are in all institutional training centres. However, trainees usually expect participant-centred training, whereas most of the specialists-practitioners serving as trainers in training institutions are not familiar with participatory and interactive training methods. At best, they can deliver a good lecture.

Ministerial experts conduct some courses, but many institutional training centres also rely on the assistance of foreign experts through bilateral programmes established between a Lithuanian ministry and a foreign government ministry. The Ministry of Health Care, for example, runs a seven week long training course in co-operation with its Danish counterpart. Danish experts provide six weeks of training in Lithuania, followed by a one-week course trip to the Danish Ministry of Health Care. The programme appears to be working very well.

PATC is unique among training centres in so far as it widens the range of available high quality trainers by signing collaborative agreements with different private training institutions and non-profit organisations. Specific training topics can therefore be covered if need arises.

\section{Needs Assessment and Content of Training}

There were very few attempts to make an organised study of training needs in Lithuania. In 1994, the UNDP branch financed a broad survey carried out by the private consultant firm Baltijos tyrimai. It led to some changes in the PATC curriculum.

As part of a bilateral agreement between the Ministry of Interior of the Kingdom of Denmark and PARLA, Danish consultants have started a special research project in early 1996. The project seeks to identify the general skills required to perform the tasks of a civil servant, how to meet the needs for training and how to organise such training. Survey results were presented in June 1996 in Druskininkai during the special conference organised by PARLA.

At present, training bears only little relation to needs assessments. Institutional training centres offer their customers training which is approved by their supervisors. In most cases, training subjects are therefore linked to the activities of a particular ministry.

PATC is trying to carry out a systematic analysis of training needs in the Lithuanian civil service. UNDP support was and possibly will be of great value in this context. 
Unfortunately, as was stressed before, there is no clear division of training subjects proposed by the different training institutions. Furthermore, institutional training centres tend to disclose information about their training plans only to the staff of their ministry and hesitate to divulge such information even to PARLA.

Universities, non-profit organisations and private consultancies are much more interested in providing such information, and publish their training schedules, special booklets and catalogues. The PATC advertises and markets its products and services in a catalogue listing centre courses. This catalogue is mailed to the ministerial heads of personnel and distributed to the participants of conferences or courses. The centre's programme managers also visit the various ministries and talk to the heads of personnel about what the centre can do for them. The PATC catalogue offers 31 different training programmes on an annual basis, with some repeats during the year.

The purpose of training is to increase the efficiency of civil servants and to make them more effective and responsive in carrying out their responsibilities. All contracted trainers are able to provide a high quality training in management, economics, legislation and political science.

The most popular seminars at PATC are on problem solving and decision making, leadership, communication and motivation; conflict resolution in the work place; management of change; planning, organising, directing and controlling the work of others; performance management; staff recruitment and selection; organisation, remuneration and discipline in the work place, among others.

\section{8. $\quad$ Target Groups}

Training institutions usually provide training for all kinds of target groups. In the future, there may be some degree of specialisation among training centres with, for example, PATC taking care of the training of the top civil service and Dainava training middle management. This will depend on how successful the PARLA will be in drafting a civil service development concept.

\section{Training Formats}

At present, most training institutions focus on offering short-term courses in response to temporary demand (see Tables). Few institutions, such as the Profession Training Centre specialise in long-term courses. Long-term study leaves, study tours or internships are often only possible if they are funded by foreign aid and administered by an international training programme, and if the employer agrees. Unfortunately, there are no exchange programmes between Lithuanian institutions. Internships and on-the-job training was popular in the Soviet era, but those methods are discredited today.

\section{Development of Training Curricula}

Training programmes of most civil service training institutions are designed for practitioners; ad hoc training cannot be entirely avoided. On the other hand, the idea of an advanced curriculum is appealing, and training institutions usually have advisory bodies made up of academics and practitioners which help develop these. Unfortunately, there is no information on any collaboration between training institutions in this context.

From a course design and development perspective, the main problem for the trainers and trainees in all training institutions is the lack of training materials. Civil service training institutions do not have course 
manuals for every course. Thanks to foreign aid, some modern textbooks and manuals are now available. They are usually written in English and naturally have to be translated but not all training institutions can afford to pay for this.

\section{Evaluation}

Training institutions evaluate the success of their courses in a variety of ways, depending on their legal status. Self-financed institutions refer to market evaluation, in order to determine whether a particular course is required on a continuous basis and is therefore of high-quality. State-financed institutions can ignore the interest of trainees in particular training courses since they receive an annual budgetary contribution for their activities in advance. Their staff, including trainers, are guaranteed their fees and salaries. Trainees in institutional training centres are requested by their direct supervisors to participate in training. In most training institutions, during a given course, programme managers or other institutional representatives often sit in the back of the classroom and observe the participants' reactions. Some training institutions, including PATC, have also designed a course evaluation questionnaire to measure participants' reactions after having taken their course.

Most training institutions urgently need more expertise designing and developing courses and training curricula. PATC in particular needs more foreign expertise on subjects such as recruitment examinations and competitive selection techniques, and public service staff retention, as outlined in the recently adopted Law on Officials.

\section{Planned Changes and Further Developments in the Training System}

The PARLA is going to draft and present for discussion the overall concept of a civil service training system. The ministry is promoting three different forms of civil service training. The first will be basic education for the civil service, aiming to prepare young people for the civil service and familiarise them with their new duties. The second aims at the development of professional skills and abilities of acting civil servants. The third form responds to arising needs for retraining civil when their duties and responsibilities change in a new post.

As the Law on Officials obliges heads of governing institutions to periodically evaluate the job performance of their employees and to review their qualification according to adopted qualification requirements and job descriptions, training should be linked to those conditions. For some officials, in-service training is therefore becoming obligatory.

The government issued a decree establishing the residential training centre Dainava which will provide two to three-week training courses for ministerial and municipal managers. It should work in co-operation with PATC which may play the role of providing methodological support, trainers and materials. PARLA officials have the declared a goal of setting up a system of co-ordination between institutional training centres and harmonising the rules for financing their training activities. In other words, the ministry is planning to define what kind of training is needed, how it should be developed, who should provide and organise it and how it will be financed. 


\section{Conclusions}

Administrative decision-making in Lithuania is still highly centralised. Most decisions are taken at the leadership level. Civil servant responsibilities therefore presently fall within a rather narrow spectrum. Effective preparatory work in decision making demands that those facts bearing upon decisions be evaluated as broadly as possible. This requires developing new kinds of networks and team-based working methods. Lithuanian politicians and administrators understand that the present hierarchical leadership model and management are no longer adequate for a future in which administrative business must be mastered on a broad basis. It is essential for Lithuania to develop modern management models. There is also an urgent need to formulate a management strategy and implementation model. International expertise and support are still required in training needs analysis.

The Association Agreement with the European Union requires EU legislation to be integrated into Lithuanian law. This is an enormous challenge for the entire legislative drafting organisation. The current standard and skill of legislative drafting is inadequate. Training and effective rules for drafting legislation will be needed to improve the quality of legislative preparation.

In the growing market for training, it will be necessary to clearly define the specific role of each of the training institutions. Despite the present economic problems and the forthcoming parliamentary and presidential elections (politicians tend to refrain from discussing the budget during election campaigns), it can be hoped that the next few years will see some positive changes in civil service training. 


\section{TRAINING PROFILE}

POLAND

(As of April 1996) 


\section{Introduction}

Poland is located in the Centre of Europe (borders with Russia, Bielorussia, Ukraine, Slovak Republic, Czech Republic and Germany) with a territory of $322577 \mathrm{~km}^{2}$. Total population in 1994 was 38544000 . Poland is a Parliamentary Republic. The head of the State is the President of the Republic elected in free elections for a 5 year term. The Council of Ministers is presided by the Prime Minister.

In 1994, the Central Public Administration employed 133400 persons of which 102700 work within the governmental administration (including its Special Administration (Customs, Treasury Control, etc., at territorial level) and 30700 in territorial Offices of general governmental administration.

The Central Governmental Administration is composed of 18 Ministries (including the Office of the Council of Ministries), 14 Central Offices and 6 Governmental Agencies.

Poland was the first among the central and eastern European countries to enter into the transition period after the first free parliamentary elections were held in 1989. This also meant that Poland was the first country which had to deal with the problems created by a governmental administrative apparatus which was little more than a facade and an executor of decisions taken within a parallel and enormous Communist Party administration. In this situation, it is obvious that one of the first problems facing the new democratic governments was providing public administration with adequate resources (know-how, personnel capacity, knowledge and an organisational frame) in order to perform the tasks that a democracy demands of its administration. These changes had to be enacted in one of the worse economic environments - GDP dropping dramatically, triple-figure inflation, at a time when effective and efficient government work was in great demand.

One of the first steps taken was the decision to carry out a Public Administration Reform. A Plenipotentiary of the Government for Public Administration Reform was appointed and the first, but most important, reform was undertaken with the creation of the first law on self-government in 1990.

Before transition, the training system was one of apparently well established legal and organisational frameworks. In the 1980s, the general organisational framework for training public administration employees was provided by several laws among which the most important were: the law of 16 September 1982 on governmental administration employees, and the governmental decree of 8 November 1982 on the administrative apprenticeship and performance assessment of governmental employees.

Taken together, these laws and several ministerial decrees determined the government employees' training system, composed of:

- The administrative apprenticeship: a 12 -month in-service training programme ${ }^{10}$, to provide new public administration employees with theoretical and practical skills indispensable in performing the duties of

10. The term pre-service training used mostly for training designed and delivered by the educational system or other specialised institutions to prepare future personnel for the needs of the public administration. In-service training is used for training delivered to people currently employed in the public administration. 
public servants ${ }^{11}$. This obligatory training was culminated in a final exam given by a special commission. The Commission was designated by the head of the organisation (Minister, Voivod, etc.).

- Educational programmes: a government employee could be sent to secondary school or university to complete his/her education. This often resulted from a performance appraisal and was proposed by the employees' manager.

- Training programmes: post-graduate, long- and short-term training courses (general or professional), seminars, conferences and political training.

In order to comply with these regulations, a co-operation network was set up among the personnel departments (in ministries, central and voivod offices) and a group of organisations, including: The Institute of Management and Administration, several ministerial institutes, the Centre for Postgraduate Studies for Government Administration Employees, ministerial and territorial governmental employees' Training Centres, universities and several professional associations (Polish Economic Association, Main Technical Organisation, etc.).

At first glance, it may appear that the system was coherent and complete, and that the training of thousands of public administration employees per year in a wide range of training courses produced a very satisfactory situation. But in reality, as the Prime Minister stated in the Council for the In-Service Training of Public Administration (CITPA) in 1993, neither the educational principles nor their implementation fulfilled the existing demands of either the offices or their employees. The training was declarative, very formal, full of wishful-thinking and very ideological, which was ineffective for improving public administration effectiveness.

After the first non-communist government was created in 1989, training was one of the first issues to arise in the very early stages of reform. The need to prepare personnel for the needs of a non-partisan administration in a new state, sovereign and with a free-market economy, was also a matter of confidence, as former Prime Minister Tadeusz Mazowiecki stated this year during a conference held in the National School of Public Administration (NSPA).

In a situation somewhat comparable in social climate to that of France in 1945, the NSPA was created in 1990. Its aims were similar to those leading to the creation of the French Ecole Nationale d'Administration (ENA): to offer a postgraduate two-year programme to prepare young, non-partisan professionals to take up managerial or even executive positions within the public administration. The impartiality, effectiveness and efficacy together with a highly legalistic approach of the graduates of the NSPA were to ensure the new parliament and government that their decisions would be properly implemented. The school acquired its legal status in the law of 14 June 1991, when the first group of 35 students was already recruited through multi-level competitive examinations.

The creation of the NSPA within the first year of the reform shows how substantial the need to prepare highly educated managers for the administration was and how crucial the training issue was at that time.

11. As Poland currently plans a major reform (the Civil Service Reform), the term Civil Service/Servant is used in this report only in connection with future development and legislation. The term Governmental Administration Employee applies to all Governmental Administration Employees (central and territorial). The term Public Administration Employee or Public Servant designates employees of the governmental administration, Central State Administration (Parliamentary Administration, Presidential, Judicial) and self-government administration. 
Within the framework of the projected Public Administration Reform, one of the main goals was the creation of the Civil Service Law. Since 1990, several commissions, committees and task forces were appointed to prepare the law and statutes concerning this reform. Between 1993 and 1995, several drafts of a Civil Service Law were prepared (due to frequent changes of government), but none were voted on in parliament.

While training issues were perceived as one of the fundamental problems to be resolved by the new regulations, no legal or organisational steps were taken until 1993. In May, a Council for the In-Service Training of Public Administration (CITPA) was created by Prime Ministerial decree. Ms Maria Gintowt-Jankowicz, founder and head of the NSPA, and alumna of its first graduating class, was named President of this advisory body. The 8 honourable members of the Council include one Member of Parliament, the directors of the Bureau of Personnel of the Department of Public Administration and of the Department for International Aid within the Council of Ministers as well as specialists in the field of in-service training.

The following goals set for the Council in the Decree are worth mentioning:

- integrate an effective system of in-service training;

- adapt the in-service training system to the needs of public administration reform;

- evaluate the quality and adequacy for public administration of established and projected training programmes.

The CITPA was active for 8 months during which the most thorough research on training in public administration was accomplished, with an international conference organised by SIGMA and an official paper presented to the Prime Minister in August 1993: "Grounds for the Governmental Policy on Training Administration Employees in the years 1993-1994".

CITPA documents were of great importance in identifying training system needs of the public administration. Since then, no other body has carried out research or formulated basic standards for training using such a broad approach. Official Council papers are still very important for anyone studying this issue in Poland.

\section{Objectives of Training}

Since 1989, Poland has gone through a period of major reforms. The has been almost entirely transformed to a market economy, and there has been strong growth during the last two years.

Administrative reform is not so obvious, however those ministries and offices dealing with the economy, the market and social policy have been substantially transformed in an effort to adjust their capacity to the needs of the changing socio-economic environment. Within the public administration, only the self-government reform has been fully accomplished.

For next year, a major reform of the economic and administrative centre of the government is planned. Several existing ministries are to be abolished and new entities created (i.e. the Treasury, the Committee 
for European Integration, the Ministry of Administration and Internal Affairs etc.). Civil Service Law is on the parliamentary agenda and the reform of the administrative centre of the government being prepared ${ }^{12}$.

Poland now faces a major period of administrative reform; CITPA training objectives are more important than ever:

\section{Immediate Goals:}

- training to meet the new demands created by the changing economic and social environment of administration, implementation of new statutes and laws (Public Procurement, Finance Management and Control);

- training to improve job performance of public administration employees by providing them with general skills such as foreign languages, computer literacy, etc.

\section{Long-Term Goals:}

- prepare public administration employees for the European integration process;

- prepare the implementation of a Civil Service Law;

- improve the rationalisation of public administration performance;

- increase the efficiency of public administration performance;

- improve cost- effectiveness of public administration performance;

- Develop managerial skills among executives.

An over-riding training need is to prepare a large number of public administration employees for European integration. Poland is currently applying for membership in several international and supranational organisations such as NATO, OECD and the European Union, whence the need for governmental employees to possess basic (foreign languages, knowledge of European procedures) and more specific skills (negotiation skills). Furthermore, the awareness of public servants on international issues has to be increased dramatically in the next few years. Fulfilling these needs has been stated as an explicit objective of public sector training on several occasions, among others in the official document "Grounds for the Governmental Policy on Training Administration Employees in the years 1993-1994". The need also resulted in the creation of the Polish branch of the College of Europe, a unique post-graduate training institution whose main aim is to prepare public servants to work and deal with the institutions of the European Union

An informal objective of training is the improvement of public services. A pro-client orientation must be. This principle has been highlighted by the NSPA to its students from the beginning and was somewhat reflected in the name chosen for its second graduate generation: "Pro publico bono".

The experience of the transition to democracy has been very important for the public administration. The basic concept of a State of Law has been widely recognised and the demands of the public for fast, effective and efficient services are growing rapidly - a development clearly reflected in the mass media .

However the greater demand for training was and still is being created by rapidly changing laws, hence the popularity of specialist training in legal and financial matters.

12. A package of five relevant drafts together with the proper accompanying documents was discussed and approved overall by government on 27 February 1996. 


\section{Legal Framework}

The debate about drafting a new constitution, which is currently underway has never touched on issues of the public service and the training of officials. These topics have been among the most important in the ongoing debate (since 1990) on civil service reform.

In 1989, the situation in Poland was somewhat different from that of other central and eastern European countries. Since 1982, the law "on governmental administration employees" (a specific civil service statute) provides public administration employees with a set of rights including stability of employment as well as a set of obligations uncommon in the labour code. In this situation, the need for new regulations is not widely recognised. Several amendments to this law have been passed (the most important in 1994), but the principles of both the law of 16 September 1982 and the governmental decree of 8 November 1982 on "the administrative apprenticeship and performance assessment of governmental employees" are still in place.

According to these laws, the public administration employee is still obliged to ,develop his/her professional knowledge"13 and his employer is required "to provide the governmental administration employee with proper conditions to carry out the duties stated in the law"14. The public administration employee is not obliged in any other, more specific way to take part in any training programme, nor is his promotion linked directly to training.

Under the provisions of the Decree of the Minister Chief of the Office of the Council of Ministers from 16 August 1987 "on the development of professional knowledge of personnel employed in territorial governmental administration" the territorial offices of governmental administration (Voivodship offices) are obliged to "inspire, organise and control the professional development and training of public servants employed in their offices" official obligation to governmental administration employees. The results of training are noted in the personnel file of each employee and are taken into account during performance assessments." ${ }^{16}$

\section{4. $\quad$ Funding}

The Polish Budgetary Law grants each ministry, central and territorial office of the government its own budget, and the head of the office (Minister, Head of Office or Voivod) allocates it. Consequently, the amount to be spent on training each year is decided internally. No official records of the amount spend on training within public administration are available.

Research conducted in 1993 by the CITPA provided some information on the training expenditure of 1992. Unfortunately, collected data was neither accurate nor adequate, and is therefore of little help for the purposes of this work. Following the CITPA research, the Bureau of Personnel, Training and Organisation

13. The law of 16 September 1982 "on the governmental administration employees" Chapter 3, Article 17.

14. op. cit.- Article 17.

15. Decree of the Minister Chief of the Office of the Council of Ministers from 16 August 1987 "on the development of professional knowledge of personnel employed in territorial governmental administration"- $\$ 1.1$.

16. $\quad$ op.cit.- $\$ 1.3$. 
in the Office of the Council of Ministers gathered relevant data from the Voivodship offices in 1994, but it remains

unprocessed. The CITPA also attempted to obtain information on the ratio between internal funding and external (bilateral aid, Phare programmes, USAID, World Bank), but this data was not available.

For this report, a survey was conducted in February 1996, to obtain reliable data on training and finance. Of the 15 ministries and 1 central office requested to provide information, 13 replied.

The data gathered shows than in the years 1992-1995, the total spending for training of ministerial employees (in the 13 ministries) has been growing and a disproportionately large increase is planned for 1996.

Since the rate of inflation for these years has been quite substantial, ranging from 35 per cent in 1992 to 22 per cent in 1995, it seems more appropriate to compare the total spending for training purposes to the

Total spending for training in 1992-1996 in 13 Ministries

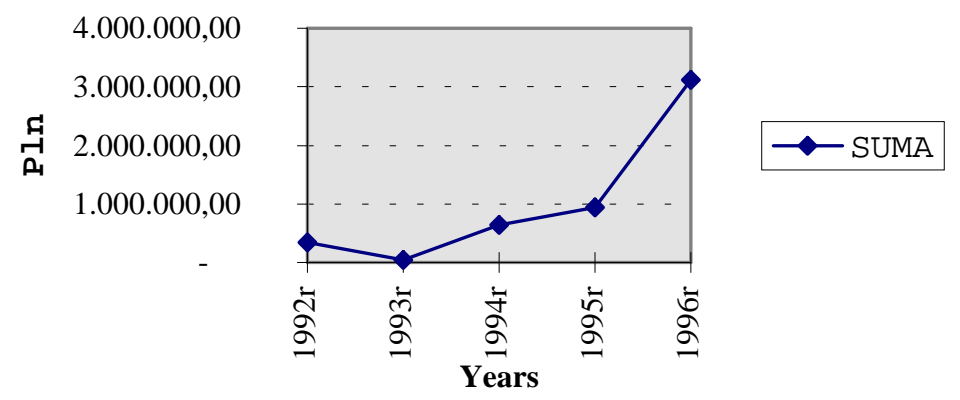

total spending for salaries and their derivatives in the quoted ministries. This indicator varied in the researched years from 0.11 per cent to 1.47 per cent, with 3.18 per cent expected in 1996.

\section{Total spending on training as \% \\ of total spending on wages and \\ their derivates}

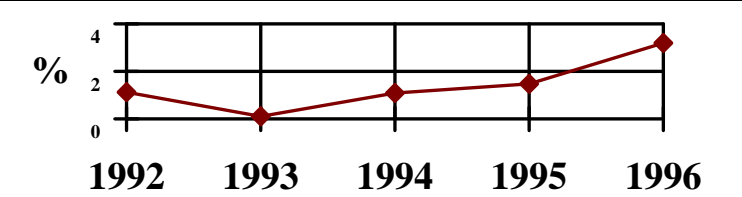

Training expenditures represents around 0.4 per cent of total ministerial budgets and variations were insignificant.

Training for public administration employees is free of charge to participants, and cover travel expenses. Some kinds of educational training (when the employee is sent to university to complete his/her higher education) may be part-financed at the rate of 50 per cent by the employer. 
It is obvious that Poland is a major recipient of foreign aid within Central and Eastern Europe. Bilateral and multilateral grants have been made available since 1990 and have been used widely in the reform process. As far as public administration reform is concerned, vast sums were spent on the reform of self-government, including for training employees and elected members of local councils.

Public administration has been provided with aid funds from several sources: Phare, USAID, Know-How Fund, etc. These funds are aimed mainly at the transfer of knowledge, know-how and expertise. A large part of these funds was spent on training governmental administration employees, self-government employees, etc.

No central data on the amounts spent on training central government administration employees exists, as several ministries manage aid funds in a decentralised manner and training financed by these resources is aimed at their employees, employees of territorial and special administration (Treasury offices, Customs, Control Chambers, etc.).

The survey quoted earlier showed, however, that wherever such funds were made available, they constituted an important part of the training budget. In those ministries reporting the use of aid funds for training, their ratio of ministerial training budget stood at around 191 per cent in 1994, 303 per cent in 1995 and 378 per cent. It has to be noted that only 7 of the 13 responding ministries reported using aid funds for employee training.

\section{Training Institutions and Legal Status}

This profile includes information on training, which means that several secondary and university level educational institutions will be discussed briefly, for they aim at prepare students to apply for jobs within the public administration (government and self-government). Forty secondary schools around the country prepare young students in the special field of Technician in Administration, following a curriculum developed with the participation of the Office of the Council of Ministers comprising the following topics:

\begin{tabular}{|l|c|}
\hline \multicolumn{1}{|c|}{ Subject } & No. of Obligatory Hours \\
\hline Basic legal terminology & 19 \\
\hline Constitutional Basis of Polish Governmental System & 38 \\
\hline Administration and Administrative Law & 87 \\
\hline Financial Law & 64 \\
\hline Civil Law & 64 \\
\hline Labour Law and Social Security & 113 \\
\hline Economic Law & 68 \\
\hline Economy & 68 \\
\hline Organisation of the State Economy & 116 \\
\hline Accounting & 185 \\
\hline Statistics & 68 \\
\hline Typing & 132 \\
\hline Office Organisation and Technology & 64 \\
\hline Data Processing & 96 \\
\hline Sociology and Social Psychology & 68 \\
\hline Foreign Language & 265 \\
\hline Ethics & 26 \\
\hline
\end{tabular}


State and several private universities have special programmes in administration, preparing their students for public administration jobs. In 1994, only 5 Universities provided full Masters Degree Courses in administration: State Universities of Lodz, Wroclaw, Bydgoszcz, Radom and the private Higher Business School in Warsaw. Other higher education institutions offer studies in Political and Social Sciences as well as other specialties useful to public administration. The administration itself seeks to employ graduate lawyers and economists.

\section{Pre-service training}

Two training institutions, both created after 1989, offer post-graduate courses:

\section{National School of Public Administration}

Created in 1991 as a governmental organisation funded from the budget of the Office of the Council of Ministers. The statute granted to the school by the Prime Minister in August 1991 ensures autonomy and, at the same time, close association with the institutions of public administration.

The training curriculum is based on concepts elaborated in 1990-1991. It is constantly being developed and modified in accordance with the changing needs of public administration. The curriculum was drafted after consultations with national universities, including ENA, the University of Southern California and the European Institute of Public Administration in Holland. The training favours active training methods (workshops and seminars) instead of pure lecturing:

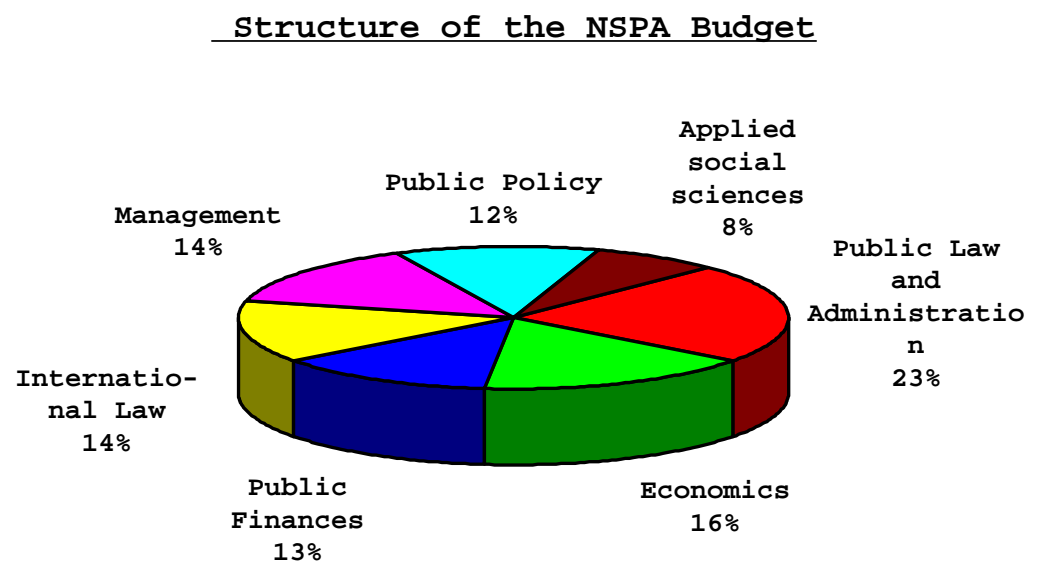

The programme comprises a broad scope of topics: public law and administration, economics, public finance, international law and relations, management, social sciences, ethics. The school also offers foreign languages (two obligatory) and computer training. Students spend three months doing national and international internships.

So far, the School has produced four generations of graduates and 188 alumni have taken up employment in public administration, ranking from the post of main specialist to Department Director or Head of Office. NSPA graduates must work within the public administration for a period of five years after graduation. 
Although the school is financed mainly from the national budget, international aid has been of great importance to its development i.e.: Phare, USAID and also bilateral funds such as the Know-How Fund or the French Fondation France-Pologne.
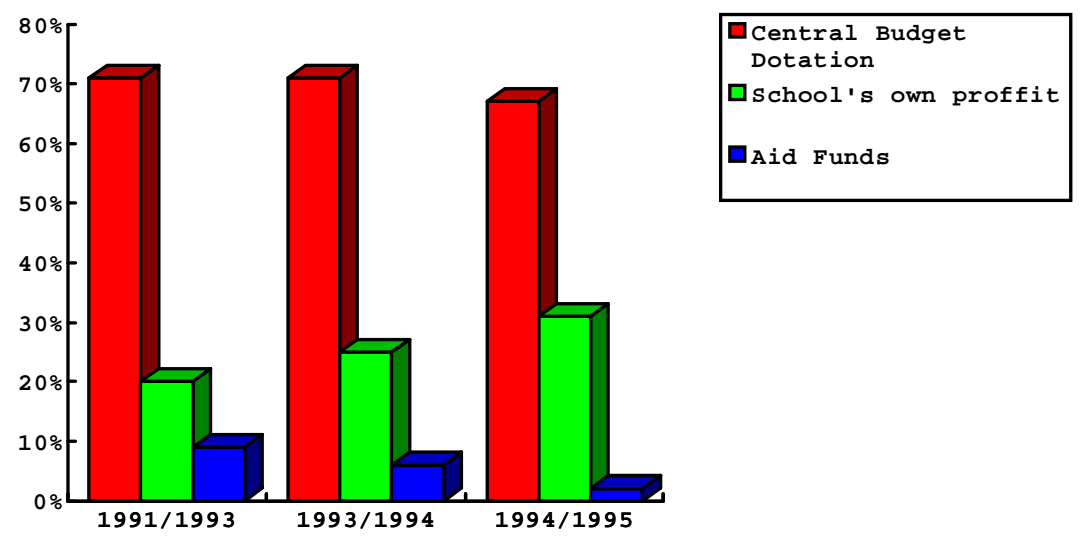

Only courses offered by NSPA can justifiably be regarded as pre-service training, as only they guarantee graduates a position in the public administration.

\section{The College of Europe ${ }^{17}$}

The idea of setting-up a branch of the College of Europe in Poland was first floated in 1990. The appointment of the Plenipotentiary of the Government for European Integration and Foreign Aid in January 1991 gave a strong impulse to the implementation of this idea.

The Bureau of the Plenipotentiary of the Government for European Integration and Foreign Aid recruits students every year to be trained in Brugia and at the branch in Natolin. Candidates must be graduates in law, economics, history or social sciences, 30 years or younger and must speak fluently both English and French. However, the graduates of the college have no obligation to work within the public administration after completion of the course and they can seek employment within the private sector.

Other universities also offer some postgraduate studies in administration, administration and management or public administration. In 1994, 23 educational institutions provided this kind of training. They reported $^{18} 4792$ students of which 1175 were actually public servants ${ }^{19}$

\section{In-service training}

A number of public administration training centres (ministerial and regional) offer in-service training. These entities were created in 1983 after the laws on governmental administration employees and their training had required some mandatory training (apprenticeship). The centre's legal status was laid down in

17. See Annex 1 for further information on the system of training in the area of European integration.

18. See: Education for Public Administration, Warsaw, 1994.

19. Eight schools did not indicate the number of students who are public servants. 
December 1983 by the Decree of the Minister of Labour and Minister of Finances: "on the organisation and operation of ministerial and Voivod training centres, training for the personnel and the principles of covering the costs of training and educating employees for the governmental administration". Training centres were established either by the respective Minister (ministerial training centres) or Voivods (regional training centres)

The legal framework envisaged the setting-up of training centres employing trained trainers and educational staff, offering suitable training rooms, equipped with essential teaching aids. The training centres were to be financed from the budgets of the ministries or Voivodships. The centres were managed by a Director appointed by the respective Minister or Voivod.

Ministerial training centres offered in-service training for the managerial personnel of ministries and central offices, for public servants employed in the ministries, for managers and specialists employed in organisations under the ministerial control, for managers from Voivodship offices and for managers from state-owned enterprises.

Regional training centres offered training for managers of Voivodship offices, employees of territorial governmental administration, and for self-government managers.

Under the new budgetary law, the ministers and voivods are no longer obliged to finance their training centres from their respective budgets. This has produced severe problems for the directors of centres that had to become financially self-sufficient at a time when the training budgets in both the central and territorial governmental administrations were shrinking dramatically. Training centres with accommodation facilities began to offer hotel services to the public; restaurant and catering were also used to attract the necessary financial resources.

In 1992, only 18 regional training centres existed; at present, only 7 still offer training courses to governmental and self-governmental administrations. There were 10 ministerial training centres in 1992, while the survey conducted in 1996 revealed only 5 out of the 13 ministries to still retain such centres. None of these received budgetary contributions from their ministries in 1995. Both regional and ministerial training centres are financially self-sufficient, and must offer their services on the market. A stronger economy increases the demand for training so the remaining centres are likely to survive.

Overall, training centres are now largely autonomous. They offer training and other services, but charge even their supervising organisation for it. Voivods do not tend to influence staffing and curriculum development of their training institutions. Given that ministerial centres offer highly specialised training (training for example tax inspectors), they have to co-operate more closely with ministries and central agencies in curriculum development.

Originally, training centres were subject to public law. Today the situation is unclear as the decree of the Ministers of Labour and Finances is no longer binding and no other legal framework has been created.

The NSPA is obliged by its statute to provide the governmental administration with training. In the first 3 years of operation, the school obviously concentrated its efforts in the development of its pre-service curriculum. Starting 1994, the School offered seminars on macro-economic policy and strategic planning. It also held training-courses in management, public policy analysis, foreign language training (short- and long-term), information technology, etc. The school developed and implemented two short-term training curricula in co-operation with the Office of the Council of Ministers and the Ministry of Privatisation. 


\section{No of Governmental Employees Trained in 1994-1995 at the NSPA}

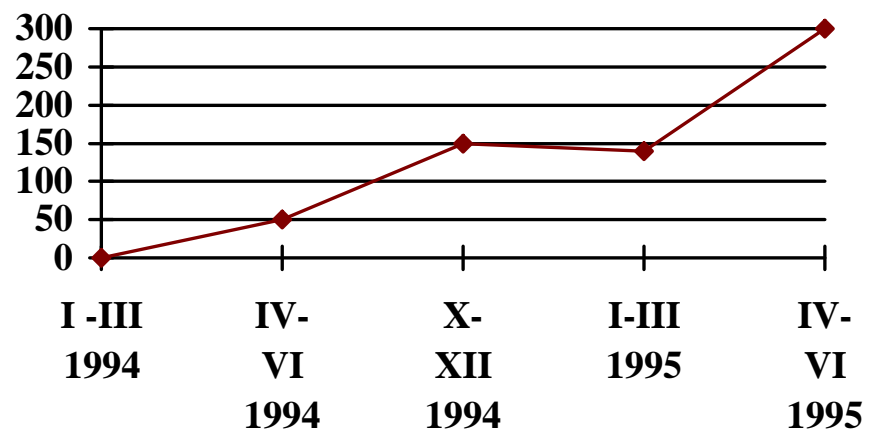

The training market is growing rapidly. It is hard to say how many private institutions are offering training to public administration at present. Statistical data gathered by the CITPA showed that more than 120 training institutions provided training for central governmental administration in Warsaw in 1992 alone. Ministries, agencies and Voivodship offices are legally obliged to offer training to their personnel and it can be provided through a wide range of organisations.

Public or private training organisations offering their services to public administrations compete with each other. Private institutions are often able to offer training at lower prices, as public institutions often have premises to maintain. Public training centres offer seminars and conferences with lectures provided by high-ranking ministerial officials are usually popular outside the Capital. Course quality in private and public institutions are comparable.

\section{Teaching Personnel}

One of the major problems identified by CITPA in its official document was the issue of training the trainers: "there is an urgent need to prepare professional trainers and training specialists for the administration. They should have the same position in each central or territorial office and have the knowledge and skills necessary to:

- assess training needs for each organisation;

- develop and implement own training programmes;

- contract-out training; and

- manage training (organise, co-ordinate and plan).

In reports recently completed on the needs of special training programmes financed out of Phare, it was discovered that most of the regional training centres do not have their own training staff. Usually they contract trainers from universities or from the administration. They are not suitably prepared for teaching adults and their training methods are often obsolete, and their training is less efficient than it could be. Not even the NSPA employs permanent teaching staff.

All trainers are employed on a labour code status, their remuneration depends on the local market and ranges from about ECU 20-100 an hour. The private sector usually offers better pay. Furthermore, private institutions often employ permanent teaching staff — the private sector in Poland is developing rapidly 
and the training budgets of private enterprises are growing accordingly. Public servants are usually remunerated while offering lectures, their fee depending on their positions within the administration.

Ministries, agencies and Voivodship offices do not usually employ trainers to give on-the-job training or short training courses. If the need arises, one of the employees provide training. Generally, public servants do not receive extra pay for this.

\section{Needs Assessment and Content of Training}

In 1993, CITPA gathered data about the content of training provided to governmental employees by their offices. The researchers created the following typology of training provided:

Specialised Training, including all kinds of training needed for performing a specific job

\section{General Training:}

- Administrative apprenticeship;

- Foreign languages;

- Computer literacy;

- Accounting;

- Taxation;

- Privatisation and Reprivatisation processes;

- Organisation and Management;

- Economic training;

- Public Administration;

- Jurisdiction of the Main Administrative Court;

- International Internships;

- International Relations.

\section{Education:}

- Postgraduate studies in Law and Public Administration;

- Postgraduate Economics;

- Legal Adviser apprenticeship;

- Other postgraduate university studies;

- Specialised Studies;

- Home study courses;

- Master's Degree Studies.

The results of the study showed specialised training to be the most popular format. It also showed that for 1992 fewer than 40 per cent of the governmental offices organised any kind of institutionalised training other than the obligatory administrative apprenticeship which was conducted in only 28 per cent of the ministries and central offices. Among general training programmes the most popular were financial training of all kinds, training on privatisation and reprivatisation processes as well as foreign languages and computer literacy. In 1992 there was little training on European integration and international co-operation. Possibilities for foreign internships were limited - only 24 per cent of the offices did sent at least one employee to this kind of training. 
Training and education as reported by Ministries for 1995 by subjects covered
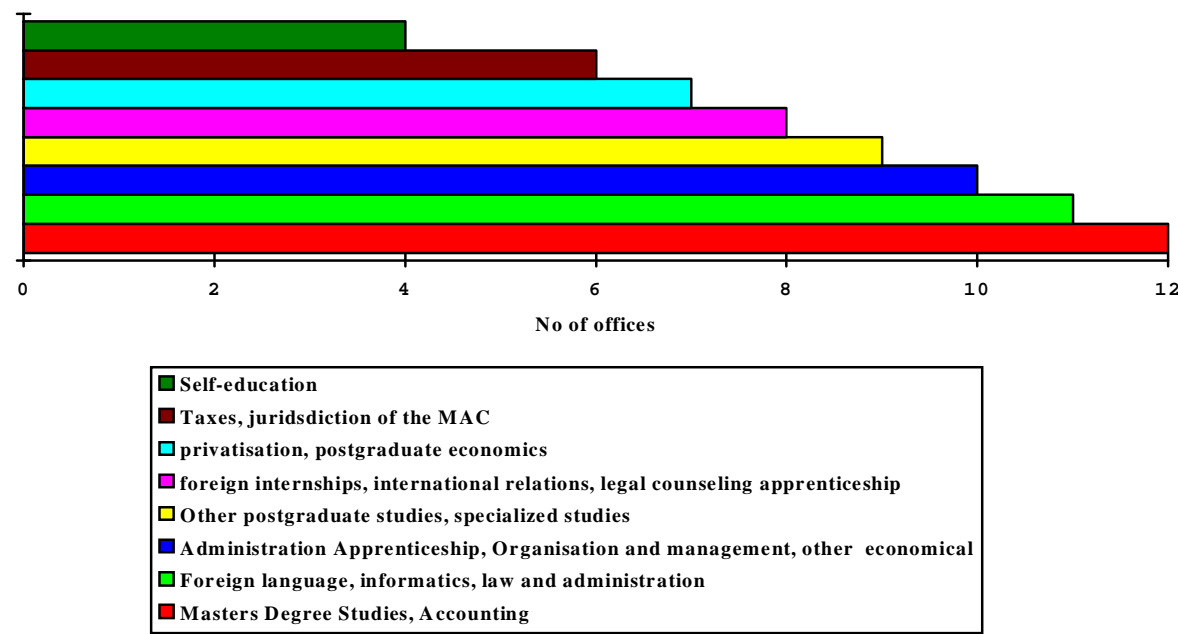

The research undertaken in 1996 showed some changes in training content. All ministries reported having organised institutionalised training in 1995. Foreign languages and information technology are still the most popular kinds of training provided. Administrative apprenticeships were organised in 10 of the 13 responding ministries. International relations and issues concerning European integration were offered by $2 / 3$ of the ministries, demonstrating the growing interest in these issues. Foreign internship possibilities also increased in 1995, with $2 / 3$ of the ministries sending their employees to this kind of training.

A need for new kinds of training has also arisen in the recent years. For example, 25 per cent of the offices reportedly organise training on public procurement (the relevant office was created in 1995)

In addition to the administrative apprenticeship final exam, discussed above, no other kind of general in-service training culminates with a formal examination. All kinds of educational training (Master's Degree studies, post-graduate, etc.) are obviously subject to examinations according to the educational law of the country.

The NSPA has defined the following set of entry requirements for pre-service training programmes:

- be 32 years of age or younger;

- have a Masters Degree;

- fluency in at least one foreign language.

The entry exam for the NSPA is a 4-step competitive procedure:

1. a general knowledge test;

2. a foreign language test;

3. a written examination requiring an essay on a topic lectured upon earlier;

4. a qualifying oral examination held by a Qualifying Commission.

There were 421 candidates in 1995 of which 226 passed stage 1, 168 trough stage 2, 125 passed the written examination. 57 candidates qualified to enter the NSPA. 


\section{8. $\quad$ Target Groups}

In its official document of 1993, CITPA pointed out the need for a precise definition of the target groups for training within public administration. The Council believed that in accordance with the planned civil service law, there was the need to develop training curriculum for three groups: managers; autonomous personnel; and other personnel

The Council proposed that the NSPA be responsible for training managers (including the development of training curricula, methodology of training, organisation and providing of training) to be given to. At the same time, the NSPA was to develop training curricula for and oversee the functioning of ministerial and territorial training centres that would be responsible for providing training for autonomous personnel. Regarding the remaining personnel, CITPA proposed the abolition of the administrative apprenticeship and the creation of an obligatory pre-service training course, without specifying who should be responsible for it.

In response to the 1996 survey, ministries reported to have trained an average of 57 per cent of all personnel, of which 7 per cent were managerial staff, 44 per cent autonomous staff and 49 per cent the remaining staff. Bearing in mind that managerial staff accounts for roughly 7.86 per cent of the total staff within the central governmental administration, it may seem that enough attention has been paid to the training of this target group. Yet, only an average of 59 per cent of managers employed within the ministries was given some training in 1995, while 112 per cent of remaining staff (ranging from secretaries to desk officers, typist, etc.) was trained. Comparing these figures to the subjects of training provided, it is obvious that secretarial and auxiliary staff were given training in basic skills such as languages and information technology.

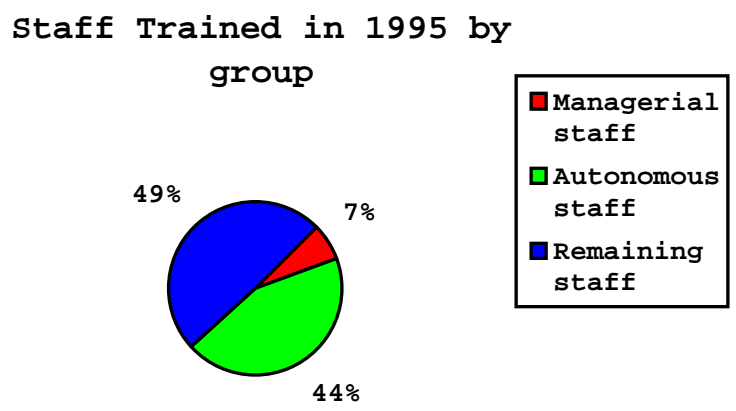

Training courses in management, international relations and foreign internships were provided to managers and to autonomous staff, the latter concentrating on specialised training: taxes, accounting, specialised studies.

\section{Development of Training Curricula}

The transformation taking place in Poland since 1989 has created a situation in which new administrative needs raised the need for new training curricula for those institutions offering pre-service training. Attention was paid to secondary school programmes educating for the specialisations of Administration and Office Work Technicians. The new generation of public administration employees needed to acquire not only legal and economic knowledge, fluency in foreign languages and computer literacy but also the skills necessary for the practical use of this knowledge, as well as ethical and cultural behaviour patterns 
indispensable for a civil servant. Training curricula for all secondary-level vocational schools are prepared by the Ministry of Education.

With these principles in mind, the Minister-Chief of the Office of the Council of Ministers appointed a Team of Experts for Evaluating Training Curricula for the Vocations of Administration and Office Work Technicians. The team of experts was composed of academics, representatives of NSPA, of the Foundation for Local Democracy, of secondary schools providing pre-service training and finally of employees of the Office of the Council of Ministers. This team evaluated training-curricula for both vocations $^{20}$ and then submitted these to the Minister-Chief for his signature. These curricula were transmitted to the Ministry of Education for implementation in 1993.

With regard to in-service training, the CITPA was supposed to create the background for training-curricula creation. In the "Grounds for the Governmental Policy on Training Administration Employees in the years 1993-1994", CITPA proposed the creation of three training curricula for in-service training of the target groups mentioned earlier. These were introduced only after a serious debate on who should prepare the curricula, evaluate and implement them. To CITPA, it appeared quite obvious that the NSPA should be responsible for formulating curricula.

Currently, training follows mainly an ad-hoc identification of needs made by the ministries themselves and used to identify suitable training programmes available on the market.

In 1995, the Office of the Council of Ministers decided to prepare the grounds for the creation of a training system for public administration to be financed by the Phare OMEGA Programme designed to aid public administration reform.

Terms of Reference were prepared and a consortium, presided by the Danish School of Public Administration, was appointed by a restricted tender to execute the project. The consortium elected shows clearly that Poland's public administration has decided to seek co-operation with other European countries in projecting its in-service training system.

The project does acknowledge that building a sound structure for the continuous training of public administration will be a long process. However, some key elements of the training structure should be put in place immediately. The project will:

- determine training needs both for the whole public administration and for individual positions within public administration;

- develop institutional structures and responsibilities for the training system;

- develop procedures for the designing and validating curricula and training materials;

- establish sound funding principles;

- develop fundamental rules and regulations (including the legal basis).

20. See Section 7, "Needs Assessment and Training Content". 


\section{Planned Changes and Further Developments in the Training System}

In 1995, the government introduced a draft Civil Service into the parliamentary process. The set of documents included drafts of other laws (decrees) for the civil service.

Article No. 37 pt. 6 of the draft obliges the civil servant to develop his/her professional knowledge making the training performance one of the main factors to be taken into account during performance appraisal.

At the same time, the draft Civil Service Law introduces four categories of civil servants and specifies the examinations to be passed to enter any of these. A draft decree of the Council of Ministers "on the basis and conditions of organising and conducting of training for the civil service" states that civil servants are to be trained according to the needs of their civil service group qualification, their function and job. Training is defined as having the following purposes:

- prepare public administration employees qualified for appointment within the civil service to perform their tasks;

- develop and improve general knowledge and professional qualifications for the performance of their actual job;

- develop and improve the knowledge of civil servants in view of their envisaged promotion.

All training that is part of the civil service training programme will be free of charge for the participant and obligatory. Training curricula for the civil service are to be prepared by the Civil Service Commission. The civil servant will be allowed to seek training independently and will be granted paid leave for this but the costs of such training will have to be borne by the participant.

Different kinds of training will be organised by the ministries and offices themselves. In each ministry, a Plenipotentiary for Training will be appointed and his/her duties will among others be:

- prepare one or several-year training plans for the office/ministry;

- training-needs assessment for the office/ministry;

- evaluate individual training requests and their submission for approval to the General Director of the office/ministry;

- recruit or approve trainers for training delivery;

- manage financial matters concerning training;

- the management of training files;

- co-operate with the Civil Service Commission on training matters.

The draft law also states that trainers for civil service are to be: academics, research- and didactic employees from the Polish Academy of Sciences or other research or scientific Institutes, as well as eminent specialist-practitioners.

In sum, the projected Civil Service reform will introduce obligatory training and draw a clear distinction between pre-service, in-service and promotion training. Civil Service Category Examinations will be preceded by training courses, their curricula will be prepared by the Civil Service Commission. Training will increase enormously in status. Training will be delivered mainly by the ministries and governmental offices themselves and where this is not possible, the law will allow a contracting-out of training. 


\section{ANNEX 1. THE SYSTEM OF TRAINING IN EUROPEAN INTEGRATION}

The existing system of training on European integration was established over the last five years. Its basic form consists of university studies, which have developed European integration as a discipline over the last few years, within the framework of MA and post-diploma programmes, usually lasting two semesters. The network of 11 European research and study centres plays a major role in the area of European studies for which the development of research and training in the area of European integration is a principal statutory function.

The growing presence of European issues in research programmes and didactic activities is largely due to successive tranches of the Jean Monnet Action for Poland assistance programme, which presently includes 28 post-secondary institutions. In the 1995/96 academic year, as a result of this programme 11 "European" chairs developed didactic and research activities, 39 regular lecture series were conducted, 13 European modules were included in other lecture series, and a total of 11 doctoral dissertations were recorded. Activities were accompanied by research programmes and various types of publications. Different forms of European studies are also being developed independently of assistance programmes.

Vocational training and upgrading civil servants is an important and regular component of the system of training in European integration. It is done in various ways, including the so-called European path which plays an increasingly significant role. This form of training is being offered to an ever greater extent, and in the future, especially once the civil service act takes effect, to absolutely all employees of the central administration, who already work or are taking up employment in organisational entities of central ministries and offices responsible for carrying out tasks associated with European integration.

\section{Current European Path Training:}

Stage 1 - High Level Post-Secondary Interdisciplinary General Studies:

- Fee-paying studies in post-secondary schools with European research and study centres as contributors, for the currently employed.

- The University of Warsaw as of 1992. 170 graduates of intensive one-semester courses and 46 graduates of two-semester courses.

- Central School of Commerce (Warsaw); a two-semester course with 34 graduates (ministry and central office civil servants). 250 total graduates from these two institutions.

- 24 graduates from the European College branch in Natolin, and 16 graduates since 1992 from the parent institution in Bruges, for a total of 40 graduates.

- European Integration Studies (since 1995) at the Natolin European Centre, through co-operation between the Office of the Plenipotentiary and France's ENA and the France-Poland Foundation. The first graduating class (June 1996) included 43 representatives of central ministries and offices. 
Stage 2 - Vocational Traineeships:

- Three-months at the European Commission in Brussels, 20 people per year, for young civil servants from entities responsible for European integration, legal departments of central ministries and offices. 128 trainees by the end of July 1996.

- Individual study traineeships at institutions of the European Union; experts and senior civil servants.

- Traineeships in government administrations of European Union member states (no age limitation) from several days to a month. 124 trainees since 1995.

Stage 3 - Ongoing Specialised Training:

- Regular cycle of two- and three-day specialised seminars at the European Institute in Lodz. 1994: 6 seminars for 286 trainees; 1995; 21 seminars for 1012 trainees; 1996: 35 seminars for 1700 trainees. 1997 target: approximately 50 seminars per year for the central administration. Total in July 1996 $2208 *$ trainees.

- Thematic seminars and lectures for specific departments, or on an inter-departmental basis, organised directly by the Office of the Government's Plenipotentiary for European Integration and Foreign Assistance (approximately $1800^{*}$ trainees), or by individual ministries and offices, in co-operation with Union member states and participation since 1991 in seminars lasting from one to four weeks devoted to European integration issues: 207 trainees in France, 72 trainees in the United Kingdom, 42 trainees in Denmark, for a total of 321 central administration civil servants.

"Person-seminars". 


\section{TRAINING PROFILE}

ROMANIA

(As of April 1996) 


\section{Introduction}

Following the people's revolt of December 1989, the Republic of Romania embarked upon a new road which opens up the prospect of restored democracy, a market economy and full reintegration into European political and cultural life.

The Constitution approved by the Constituent Assembly on 21 November 1991 and validated in the referendum of 8 December 1991, proclaims Romania to be a democratic and social state based on the rule of law, in which human dignity, civic rights and freedoms, personal development, justice and political pluralism are supreme and guaranteed values (Article 1). It defines three public authorities: legislative, executive and judiciary, and provides the framework for their collaboration.

The government ensures domestic and foreign policies and is responsible for the general management of public administration. Public administration in territorial administrative units is based on the principles of local autonomy and decentralisation of public services. Local councils and mayors, elected by direct popular vote, are the public administration authorities in villages and towns. The county council is the public administration authority that co-ordinates the activities of all villages and town councils within a county. The government appoints a prefect as head of each county, including one for the Bucharest municipality.

\section{Basic Data}

- territory: $237500 \mathrm{~km}^{2}$;

- population: According to the 7 January 1993 census returns, the population was 22755260 (95.8 inhabitants $/ \mathrm{km}^{2}$ ) 89.4 per cent of whom were Romanians and 10.6 per cent were ethnic minorities;

- capital: Bucharest municipality;

- administrative division: 41 counties, 80 municipalities, 182 towns, 2688 communes, 13102 villages.

Basic Educational Data (for school year 1992-1993)

The system of state education is free of charge at all its levels and includes pre-school for children aged 3 to 6, primary school grades 1-4, secondary school grades 5-8, high school grades 9-12. School is compulsory through junior years 9-10. Vocational and foremen's schools are 1-2 years long, higher education is $4-6$ years.

At the beginning of the school year, 4569255 pupils were enrolled. (See Annex 1 for 1993.) The school-going population per 10000 habitants was 2 171, of whom 83 were higher education students.

After almost half a century, the first private educational units reopened in 1990 (See Annex 2). Private education is considered to be an alternative or a complement to state education.

\section{The Role of Public Administration in Promoting Economic Reform}

The functional role of public administration in socio-economic development may vary greatly among countries, and reflect the specific needs of the ruling elite as well as the general population. Their specific are closely related to the stage of economic development, social structure, ethical and cultural values, as well as to the political and administrative conditions of a given society at a given time. In this respect, the 
situation of eastern and central European countries is very particular and varied, given the different starting points.

\section{Policy Planning and Management}

The government assumed the task of reforming all components of economic and social policy, taking into account both the conditions of economic and social development and the need for a broad international opening. The reform constitutes the essence of the transition to a market economy, of the efforts to place the economy back on the track of development and of reintegration into the European and international economic flow.

In order to maintain the progress the reform process, the executive emphasised the need to continue to build up the institutional system and to complete the legislative framework required for a market economy, so that economic actors can respond appropriately to free enterprise and competition.

The government had to take certain unpopular measures to ensure that reforms proceed and for creating the conditions favourable economic growth. Such difficult corrective measures as prices liberalisation for most products, the elimination of production and consumption subsidies, the introduction of new taxes and fiscal regulations gradually led to encouraging economic developments, stemming price rises and inflationary pressures with favourable effects on the cost of living. The economic reform policies were geared to the need to stabilise the economy as a whole.

Privatisation is the most important process and determines the length of the transition to a market economy. Thus law No. 55/1995 pursued the acceleration of the privatisation process while rapidly shaping ownership structures respectful of social equity.

Other very important laws were drafted and a set of ordinances and resolutions issued to:

- create a special institutional framework for changing the ownership structure and managing state property (State ownership Fund, five Private Ownership Funds, National Privatisation Agency, Romanian Development Agency);

- promote organisational, institutional and legislative measures to ensure the adequate functioning of the goods and services market;

- regulate and organise the labour market;

- restructure and develop the banking and insurance system;

- organise the basic institutions and the legislative background for the creation of the capital market (Stock exchange, National Commission of Stock Exchange);

- improve the fiscal and budget system;

- promote reform programmes in health care, education, social security, etc.

Conceived to first stimulate the forces of the market, the structural policies:

- liberalised prices

- develop financial and managerial reform of state-owned economic agents;

- promote an income policy in line with the evolution of efficiency indicators;

- regulate the administration of the public sector, develop the state monopoly and ways to make public corporations (regies autonomous) efficient;

- create incentives meant to help develop the private sector;

- apply large-scale privatisation programme (MEBO, law no. 55/1995);

- grant fiscal incentives to certain categories of economic agents; 
- further liberalise foreign trade, stimulate export and foreign investments.

For each of these problems, specific laws have been adopted. The policies promoted assume that the local and central public administration is the major factor in implementing the socio-economic reform programme at the macro- and micro-levels because it covers virtually all fields and sectors of activity, and is in direct and permanent contact with the population.

The governance programme established concrete objectives and priorities for the reform of public administration, and adequate ways and means for its implementation. The has been tightly correlated to reforms in other areas of the socio-economic activity and to the reform of local public administration. Its main goal has been to secure that elected authorities function and carry out their responsibilities effectively. This goal focused on four factors:

- improving the juridical framework of the organisation and functioning of the local public administration (Law No.69/1991 on the local public administration, Law No.70/1991 on local elections, new regulations regarding local public finances).

- develop and diversify the public services. Local responsibilities include water supply, sewerage, street maintenance, waste collection, among others.

- professional training of personnel to ensure the success of the next stages.

Certain steps have been taken so that the process of economic, social and administrative reform is accompanied by training at university, post-graduate and doctoral levels for specialists in political science, social communication and public relations, management, public administration and international relations. The same attention is being given to the employees of NGOs, economic agents, trade union organisations, who can benefit from this kind of training upon request.

- the ever stronger promotion of social dialogue in the public administration.

The adequate institutional framework has been established, both at central and local levels, to ensure that co-operation with civil society and with established bodies of interest representation on public administration issues become systematic, organised and responsible.

\section{Civil Service Reform}

According to the constitution, central and local-level public services must observe the legislative framework. Other stipulations to be observed in providing public services are financial legislation, customs legislation, etc.

Public administration legislation plays an important role in developing public services. The law on local public administration was given high priority and was adopted in 1991 before the constitution was adopted.

The legislative framework for the organisation and responsibilities of central administration has been realised during these 5 years by stipulations corresponding to current requirements. (See Annex 3 ). It is important to mention that achieving the reform objectives and tasks in the central and local public administration depends on training the personnel and on their good knowledge and strict observance of legal provisions and other normative acts. 


\section{The Public Administration Training System Before Transition}

Professional training started during the 1970s with the creation of a legal framework and the building up of an appropriate institutional framework. A national training system was created which recognised professional training to be both a right and a duty for each employee.

Laws No. 2/18 March 1971, concerning the perfecting professional training of the employees from all socialist units; No. 12/21 October 1971, on employment and promotion of the socialist units' personnel, No. 10/1972 - Labour Code, all establish the appropriate legal and organisational framework (See Annex 4).

It was in this context that institutes and specialised centres were created. Within middle and higher education, new colleges, high schools and facilities with special sections appeared. Special institutions for training central and local administration managers such as CEPECA and Stefan Gheorghiu Academy were created. Even if training curricula were political, some innovative programmes were developed by these institutions with the support of UNDP (Annex 5).

Professional training became less important slowly, because the centralised political and economic system did not permit information to circulate freely. Furthermore, access to modern technologies and training materials was limited. Human resources in the public administration were therefore developed in a context of:

- limited access to new technologies and speciality documents;

- difficult exchange of ideas and information with similar international;

- no motivation and unrecognised professional competence, creativity or innovation;

- no professional perspectives due to a rigid, inflexible promotion system based mainly on political or age criteria rather than on job performance;

- standardised personnel structure with very small salary differences.

Despite unfavourable conditions, public administrators formed before 1989 were of high professional standard because the education system ensured the appropriate conditions for a strong general culture and theoretical training in different specialisations. It must be also said that many professionals individually sought training in order to overcome these difficulties.

\section{Objectives of Training}

The objectives pursued by the training activity mainly stem from the concept of "public service," at the basis of the public administration system activity. (See Annex 6) The public service concept was defined before the second World War. It has basically remained unchanged since; but techniques and realisation were influenced by the scientific and technical evolution and by the political context of public services.

Training activities play an important role in increasing the quality of public services. Objectives include:

\section{Changing the Mentality of Service Provider at the Decision-Making and Operative Levels:}

Changing mentality is a long and difficult process that can succeed only through sustained training activities and when a legal framework clearly expresses the functions of local communities and deconcentrated services The level of corruption in the public sector must be reduced, and this can occur by changing mentality. 
Providing Permanent Training for Elected and Appointed Officials to Increase Public Administration Efficiency and Performance:

A modern public service cannot be established without considering training logistical assets necessary for providing the required public service: workspace, offices, computers, etc.

Training for central and local public administration is provided in different forms at universities, post-university institutions, in short-term courses in a system described below. In the future, course curricula will be harmonised and developed according to internal demands and European law and practice.

A widely acknowledged training objective is to guarantee the rule of law.

Providing Appropriate Assets in Order to Increase the Quality of Public Services and Information Flows:

As far as assets are concerned, special attention will be paid to information technology in public administration in order to facilitate information flows between central and local administrations.

\section{Conclusion:}

Public service training objectives must respond to the main goals of modernising public service which should:

- offer the necessary judicial and administrative knowledge to enable public servants to fulfil their functions;

- provide the necessary knowledge and techniques to innovate and modernise public administration;

- increase decision-making competencies and provide the necessary tools for analysing public policies;

- increase efficiency;

- offer the possibility to fully discern the issues in development strategy in a specific context;

- offer the opportunity to evolve from a bureaucrat culture to a complex corporate culture by providing analytical tools to realise modern planning, management, organisation, human resource management, communication, public image, controlling and evaluating results;

- develop managerial skills;

- support the public services adaptation process to international co-operation and European integration.

\section{Legal Framework}

The debate about drafting a new Constitution did not touch on issues of the public service or the training of officials. Other legislative activity concerning education was deemed important by the Ministry of Education, the government and Parliament. Between 1990 and 1995, many legislative documents were adopted, the most important was Education Law No. 84 /1995. The resulting legal framework stipulates very clearly stipulates the responsibilities of central, county and local authorities.

However, it is important to mention that the legislation presented in its first chapter concerning professional training still operates at present, even if new regulation and laws were adopted after 1989. The Labour Code is applied by the regulations presented in Annex 4. 
The new Education Law (84/1995) confirms the training forms for each level (Pre-university, university and post-university) and also specifies ways to provide continuing permanent education. Law No. 30/1990 concerning the selection for recruitment on the basis of competence and skill must be added.

All of these laws show that professional training represents a right and an obligation for each worker and a condition for employment and promotion. However, these issues are not defined precisely by any legal regulation. Consequently, employment and promotion can be decided upon without taking these broad rules into account.

It must also be said that the national system of professional training established by law 2/1971 does not function properly because of major changes generated by the transition process. This implies a reconsideration of certain issues.

An analysis of the present situation leads to the following conclusions:

- At present, no coherent and homogenous training system exists for public administration servants. A system specific to Romanian history, economy, social life, culture and policy should be developed in accordance with existing European training systems. Government decision No. 542/1995 concerning the re-organisation of the NSPAS sketches such a training strategy.

- The draft law concerning the status of civil servants has not been adopted so far. The status of the civil servant is essential for modernising public services, given the impact on the employees in public administration (rights and obligations). This law was formulated in close co-operation and with the support of foreign experts and is currently being studied by the Judicial Commission of the Senate. It will provide a general framework for civil servants employment conditions (recruitment, promotion, appointment, retirement, arbitration) and will add some conditions concerning training rights. Each category of civil servants, either elected or appointed, will have specific provisions according to their activity. The complexity of these judicial stipulations, and their influence on the administrative requirements, gave rise to an active and serious debate. It is worth mentioning that within the Phare Programme for public administration reform, a specific component is dedicated to public service ethics.

Training the public service can therefore be said to constitute a priority, but various issues remain unsettled. A clear legal framework is needed to establish the organisational and operational framework for the training system at national level, and to emphasise pre-service training and continuing training in the employment and promotion processes respectively.

\section{4. $\quad$ Funding}

The entire infrastructure of the public education sector is financed from the national budget. Some exceptions - taxes - are being used to finance higher education institutions. In 1995, the public education system was financed from the national budget at a rate of about 3 per cent of GDP. For 1996 and the following years, Article 2 of the Education Law stipulates that "In Romania, education represents a national priority." Article 169 stipulates that "Financing the state education is supported by the national budget with at least $4 \%$ of GDP."

The structure of the national budget is arrived at by establishing and financing the highest priority areas for strategic areas, nationally. Budgetary allocation to education is meant to depend on the classification of expenses for each area in the national development strategy framework. 
In fact, however, the minimum 4 per cent of GDP is not respected; the allocation is less and represents the money remaining after the distribution among other fields of activity. For post-university civil servants training activity, expenses are borne by units interested in training their employees: "The fees for adult professional training courses are supported by the beneficiaries or by interested units" (Article 136, alignea 2; Education Law No. 84/1995).

The ministries and other central and local administration bodies do not have, for the moment, specific budgets for training, which means that the expenditure for this purpose cannot be identified. It is hidden in different budgetary items which can be used according to the discretion of the head of the respective organisation.

For the needs of this document, some research was conducted in order to obtain reliable data on training and its financing. Of the 19 ministries contacted, 15 replied. Data analysis thus obtained shows that the ministries had allocated only 0.2 per cent of their 1995 budget for training activities. 1990 data is not significant because of ministerial reorganisation (See Annex 7).

However, the data concerning the training allocation for central and local public administration are incomplete and often imprecise. It would be useful to know how much money, on average, local public administration allocates to training its personnel. In this context, it is important to mention that the government decision 542/1995 concerning the reorganisation of the National School of Political and Administrative Studies stipulates that, from this year on, local authorities should allocate a certain amount of their budget to training office-workers.

The funds granted by central and local administration for training were also increased by external grants. Romania is a major recipient of foreign aid within the CEEC. Bilateral and multilateral grants have been made available since 1990 and widely used in the reform process.

From 1990 to 1994, Romania was allotted approximately 540 million ECU of non-reimbursable assistance from the European Union. On the whole, the Phare Programme has been a significant contribution to the support of the reform process. Almost two thirds of the Phare funds allotted to Romania were directed to economic development and to the private sector. Approximately one quarter of the funds was used for human resources development and the remaining funds of approximately 15 per cent - were mainly used for preliminary technical assistance to customs, statistics, public administration, communications and energy.

Throughout the period, Phare support concentrated on assisting government institutions in defining medium- and long-term objectives, in the elaboration of necessary legislation and regulations, in the development and equipment of institutions, in the improvement of professional competence and of professional training capacities.

An important proportion of these funds has been spent on training central and local public administration employees. Centralised data on the amounts spent is not available. Information on the ratio between internal and external funding (bilateral aid, Phare programmes, UNDP, USAID, World Bank, Know-How Fund etc.) for public servants' training is not available.

Pre-university and university state institutions are state funded and determine their organisation and functions autonomously. All other professional training institutions are organised on a self-financing principle and are therefore autonomous in managing their budgets. After 1990, new public institutions, centres or foundations dedicated to professional training were created. Some were established entirely or 
partially with external financing; all may be sponsored. For the moment, no precise statistics about such institutions exist.

\section{Training Institutions and Legal Status}

Central or local staff training is being provided by specialised lycées, colleges, universities, postgraduate education, short-term courses etc. In principle, the system of initial and permanent training is decentralised, with special emphases on each training level:

- high or middle skills;

- on each working level: central, regional, local;

- on financing resources: from budget, mixed, self-financed etc.;

- on propriety principle: public or private.

\section{Education for Public Administration}

Initial training for the middle and higher educated personnel working in the public service is provided by special high-schools, colleges and universities.

For some specific fields of activity, a coherent pre-service and in-service education system is already in place (Ministry of the Interior, Defence, Justice, Education and Health). Here, there are also special high-schools and faculties and different forms of continuous training.

Other special skills required in public administration are usually taught in some other state or private pre-university or university institution with an economics, judicial or social profile.

The following Table presents the main institutions (1995) specialised in training for public administration: 


\begin{tabular}{|c|c|c|c|}
\hline Skill Level & $\begin{array}{l}\text { Legal Status } \\
\text { Field of activity } \\
\text { Duration }\end{array}$ & $\begin{array}{l}\text { Number of } \\
\text { Institutions* }\end{array}$ & $\begin{array}{l}\text { Students } 94 / 95 \\
\text { a) Total } \\
\text { b) (Graduated) }\end{array}$ \\
\hline \multirow[t]{9}{*}{ A. Higher skills } & 1. University Administration & & \\
\hline & $\begin{array}{l}\text { 1.1. Post graduated studies } \\
\text { ( } 2 \text { years) }\end{array}$ & $\mathrm{S}=1$ & \\
\hline & $\begin{array}{l}\text { 1.2. Post - graduate courses } \\
\text { (1 year) }\end{array}$ & $S=1$ & \\
\hline & $\begin{array}{l}\text { 1.3. Faculties with administrative } \\
\text { sciences profile } \\
(4-5 \text { years })\end{array}$ & $\mathrm{N}=13$ & \\
\hline & $\begin{array}{l}\text { 2. Colleges - Administration } \\
\text { profile - Secretariat }{ }^{21} \\
\text { ( } 3 \text { years) }\end{array}$ & $N=14$ & $\begin{array}{l}\text { Total } 1.3+2= \\
15424\end{array}$ \\
\hline & 3. University ${ }^{22}$ & & \\
\hline & $\begin{array}{l}\text { 3.1. Juridical sciences } \\
(4-5 \text { years })\end{array}$ & $\begin{array}{l}\mathrm{S}=7 \\
\mathrm{P}=15\end{array}$ & \\
\hline & $\begin{array}{l}\text { 3.2. Economics } \\
(4-5 \text { years })\end{array}$ & $\begin{array}{l}\mathrm{S}=85 \\
\mathrm{P}=24\end{array}$ & \\
\hline & $\begin{array}{l}\text { 4. Economy colleges } \\
(3 \text { years ) }\end{array}$ & $\mathrm{N}=4$ & $\begin{array}{l}\text { Total } 3+4= \\
47712\end{array}$ \\
\hline \multirow[t]{5}{*}{ B. Middle skills } & $\begin{array}{l}\text { 1. Post-lycées institutions } \\
\text { finances, bookkeeping, } \\
\text { administration (including profile } \\
\text { sections) ( } 2 \text { years) }\end{array}$ & $\mathrm{N}=90$ & $\begin{array}{l}\text { Total }=5556 \\
\text { Graduated }=3068\end{array}$ \\
\hline & $\begin{array}{l}\text { 2. Economic and administrative } \\
\text { lycées ( } 4-5 \text { years) }\end{array}$ & $\mathrm{N}=49$ & \\
\hline & 2.1. Finances - Bookkeeping & & $\begin{array}{l}\text { Total }=26230 \\
\text { Graduated. }=6100\end{array}$ \\
\hline & 2.2 Administration and services & & $\begin{array}{l}\text { Total }=4298 \\
\text { Graduated }=890\end{array}$ \\
\hline & $\begin{array}{l}\text { 2.3. Statistics and information } \\
\text { technology }\end{array}$ & & $\begin{array}{l}\text { Total }=419 \\
\text { Graduated }=60\end{array}$ \\
\hline
\end{tabular}

* S:State institutions

P: Private institutions

$\mathrm{N}$ : Number

21. See Annex 10.

22. In these institutions specialised personnel are trained for the entire work force market, a significant part is employed in the public administration. 
Pre-service personnel training for those in the public administration is provided by different institutions, according to the trainee's speciality and skill level. Some objectives are specific, other are general. The degree of institutional subordination is of a pyramid type and the degree of autonomy is horizontal. This is clear in the training programmes process. Some curricula are national, others are local.

\section{In-Service Training}

With regard to continuous training of central public administration, the situation is very complex:

- Generally, each ministry has a training centre or a specialised institution to train its own personnel, according to HG 179 / 1990; some recently became autonomous. (Annex 11) Most training institutions belonging to the ministries are specialised to serve their needs exclusively. In the training process, the ministries also collaborate with other specialised centres.

- After 1990, new centres/specialised institutions, public or private, were created, especially in management, marketing, foreign affairs, foreign languages, information technology (See International Foundation for Management Year Book 1995/1996 and Annex 12).

- For training appointed public servants in the central administration, a Centre for Training Public Servants in the Local and Central Public Administration was created in Bucharest by government decision No. 542/1995.

- A range of courses, seminars, and conferences addressing mainly central administration was developed with the support of EU, UNDP, ILO, BERD, World Bank, G 24, OECD, etc.

- For ongoing or permanent training of appointed and elected public servants in the local public administration, five autonomous centres have been established by governmental decision No. 542/1995 in Bucharest, Iasi, Cluj, Sibiu and Craiova. For the first three months, the establishment and operation of these centres is financed from the budget and Phare funds. The centres are autonomous and financed from local budgets, and the methodological guidance is provided by the National School of Political and Administrative Studies. In the future, these centres will have to define their own methodology and curricula, depending on trainees needs. It should be underlined that in the organisation and running of these territorial centres non-government bodies of the authorities of the local public - The Association of the Presidents of County Councils, The Federation of Municipalities in Romania and The Federation of Towns - also have a say.

- There are distinct courses for training public servants in the international assistance programmes available to support the administration reform. Modules within such courses will also be developed within the Phare and SIGMA Programmes.

At present, there is no institution or other training body able to co-ordinate the training activities addressed to civil servants. As far as pre-service training is concerned, only the National School of Political and Administrative Studies' training courses may be considered entirely pre-service training specifically for the public administration. This institution provides initial and permanent training for central and local public administration.

Considering the above and according to the governance programme passed by Parliament, on 21 July 21 1995, Parliament passed and the government adopted decision No. 542, on the merger of the NSPAS, subordinated to the Ministry of Education, the Institute of Management, subordinated to the Ministry of Labour and Social Protection, and the Training Centre for Local Public Administration Personnel, 
subordinated to the Department for Local Public Administration (See Annex 13). This measure ensures that the process of economic, social and administrative reform is reinforced by training specialists at university, post-graduate and doctoral levels in the political science, social communication and public relations, public administration and international relations. Personnel in non-governmental public institutions, economic agents, and trade union organisations, can also take advantage of this continuation Romanian education traditions in accordance with international norms and standards.

Post-graduate training will be provided in two-year courses within five departments and by follow-up courses of up to three months at The Centre for Training Public Servants in the Local and Central Public Administration and at IROMA; university training will be provided by two faculties and five colleges. Professional training and improvement of civil servants in the autonomous local public administration will be provided by these five autonomous territorial centres.

\section{The Legal Status of Training Institutions}

Training institutions are subject to public and private law. High-schools (specialised lycées) and state institutions are financed by the national budget and are organised under the Education Law settlements which have university autonomy.

Training centres, subordinated to ministries are, in general, autonomous and self-financed. Their training programmes are established in accordance with the ministries' demands. Only the few centres financed from budget feel the influence of ministries/agencies on staffing and curriculum. Other public and private institutions/centres as well as foundations are autonomous, self-financed and operate on market principles. There is little competition between public and private institutions for the moment, since public institutions represent a large majority. But self-financed institutions compete because each tries to offer the best price-quality relationship.

\section{Teaching Personnel}

The diversity of teaching personnel reflects the great number of training profiles. Generally speaking, trainers either come from a public institution with direct responsibilities in this field, or from other institutions with demonstrated training competence.

Trainers are selected according to specific training needs in:

- central and local administration;

- research units;

- education units;

- academies;

- universities;

- scientific associations;

- specialised institutions;

- private agencies, foundations.

Foreign consultants and trainers also play an important role in some international training programmes. The trainers' responsibilities are certified and they have a contract for a specific duration or have a special collaboration contract, or are paid for each activity according to applicable laws. Teaching quality is considered to be good. 
The total number of trainers cannot be estimated, since the same trainer may offer training activities in several institutions.

In general, civil servants training institutions except academies and universities do not have a large number of full-time staff but use part-time trainers or pay the trainers on a contract basis, according to laws HG 281/1993 and Remuneration Law 14/1991. The contract defines the level of remuneration, the time allotted for completing a particular task and other conditions.

Full-time teaching staff must possess:

- an academic degree;

- knowledge of at least one foreign language;

- experience in comparable work, management or consulting;

- professional public activities;

- publications.

Part-time teaching staff qualifications focused more on experience and successful practice.

It is interesting to note that the salary level for teaching staff is below the national remuneration average. At present, training personnel remuneration is increasing, but the highest monthly salary for a training expert is still no more than 340700 lei, and 470000 lei for university professors. (exchange rate: about 2900 lei/\$). For teaching staff in the private sector, there is no precise data, but remuneration is estimated to be 2-3 times higher than that of teaching staff working in public institutions.

Generally, teaching personnel is university educated, has pedagogical expertise and practical experience. Trainers are able to respond to specific training needs and to analyse and formulate solutions for practical problems encountered in public administration activity.

However, in many cases the trainers themselves need to be trained in order to acquire new training methods, to apply participative and active training methods, to conduct case studies and to use multimedia facilities. To keep up with the rapid transformation process, public administration trainers also need to have their knowledge continuously updated in specialised institutions abroad.

\section{Needs Assessment and Content of Training}

In order to raise the level of higher office-workers and public administration managers they must complete, in addition to higher education, some post-graduate courses focused on developing their abilities to carry out the specific functions of public administration. Middle office-workers face new challenges such as modernising their work by learning to use new technologies and acquiring new communication and computer skills.

Changes in the initial and permanent training activity are thus necessary and training programmes focus increasingly on problems of public management in order to create an efficient and modern public administration.

The re- integration of Romania into European structures implies:

- modernising the public administration system;

- reforming human resource management; 
- raising the level of skills.

Needs assessment and training content therefore depend on:

- acquiring training experience in the field;

- the requests formulated by the public administration institution leaders and the individual training needs identified by training institutions;

- legal and functional changes in the public sector;

- the requests to adapt the administrative structures to European standards.

Content of training programmes includes:

- general training (legislation, political science, economy, management, foreign languages, computer literacy, public administration, international relations, etc. );

- specialised training including everything for performing a particular job.

The most often requested subjects are:

- education policy;

- public school administration policy;

- information technology and the administration system;

- management of change;

- performance management;

- human resource management;

- management of finance;

- management of education;

- total quality management;

- strategic management;

- problem solving and decision making;

- conflict resolution;

- general and financial legislation;

- project management;

- statistics and administrative organisation of institution;

- leadership, communication and motivation;

- the psycho-sociology of leadership and organisations.

Knowledge transfer from advanced countries has led to important changes in teaching methods and training content. International co-operation improved the quality of training and consulting activities.

Admission to the various pre-service training programmes depends on examinations. Universities can be attended after passing difficult oral and written entrance examinations. Each institution creates an authorised commission for examination and re-examination when results are contested. Private universities do not normally organise examinations but only tests and only when number of candidates exceeds the number of available places. Each institution establishes examination topics on the basis of specific profiles or according to applicable legislation.

Some institutions also have a range of initial requirements for access to the examination (NSPAS has defined the following entry requirements for participation in postgraduate training: to be 32 years of age or younger, to have a Master's Degree and to be fluent in at least one foreign language). 
For other training formats, especially for professional courses, there are no preconditions, but only tests to determine participant level.

\section{8. $\quad$ Target Groups}

It is understood that modern public services cannot be provided without continuous staff training and the education of experts in several fields. Currently, almost 118000 civil servants are employed in the central public administration, more than 40000 as local and county councillors,

5900 mayors and deputy-mayors, and more than 7000 persons engaged in the technical and special services of the institutions of local and county administration (See Annexes 8 and 9).

In addition, there are personnel working in technical services of the economic agents placed under the authority of local and county councils, and civil servants involved in the services of ministries that are deconcentrated within the administrative-territorial units. Many of these lack proper training and experience to ensure efficiency. In accordance with the new objectives, training programmes target various groups. However, the specific nature of the training needs of two main categories of civil servants must be recognised:

\section{Management, Technical and Special Personnel}

Civil servants in this category need to be trained in order to improve efficiency and quality. Each public administration unit has to develop a training plan which must take into account: service - personnel beneficiary, according to the office - worker status and tasks. Legal regulations concerning the list of public functions at central and local level, and the minimal conditions required for each position.

\section{Political Representatives}

The members of this category need training in order to clarify their position in the public administration system and to acquire managerial knowledge to increase their efficiency. Programmes differentiate between various personnel categories, decision making or execution responsibilities. The training process is based on modules; some provide general knowledge for all personnel categories (legislation, basic administration topics, information technology, foreign languages etc.),others are dedicated to individual personnel categories.

In selecting the target group for professional training, several criteriai are taken into account: educational level; position; and field of activity.

For the top level, training is required in politics, social communication and public relations, management, public administration, international relations, regional or local strategic programming, decisions making, etc. All training for civil servants is designed to introduce modern management techniques in the public sector.

\section{Training Formats}

The education of public administration staff is usually provided by specific institutions or is offered on-the-job for training staff with middle education level (See Annex 14). For employees with higher education degrees, pre-service education of 4-6 years is organised by universities or faculties. Senior office-workers and managers are trained in order to develop their abilities in administrative, economic, 
social, judicial and political areas so as to enable them to face successfully resolve any specific problem which might come up in public administration activity.

Post-graduate education is organised by different universities and post-university schools as:

- on-going studies;

- MA programs;

- post-graduate academic courses;

- perfecting courses.

Professional in-service training for civil servants is provided as:

- on the job training under the direct control of supervisors;

- short-term courses organised inside the institution, or in other similar institutions or specialised centres;

- individual training programmes with periodical evaluation;

- long-term training programmes in the country or abroad;

- study tours and visits.

Periodic meetings are held for different categories of civil servants, information days, conferences, seminars, workshops, experience exchanges.

Ministries, central public administration bodies, local bodies and public institutions are responsible for organising the training programmes designed to improve public administration activities.

\section{Development of Training Curricula}

The curricula of training programmes are established by the education institutions together with ministries and central and local administration bodies. Each institution develops its own curriculum, according to the principles of university autonomy, but respecting the needs of interested bodies.

University training curricula are the product of long professional debates; these programmes are being improved as practical experience increases. The curricula will most likely be harmonised and developed according to domestic requirements and European practice and legislation.

At all other institution, training curricula are linked to central and local public administration activities and their development depends on new tasks for public administration (i.e. when new legal measures define new tasks or require new ways of completing existing tasks, the training curricula are modified to meet the new demand).

Training institutions also respond to a range of needs by offering specific programmes on subjects such as new bookkeeping systems, VAT implementation, adaptation of the customs system to the association agreement, harmonisation of internal legislation with European legislation, social protection, restructuring management, privatisation, SME creation, quality of services, etc.

In developing their curricula, educational institutions also collaborate with similar institutions at home and abroad, in order to respond to a range of specific priorities. 
Public and private are most flexible in their ability to respond to specific needs. They are self-financing and are interested in adapting very quickly to the needs of the public sector. They are publishing their training schedules, special booklets and catalogues.

Public administration activity changes has led to new courses ${ }^{23}$.

- European Community law;

- organising international fairs;

- the European association agreement;

- strategic management;

- human resources management;

- SME management;

- environment protection;

- social protection;

- marketing;

- ecology;

- durable development;

- GIS (Geographic Informatic System) utilisation in land and urban planning;

- European integration;

- economic and employment development strategy;

- financial management, etc.

Special attention is being paid to training specialists in European Community problems. A postgraduate study programme on Community problems is planned in Bucharest for DEA and in Iasi for MASTER.

See Annex 14 for the training curricula of NSPAS, the Public Administration Department and the Territorial Centre Bucharest.

\section{Evaluation}

The Ministry of Education is responsible for organising the evaluation of training institutions offering university and pre-university education. The evaluation of the new private or state universities is undertaken by a specialised autonomous body, the National Council for Academic Evaluation and Accreditation. Pre-university institutions are evaluated by a Commission of experts from the Ministry of Education.

Criteria (qualitative indicators) are stipulated in the law 88/1993 and in the CNEAA documents concerning academic evaluation of higher education institutions:

- legal and organisational framework, mission and objectives;

- students, admission, numbers graduated, performance;

- teaching staff: position, structure, specialisation;

- content of education process: plans, programmes, teaching materials, control;

- scientific research activity: themes, personnel, financing, validation;

- assets: space, equipment, services;

- finances: budget, incomes, taxes, financial management, non-profit character.

23. Selection of central and local administration bodies' questionnaire responses. 
Students are evaluated on a scale ranging from 1 to 10 . Depending on the training format, students graduate by:

- passing theoretical or practical examinations;

- passing written or oral exams;

- taking part in intermediary or final tests;

- writing a graduation thesis/dissertation.

Qualification level — very good, good, satisfactory, bad; or simply admitted/rejected - is recorded. Graduation is certified by a document issued by the training institution.

Training institutions evaluate course success in a variety of ways, depending on their legal status. Self-financed institutions are evaluated by the market. State-financed institutions evaluate their training programmes in two ways :

- internal evaluation by the scientific structures of the training staff;

- external evaluation by participants superiors.

Formal evaluation criteria are lacking for the moment. Courses are simply delivered within appropriate quality standards for content, trainers, teaching materials and methods, etc.

Course content and the quality are also evaluated by participants who complete an evaluation questionnaire on content, performance of trainers, trainers' skills, teaching materials, suggestions for course development, etc. The answers are usually taken into account when developing future curricula or inviting trainers, etc. There is no organised, institutionalised connection between performance evaluations in training courses and promotion.

\section{Planned Changes and Further Developments in the Training System}

In the process of transforming public administration, two basic objectives are pursued: to increase its effectiveness and to adapt its structure and functions to the needs of the accession to the European Union. A long-term Strategic Programme through the year 2000 includes the following goals and activities:

\section{Central Administration Will:}

- develop the organisational system of ministries and other central administration bodies according to applicable laws;

- increase public administration efficiency, with an emphasis on ministries and other central administration bodies activity, including public services;

- improve the manner of respecting and carrying out laws and government decisions.

\section{Local Administration Will:}

- improve its activity;

- strengthen local autonomy;

- decentralise the public service. 


\section{Other Priorities:}

- accelerate the process of modernisation in public administration according to the national strategy of accession to the EU; to the National Informatisation Programme and to other regional or European Community development programmes;

- ensure the rule of law in the activities of all public administration authorities;

- increase the competence and responsibility of the entire public administration staff.

Realising these goals requires developing a sustained training activity for central and local public administration staff (elected and employed).

In general, public administration training issues cannot be separated from the development of the legal and regulatory framework for the civil service. This refers to the status of civil servants, to the national strategy of civil servant training and to the future ministries law, all of which will lead to important changes.

Foreign expert participation in different training programmes and the external financing of these programmes is also very important for elaborating a training strategy, designing new courses, training existing trainers, creating modern multimedia applications adapted to Romanian circumstances.

The 5 million ECU Phare Programme for public administration, begun in 1996, plays an important role in this context of change and further developments. This programme aims primarily to encourage public administration reform and to improve public administration performance according to market economy principles in a democratic society. Short-term objectives :

- Develop training competencies in order to offer the necessary knowledge, skills and competencies to the public service and political management to fulfil the new responsibilities. The programme will help to:

- design a training policy which should include the entire public sector;

identify the requested institutions and implementation context for efficient in-service and pre-service training;

- develop human resources training and management abilities in all ministries and central administration institutions by training personnel in specific fields: training policies, training needs analysis, techniques to evaluate the training institutions and programmes.

- To modernise the organisational, administrative and management abilities of ministries and central administration bodies.

- To develop public service ethics, transparency and co-operation with the private sector and non-government organisations.

Programme activities will be in accordance, whenever possible, with other international programmes operating in the central and local public administrations (multinational and regional Phare programmes, EBRD, Know-How Fund) in order to realise the goals with maximum efficiency. 


\section{Identification of Problems in Training}

The actual transition process requires a range of specific priorities and efforts in order to satisfy the national reform strategy and various pressures and dynamics which are difficult to predict at present.

Considering the strategic perspective of the administration system, the short, medium and long-term objectives are to:

- train professional office-workers to implement the reform programmes;

- create a professional and efficient training concept, based on international standards and appropriate skills and competencies;

- develop patterns of managerial behaviour and inter-active partnerships, with a significant impact on public opinion, able to implement specific reform tactics and strategies;

- elaborate and introduce new efficient methods in the employment and promotion process in order to attract the best office-workers and new graduates for the public administration;

- encourage those working in public administration to understand the process of decentralisation and to promote the delegation of decision making from top to intermediary levels;

- develop efficient consulting activities for government authorities;

- develop a public education service based on a professional and efficient ethos, on correct and in-time solutions, on a good price-quality ratio, which could preserve high education standards;

- promote new institutional forms in order to stimulate communication and up-to-date information flows, adapted to specific public administration needs.

Meeting these objectives means:

- creating specific training programmes;

- adapting existing services;

- developing institutional collaboration at national and international levels, and collaboration between the public and private sectors.

Meeting the objectives defined already is not easy, given the problems:

- lack of necessary funds for training activities, which influences the number of trained civil servants, training quality, level of training equipment, etc.;

- lack of a specific management culture and, hence, the need for management education at all levels;

- lack of specialised trainers; shortcomings of the psychology of administrative activity and of the attitude to training;

- lack of modern techniques and methods and of some necessary modern training tools. 


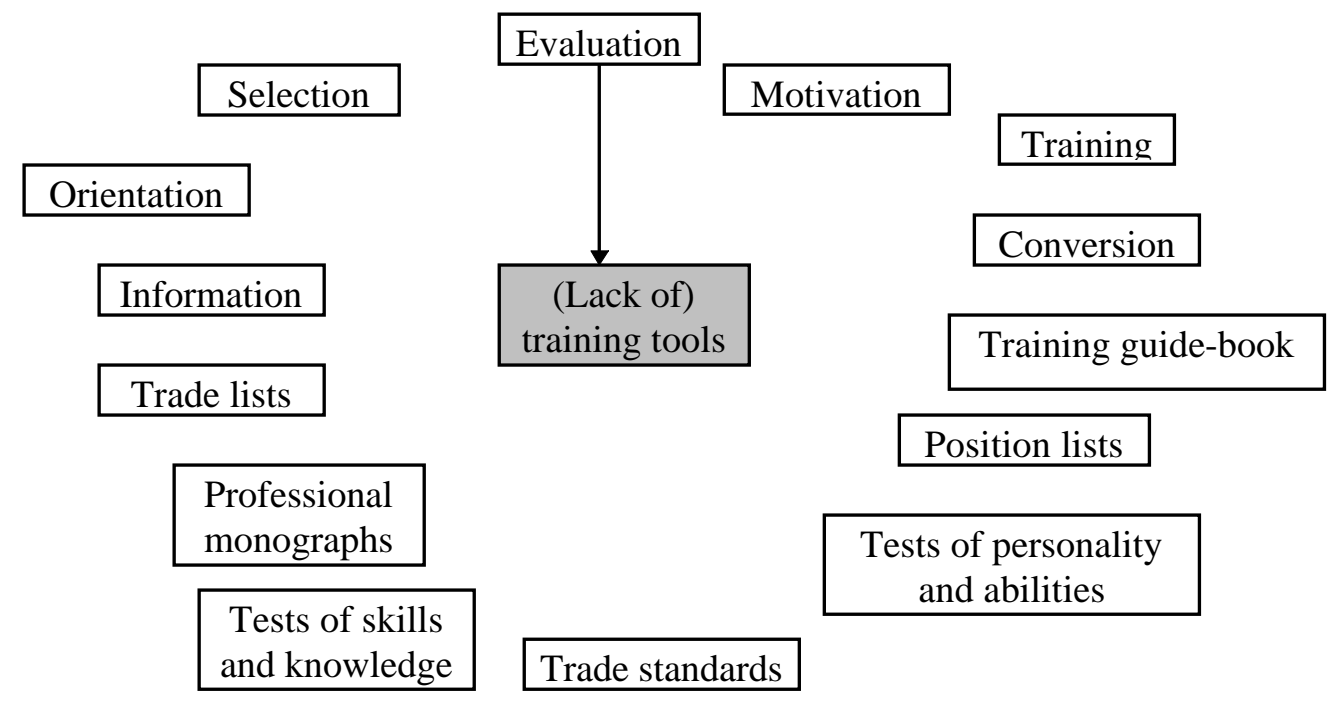

\section{Conclusions}

A stable and strong administration may positively influence speed, quality and intensity of changes in the education process and also guarantee the application of the relevant laws. In this sense, education and training activities become very important for progress in Romanian society. The success of pre-service and in-service professional training and the possibility to monitor, validate and evaluate human resources depends in the short, medium and long-term, on the success of administrative reform. The quality and efficiency of training objectives and programmes are determined by the quantity and quality of local resources, by the adjustment and self-adjustment process and by the public administration's attitude towards public services and the private sector.

In Romania, today, almost everybody is aware that:

- investments in training human resources is the most efficient investment;

- ensuring efficient public administration makes management issues increasingly important;

- as long as management problems in public administration remain unresolved, reforms will not meet their objectives.

The government therefore makes every effort to focus its attention on the central and local public administration development priorities. This report demonstrates that all decision makers and officials are very interested in promoting and continuing efforts to create an efficient, democratic and modern administration based on permanent professional training. 
ANNEX 1. THE EDUCATION SITUATION IN 1993

\begin{tabular}{|c|c|}
\hline $\begin{array}{l}\text { Education } \\
\text { - Units } \\
\text { - } \quad \text { School population } \\
\text { - } \quad \text { Children in kindergartens }\end{array}$ & $\begin{array}{r}1993-1994 \\
29375 \\
4569255 \\
712136\end{array}$ \\
\hline $\begin{array}{l}\text { Total Pupils } \\
\text { - Day education } \\
\text { - Evening education } \\
\text { - Extra-mural education }\end{array}$ & $\begin{array}{r}3607032 \\
3504819 \\
101136 \\
1077\end{array}$ \\
\hline $\begin{array}{l}\text { Total Students } \\
\text { - Day education } \\
\text { - Evening education } \\
\text { - Extra-mural education }\end{array}$ & $\begin{array}{r}250087 \\
208898 \\
21090 \\
20099\end{array}$ \\
\hline Teaching Staff & 288621 \\
\hline $\begin{array}{l}\text { Higher education (excluding private education) } \\
\text { - Higher education institutions } \\
\text { - Facilities } \\
\text { - Total enrolment } \\
\text { of whom: } \\
\text { Short education (colleges) } \\
\text { - Teaching staff }\end{array}$ & $\begin{array}{r}63 \\
262 \\
250087 \\
9191 \\
19130\end{array}$ \\
\hline
\end{tabular}

Students Enrolled by Speciality in Academic Year 1993-1994 (Day, evening and extra-mural education)

\begin{tabular}{|c|c|}
\hline Total & 250087 \\
\hline Technical & 111145 \\
\hline Medicine and pharmacy & 25738 \\
\hline Economics & 39867 \\
\hline Judicial & 14854 \\
\hline University-pedagogy & 54297 \\
\hline Artistic & 4186 \\
\hline
\end{tabular}


ANNEX 2. PRIVATE EDUCATION AT ALL LEVELS

\begin{tabular}{|l|c|c|c|c|}
\hline \multirow{2}{*}{} & \multicolumn{2}{|c|}{ Education Units } & \multicolumn{2}{c|}{ School Population Enrolled } \\
\cline { 2 - 5 } & $\mathbf{1 9 9 2 - 1 9 9 3}$ & $\mathbf{1 9 9 3 - 1 9 9 4}$ & $\mathbf{1 9 9 2 - 1 9 9 3}$ & $\mathbf{1 9 9 3 - 1 9 9 4}$ \\
\hline Pre-school education & 16 & 14 & 451 & 686 \\
\hline Secondary school education & 4 & 4 & 1194 & 1201 \\
\hline $\begin{array}{l}\text { Vocational and } \\
\text { complementary apprentice } \\
\text { education }\end{array}$ & 34 & 21 & 18296 & 11048 \\
\hline $\begin{array}{l}\text { Speciality post-lycée and } \\
\text { technical foremen education }\end{array}$ & 23 & 20 & 2807 & 2841 \\
\hline \begin{tabular}{l} 
Higher education \\
\hline
\end{tabular} & 328 & 316 & 85000 & 110880 \\
\hline
\end{tabular}




\section{ANNEX 3. CENTRAL PUBLIC ADMINISTRATION STRUCTURE}

\section{Ministries}

- Foreign Affairs

- National Defence

- Justice

- Interior

- Finance

- Labour and Social Protection

- Commerce

- Tourism

- Industry

- Agriculture and Foodstuffs

- Transport

- Communications

- Public Works and Regional Planning

- Water, Forests and Environmental Protection

- Education

- Research and Technology

- Culture

- Health

- Youth and Sport

Other Speciality Central Authorities of Public Administration

1. Under Government Subordination:

- Bureau for Legal Metrology

- State Secretariat for Religions

- State Secretariat for Disables

- State Secretariat for the Problems of the 1989 Revolution

- The National Agency for Privatisation

- Romanian Agency for Development

- National Commission for Prognosis

- State Office for Inventions and Trade Marks

- Romanian Office for Standardisation

- National Commission of Informatics

- Office for Consumer Protection

- National Commission for Statistics

- National Administration of Material Resources

- Office for Special Protection

2. Autonomous Authorities:

- National Defence Supreme Council

- Romanian Intelligence Service

- Legislative Council

- Cours des comptes 


\section{ANNEX 4. PRINCIPAL LEGAL ARTICLES CONCERNING PROFESSIONAL TRAINING FOR CIVIL SERVANTS}

\section{Law No. 2/1971 on perfecting professional training of socialist units staff}

\section{Chapter I}

Article 1. In the Socialist Republic of Romania, perfecting professional training represents a fundamental duty and a permanent obligation for the leadership staff of the socialist units .... In order to develop this activity in a systematic manner, the national system for perfecting the professional training or all workers was created in 1971.

Article 2. Perfecting professional training means to:

- recycle;

- polyqualify;

- requalify;

- acquire modern methods and procedures in leadership and scientific work and production organising fields.

Article 3. Perfecting the professional training by:

- a) on the job training under the direct supervisor's supervision;

- b) courses organised in the units or elsewhere and in specialised centres for preparing staff;

- c) individual perfection programmes with periodical evaluation;

- d) Practical activities and specialised programmes in their own or other units, national or abroad;

- e) graduation, after taking the job, from an education institution, including post-university education;

- f) MA degree.

Article 6. Ministries, other central organisms, executive committees, popular departments, Bucharest local council and the subordinate units organise perfection professional training for workers by activity profile.

Law 12/1971 concerning the employment and promotion the staff working in the state socialist units

\section{Chapter I: General Dispositions}

Article 4. Personnel employed in the state socialist units has the following legal rights:

- a) to work in its own profession or job, according to education level or other completed forms of training.

- e) to get grants and other facilities in order to perfect professional preparation. 
Article 5. Personnel employed in the state socialist units have the following duties:

- e) permanently improve professional level, to take and complete appropriate courses organised by the unit of employment.

By "state socialist units" the present law means ministries, other central organisms, the executive committees of popular country councils, communal councils and all subordinate economic, social, cultural and administrative units.

\section{Chapter II: The Mode of Employment and Promotion of the State Socialist Units Staff}

Article 7. Employment and the promotion is made on a competitive examination basis. The examination is organised when several candidates compete for a single vacant position.

Article 10. Staff employment is made according to:

- a) level of education and any other completed training courses

- b).required experience

- c).former professional activity

- d).examination results

- e).behaviour in society.

Article 13. In a leader ship position, a person can be promoted when s/he has:

- a).the education and the experience required

- b).appropriate skill and is interested in perfecting his/her professional preparation

- c).very good results in accomplishing the tasks;

- d).good examination results.

\section{Law No. 10/1972 The Labour Code}

Article 13.

1. Production, employment in appropriate working positions and promotion to higher levels depends on perfecting professional, political-ideological and general responsibilities for each worker.

2. Continuing professional training represents an essential part of the CPR policy in order to build socialism and communism, a fundamental condition for ensuring the skilled and active participation of the workers for the prosperity of the socialist nation.

3. For this purpose, the national system for perfecting professional training offers appropriate ways and forms for all the workers to acquire new skills and competencies.

\section{Law No. 84/1995 - The education law includes in Chapter IV some settlements concerning the permanent education}

Article 135. Ministries, autonomous regies, commercial societies, any individual or juridical persons may organise independently or together with educational units, training courses for adults in order to increase the skills and competencies of their employees or, of future employees.

Article 136. Training expenses in this system are borne by the beneficiaries of the interested institutions. 


\section{ANNEX 5. THE TRAINING SYSTEM BEFORE TRANSITION}

The Stefan Gheorghiu Academy was created in 1971 to train staff in leading positions in politics, economics, ideology and organisation, along with the Central Committee of Romanian Communist Party.

Sections:

- Institute introducing staff to social and political leadership problems.

- Central institute for training staff of the state economy and administration.

- Journalism faculty.

- Centre for perfecting political and ideological preparation of political and social science teaching staff.

- Central school for trade union staff.

- Central school for the staff of the Youth Communist Union.

- Courses to train the heads of agricultural production co-operatives.

- Centre for training party staff.

- Centre for perfecting top-level staff in economy and administration.

- Centre for training diplomatic and foreign affairs staff. 


\section{ANNEX 6. PUBLIC SERVICES}

Pr. Paul Negulescu defined the public service as an administrative organism, with determined competencies, financed by the general budget of public administration created either by the state, the county or commune in order to satisfy a public need and ensure regular and permanent application.

Public service is therefore seen as an activity of general interest. Public authorities are those deciding when and how the public service is to be realised.

In Romania, public services can be classified according to the following criteria:

a) The extension of the interest to be fulfilled (social request, national interest and social request at local level, commune, town, county, local interest).

b) According to the nature of organised public services (administrative public services or commercial-industrial public services).

c) According to the applicable legal regulations.

- administrative regime (public services and subordinate institutions organised and acting as administrative authorities);

- mixed regime of administrative law and private law (private initiatives fulfilling public service tasks sanctioned by specific laws).

d) Organisation.

- by administrative authorities: ministries, departments, directorates, offices, local councils, mayors, county councils;

- public institutions: schools, universities, hospitals, radio and television;

- organisations co-ordinated by public authorities;

- associations and foundations established on private initiatives and developing an activity of public interest;

- private initiatives fulfilling public service as a result of contracting out.

The Romanian Constitution regulates the public administration system at the national and the local levels. The first refers to state authorities who perform public services of national interest. The second concerns local authorities who perform public administration as a consequence of the principle of local autonomy (elected authorities) or as decentralised ministries' services.

State authorities who perform public services of national interest are legally organised as authorities of central public administration in specific fields (ministries) subordinated to the National Government or as "specialised bodies under Government subordination or as autonomous administrative authorities" if the law recognises this competence. 
Autonomous administrative authorities are established by laws on state organisation.

According to Article 122 of the Romanian Constitution, "decentralised public services of the ministries and other central bodies" are organised at country level, led by the prefect as the local representative of the National Government (police inspector, education inspector, health department, culture department, etc.).

Local public administration authorities such as local councils and mayors who perform public services of local interest as autonomous authorities are organised in accordance with the Local Public Administration Law.

County councils are organised under the same conditions at county level; their role being to co-ordinate the activities of local councils in order to perform public services of county interest.

In order to realise their activities, public administrative authorities adopt and issue administrative acts, whether regulatory or individual.

Another range of public services is organised by public institutions created to satisfy specific interests of citizens. These institutions are created, organised and abolished by law or, legally by Parliament, Government, ministries or other central and local public administrations.

General schools, high schools, universities, medical units, polyclinics, hospitals, the National Radio and Television Society, are examples of such institutions. They provide mainly practical activities, and only in special cases issue administrative acts such as diplomas, medical certificates, etc.

A different type of public service is represented by the autonomous administration (public establishments) which, according to law No. 15/1990, are created, organised and abolished by Government or county and local councils decisions. This type of public service may be of national and local interest and is therefore subordinated to Government, ministries or comes under the authority of county or local council. Institutions of this type are created in order to satisfy some specific public interest such as producing goods, performing works and services, transport activities for persons and goods, communication services (telephone, mail, etc.).

Finally, public services such as associations and foundations (public utility establishments) are created by private initiatives, partly as non-profit organisations.

Public services of national or local interest may be contracted out to the private sector. 
ANNEX 7. MINISTERIAL BUDGETS ALLOCATED TO PROFESSIONAL TRAINING

\begin{tabular}{|c|c|c|c|c|}
\hline \multirow[t]{2}{*}{ Ministry } & \multicolumn{2}{|c|}{$\begin{array}{l}\text { Amount Allocated to Professional } \\
\text { Training ( } \% \text { of budget })\end{array}$} & \multicolumn{2}{|c|}{$\begin{array}{c}\text { Total Personnel Trained } \\
\text { Annually }\end{array}$} \\
\hline & 1990 & 1995 & 1990 & 1995 \\
\hline \multicolumn{5}{|l|}{ Foreign Affairs } \\
\hline \multicolumn{5}{|l|}{ National Defence } \\
\hline \multicolumn{5}{|l|}{ Justice } \\
\hline \multicolumn{5}{|l|}{ Interior } \\
\hline Finance & 0 & 0 & 0 & 21593 \\
\hline Labour and Social Protection & 0 & 0.6 & & \\
\hline Commerce & 0.02 & 0.09 & 58 & 69 \\
\hline Tourism & 0 & 0.02 & 1421 & 1706 \\
\hline Industry & 0 & 0.1 & 1500 & 7000 \\
\hline Agriculture and Foodstuffs & 0 & 0.01 & & \\
\hline Transport & \multicolumn{2}{|c|}{ no available data } & 3420 & 6948 \\
\hline Communications & 0 & 0.14 & $\begin{array}{c}\text { beginning } \\
1992\end{array}$ & 5984 \\
\hline $\begin{array}{l}\text { Public Works and Regional } \\
\text { Planning }\end{array}$ & 0.05 & 0.6 & & \\
\hline $\begin{array}{l}\text { Water, Forests and Environment } \\
\text { Protection }\end{array}$ & & 0.202 & & \\
\hline Education & & & \multicolumn{2}{|c|}{$\sim 5500$} \\
\hline Research and Technology & & & 2071 & 2034 \\
\hline Culture & & 0.037 & 6281 & 5175 \\
\hline Health & 0.01 & 0.01 & & \\
\hline Youth and Sports & 0 & 0 & & \\
\hline
\end{tabular}

Note: Blank cells indicate that the respective ministry did not respond to the questionnaire. 
ANNEX 8. EMPLOYMENT BY BRANCH OF THE NATIONAL ECONOMY 1993

Figures in 000s

\begin{tabular}{|l|c|}
\hline $\begin{array}{l}\text { Public administration and defence; } \\
\text { compulsory social assistance }\end{array}$ & $\mathbf{1 1 7 . 2}$ \\
\hline Agriculture & 3537.4 \\
\hline Sylviculture, forestry and hunting & 77.3 \\
\hline Industry & 3030.6 \\
\hline Constructions & 574.0 \\
\hline Trade & 584.6 \\
\hline Hotels and restaurants & 131.1 \\
\hline Transport & 497.0 \\
\hline Post and communications & 94.9 \\
\hline Financial, banking and insurance activities & 65.4 \\
\hline Immovable dealings and other services & 416.8 \\
\hline Education & 432.0 \\
\hline Health and social assistance & 307.6 \\
\hline Other & 196.1 \\
\hline & Total \\
\hline
\end{tabular}




\section{ANNEX 9. CENTRAL ADMINISTRATION PERSONNEL}

\begin{tabular}{|c|c|c|c|}
\hline Ministry & Total Personnel & $\begin{array}{l}\text { Total Personnel } \\
\text { (own apparatus) }\end{array}$ & $\begin{array}{c}\text { Total Personnel } \\
\text { (subordinate } \\
\text { units) }\end{array}$ \\
\hline \multicolumn{4}{|l|}{ Foreign Affairs } \\
\hline \multicolumn{4}{|l|}{ National Defence } \\
\hline \multicolumn{4}{|l|}{ Justice } \\
\hline \multicolumn{4}{|l|}{ Interior } \\
\hline Finance & $49500 *$ & & \\
\hline Labour and Social Protection & $9493 *$ & & \\
\hline Commerce & & 340 & \\
\hline Tourism & & 122 & \\
\hline Industry & $840^{*}$ & & \\
\hline Agriculture and Foodstuffs & 45 999* & 469 & 45530 \\
\hline Transports & $141045^{*}$ & & \\
\hline Communications & & 78 & \\
\hline Public Works and Regional Planning & $1145^{*}$ & 325 & 820 \\
\hline $\begin{array}{l}\text { Water, Forests and Environment } \\
\text { Protection }\end{array}$ & $3100^{*}$ & 200 & 2900 \\
\hline \multicolumn{4}{|l|}{ Education } \\
\hline \multicolumn{4}{|l|}{ Research and Technology } \\
\hline Culture & $713^{*}$ & & \\
\hline Health & $271466^{* *}$ & 167 & 187651 \\
\hline Youth and Sport & 3909 & & \\
\hline
\end{tabular}

*including decentralised structures at regional level;

**including sanitary sector at regional level.

Note: Blank cells indicate that the respective ministry did not respond to the questionnaire. 
ANNEX 10. STATE OR PRIVATE HIGHER EDUCATION INSTITUTIONS USING THE WORD ADMINISTRATION IN THEIR TITLE

\begin{tabular}{|c|c|c|c|}
\hline Institution & & The Authorised Profile & Specialty Education Form \\
\hline $\begin{array}{l}\text { Christian University "Dimitrie } \\
\text { Cantemir" of Bucharest }\end{array}$ & $\begin{array}{l}\text { Faculty of Judicial and Administrative } \\
\text { Sciences Bucharest }\end{array}$ & Judicial sciences & Judicial and administrative sciences \\
\hline $\begin{array}{l}\text { University of Ecology } \\
\text { of Bucharest }\end{array}$ & Faculty of Management & Economy & $\begin{array}{l}\text { Financial and administrative } \\
\text { management }\end{array}$ \\
\hline $\begin{array}{l}\text { University College - "Fortuna" } \\
\text { of Bucharest }\end{array}$ & Office skills University College & Administration secretariat & Office skills \\
\hline University of Bucharest & $\begin{array}{l}\text { Faculty of Political and Administrative } \\
\text { Sciences } \\
\text { University College for Administration } \\
\text { and Secretariat Bucharest }\end{array}$ & $\begin{array}{l}\text { Administrative sciences } \\
\text { Administration secretariat }\end{array}$ & $\begin{array}{l}\text { Public administration } \\
\text { Office skills }\end{array}$ \\
\hline $\begin{array}{l}\text { Economy Studies Academy } \\
\text { of Bucharest }\end{array}$ & Faculty of management & Administration sciences & Public administration \\
\hline $\begin{array}{l}\text { University "Babes-Bolyai" } \\
\text { of Cluj-Napoca }\end{array}$ & $\begin{array}{l}\text { Faculty of Politics and Administrative } \\
\text { Sciences }\end{array}$ & Administrative sciences & Public administration \\
\hline $\begin{array}{l}\text { "OVIDUS" University } \\
\text { of Constanta }\end{array}$ & $\begin{array}{l}\text { Faculty of History and Administrative } \\
\text { Sciences } \\
\text { University College of Technology, } \\
\text { Economy, Informatics and } \\
\text { Administration Constanta }\end{array}$ & $\begin{array}{l}\text { Administrative science } \\
\text { Administration secretariat }\end{array}$ & $\begin{array}{l}\text { Public administration } \\
\text { Office skills }\end{array}$ \\
\hline University of Craiova & $\begin{array}{l}\text { University College of Technology, } \\
\text { Informatics and Administration } \\
\text { Craiova } \\
\text { University College of Economy, } \\
\text { Administration and Informatics } \\
\text { Drobeta-Turnu-Severin }\end{array}$ & $\begin{array}{l}\text { Administration secretariat } \\
\text { Administration secretariat }\end{array}$ & $\begin{array}{l}\text { Office skills } \\
\text { Social administration, secretariat } \\
\text { Office skills }\end{array}$ \\
\hline $\begin{array}{l}\text { "Dunarea de Jos" University } \\
\text { of Galati }\end{array}$ & $\begin{array}{l}\text { Faculty of Economic and } \\
\text { Administrative Science } \\
\text { University College of Economy, } \\
\text { Informatics and secretariat Galati }\end{array}$ & $\begin{array}{l}\text { Administrative sciences } \\
\text { Administration secretariat }\end{array}$ & $\begin{array}{l}\text { Public administration } \\
\text { Local administration, secretariat }\end{array}$ \\
\hline $\begin{array}{l}\text { "Alexandru I. Cuza” University } \\
\text { of Iasi }\end{array}$ & $\begin{array}{l}\text { Faculty of Economic Sciences } \\
\text { University College of Informatics and } \\
\text { Administration Iasi }\end{array}$ & $\begin{array}{l}\text { Administrative sciences } \\
\text { Administration secretariat }\end{array}$ & $\begin{array}{l}\text { Public administration } \\
\text { Office skills }\end{array}$ \\
\hline University of Petrosani & $\begin{array}{l}\text { University College of Technology and } \\
\text { Administration Petrosani }\end{array}$ & Administration secretariat & Office skills \\
\hline $\begin{array}{l}\text { "Petrol-Gaze" University } \\
\text { of Ploiesti }\end{array}$ & $\begin{array}{l}\text { University College of Technology and } \\
\text { Administration }\end{array}$ & Administration secretariat & Office skills \\
\hline $\begin{array}{l}\text { "Eftimie Murgu" University } \\
\text { of Resita }\end{array}$ & $\begin{array}{l}\text { Faculty of Economic and } \\
\text { Administrative Sciences }\end{array}$ & Administrative sciences & Public administration \\
\hline $\begin{array}{l}\text { "Lucian Blaga" University } \\
\text { of Sibiu }\end{array}$ & $\begin{array}{l}\text { Faculty of Judicial and Administrative } \\
\text { Sciences }\end{array}$ & Administrative sciences & Public administration \\
\hline $\begin{array}{l}\text { "Stefan cel Mare" University } \\
\text { of Suceava }\end{array}$ & $\begin{array}{l}\text { Faculty of Letters and Sciences } \\
\text { University College of Technology and } \\
\text { Administration Suceava }\end{array}$ & $\begin{array}{l}\text { Administrative sciences } \\
\text { Administration secretariat }\end{array}$ & $\begin{array}{l}\text { Public administration } \\
\text { Office skills }\end{array}$ \\
\hline $\begin{array}{l}\text { "Valachia" University } \\
\text { of Targoviste }\end{array}$ & $\begin{array}{l}\text { Faculty of Sciences } \\
\text { College of Economy and } \\
\text { Administration Targoviste }\end{array}$ & $\begin{array}{l}\text { Administrative sciences } \\
\text { Administration secretariat }\end{array}$ & $\begin{array}{l}\text { Public administration } \\
\text { Office skills }\end{array}$ \\
\hline $\begin{array}{l}\text { "C. Brancusi” University } \\
\text { of Targu-Jiu }\end{array}$ & Faculty of Sciences & Administrative sciences & Public administration \\
\hline University of Targu-Mures & Faculty of Letters and Sciences & Administrative sciences & Public administration \\
\hline $\begin{array}{l}\text { "Politehnica" University } \\
\text { of Timisoara }\end{array}$ & $\begin{array}{l}\text { University College of Technology and } \\
\text { Administration Timisoara }\end{array}$ & Administration secretariat & Professional communication \\
\hline $\begin{array}{l}\text { University College of Economy } \\
\text { and Administration of Baia Mare }\end{array}$ & Economy & & \\
\hline
\end{tabular}

Note: Public administration personnel is also trained in other higher education institutions, especially in: law, finance-economy, bookkeeping, information technology for administration, management and financial-management, environment engineering, urban engineering, etc.

The list does not include NSPAS (Annex 14). This Table comes from HG. No. 568/1995.. 
ANNEX 11. CURRENT TRAINING CENTRES FOR MINISTERIAL PERSONNEL

\begin{tabular}{|c|c|c|c|}
\hline Ministry & Subordinate Training Institution & $\begin{array}{l}\text { Budget- } \\
\text { financed }\end{array}$ & Self-financed \\
\hline \multicolumn{4}{|l|}{ Foreign Affairs } \\
\hline National Defence & $\begin{array}{l}\text { ? Military Technical Academy } \\
\text { ? Vocation post-college schools } \\
\text { ? Military colleges }\end{array}$ & $\begin{array}{l}\Delta \\
\nabla \\
\nabla\end{array}$ & \\
\hline Justice & $\begin{array}{l}\text { National Institute of training and perfecting for magistrates } \\
\text { Military school for training and perfecting the penitentiary } \\
\text { non-commissioned officers }\end{array}$ & $\begin{array}{l}\Delta \\
\nabla\end{array}$ & \\
\hline Interior & $\begin{array}{l}\text { ? Police Academy } \\
\text { ? Vocation post-college schools } \\
\text { ? Military colleges }\end{array}$ & $\begin{array}{l}\diamond \\
\diamond \\
\diamond\end{array}$ & \\
\hline Finance & - & & \\
\hline $\begin{array}{l}\text { Labour and Social } \\
\text { Protection }\end{array}$ & - & & \\
\hline Commerce & - & & \\
\hline Tourism & National institute for training and management in tourism & & $\diamond$ \\
\hline Industry & $\begin{array}{l}\text { Institute of management and informatics } \\
\text { Training centre for the personnel working in industry }\end{array}$ & $\diamond$ & $\diamond$ \\
\hline Agriculture and Foodstuff & $\begin{array}{l}\text { Innovation and training centre for development in Carpati } \\
\text { Perfecting centre for state agriculture personnel Crevedia } \\
\text { Perfecting centre for private agriculture personnel Baneasa } \\
\text { Perfecting centre for mechanisation agriculture personnel Stefanesti } \\
\text { Perfecting centre for horticulture personnel } 30 \text { Decembrie } \\
\text { Perfecting centre for the economy personnel from Dobrogostea }\end{array}$ & $\diamond$ & $\begin{array}{l}\diamond \\
\diamond \\
\diamond \\
\diamond\end{array}$ \\
\hline Transport & $\begin{array}{l}\text { Railroad training and documentation centre } \\
\text { Training centre for airline personnel } \\
\text { Training centre for merchant marine personnel and } \\
\text { harbour Constanta } \\
\text { Training centre for river navigation personnel }\end{array}$ & & 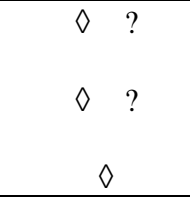 \\
\hline Communications & (ROMTELECOM training and documentation centre ) & & $\begin{array}{l}\diamond+ \\
\text { Phare }\end{array}$ \\
\hline $\begin{array}{l}\text { Public Works and Regional } \\
\text { Planning }\end{array}$ & - & & \\
\hline $\begin{array}{l}\text { Waters, Forests and } \\
\text { Environment Protection }\end{array}$ & - & & \\
\hline Education & $\begin{array}{l}35 \text { secondary schools } \\
48 \text { school centres } \\
41 \text { didactic staff centres } \\
7 \text { interdepartmental methodology centres } \\
\text { School inspectorates } \\
\text { University human resources training centres }\end{array}$ & $\begin{array}{l}\Delta \\
\nabla \\
0 \\
0 \\
0\end{array}$ & \\
\hline Research and Technology & - & & \\
\hline Culture & $\begin{array}{l}\text { Training centre for the personnel working in the culture and art } \\
\text { fields } \\
\text { Post-college and post-university }\end{array}$ & & $\diamond$ \\
\hline Health & $\begin{array}{l}\text { Institute of post-university and continuous training for doctors and } \\
\text { chemists } \\
\text { Perfecting and higher speciality training "Nursing" }\end{array}$ & $\begin{aligned} & \diamond \\
&+ \text { WB } \\
& \diamond \\
&\end{aligned}$ & \\
\hline Youth and Sport & - & & \\
\hline
\end{tabular}

Note: Blank cells and "?" indicate that the respective ministry did not respond to the questionnaire. 
ANNEX 11 (continued)

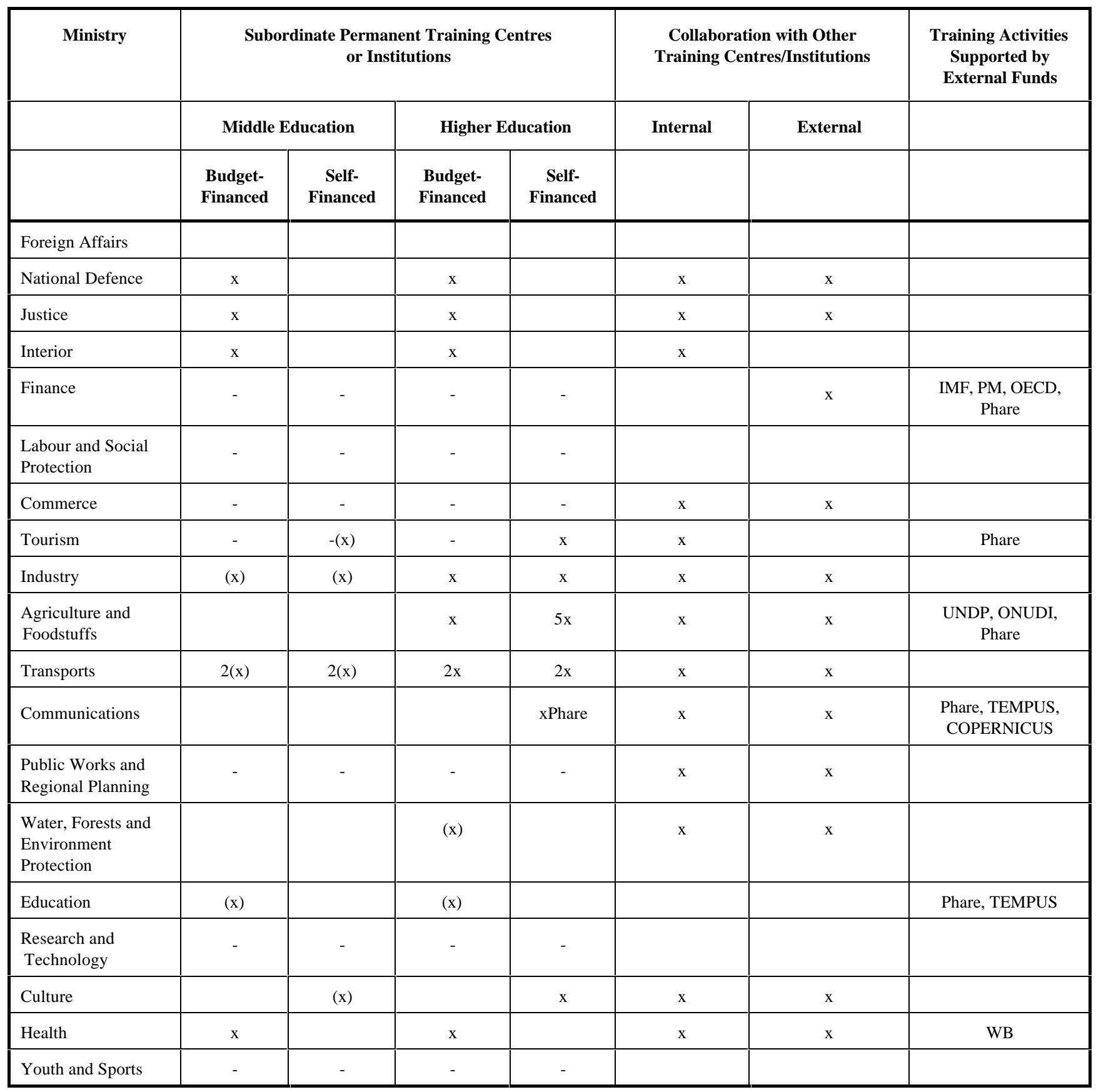




\section{ANNEX 12. THE MOST IMPORTANT STATE OR PRIVATE TRAINING INSTITUTIONS COLLABORATING WITH INTERESTED MINISTRIES}

1. Academy of Economic Sciences

Universities (Bucuresti, Brasov, Iasi, Sibiu....)

National School for Political and Administrative Sciences

2. Romanian Institute of Management (IROMA)

International Foundation of Management (FIMAN)

Centre of perfecting, consultancy and management for foreign trade (PERCOMEX SA)

Centre for implementing performance management (CIMP SA)

Centre of management and technology transfer (CEMATT SA)

Centre of informatics training (CPI)

Black Sea University Foundation

Magurele training centre

National centre for training, consultancy and management for quality control

Training centre for RENEL workers

ROMTELECOM training and documentation centre

Centre for organising, computing and training the employees in the food industry

(COCPCIA SA)

Training centre for the personnel working in handicraft co-operative societies (CEPECOM SA)

CODEX SA

CEDRU SA 
ANNEX 13. SECONDARY EDUCATION BY TYPE 1993/1994

\begin{tabular}{|l|r|r|r|r|}
\hline \multicolumn{1}{|c|}{ Type } & Lycées & $\begin{array}{c}\text { Pupils } \\
\text { Enrolled }\end{array}$ & Graduates & $\begin{array}{c}\text { Teaching } \\
\text { Staff }\end{array}$ \\
\hline Theoretical lycées and colleges & 435 & 296324 & & 18550 \\
\hline Industrial lycées & 465 & 217524 & & 25557 \\
\hline Agricultural lycées & 129 & 43691 & & 4773 \\
\hline Forestry lycées & 6 & 2977 & & 243 \\
\hline Health lycées & 23 & 3605 & & 328 \\
\hline Economic, administrative and services lycées & $\mathbf{5 1}$ & $\mathbf{6 2 2 6 8}$ & & $\mathbf{3 0 9 9}$ \\
\hline Informatics lycées & 10 & 40975 & & 645 \\
\hline Metrology lycées & 1 & 1299 & & 55 \\
\hline Masters schools & 36 & 18909 & & 2035 \\
\hline Art lycées & 38 & 8440 & & 2289 \\
\hline Sport lycées & 24 & 12836 & & 993 \\
\hline Military lycées & 8 & 3904 & & 267 \\
\hline Theological seminaries & 47 & 8804 & & 556 \\
\hline Special lycées for the disabled & 4 & 865 & & 98 \\
\hline & 1277 & 722421 & $166890^{24}$ & 59488 \\
\hline
\end{tabular}

24. This is the most recent figure available which refers to the year 1992/1993. 


\title{
ANNEX 14. CURRICULA OF THE NATIONAL SCHOOL OF POLITICAL AND ADMINISTRATIVE STUDIES AND OF THE PUBLIC ADMINISTRATION TRAINING CENTRE, BUCHAREST
}

\author{
National School of Political and Administrative Studies
}

\section{History and Legal Status}

During the academic year 1990-1991, the Administrative Sciences Sector functioned as a special part of the Faculty of High Political Studies, part of the University of Bucharest, according to HG 5511990.

The idea of organising this speciality grew from the need for a new generation of professionals in order to provide a recruiting base for public office personnel of higher state administration. According to HG 183/1991, the SNSPA was established as a part of it, the speciality of Administrative Sciences became a sector on its own within the structure of the school. The creation of this speciality and this sector were suggested by the existence of similar institutions in other countries: Ecole Nationale pour l'Administration (ENA) in Paris or the European Institute for Public Administration in Maastricht.

\section{Mission and Strategic Objectives}

- To train high level specialists for working in government structures, and more exactly in the management structures of central and local public administrations.

- To train specialists in the spirit of the new laws, according to the competencies resulting from the decentralisation process in the public administration.

- To create an appropriate framework for scientific research with emphasis on practical issues, able to provide solutions for specific problems arising from local needs and legal norms, and also to create a larger and more professional team.

\section{Curriculum}

The curricula were designed on the basis of a comparative analysis of similar schools and faculties: ENA in Paris; the European Institute for Public Administration in Maastricht and National Institute for Public Administration in Romania (an institution which operated between the world wars) and according to present needs of public administration.

As a consequence, the curricula contains the following range of legal topics, in order to ensure student homogeneity: administrative law, constitutional law, private law institutions, Romanian public administration history etc. It also offers economics and finances in public administration, international commerce, world economy. A range of techniques and methods of analysis and management in public administration are being taught: administrative science, foreign administrative structures and institutions, public administration management, legal techniques and ways to interpret legal regulations.

Courses are largely compulsory, give the permanent changes of laws and institutions in the administrative restructuring process. 


\section{Public Administration Training Centre, Bucharest}

\section{General Presentation}

CTPPRAFAPL Bucharest was established by HG 542 / 1995 as a legal, public institution, on a self-financing basis. The main objective of the centre is to deliver professional training programmes (cycles no longer than three months) for elected representatives and office employees of local public administration.

CTPPRAFAPL Bucharest is responsible for training activities for eleven counties (Arges, Buzau, Braila, Calarasi, Constanta, Dimbovita, Giurgiu, Ialomita, Prahova, Tulcea, SAI and Bucharest) and has an associated centre FORDOC Institute Calarasi (created in partnership between Calarasi Department and Charante Maritime Department France).

For the initial endowment, the centre received funds from the National Government and the EC. It now has modern training equipment adapted to specific needs.

CTPPRAFAPL Bucharest has a multi-functional profile, including training and retraining programmes, consulting activities, scientific studies and research, informing and documentation, information technology activities and specialised services.

The centre functions in observance of international standards and norms. This includes in its training curricula:

\section{General Modules}

- local public administration: notion, principles, competencies, ways to fulfil these competencies;

- system of local public administration bodies organisation, attributes, competencies;

- separation of state powers;

- administrative act;

- attributes of guardianship and authority;

- civil status attributes;

- administration and the protection of the public domain;

- local budget: elaboration, adoption, execution;

- the status of public office workers;

- management in public administration.

\section{Specific Modules for Different Public Functions}

Presidents and vice-presidents of county councils; mayors, vice-mayors, directors and chiefs of county and local councils; public administration inspectors; personnel reviewer; agricultural agents; civil-status office workers; public services accountants; commerce inspectors; cashiers, etc.

\section{Specific Modules for Local Elected Representatives}

Making administrative decisions; communicating techniques and strategies, problems analysis methods and solution selection methods; creating public images of institutions and representatives; conflict resolution; local development strategies, agencies, networks, partnerships; identifying peoples' needs; involving people; marketing the regions; human resources management; SME management; European integration at local communities level; election management; financial management etc. 
Centre experts have a vast theoretical and practical experience in public administration research and training activity, recognised either at home and abroad. They were involved in co-ordinating and carrying out activities of the following higher education institutions: Phare DELOG programme for local development in Romania, co-operation with Bocconi University, Birmingham University, CWPT Paris, etc. At present they develop international links with similar EU bodies.

As of Summer 1996, the new Public Administration College Bucharest will function alongside the centre. 
TRAINING PROFILE

SLOVAK REPUBLIC

\author{
(As of April 1996)
}




\section{Introduction}

The Slovak Republic (SR), established as an independent state in 1993, is a multinational state with 11 nationalities and with a total population of 5.356 million. Since 1989, there have been 6 governments. These changes have had a strong impact on both the dynamics and the level of conceptualisation of public sector reform. The present government, a coalition of 3 parties, has been in power since December 1994. (For the distribution of employees in the SR national economy, see Annex 1).

In the past, the SR had a two-tier system and was divided into 38 districts and 121 sub-districts. A new law, passed in June 1996, has subdivided the country into 8 regions and 79 districts. The former district and sub-district offices have taken over the responsibilities of the former regime's National Committees. Public administration today consists of state administration (See Annex 3) and self-government carried out in the regional and district offices. These are national budgetary organisations fully financed by the government. Public administration is therefore carried out by: state bodies; non-state bodies (such as local self-government); and other public legal corporations without self-government status but which are responsible for acting within the public sector.

In contrast to the former system, the current concept of public administration draws a sharp distinction between state administration and self-government. At the central level of state administration there are, according to the SR National Parliament law No. 347/1990, 15 ministries and several governmental central state administrative bodies. (See Annex 2)

\section{The Training System}

Under the former regime's Institute for National Committees (INC), the Heads of the National Committees had the opportunity to take a three-year training programme. The programme was officially the equivalent of "normal" graduate studies at the Faculty of Law. The INC has since become the Institute for Public Administration. The National Enlightenment Institute also played an important role in the training system of the former regime. The Enlightenment Centres functioned at the regional level. The ministries had their own training institutes, the majority of which still exist.

\section{Objectives of Training}

The Ministry of the Interior occupies the primary position in the general state administration together with the Ministry of Finance, determines the system of district and sub-district staff, administrates the budget of district and sub-district offices, co-ordinates and controls their activities, etc. In co-operation with other ministries, it also prepares and carries out expert training of state administration staff. The Ministry of the Interior co-ordinates education in the public sector according to government order No. 176/1991. The Institute of Public Administration is responsible for this training and Order 176 specifies the employee standards required at the district and sub-district offices. Content of training is based on the results of a survey of district and sub-district offices, conducted by the IPA. Training subject material is based upon requirements specified by government and by the regions. The IPA training programme also receives international support, primarily from the Phare Programme.

The over-riding objectives of training in public administration are to:

1. Develop knowledge and special skills in:

- Political science, law and the legal system; 
- Private and public law with an emphasis on administrative law;

- Principles of economics, mainly public sector economy;

- Communication with the public;

- Principles of administration and management of state and public office;

- Philosophy, sociology and psychology;

- Foreign languages;

- specific expert occupational abilities.

2. Personal development with regard to:

- General intelligence

- Respect for ethics;

- Responsibility and creativity;

- Flexibility and strategic thinking;

- Organisation and leadership;

- Inter-personal communication and self-discipline.

There is no governmental order for the systematic training of the employees in central state administration. Training at this level is based mainly on non-governmental initiatives (if acceptable) and international offers.

\section{Legal Framework}

Before 1989, few laws existed dealing with public administration. The legal framework of public administration was provided with the administrative procedure act No. 71/1967. This act is still in force but has been amended several times. Although there is a general consensus that a new act should be passed, it has not been included in the current legislative plan of the government.

Since the dissolution of Czechoslovakia on 1 January 1993, the legislation of the Czech Republic concerning public administration has evolved somewhat differently from that of the Slovak Republic whose Constitution was prepared in a great rush during the summer 1992 and was passed by the Parliament on 1 September 1992. It was drawn up by experts from the Movement for a Democratic Slovakia and the Party of the Democratic Left. The Labour Code defines and regulates the general form of employer-employee relationship, but it contains no expresis-verbis notion of public administration. It does refer to the Salaries Act only in the case of remuneration of employees in contributional and budget organisations, a category to which public administration organisations clearly belong.

The Labour Code gives each employee the right to participate in training. The legislation of the Slovak Republic does not regulate the obligations of employees. Act 232/1992 on Public Colleges and the establishment of the Police Academy covers the issue of training civil servants who are under no obligation to participate in training. This issue is being addressed in the new draft Public Administration law.

Since 26 March 26 1991, civil servant training is carried out according to governmental order No. 176 (See Annex 4) which establishes requirements for holding office in district and sub-district authorities, require expect expertise. Some ministries regulate the requisite expert capability for holding an office through special governmental orders: No. 163/1992 for the Ministry of Environment; 558/1992 for the Ministry of Social Affairs, Work and Family on expertise in the Institutes of Social Welfare; 446/1992 for the Ministry of Social Affairs, Work and Family on expertise in social welfare administration; 446/1992 
for the Ministry of Interior on fire-fighting expertise; 275/1992 for the Federal Ministry of Control on verification expertise; governmental order 220/1992 on police expertise.

No legal prerequisites exist for career development but this issue will be covered by the Public Administration law.

\section{4. $\quad$ Funding}

Each ministry has its own training budget. In general, state administration training is fully covered by the state budget while local self-government training is partly financed by participant fees. (Some training institutions, both state and non-state institutions, offer courses for fees)

The Ministry of Justice provides an example of the development of ministerial training budgets over time:

\begin{tabular}{|l|r|r|r|r|r|r|}
\hline & $\mathbf{1 9 9 0}$ & $\mathbf{1 9 9 1}$ & $\mathbf{1 9 9 2}$ & $\mathbf{1 9 9 3}$ & \multicolumn{1}{c|}{$\mathbf{1 9 9 4}$} & \multicolumn{1}{c|}{$\mathbf{1 9 9 5}$} \\
\cline { 2 - 7 } SK by 000 & 548 & 493 & 585 & 602 & 898 & 1233 \\
\hline US\$ & 18267 & 16434 & 19500 & 20067 & 29934 & 41100 \\
\hline
\end{tabular}

\section{Training Institutions and Legal Status}

\section{Education for Public Administration at the Universities}

Material on the subject of public administration education has been prepared by the Ministry of the Interior. Part of this material summarises undergraduate and graduate education available for public administrators at universities. Study programmes are divided into useful and less useful programmes for public administration. The legal status of these programmes is defined by the 1990 High School Education law. (See Annex 5 Universities and public administration education.)

\section{Public Administrators' Education Organised by Ministry}

The ministries are organising training programmes in their own training institutions (most were established before 1989) or through by state and private institutions. There is no systematic training programme for top central public administrators at present.

\section{Interior}

This ministry educates local state administrators as well as self-government officials. The education of employees of district and regional offices is established by governmental order No. 176/1992 and the Institute of Public Administration is responsible for carrying it out. The order defines the need for systematic training. IPA also organises short- and long-term training programmes for other branches and for self-government in addition to that which is dispensed at the Ministry of the Interior.

\section{Agriculture}

This ministry verifies the expertise and capabilities of its employees in accordance with the governmental order No. 176/1992 through the Agroinstitute in Nitra, and the Zvolen Institute for the Advanced Education of Employees in Forestry and Water Economy. 


\section{Transport, Post Offices, and Telecommunications}

There is no special training institute or education programme beyond the regular secondary school and university system.

\section{Construction and Public Works}

Education is managed directly through the Institute for Education and Services in Bratislava which offers courses in languages, computers, law, and other programmes.

\section{Economy}

Four specialised training institutions: the Institute of Foreign Trade in Bratislava; the Institute of Trade and Travel in Nitra and Jelenec; the Institute for the Education of Top Management (IMB state enterprise) in Bratislava; and the Institute for Professional Preparation and for Re-qualification in Bratislava.

\section{Environment}

Employee education for the district and regional offices is based on governmental order No. 163/1992, which defines the standards required of the environmental state administration. The responsible body is the Slovak Environmental Agency in Banská Bystrica.

\section{Finance}

Education of the local state administration is provided by the Central Tax Directorship (attestations of tax employees), the Central Custom Civil Service, and the Civil Service of Financial Control.

\section{Culture}

Education of local state administration is provided by the Institute of Public Administration. The ministry does not have its own established training requirements.

\section{Education}

District and regional office employee training is provided by the Institute of Public Administration. Other employees participate in seminars organised by the State Pedagogic Institute.

\section{Health}

Works according to a prepared educational system for physicians, pharmacists, and health-care civil servants. Training is managed by the Institute for the Further Education of Health Services Employees.

\section{Administration and Privatisation of National Property}

Organises only short-term courses for its employees.

\section{Labour, Social Affairs, and Family}

Conducts training for the employees of Labour Offices at the Centre for Education and Re-qualification in Povazská Bystrica. The education of social affairs local state administrators and of the employees at the institutes of social welfare is based on order No. 558/1992 of the Ministry of Labour, Social Affairs, and 
Family. This training process is prepared and organised by the Centre of Social Welfare Services in Poprad and by the Institute of Public Administration in Bratislava. In co-operation with the Faculty of Pedagogy, Comenius University, the ministry provides education to social workers of district and regional offices through BA and MA executive study.

\section{Foreign Affairs}

Qualification is organised with a two-year full-time postgraduate study programme at the Institute of International Relations, Faculty of Law, Comenius University. There is no other training programme.

\section{Justice}

Training is based on law No. 335/1991 pertaining to judges and courts, and law No. 80/1992 pertaining to courts and court districts. These laws define the state administrative duty of the Ministry of Justice to organise and manage the preparation of lawyers, judicial candidates, junior judges, and senior judges to expert levels. The expert guarantor is the ministry, the programme is conducted by the Institute for the Further Education of Employees at the Trencianske Teplice branch of the Ministry of Justice.

\section{Training for Self-government}

The Association of Towns and Municipalities has created the Foundation for Self-government Education with eight regional centres.

Training focuses on:

- economic and legal issues;

- social insurance;

- tax system; accounting;

- entrepreneurial strategies;

- developing tourism;

- environmental issues;

- public management;

- the democratisation process.

Training is developed with the support of Phare and several other foreign sponsors.

\section{Teaching Personnel}

Trainers are recruited by subject and each institution running a programme is responsible for selecting its own trainers. For example, the Institute of Public Administration has five permanent trainers and 130 visitors from Ministry of the Interior, other ministries, central governmental bodies and the academic world. Visitors from the Ministry of the Interior are not paid for providing training (they could be, but the institute considers this to be part of their professional duties), others receive 120 SK (4 US\$) per hour. This sum is flexible according to the status and budget of the institution: at Academia Istropolitana, City University, etc. the pay is around 200 SK (6.50 US\$) per hour. These institutions are semi-budgetary and cover trainers' wages from different grants. Private training institutions offer wages up to three or four times higher. By comparison, visiting assistants at universities receive 60 SK (2 US\$) per hour, visiting assistant professors 80 SK (2.50 US\$) and visiting professors 100 SK (3.30 US\$). 
In training institutions other than the Institute of Public Administration, trainers come from:

- Public administration: central state, local state, self-government.

- Universities.

- Specialised institutions: City University, Bratislava; ZMOS Association of Towns and Municipalities; Foundation for Self-government Education; Association of Self-government Principles; private agencies.

- Foreign organisations supported by: Phare project; CNFPT, Paris; grants, foundations; bilateral governmental agreements.

\section{Needs Assessment and Content of Training}

Central state administration bodies conduct their own needs assessment based on an analysis of the qualification structure of their employees. In addition to defining the conditions for accepting employees in public administration, ministries and other central state administration bodies also formulate criteria for employee mobility based on age structure in public administration, on the educational structure of their staff and on the vertical and horizontal distribution of employees. Training needs are identified in the process of formulating these conditions and criteria.

Such efforts at training needs assessment are complemented by the surveys conducted by different training institutions among public administrators, and by consultations with foreign experts from Phare, or from universities abroad (Birmingham University, Giessen University and many others).

Regarding the content of training, universities deserve mentioning. Their study programmes prepare experts in public administration in:

- public law;

- public economy and finances;

- regional economy and planning;

- public administration and management;

- information and management systems;

- traffic and communication systems;

- geography and public administration;

- education of adults;

- social work;

- social pedagogy;

- public culture;

- school management;

- social and enlightenment work;

- environment;

- land and agriculture management;

- enterprise management;

- public administration.

For the most part, university study programmes cover a variety of specialised branches of education. Currently; here are only two actual public administration study programmes: Public Economy and Administration at the University of Matej Bel and Public Administration at the University P.J.Safarika. 
Examinations follow a traditional format in accordance with the High School Education law. The educational content is managed by specific departments and by the Academic Senates of each faculty. Programmes are accredited by the Ministry of Education.

The Academia Istropolitana was established in 1990 and offers a two-year post-graduate study programme in Public Administration. The academy is directly managed by the Ministry of Education and is a semi-budgetary institution. Two thirds of its budget comes from a variety of different foreign grants, one third (4 200000 SK - 140000 US\$) comes from the Ministry of Education. The programme is not accredited, the students receive a certificate. It is based on close co-operation with EIPA Maastricht and other schools of public administration. The programme is evaluated by students, foreign experts, and the employment market and reflects the relationship between supply and demand. Success is based on the interests of the students and of future employers. (At present AI has 13 permanent staff, 29 Slovak visitors, 46 visitors from abroad and 3 long-term visitors form abroad.)

In addition to University education, a great number of training activities are being organised by ministries and their subordinated training institutions. (See Annex 6 for content, target groups and training formats).

\section{Target Groups}

Target groups can de distinguished according to whether training is mandatory or voluntary. For those taking part in obligatory in-service training, the IPA organises six accredited courses. Accreditation is based on the decision of Accreditation Committee at the Ministry of Education both for qualification and re-qualification training. Target groups are defined in the Proposal for Accreditation prepared by institution organising the courses

Others have to attend obligatory expert capability courses with attestation (Target groups are defined by law.) Specialised professional qualifications are required for the following positions:

- deputy head of a public administration bureau;

- archives and records;

- municipal relationships and co-operative measures;

- legal departments;

- rationalisation and information technology;

- statistics and records;

- personnel and wages;

- forestry and water management;

- agriculture;

- administration of budgetary and semi-budgetary organisations;

- transport;

- private enterprise of citizens, trade, the tourist trade and local management;

- administration and registry;

- finance and trusteeship;

- budgeting and accounting;

- travel;

- housing;

- economic administration;

- control;

- culture; 
- health;

- social services;

- regional development;

- civil defence and mobilised tasks of state;

- secretarial offices;

- juvenile custody, physical education and sport.

For those attending voluntary in-service training courses which target groups defined by the employer, see Annex 6.

\section{Training Formats}

Accredited and attested courses are long-term in-service courses, organised in modules and conditional upon attestation, and level. A distinction is made between top management, middle management and staff. There are no pre-training courses at present. Education is considered permanent, qualification levels are defined by law. The majority of training is organised in short-term courses of one or more days of seminars or lectures, without certificate (See Annex 6).

\section{Development of Training Curricula}

Training curricula reflect the public sector reform process (See Annex 5). Usually, curricula are prepared in co-operation with foreign experts, academics, target groups and ministries. Expertise and attestation are defined by law, governmental orders and ministerial notification.

The procedure for accredited courses is defined by governmental order: project proposals have to be prepared by the organising institution (including curricula, trainers, format, target groups, budget, technical equipment); the Accreditation Committee assigns two judges/critics and then selects according to their evaluations.

Private institutions are more complicated. Some branches of public administration reject such offers because of state interests, some because of higher prices. If there are other sources (Phare, etc.), training institutions compete. Some state training institutions behave like private ones (semi-budgetary) but their prices are still often lower.

\section{Evaluation}

Each training participant is generally required to prepare a written evaluation of the course and occasionally the trainer. The most important evaluation process is the feedback regarding courses being offered. Institutions continually conduct surveys and market research among target groups. Success is based on the balance between supply and demand.

Some differences in evaluation procedure do exist:

- Obligatory courses culminating in attestation or accreditation. The government has identified 26 positions for which employees must pass examinations indicating the requisite levels of expertise and has also designed general and specific content. Evaluation and verification train are done by ministerial institutes, ministries and expert guarantees. 
- Voluntary courses, with or without certification. Participants themselves attest to the value of these programmes when they are considered for salary increases or promotions. The value of these courses also lies in the good reputation of the training institution or is based on official agreements with the employer who must sign the application form of the participant and cover the fee. This financial investment is indicative of a positive evaluation of the course.

\section{Planned Changes and Further Developments in the Training System}

In December 1995, the Ministry of the Interior prepared its Public Administration Training Strategy which aims primarily to systematically educate and improve the qualifications of public administrators.

Target groups:

- Top management, experts and administrators of central state administration and other central bodies;

- Heads of local state administration bodies;

- Top management, experts and other administrators of local state administration (general and specific);

- Selected top managers and administrators of the organisations of different public administration branches established by central and local bodies of state administration;

- Top managers, experts, administrators carrying out the economic management of bodies of local and regional administration;

- Mayors;

- Deputies of local and community governments.

The training format envisaged comprises both pre-service and in-service training. Pre-service is organised through secondary, higher education, and university education. In-service training will take three forms: adaptation; specialised qualification; positional.

Adaptation will be for entrance level and preparation level, with both a theoretical and a practical component. Specialised training refers to the first expert attestation, positional training to the second expert attestation. Further education will comprise re-qualification, innovative and supplementary training.

An important part of the Strategy is international co-operation, to be based on:

- Bilateral agreements between central bodies of state administration, bodies of self-government, and foreign partners;

- Co-operation of educational institutions within the European network of institutes of public administration at the Council of Europe;

- International programmes supporting public administration reform.

\section{Identification of Problems in Training}

The Strategy is the result of problems identified in public administration training:

- Inadequate qualification structure;

- Lack of stable employment in conjunction with inadequate expertise;

- Absence of conceptual work;

- Lack of motivation of employees in public administration;

- Lack of co-ordination of current training activities; 
- Limited financial resources;

- Lack of opportunities to function on market principals.

Neuralgic points of a training system are trainer quality and capacity. The scarcity of qualified trainers is combined with problems in motivating and focusing specialists - skilled trainers from the public administration. Special programmes must be started to train trainers, to find mechanisms to motivate them to take up permanent training jobs. OECD and Phare could be very helpful in fulfilling this task.

\section{Conclusion}

Several factors determine the role and status of public administration training.

\section{Social:}

- Re-constructing the entire public administration sector;

- New public administration tasks and ompetencies;

- Division between state administration and self-government;

- Shortage of financial resources (also in the education system).

\section{Educational:}

- An unfavourable education structure (only $1 / 5$ of local state administrators are university educated);

- Lack of co-ordinated education and training activities (co-ordination will start in 1997 by the Institute of Public Administration and Governmental Office);

- The absence of a legal framework for co-ordinated and complex education and training of public administration;

- The status of the public administrator.

\section{Internal Training:}

- No training for top management;

- No pre-service training;

- The organisation of in-service training by branches of different ministries oriented more towards technical skills (languages, computers, interpretation of new laws) rather than expert skills;

- Lack of co-operation among ministries and their institutes;

- Lack of trainers and specialists;

- No fully developed evaluation system of training.

\section{Sources:}

Stefan Grman: Organisation and Main Competencies of the Government and Central Organs of State Administration, Institute of Public Administration, Bratislava, 1995.

Erika Kucerová: Organisation and Competency of Local State Administration Organs, Institute of Public Administration, Bratislava, 1995.

Ministry of the Interior: Education Conceptualisation in Public Administration, Bratislava, December 1995. 
Institute of Public Administration: Study Programme, ON No. 6, 1996.

Institute of Public Administration: Programme of Educational Activities, 1995, Bratislava.

IMB Institute for Education of Top Management: Offers 1995.

Institute for Professional Preparation and Re-qualification: Offer of Seminars, 1996.

Institute for Foreign Trade: Offer of Expert Educational Activities, 1995.

Elena Blazickova, Head of the Department for personnel development and education, Ministry of Finance: Information on personal development, education, and training of employees at MF and international educational activities in 1993-1995.

P. Horsky, Ministry of Construction and Public Works: interview.

Institute of Education and Services: Offer of Educational Activities, 1996.

V. Balázova, Ministry of Justice, interview, March 1996.

B. Luknár, Head of the Department of Personnel Management and Education, Ministry of the Environment: Information about the activities of the ME in environmental education, Bratislava 1995.

M. Klímová, Director of the Personal Department, Ministry of Foreign Affairs: Information about further education in the branch of MFA., March 1996.

Z. Dianová, Director of the Foreign Affairs Department, Ministry of Transport, Post Offices and Telecommunication: Information, March 1996.

Ministry of Justice: System of education of juridical candidates, junior judges, and senior judges and other court employees in the SR, Bratislava, July 1995.

Minister of Justice: Information about the education system of court employees, Government Material, Bratislava, August 1995.

S. Prokes, Ministry of Agriculture, Department of Personnel Management and Education: Education of Employees of the Ministry and in Organisations in the Agricultural Branch, Bratislava, March 1996.

P. Roth, Director of Personnel and Social Management, Ministry of Labour, Social Affairs and Family: Information on Training, March 1996.

J. Sauer, Director of Personnel Management, Ministry of Economy. 
ANNEX 1. DISTRIBUTION OF STATE EMPLOYEES

\begin{tabular}{|ccc|}
\hline \multicolumn{3}{|c|}{ State Employees by Thousands Total } \\
$\mathbf{1 9 9 2}$ & $\mathbf{1 9 9 3}$ & $\mathbf{1 9 9 4}$ \\
1995 & 1991 & 1995 \\
\hline
\end{tabular}

\begin{tabular}{|l|r|r|r|}
\hline \multicolumn{4}{|c|}{ State Employees by Sector } \\
\hline & $\mathbf{1 9 9 2}$ & $\mathbf{1 9 9 3}$ & $\mathbf{1 9 9 4}$ \\
\hline Agriculture and fishing & 246 & 209 & 183 \\
\hline Industry & 576 & 547 & 517 \\
\hline Construction & 128 & 106 & 93 \\
\hline Wholesale and retail & 101 & 88 & 78 \\
\hline Hotels, restaurants & 13 & 21 & 11 \\
\hline Transport, communication & 85 & 141 & 36 \\
\hline Banking, insurance, financial intermediation & 15 & 20 & 25 \\
\hline Other business services research & 77 & 69 & 62 \\
\hline Public administration and defence & 59 & 77 & 71 \\
\hline Education & 184 & 169 & 172 \\
\hline Health and social work & 126 & 128 & 127 \\
\hline Other community services & 36 & 39 & 40 \\
\hline Unemployment rate (\%) & 10.4 & 14.4 & 14.8 \\
\hline
\end{tabular}




\section{ANNEX 2. CENTRAL STATE ADMINISTRATION STRUCTURE}

\section{National Advisory Bodies:}

- Legislative Board;

- Governmental Board for Public Administration;

- Transformation Board (at present without members);

- Governmental Board for Integration of the SR into the EU;

- Governmental Board for the Media;

- Governmental Board for Nationalities;

- Co-ordination Committee for Health-Care for the Less Advantaged;

- Co-ordination Board for Health Support;

- Governmental Board to Support Export;

- Committee of Ministries for Drug Dependence and Drug Control.

According to the SR National Parliament Law No 347/1990, there are 15 ministries:

- Labour, Social Affairs, and Family;

- Agriculture;

- Transport, Post Offices, and Telecommunications;

- Construction and Public Works;

- Economy;

- Environment;

- Finance;

- Culture;

- Education;

- Health Services;

- Interior;

- Foreign Affairs;

- Justice;

- Defence.

\section{Governmental central state administrative bodies:}

- Governmental Office;

- Statistical Office;

- Nuclear Regulatory Authority;

- Authority of Geodesy, Cartography, and Cadastre;

- Antimonopoly Office;

- Office of Standards, Metrology, and Testing;

- Industrial Property Office;

- Administration of National Material Reserves;

- Office for Occupational Safety;

- Office for the Strategy of Societal Development, Science and Technology. 


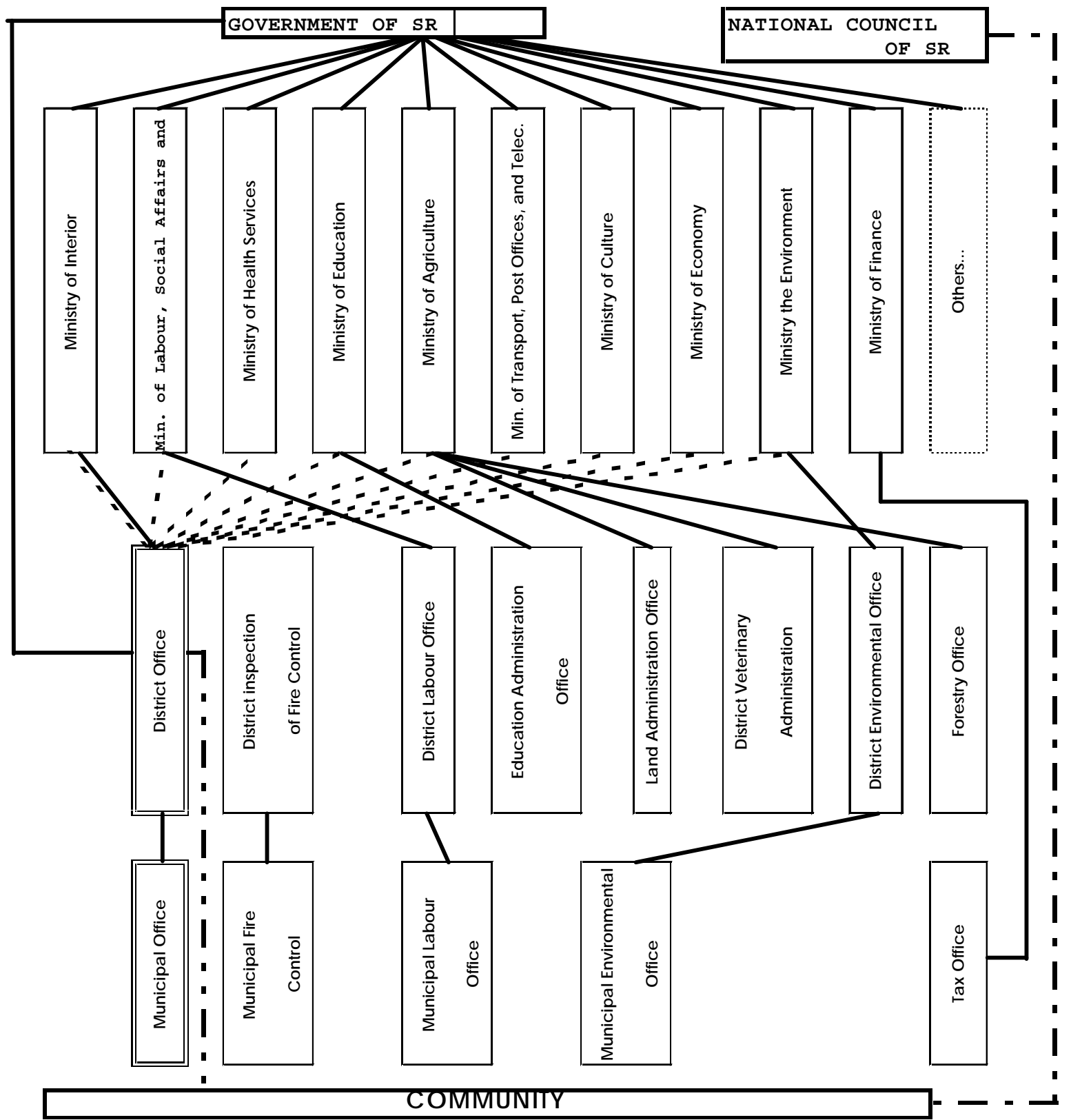

\footnotetext{
- direct control

- - methodical control of state service performance and economical control

- - appeal against the decisions of municipality in administrative process

- - abolition or unlawful municipal regulations
} 


\section{ANNEX 4. GOVERNMENTAL ORDER NO. 176}

\section{AMENDMENT}

\section{Examination preparation and subject-matter for specialised professional qualification}

I. The subjects to be prepared for the examination for all functions requiring specialised professional qualification $(\$ 1)$ include:

Knowledge of:

- organisation and competencies of local public administration and regional;

- self-administration;

- regional and legal division;

- organisational and basic competencies of the government and central bodies of public administration;

- content of the Constitution.

Practical application of office procedure in:

- administrative adjudication;

- computer use.

Use of the official language.

II. The content of specialised professional qualifications for specific positions requires advanced knowledge and practical application of office procedures:

1. Deputy head of a public administration bureau:

- legal regulations of budgetary rules;

- Labour Law;

- Civil Code and the Economic Code (the Commercial Code);

- regulations adjusting controls in public administration, including methods.

2. Archive management:

- legal regulation on archives, documentation service, and pre-archive care;

- wage regulations;

- basic statistical methods;

- public administration information system.

3. Relationships and co-operative measures with municipalities:

- electoral law on local self-administration;

- regulations concerning municipal property and its arrangement.

4. Legal departments:

- selected sections of administrative, civil, economic (business), financial and labour laws

5. Rationalisation and information technology:

- management theory and work organisation;

- programming;

- conception and functioning of the automatic information system of local public administration. 
- statistical methods;

- statistical legal regulations;

- programming;

- regional and administrative state organisation.

7. Personnel and wages:

- selected sections of the labour law;

- appropriate salary regulations.

8. Forestry and water management:

- legal regulations on forests, forest management, water management and hunting, forest and land conservation, conservation and use of natural resources, local planning and building rules, nature conservation, economic maintenance of forests, on registration of immovable assets, land cadastre, on the biology of animals, improvement of hunting zones, guns and ammunition, organisation of forestry and water management, and flood protection.

9. Agriculture:

- regulations on land and its management, regulations on disposing of land, land asset preservation, registration of immovable assets, land cadastre, land bonification, economic-technical land regulation, and nature conservation, fishing, geological research and work, and on managing private farmers.

10. Administration of budgetary and semi-budgetary organisations:

- legal regulation on budgetary rules;

- regulations on so-called small and large-scale privatisation;

- economic (trade) law.

11. Transport:

- legal regulations on local planning and building rules;

- legal rules on transport and traffic management.

12. Private enterprise of citizens, trade, the tourist trade and local management:

- selected sections of the Civil Code;

- legal regulations on housing ownership, and on rental and subletting of non-residential places;

- regulations on so-called small and large-scale privatisation;

- legal rules on domestic trade, catering industry, re-privatisation of operating units, trade, manufacturing, land (restitution laws), and prices.

\section{Administration and registry:}

- from legal regulations determining electoral procedure for lawmaking assemblies and for municipalities, and elections of lay judges, voting procedures of municipal citizens, ensuring the rights of citizens to associate and assemble, registry service, registry administration, family law relations, use and alteration of name and surname, verification of signatures and transcripts, matters of citizenship, delivery of documents abroad, announcement and filing of citizens' place of residence and citizens' petition of rights. 


\section{Finance and trusteeship:}

- regulations on property rights and regulations on prices;

- law on the regulation and arrangement of municipal property;

- legal regulation of budgetary rules and budgetary management;

- accounting;

- regulations on so-called small and large-scale privatisation.

15. Budgeting and accounting:

- regulations on property rights;

- legal regulations on budgetary rules and budgetary management;

- tax regulations;

- regulations on the discarding of bookkeeping vouchers;

- accounting.

16. Travel:

- legal regulations on travel;

- legal regulations on local planning and building orders;

- legal regulations on nature conservation.

17. Housing:

- legal regulations on housing, on the personal ownership of flats, and on rental and subletting of non-residential places;

- restitution laws;

- legal regulations on private enterprise.

\section{Economic administration:}

- regulations on the property of municipalities and its arrangement;

- accounting;

- legal regulation of budgetary rules and budgetary management.

19. Control:

- legal regulations determining areas of control, methodology, property of rights relations, budgetary management, management of state property, accounting, privatisation and denationalisation, public enterprise, public consumption, prices, statistical methods and information technology, administrative, financial, economic, mercantile, and labour law, arrangement of municipal property, taxes, the environment, petitions and complaints.

\section{Culture:}

- legal regulations on state cultural heritage preservation, and on museums and galleries;

- legal regulations on the subject of the media and mass media;

- legal regulations on health care, on state health control, and on regressive compensation;

- legal regulations on public cultural undertakings and on the state fund of culture. 


\section{Health:}

- rules on state health policy;

- structure and management of health care;

- legal regulations on health care, on state health control, and on regressive compensations;

- regulations concerning hygiene.

22. Social services:

- legal regulations on social security;

- selected sections of the Civil Code, the law of civil procedure, and from legal regulations on employment;

- content of agreements between trade union deputies, employers and government.

\section{Regional development:}

- rules and methods on the planning and implementation of regional development and production of long-term concepts;

- legal and financial regulations concerning regional planning;

- work methods in conjunction with social-economic information;

- legal regulations on the environment.

24. Civil defence and mobilisation:

- regulations in the area of defence and civil defence.

\section{Head of a Secretarial Office:}

- management theory, work organisation and records service organisation;

- administrative tasks;

- programming.

26. Child custody, physical education and sport:

- legal regulations on the state care of children and young people;

- legal regulations on physical culture. Special professional competency as a prerequisite for holding positions at county and district offices. 
ANNEX 5. UNIVERSITIES AND PUBLIC ADMINISTRATION EDUCATION

\begin{tabular}{|l|c|c|c|c|}
\hline \multirow{2}{*}{ University } & \multicolumn{2}{c|}{ Adequate Programmes } & \multirow{2}{*}{ Partly Adequate } \\
\cline { 2 - 5 } & BA & MA & Courses & \\
\hline Comenius & 12 & 4 & & several \\
\hline Trnava & 2 & 2 & & 3 \\
\hline Agriculture/Nitra & & 2 & & several \\
\hline Economic/Bratislava & 1 & & 3 & several \\
\hline Matej Bel/ Banská Bystrica & 1 & 2 & 1 & several \\
\hline Technical/Kosice & 1 & 1 & & several \\
\hline Pedagogic/Nitra & 2 & 2 & & \\
\hline Technical/Zvolen & & & & 2 \\
\hline Traffic,Com./Zilina & 1 & 3 & 1 & 1 \\
\hline P.J.Safarik/Kosice & & 3 & & \\
\hline Some MA programmes continue to PhD. level & \\
\hline
\end{tabular}




\section{ANNEX 6. TRAINING ORGANISED THROUGH STATE TRAINING INSTITUTIONS}

\section{The Ministry of the Interior}

\section{The Police Academy of the Slovak Republic (established 1992)}

Content: University education and scientific knowledge in security services studies. The PA provides programmes in: traffic control police; uniformed police; personal and property protection; border police; immigration police; criminal police; civil defence and fire-fighting and civil security services with specialisations; civil defence; public services; fire fighting.

Target groups: Only certain candidates are eligible for admittance into the PA as a departmental school of the Ministry of the Interior: the candidate must be in the service of the Ministry of the Interior or of another security service; must have successfully completed secondary school as evidenced by the school-leaving examination, must be a graduate of the special police school; must have at least two years practice with the police security services; must successfully pass the entrance examination, health conditions must correspond to the requirements of the police and security services employees. The entrance examinations consist of a test of general knowledge, a language test, a psychological test, and a physical examination.

Training format: The PA provides university study (BA), postgraduate study (MA), and continuing education. University study is organised as a complete programme (masters) or as a comprehensive part of university education (bachelors). It is carried out as either a full-time or an extra-mural study programme.

\section{The Institute of Public Administration}

Training is organised in 3 lines:

1. Courses based on accreditation from the Ministry of Education for employees in state administration and self-government. Applicants are selected according to their social position and according to the order in which their application forms are received. Courses are obligatory for defined positions. There are final exams. There are 2 such courses:

\subsection{A two-year course of archival services:}

Content: Introduction to archives services, history of administration, document services, evidence, analysis, and use of archives, state language, legislation in public administration.

Target groups: Employees of state district and regional archives.

Training format: In-service training, 300 hours in 8 weeks modules, with a final examination. This obligatory course is prepared in co-operation with the Ministry of the Interior. 


\subsection{A programme course, Basis of Control:}

Content: Control systems: the Law on state control; regulations regarding control; external and internal control; state administration and regionalism; trade law; enterprising; tax system; budgetary regulations; price regulations; defence of the customer; offence; control of self-government; social insurance; application of control; co-operation with the courts; psychological aspects of control; the culture of oral and written language.

Target groups: Control employees in central state administration, employees in local state administration, supervisors of towns and communities.

Training format: In-service, 83 hours in two-week modules. The Governmental Office of the SR guarantees the training in co-operation with the Supreme Control Office, the Ministry of Finance, and the Ministry of the Interior. Obligatory for all target groups, final written and oral examinations.

1200 SK (40 US\$) participation fee.

2. Specialised courses, finalised by certification, participation depends on applicant interest:

\subsection{Methods and Techniques of Control:}

The content is prepared according to the demands of central state administrations and the Ministry of Finance.

Target groups: Employees of control departments at ministries and other central state administrations, employees of local state administrations, and self-government. All candidates must have complete Basis of Control course.

Training format: Four-day course, 29 hours with certificate. Supervision is by the Governmental Office, the Supreme Control Office, the Ministry of Finance, and the Ministry of the Interior. Fee: 510 SK (17 US\$).

\subsection{A training series in communicative optimalisation:}

Content: Self-understanding, techniques of assertion and relaxation

Target groups: Employees of district and regional offices.

Training format: In-service six-day 2 module training programme with certificate. Supervised by the Pedagogic Faculty, Comenius University, Centre for Pedagogic Services. 
3. Expert training and seminars, short-term training without certificate based on ministerial requirements and the demands of potential applicants:

Content: Prepared and specialised according to needs of different branches taking the legal system as its basis for diplomacy-communication-negotiation, management; personnel marketing, practical activities and performance in different branches, organisation, human resources, competencies, accounting and finance, interpretation of different laws.

Target groups: Employees of district and regional offices: principles; personnel departments; accountants; departments for the conservation of architecture and urban heritage; departments for consumer protection; social departments; social workers; road department; archives departments; regional development; state agenda; business departments; economic departments; departments for communication with municipalities; legal departments; registration departments as well as self-government employees.

Training formats: In-service short-term courses, two to three days, supervision by different ministries according to topic. These courses are offered following consultations with the ministries or according to their own surveys on demand.

\section{Ministry of the Economy}

\section{The Institute of Foreign Trade (IFT)}

IFT is a semi-budgetary organisation with 20 years experience in training. Currently, it offers:

\section{Extra-mural studies on International Marketing:}

Content: Financing export; accounting and controlling; export economy; international marketing strategy; international marketing; international economic law; export organisation and technique and finance; international logistics; international project management.

Target groups: Employees abroad in international organisations, diplomatic service in state and private sector.

Training format: Eleven independent modules, participants may attend all or part of the course. Export-Akademie Baden-Württemberg, Reutlingen, supervises with the training support of the German government. Each module ends with a written exam and certificate. Successful participation in many modules could mean qualification for work in international trade.

Short-term courses:

a. Diplomatic Protocol:

Target groups: Employees in the diplomatic service, top managers, and experts from ministries.

Training format: A five-day course prepared in co-operation with the private firm HOSTESSE INT Bratislava, fee of 6600 SK (220 US\$) covering study materials, accommodation, and meals. 
Target groups: Employees in state and private international trade organisations, export-import employees, bank employees.

Training format: A six-day course in co-operation with a trainer from the Economic University, fee 6300 SK (210 US\$).

c. International Marketing:

Target groups: Employees in marketing departments, entrepreneurs.

Training format: A three-day course in co-operation with a trainer from the Economic University, fee 3300 SK (110 US\$).

\section{IMB Institute for the Education of Top Management}

Target groups: State and private sector management.

Training format: Short-term courses are divided into 4 sections: foreign languages, PC, management, and small and middle-range enterprises. Applicants must pay for the course. Some courses are connected with a stay abroad. IMB also offers consultative and advisory services. Participants receive a certificate.

\section{Institute for Professional Preparation and for Re-qualification}

The main activities are a variety of seminars in co-operation with the Ministry of the Economy oriented toward Modern Management and Human Resources Development. Modern Management participants foremen - will obtain a qualification degree as a basic manager. Other seminars are designed toward personnel management. There is no official certificate, participants must pay a fee of 2093 SK (70 US\$).

\section{Ministry of Finance}

Target groups: Employees of the Ministry of Finance.

\section{Training format:}

a. Domestic training:

The Ministry of Finance offers 9 types of education:

- Adaptation training and tests: an obligatory entrance test to be taken during the first three months of employment. In 1995, 112 new employees took this test;

- Computer courses (in 1995, 37 courses with 303 participants);

- Postgraduate and long-term courses (mathematics and insurance, customs course - 5 participants);

- Extra-mural studies (international marketing, 21 days, 1 participant);

- Short-term courses (9 expert courses);

- Seminars (22 specialised seminars for 146 participants);

- Conferences; 
- Ministry fellowships. (According to governmental order No.506/1995, 20 graduates from the Universities have fellowships at the Ministry of Finance). Fellowships are regularly evaluated. Evaluation is the basis for contract and for future positions in different ministerial departments; and

- Expert practice for university and secondary school students (students from the Trade Academy, Faculty of Law, Economic University, and Academia Istropolitana gain practical work experience at the Ministry of Finance).

b. $\quad$ International training:

- OECD: multilateral custom centres in Vienna, Budapest, Copenhagen and Ankara. Since 1993, 109 ministry employees have taken part in different workshops in Vienna over 586 days; in Ankara: 2 employees, 10 days at 2 courses; in Budapest: 118 employees, 465 days at different workshops; in Copenhagen: 6 employees, 60 days and in Paris: 23 employees, 53 days. Altogether, OECD has supported 51 courses for 258 employees from the branch of the Ministry of Finance; and

- Fellowships and courses (supported by the British Know-How Fund, OECD, IMF, European Institute in Maastricht, A.D.E.T.E.F. in Paris for 27 employees).

\section{Ministry of Construction and Public Works}

The Institute of Education and Services responds to the demands of this ministry, organising its training through the Department of Architecture and Regional Development, the Department of Economic Management, the Department of Techniques, Technology, Mechanisation and Actualisation of Construction.

Target groups: Top management, middle management and other ministry employees; experts from Central, Eastern and Western Europe, central state administration, local state administration, self-government, bank employees, housing companies, airport employees, experts from social insurance companies, construction firms, top management of enterprises, trade and marketing employees, secretaries.

Training format: In-service training, no pre-training and no pre-tests. Training is used for attestations to defined positions. Training is financed from the state budget (last year it was $100000 \mathrm{SK}$, this year 900000 SK.).

Departments are doing workshops, seminars, long-term studies (two semesters) with certification, short-term courses. The Institute is responsible for attestation in several construction professions. Courses are distributed to the target groups and according to the feedback departments continue.

\section{Ministry of Justice}

\section{Institute for Further Education of the Employees at the Trencianske Teplice branch of the Ministry of Justice}

Content: The Ministry of Justice has prepared a complete system of education at its branch consisting of 8 main types:

1. Qualification, preparation, and education of juridical candidates and junior judges;

2. Expert preparation of associate judges;

3. Taking up a post preparatory to performing administrative and expert activities;

4. Expert preparation for performing in management positions; 
5. Improving expert capabilities for qualified performances of judges and other court employees;

6. Conferences, workshops, seminars;

7. Preparation of staff lecturers; and

8. Language training.

Target groups: Lawyers, judicial candidates, junior judges, senior judges, and associate judges, employees of the courts.

Training format: Courses depend on attestation and rank. A distinction is made between top management, middle management, and staff. Education is considered permanent, qualification levels are defined according to the law. Selection is done through psychological and expertise tests. Qualification preparation consists of two main parts: theoretical and practical. The final examination has both a theoretical and practical part. The education is structured sequentially from the lowest to the highest position and the examination must be passed at each level. Training is internally consistent and has three levels: adaptation study; specialised qualification study; position study.

Training can take the following forms: long-term (four year training organised in 3-8 weekly modules per year); and short-term (workshops, consultations, information days, scholarships, in-service training, leisure for education).

\section{Ministry of Agriculture}

\section{Agroinstitute}

Established in 1995, the institute has organised 103 training events for 4203 participants. Costs are covered by the sponsoring organisation of each participant.

Target groups: Employees of state and private organisations in agriculture and greengrocers.

\section{Institute for the Advanced Education of Employees in Forestry and Water Economy}

Target groups: Management and experts in forestry and water economy. There were 52 training activities with 599 participants.

Training format: Permanent education and qualification attestation.

The Ministry of Agriculture participates in the training organised by different institutions. 107 employees participated in 67 short-term seminars, 11 in 6 short-term courses (all mainly focused on the legal system, international economy, and foreign trade), plus participation in language and computer courses. Topics are suggested by the directors of the ministry departments.

All other ministries provide seminars, foreign fellowships, workshops, and ad-hoc courses on topical problems. Activities are partly supported by Phare's aid programme to central and eastern European countries. 


\section{TRAINING PROFILE}

SLOVENIA

(As of April 1996) 


\section{Introduction}

Slovenia is situated in the heart of Central Europe between the Alps, the Adriatic Sea, the Dinaric Mountain Range and the Pannonian Lowlands. The country extends over $20000 \mathrm{~km}^{2}$ and has 2 million inhabitants. Almost 90 per cent of the population are Slovene by nationality. In addition, there are Hungarian and Italian national minorities which have special rights guaranteed by the Constitution. They are also represented in Parliament. The two largest cities are Ljubljana, the capital of the country, and Maribor, each with a university. Slovenia is densely populated - one hundred inhabitants per square kilometre. Almost 3/4 of the population live in Slovenia's 50 towns. More than 50 per cent of gross domestic product (GDP) is created by the manufacturing industry. The second strongest branch is trade, followed by the construction industry, transport, etc. with tourism accounting for 6 per cent of GDP. National GDP for 1995 is 12.1 billion US\$ per year or 6050 US\$ per capita.

In September 1989, the Assembly adopted an amendment to the republican constitution whereby Slovenia obtained the foundations of a sovereign state. In April 1990, the first President of the Republic was elected. The declaration on sovereignty of the Republic of Slovenia was supported at the plebiscite held on 23 December 1990, when more than 88 per cent of the electorate voted for independence. After the introduction of a series of measures, and with the adoption of the basic constitutional charter on sovereignty and independence on 25 June 1991, Slovenia became de jure independent. The new Slovenian constitution was adopted on 23 December 1991, a year to the day after the plebiscite had been held, which provided a legitimate basis for the new political arrangement, the basic constitutional charter and the new Constitution.

\section{General characteristics of the Slovenian administrative system}

The main feature of the parliamentary democracy in Slovenia is the National Assembly, comprising 90 directly elected members and performs the classic role of a Parliament of making laws, electing the President of the Government and nominating government ministers. Besides the National Assembly, the National Council is also a part of the parliamentary circle in Slovenia. Members of the Council and the Assembly are elected directly and in both cases, territorial and corporate principles are respected. The National Council has no legislative function, its only competence is the right to veto a law which was already been passed by the National Assembly. Should the same law be passed again by the majority of representatives, the decision is final. Both the National Assembly and the National Council have got their own professional services, employing 285 civil servants.

Executive authority is represented by the President of the Republic and by the government of the Republic. The professional service of the President is organised within the Office of the President. The government of the Republic (the Cabinet) is composed of the Prime Minister and seventeen ministers, two of whom are ministers without portfolio. The government relies on the Office of the Prime Minister and other professional services, in which 932 civil servants are employed. The Office of the Prime Minister and its other professional services are headed by the Secretary General of the Government, the only exceptions being the Governmental Service for Legislation and the Governmental Service for the Reform of Local Self-government, both headed by the ministers without portfolio.

The complete administrative function is performed by fifteen ministries formed on the principle of competence. Because of the Constitutional provision that all functions of administration are performed by the ministries, there are no special organisations other than the ministries which belong to the classic state administration. In all fifteen ministries, there are 22566 civil servants: 


\begin{tabular}{|l|c|}
\hline \multicolumn{1}{|c|}{ Ministry } & Number of Civil Servants in 1995 \\
\hline Labour, Family and Social Affairs & 188 \\
\hline Economic Relations and Development & 343 \\
\hline Finance & 4104 \\
\hline Economic Activities & 152 \\
\hline Agriculture, Forestry and Food & 318 \\
\hline Culture & 146 \\
\hline Interior & 8192 \\
\hline Defense & 5692 \\
\hline Space and Environment & 1229 \\
\hline Justice & 987 \\
\hline Traffic and Communications & 339 \\
\hline Education and Sport & 159 \\
\hline Health & 197 \\
\hline Science and Technology & 218 \\
\hline Foreign Affairs & 302 \\
\hline
\end{tabular}

The territorial function of public administration is carried out by the local government units. Slovenia is divided into 58 general administrative units, employing civil servants. Apart from the local government units, the territorial functions of public administration is also organised through special branch offices of various ministries, which cover the areas of inspection services, geodesic services and national defence.

With the reform of local self-government, 147 new communities came into existence, the majority of which are rather small in area and population. Since the entire system of local self-government is in a rather dynamic state, we can state only the average current number of employees in the professional services of the communities of 2654 with a noticeable tendency to increase.

\section{Administrative system and civil servants}

In the public administration, a comprehensive civil servant system has not been established yet, though the project is in preparation. There are numerous reasons for this. The notion of the civil servant itself differs between various European systems. Which group of public service employees to classify as civil servants is resolved in accordance with every country's own tradition and culture giving rise to a variety of arrangements and definitions of the term 'civil servant'. These range from considering only certain categories of state administration employees (in its narrow sense) as civil servants to including operative workers in public services.

Slovenia was a part of the Austro-Hungarian Empire still in the early twenties of this century and directly shared its civil service system and shares the heritage of Central European tradition whose current classic 
model is the Republic of Austria. Its example was followed in some other areas as well, by the Kingdom of Yugoslavia, so that the period until World War II can be regarded as the continuation of the Austrian regulation of this system. After the war, Yugoslavia began to regulate this area. On 25 December 1957, a Federal Law on Civil Servants was passed which comprehensively regulated the system of civil servants. It established a classification system of civil servants and their promotion, training and wages. It also regulated the beginning and end of employment as well as basic rights and duties. This law defined the notion of civil servants in a very broad way, so that it included all employees of state bodies, educational, scientific and cultural organisations, medical institutions, the social security and social insurance institutions, as well as all other institutions which performed public services under the provisions of the law. Thus, a very broad definition of civil servants was used which included practically all employees within the public sector.

With the beginning of self-management socialism, the position of civil servants began to change as well. The basic idea of this political system was to equalise the position of all employees and to make it uniform within the framework of the so-called worker in associated labour. Thus, the workers in economic activities and those in public administration had an equal status. It is interesting to note that with regard to employment rights, all workers enjoyed the very high degree of protection of civil servants. A worker, either from a factory or from state administration, could only be fired for a very serious criminal offence, disorder or incompetence.

This was the situation in 1990 when Slovenia took the path of independence. One of the first measures taken by the new government was to reduce workers' rights since most of the economy had to be restructured, and unemployment was the inevitable outcome of this process. Special economic legislation was thus passed, which introduced modern labour law together unemployment and protection.

This task was somewhat harder in public administration. At the beginning the aim was to introduce the entire system of civil servants at once, but this was impossible to achieve in a short period of time. The government therefore took the decision to regulate - until the introduction of a proper system — only the most important items. The result was the Act on Employees of the State Authorities, passed on 20 April 1990.

The title of the Act itself clearly shows that the notion of a civil servant is now limited only to employees in state administration in its more restricted sense, consequently only to those working in the bodies and organisations cited above. Furthermore, the title also signifies that the Act does not introduce the notion of a civil servant yet, but limits itself to the notion of the "employee in the State administration". It also regulates certain questions connected with their status, for example: the question of acceptance at work in state administration, part of a classification system, the basis of the remuneration system, disciplinary responsibility and the questions of leaves and other absences from work. A slightly more detailed scale of individual categories of employees within the state administration, of the base value of work as well as the performance of the basic system of remuneration are defined by the Law on the Rates of Salaries in Public Institutions, State Authorities and Local Community Bodies.

State administration employees are divided into two large groups. The first group is composed of officials, i.e. employees in the state administration whose employment originates from their political activities. This entire group represents the political level of the employees in the state administration. The second group comprises the civil servants, i.e. those in paid employment whose work in administration is their basic occupation and source of livelihood.

The first group includes the 90 delegates of the National Assembly who are all employed there. Secondly, there are the Prime Minister and the ministers (17). The next category includes state secretaries who are 
generally responsible for important individual competencies within the ministries. And finally, there are also the heads of the agencies (54) within the structure of individual ministries, which manage them. They are appointed by the government on the proposal of the relevant minister and share his professional destiny. If, for example, the minister resigns, all state secretaries and heads of agencies in the structure of the respective ministry must offer their resignation.

The second group is also divided into two basic categories: employees appointed by the government on the proposal of the minister, and the category which concludes employment contracts. The top of the first category is represented by general secretaries in the ministries (9) and state under-secretaries (43). The former help the minister manage the ministry, the latter, as a rule, heads particular sections. Besides these two categories, the government also appoints, on the proposal of the minister, the Counsellors to the Government (277), the under-secretaries (62) and the Counsellors to the minister (598). These three categories perform the most demanding expert work in the ministries.

At the top of the second group are the independent advisers, followed by senior advisers, republic inspectors and advisers. For all these posts, top-level professional education and two to five years work experience is required; for civil servants such as desk officers, expert collaborators and inspectors, the higher level of professional education and up to three years work experience are required; other posts, such as administrators, financial officials, collaborators, can be occupied by those with secondary school education and up to two years of work experience.

Looking back and evaluating the role of the administration, it is impossible to expect the entire system of administrative education, including in-service training now to be established at once. Employees acquired their basic knowledge mainly in post-graduate educational programmes, but only some programmes concentrated on administrative knowledge; the exception being the higher administrative education. Educational institutions for post-graduate education organised professional training in the form of advanced study courses and professional meetings. Indeed, some ministries (justice, defence) have developed programmes of functional training for persons in special fields of work, but the beginnings of a comprehensive educational system can only be found in internal affairs.

\section{Objectives of Training}

During the last six years, the changes in the field of public administration were focused on the development of efficient administrative structures rather than on the creation of a proper system of education and training. To some extent, this resulted from the fact that there are as yet no accepted rules and regulations for employment in public administration, or definitions of the role (the rights and duties of employees) and of the importance of training in this system. In the meantime, the entire system of national education has been changed. Thus, in 1993 the new Act on University was adopted, while other educational acts were passed by the Parliament in 1996, such as the Act on Organisation and Funding of Education, the Act on Primary School, the Act on Grammar Schools, the Act on Vocational and Professional Education, and the Act on Education of Adults. Taken together, this body of legislation makes for a new basis of a proper and efficient functional training.

The absence in legislative measures on professional training does not necessary mean that no attention was paid to these questions. On the contrary, high education organisations and in-service training systems of some authorities (ministries) have taken over the main role in defining these problems. They have organised a large number of seminars, both professional and scientific, which were oriented to questions of modern organisation and programme adjustment. The most important one on this topic has been a 
distinguished study meeting, even including international participants, organised by the High School for Public Administration and the Institute for Public Administration.

Particular studies point out that today there is a relatively widely spread system of post-graduate education, while professional perfection courses, by comparison, do not receive the same attention. The data reveals that a great number of organisations have neither medium- nor long-term plans for in-service training, at least no plans determining the essential items of development: profiles of workers to be trained; the how employed persons can acquire adequate knowledge and training; how to encourage employed persons to receive in-service training; which institutions to include in educational processes, etc.

In planning further development, these deficiencies have to be overcome and some principles established to establish a contemporary system:

- Knowledge is a national priority, education represents an investment, in terms of further development;

- Organisations can meet their training needs through their own system which should be included in the national system of education, since only it ensures adequate level, prevents self-sufficiency, and provides for horizontal and vertical flexibility;

- The starting point for formulating training strategy and planning in organisations must be a fully defined personnel plan (profiles and training);

- Basic conditions for the realisation of training plans must be fulfilled: normative definition of training; mechanisms for promoting the acquisition of new knowledge; training standards and material conditions;

- Training is a constant, systematic activity, which must not be limited to the development of particular trends or levels, or to certain types of works. Various working processes require a variety of programmes.

As far as all administrative activities are concerned, adherence to these principles means creating a system of permanent education and training for public administration; improving training quality and adapting it to social, economic and administrative circumstances, increasing interdisciplinary and transdisciplinary courses in administrative studies; including some administrative and organisational contents of the programmes for public administration in other programmes - technical and sociological studies, etc. However, establishing a comprehensive training institution for Slovenian administration, and creating particular centres for functional training should be a long-term aim. Short-term aims include acquiring the new knowledge, necessary modern processes in information technology, foreign languages, and professional perfection courses for top management staff.

In comparison with the past, the scope of functional training on all levels has been improved recently. The new programmes, graduate and post-graduate, which have been created include MBA studies offered by a number of independent educational organisations and in particular by training centres of some ministries (defence, internal affairs), as well as a new Training centre established in 1990 in the Ministry of Justice for the state administration. Due to reorganisation, it later joined the training system of the Ministry of the Interior.

We have to emphasise that co-operation with international institutions and educational organisations, either in the framework of international technical assistance or on the basis of the bilateral contracts and agreements, is much more intensive lately. In this context, we should mention the two year Slovenian-Swiss project for the modernisation of public administration (MASTER project), which at the same time represents the first step towards the creation of the State Administration Academy. 
The basis for the new legal regulation of the administrative system is laid down in numerous legal documents: The and the Law on the Government of the Republic (adopted in 1993), which define its functions and structure, as well as its relation to the National Assembly and governmental services; the Administration Act (adopted in 1994) which determines the basic starting-points of legal regulation for state administration and its functions, organisation and management of the ministries, territorial organisation and functioning of public administration, relations of the ministries to government and to local government bodies, mutual relations, and the execution of inspection and supervision. The Local Self-Government Act (adopted in 1994), together with the preceding statutes, represents the legal basis for the establishment of local self-government and reorganisation of state administration. The Law on Organisation and Sphere of Activities of the Ministries (adopted in 1994) defines the structure and range of ministerial duties and functions. The status of the employees in public administration is defined in the Act on Employees of the State Authorities, while the Law on the Rates of Salaries in Public Institutions, State Authorities and Local Community Bodies provides a more detailed scale of individual categories of employees within the state administration and defines the base value of their work.

The legal basis for public administration is far from complete. Defining the entire public servants system constitutes the main task for the future. The system of professional training in and for public administration must also be defined; in particular segments, it is still based on legislation adopted before independence.

Thus, for example, the Act on Induction courses, Perfection courses and Proficiency Examinations in State Administration and Administration of Justice (adopted in 1985) defines the obligation of employees to obtain proper training at the beginning of their employment. The programme for proficiency examinations is also specified, as is proof of professional capacity for decision making in administrative procedures.

The length of induction courses differs, depending on the degree of education (six months for secondary education, 12 months for post-graduate education). The head of the respective authority is responsible for organising and implementing induction. Each probationer being trained in state administration has to pass the proficiency examination as must other employees, for whom it is prescribed by special regulations. The proficiency examination is divided into a general and special part. The programme for the general part of the exam is the same for all candidates of equal education, while the special part differs according to the candidate's area of work.

Although the new Act on Employees of the State Authorities refers to professional training, the special act regulating this are has not been passed yet. A slightly more detailed scale of categories of employees within the state administration, the base values of their work according to their education are defined in the Law on the Rates of Salaries in Public Institutions, State Authorities and Local Community Bodies. The Act also provides for promotion which — as a rule — is granted every three years, if certain conditions are met: additional functional knowledge, qualification for different professions, work-effectiveness, creativity, etc.

Employee and employer rights and duties are also specified in the collective contract in the public sector (adopted in 1991). An employee has the right to professional training for at least five days per year, if he occupies a post for which secondary education is required. Training costs are to be covered by the organisation. By contrast, an employee is obliged to take part in training if the public institution requires it. Training is therefore regarded as regular working time with the same employee rights. In part-time education (studies for persons in employment), employee rights and duties are defined in an education contract. 


\section{4. $\quad$ Funding}

One of the most important or even decisive factors is funding for training and professional courses for workers employed in public administration. If working conditions demand professional training, then the costs should be covered by the respective institution (ministry). Funding for those training formats, which are regulated by law (proficiency examination, examinations of professional perfection courses for decision making in administrative procedures), shall be part of public expenditure (budget). Furthermore, the entire infrastructure necessary for training in public sector should be funded from the national budget.

The exact amount of money available for training in public administration is not known, since the national budget does not specify it. Each ministry receives its own budget (according to the financial plan); funds spent on staff training and education is an internal decision. In the scope of their own budgetary income, some ministries do earmark a definite amount for training, but often this refers to costs of materials only.

For training and professional courses organised by external institutions (faculties, private organisations), participants have to pay whereas programmes and seminars organised by training centres of some ministries are free of charge.

It should be pointed out that the organisations (ministries) are prepared to cover the expenses for obtaining a proper education (higher degree) in various faculties or other schools. The amount of this contribution differs, depending on several factors, the main one being the necessity to acquire new knowledge.

International support in financing training for public administration has been increased recently. A great number of international institutions and countries are involved in the organisation and preparation of training programmes. Statistics for 1995 show that Slovenia co-operated with six states in various forms of international technical support. Furthermore, great support has been lent by international institutions, such as the European Union and OECD (Phare, SIGMA), and by the Swiss Confederation in the framework of the MASTER project.

\section{Training Institutions and Legal Status}

The educational and cultural level of the population represents a decisive element for the development of society. A high level of education allows for a dynamic response to change and for the formulation of a strategy enabling a society to assert itself in a broader environment. That is why education is a complex problem which not only requires the involvement of a certain number of people in various programmes of post-graduate education, but also the development of training strategy point for professional knowledge, advanced skills and motivation for persons in employment.

Considering all these challenges, the quality and success of work depends not only on the educational degree of the employed, but also on further professional qualification. Hence, in addition to the educational programmes of various schools, a system of in-service training must also exist. Unfortunately, statistics show that Slovenia devotes less attention to the forms of in-service training (in the system as a whole and in the specific field of public administration) in the past than to programmes for graduate and post-graduate education.

For presentation and comparison purposes, the general characteristics of Slovenian system of education have to be mentioned. The national educational system has several levels, including an eight year primary school, four years of secondary school, two years of college education, a three or four year higher professional education and four or five years of faculty education. Primary school education has a uniform 
programme; secondary education is divided into professional, technical and grammar schools; higher and high education is provided by specific professional schools while faculty education is offered in various scientific areas. On all educational levels, it is possible to enter educational processes on a full-time basis (pupils, students) or on part-time basis (high education organisations and secondary school programmes for adults).

In the various programmes on all levels of education, more than 360000 pupils and students are involved (1995): 214832 pupils in primary schools, 104609 in secondary schools, and 43249 students in the higher educational organisations:

\begin{tabular}{|l|r|r|r|r|r|}
\hline \multicolumn{1}{|c|}{ Schools } & Total & \multicolumn{2}{c|}{$\begin{array}{c}\text { Regular School } \\
\text { Pupil Students }\end{array}$} & \multicolumn{2}{c|}{$\begin{array}{c}\text { Part-time } \\
\text { Adult Students }\end{array}$} \\
\hline Primary schools & $\mathbf{2 1 9 2 1 6}$ & $\mathbf{2 1 7 4 3 1}$ & - & $\mathbf{1 7 8 5}$ & - \\
\hline Secondary schools & $\mathbf{1 0 2 9 9 1}$ & $\mathbf{9 5 6 2 1}$ & - & $\mathbf{7 3 7 0}$ & - \\
\hline Universities & $\mathbf{4 0 2 3 9}$ & - & $\mathbf{3 2 7 2 8}$ & - & $\mathbf{7 5 1 1}$ \\
University of Ljubljana: & 28522 & - & 24183 & - & 4339 \\
$\quad$ Colleges & 1724 & - & 630 & - & 1094 \\
$\quad$ Higher professional schools & 2059 & - & 1400 & - & 659 \\
Faculties & 24261 & - & 21675 & - & 2586 \\
$\quad$ Academies of art & 478 & - & 478 & - & - \\
University of Maribor: & 11717 & - & 8545 & - & 3172 \\
$\quad$ Colleges & 97 & - & 94 & - & 3 \\
$\quad$ Higher professional schools & 339 & - & 331 & - & 8 \\
Faculties & 11281 & - & 8120 & - & 3161 \\
\hline
\end{tabular}

In addition, individuals can also be educated in adult education institutes, which organise individual seminars and offer general, professional and vocational programmes. There were 3164 seminars and courses attended by 50488 participants, of which 27053 took part in general educational programmes and 23395 in professional ones. 7240 persons were involved in programmes for acquiring education (1995).

Besides the graduate education offered by particular schools and adult education institutes, in professional training and work training provided by enterprises and other organisations have increased noticeably over the last few years:

Education of Persons in Paid Employment in Enterprises and Other Organisations (1995)

\begin{tabular}{|l|c|c|c|c|}
\hline & $\begin{array}{c}\text { Work } \\
\text { Training }\end{array}$ & \multicolumn{2}{|c|}{$\begin{array}{c}\text { Further Professional } \\
\text { Training-Abroad }\end{array}$} & $\begin{array}{c}\text { Retraining } \\
\text { Formal }\end{array}$ \\
\hline Participants & 90033 & 219181 & 2890 & 1915 \\
$\begin{array}{l}\text { Participants per 1 000 persons } \\
\text { in paid employment }\end{array}$ & 137 & 328 & 4 & 3 \\
\hline
\end{tabular}

The general characteristics of the system of education, are reflected in the field of public administration. As the share of the entire working population with a high level of educational and professional 
qualification increases, so does that of administration employees, as much if not more. There are certain deviations from these general indicators, which are evident mainly in the level of education, qualification and dissemination of functional training.

Persons in paid employment in public administration by level of professional attainment (1995):

\begin{tabular}{|l|c|c|c|c|c|}
\hline \multicolumn{1}{|c|}{ Institutions } & Total & $\begin{array}{c}\text { University } \\
\text { Degree }\end{array}$ & $\begin{array}{c}\text { Non-University } \\
\text { Degree }\end{array}$ & $\begin{array}{c}\text { Secondary } \\
\text { Degree }\end{array}$ & $\begin{array}{c}\text { Vocational } \\
\text { Degree }\end{array}$ \\
\hline $\begin{array}{l}\text { Ministries and } \\
\text { Government Offices }\end{array}$ & 23498 & 5178 & 3497 & 11890 & 2924 \\
\hline Local Government Units & 2921 & 477 & 784 & 1239 & 383 \\
\hline Parliament Offices & 285 & 84 & 19 & 108 & 74 \\
\hline
\end{tabular}

Persons in paid employment in enterprises and other organisations (public administration) by level of educational qualification required for their positions (1995):

\begin{tabular}{|l|c|c|c|c|c|}
\hline \multicolumn{1}{|c|}{ Structure (\%) } & $\begin{array}{c}\text { University } \\
\text { Degree }\end{array}$ & $\begin{array}{c}\text { Non-University } \\
\text { Degree }\end{array}$ & $\begin{array}{c}\text { Secondary } \\
\text { Degree }\end{array}$ & $\begin{array}{c}\text { Skilled } \\
\text { Workers }\end{array}$ & $\begin{array}{c}\text { Lower } \\
\text { Degree }\end{array}$ \\
\hline Total & 7.5 & 9.1 & 21.1 & 50.4 & 11.9 \\
\hline Public Administration & 21.5 & 16.2 & 49.5 & 7.3 & 5.7 \\
\hline
\end{tabular}

The proportion is characteristic for a period of several years. Besides graduate education, the organisation and the number of participants in programmes of professional attainment and training is gradually changing.

A central national educational organisation (academy, institute), to organise and provide programmes of functional training for public administration employees and on the model of the majority of West European countries has not been founded yet. However, this does not mean that public administration employees are not receiving proper training, but only that the organisation of training is based mainly on high education institutions and the training systems of some state authorities (ministries). Furthermore, the great majority of persons employed in the administration, above all those with high and higher degrees of education, completed their training in the so-called faculties for social sciences.

Faculties, higher professional schools, colleges and courses offered:

\section{Faculty of Law (Ljubljana):}

State administration, penal law, economy law, foreign trade, international law.

\section{Faculty of Social Sciences:}

Sociology comprising chairs for theoretical sociology, personnel and social management, information technology and methodology, political science comprising chairs for theoretical political science, the analysis of politics and public administration, international relations, science of defence, communications, cultural sciences. 


\section{Faculty of Economy:}

Including chairs for economic theory, finance, management, entrepreneurship, organisation, international economy, marketing, accounting, information technology, mathematics and operational research, statistics.

\section{High School for Public Administration:}

Public administration, business administration, administrative information technology.

\section{High School for Internal Affairs:}

Public safety, national safety, criminalistics and criminology, personal protection, state administration.

\section{Faculty of Law (Maribor):}

Comprising the chairs of public administration, economic sciences, labour law, basic law and other sciences, international law and relations.

\section{Faculty for Organisational Sciences:}

Chairs of information technology, organisation, methodology, personnel, production.

\section{Faculty of Economy-Business:}

Chairs of economics, politics of economy, finance, economy law, quantitative economic analyses, organisation and information technology, political economy, marketing, international exchange.

All faculties also offer post-graduate and specialised studies as well as specific MA and doctoral programmes. Most organise studies for working persons, for scientific and professional meetings often including international participation. To a lesser extent, they offer programmes for professional attainment; some teachers participate in programmes organised by particular state authorities.

As a rule, the organisation of professional training and perfection courses in public administration takes place in organisational units (administration, division, service) for personnel matters and training of particular ministries, professional services and administrative units. Only the Ministry of the Interior and the Ministry of Defence established a comprehensive training system, within which professional training was offered to civil servants. In the past, the Ministry of Justice had its own system, however, it was merged, due to reorganisation, with the training system of internal affairs.

The organisation of the educational systems varies as does the structure of the programmes, which are being offered either independently or in co-operation with other educational organisations. The basic structure includes the following programmes for:

- The attainment of professional training or graduate programmes (secondary and high);

- Basic, for initiating the work in particular fields, in this context also the passing proficiency examinations;

- Perfection (advanced, specialised) to perform particular tasks;

- Management staff and the directors in particular fields of work;

- Beginner and advanced foreign languages; and

- Information technology. 
In the training system of the Ministry of the Interior, which is responsible for public administration, more than 8000 employees were involved in various forms of education and professional training in the last year, of which more than 900 in graduate programmes (secondary and high); 650 in basic training programmes; 1900 in special courses; 480 in training programmes of management staff, directors and other bodies; and about 1500 participants in more than 170 seminars. In addition, persons in employment (700) also participated in training, organised by other educational organisations, and in 161 different forms of seminars, courses and conventions (447 persons in employment), including some abroad:

\section{Ministry of the Interior — Training Delivered in 1995}

\begin{tabular}{|l|c|c|}
\hline & $\begin{array}{c}\text { Courses } \\
\text { Class Units }\end{array}$ & $\begin{array}{c}\text { Number of } \\
\text { Participants }\end{array}$ \\
\hline 1. Police Secondary School (4-year programme) & 18 & 551 \\
2. High School for Internal Affairs, (3-year programme) courses: & & \\
$\quad$ Public safety, criminal investigation, national security, & 5 & 343 \\
$\quad$ private investigation; & & \\
Public administration. & & \\
3. Department for Education and Training, basic programmes: & 10 & 265 \\
Police officers, criminal investigation; & 76 & 1900 \\
Public administration; & & \\
Special courses for trainees, traffic, & 15 & 330 \\
$\quad$ drug abuse, property crime, youth dealing; & 10 & 150 \\
Training of management staff; & 17 & 389 \\
Training of directors; & 3 & 385 \\
Training for other bodies. & 172 & 3613 \\
4. Military Service Training Centre & 9 & 182 \\
5. Centre (training) for Public Administration, programmes: & & \\
Professional perfection courses for management staff & & \\
$\quad$ and directors; & 17 & 693 \\
Perfection courses for the work in administrative bodies; & 10 & 792 \\
Induction courses, traineeship and proficiency examinations; & 33 & 967 \\
Seminars for particular State authorities; & 103 & 979 \\
Foreign language courses. & & \\
\hline
\end{tabular}

In the framework of the training centre for public administration more than 3600 employees of public administration participated in training activities in 1995.

Similarly, the programmes of the Ministry of Defence are divided into basic introductory programmes which take place in particular schools, specialised programmes and programmes of training in various professional areas. Thus in 1995, 360 employees were involved in basic programmes (long-term), and 5941 participated in various forms of professional training (information technology courses, courses for foreign languages, professional seminars, etc.) In addition, the Educational Centre for Protection and Rescue organised different seminars for enterprises and other organisations involving more than 4700 participants. Within international co-operation (IMET, "Mill to Mill") and bilateral agreements, the Ministry of Defence also organised professional and language training abroad: 
Ministry of Defence — Training Delivered in 1995

\begin{tabular}{|l|c|c|}
\hline & $\begin{array}{c}\text { Courses } \\
\text { Class Units }\end{array}$ & Participants \\
\hline 1. Centre of military schools: & & \\
Officers' training school; & 4 & 102 \\
N.C.O school; & 2 & 102 \\
Command/headquarters' school — seminars & 3 & 87 \\
$\quad$ for military units commanders. & & \\
2. Defence training centre: & 6 & 206 \\
Civil defence; & 6 & 90 \\
Telecommunications; & 271 & 2991 \\
Informatics. & 17 & 268 \\
3. Educational center for protection and rescue: & 4 & 90 \\
Training of units and services of civil defence; & 12 & 231 \\
Firemen's courses; & 12 & 185 \\
Informatics; & 30 & 1276 \\
Combat action; & & 4787 \\
Other professional courses and training; & & \\
Training programmes for other organisations. & & 255 \\
4. Organisation and personnel administration: & 21 & 38 \\
Training division: & & \\
Foreign languages; & & \\
Training abroad. & & \\
\hline
\end{tabular}

Within the framework of the Ministry of Finance, the third largest segment in state administration by number of employees, 195 different seminars, conventions and training programmes were organised in 1995, in which 4180 employees were involved. In pursuance of its long-term aim, the further training strategy for its employees, the ministry is preparing a project (in co-operation with the French organisation Sofreco) for establishing its own training centre:

Ministry of Finance — Training Delivered in 1995

\begin{tabular}{|l|c|c|}
\hline & Courses & Participants \\
\hline Precautions in work, fire precautions & 71 & 1395 \\
\hline Examination for customs officials & 3 & 95 \\
\hline New customs legislature & 75 & 1955 \\
\hline Accountancy & 4 & 81 \\
\hline Border crossing control & 12 & 405 \\
\hline Phare Programme & 29 & 240 \\
\hline
\end{tabular}


Nearly all other state authorities plan, but rarely organise internal professional training. Instead, they regularly send their employees to the educational programmes of universities and other institutions. Mostly these are programmes for induction to work, preparation for proficiency examinations, specialised programmes for various fields of work, for management staff and directors. All pay special attention to the introduction of new information technology, software and foreign language courses.

The only high educational organisation explicitly concerned with professional upgrading for public administration is the High School for Public Administration. Apart from the graduate programmes, it is oriented towards a wide range of questions, including the areas of public and state administrations, local self-government, public sector management, administrative operations, etc.:

\section{High School for Public Administration — Training Delivered in 1995}

\begin{tabular}{|c|c|c|}
\hline Educational Programmes & Courses & Participants \\
\hline Preparation for proficiency examinations & 1 & 45 \\
\hline Legal regulation of State administration & 6 & 400 \\
\hline Local self-government & 1 & 100 \\
\hline Management in public sector & 1 & 16 \\
\hline Decision making on administrative matters & 12 & 415 \\
\hline Informatisation of public administration & 6 & 145 \\
\hline Communications in public administration & 8 & 120 \\
\hline Financing the public sector & 1 & 14 \\
\hline Total & 36 & 1255 \\
\hline
\end{tabular}

In comparison, all other faculties are oriented mostly towards the preparation of professional, or better, scientific conventions on various topics. Thus, every year there are seminars and conventions for lawyers, sociologists, political scientists, economists and work organisers offered by the Faculty of Social Sciences, the Faculty of Economy, the Faculty of Organisational Sciences or the Faculty of Law and within its framework mostly the Institute for Public Administration, which organised a number of distinguished study meetings with international participation.

It is practically impossible to present statistically the number and extent of all professional perfection courses and training carried out by individual schools, private educational organisations and training centres of state authorities without a detailed analysis of all forms. There is no doubt that the extent of professional training in the field of state administration exceeds that in the working population as a whole with regard to both the number of participants and the time dedicated to education. On the basis of individual statistical indicators it can be assumed that on average, each employee in public administration spends at least one working week (40 working hours) per year for training.

The statistical survey gives a rather sketchy impression of the participation of civil servants in professional training abroad, especially in programmes concerned with preparing the pre-accession strategy for European Union membership. Conventions and seminars within the framework of working bodies of European and other organisations and programmes (Phare, SIGMA, OECD, Know-How Fund) are quite numerous. However, they primarily target the management of state organisations or experts in various fields, which co-operate in the preparation of this strategy.

Very few educational programmes in educational institutions for public administration deal directly with the problem of accession to the European Union, its organisation and its functioning. This does not mean that the programmes are not necessary; on the contrary, particular emphasis has been put on this issue 
within the framework of the project of structural and functional adaptation of the Slovenian administrative system. Within this context, together with international organisations Slovenia has already begun projects oriented towards raising the professional level and qualifications of state administration employees.

Thus, this year the so-called Academy for Diplomacy was established, under the auspices of the Faculty of Social Sciences and in co-operation with the Ministry of Foreign Affairs.

Under the provisions of the agreement between the Austrian Federal Administration Academy (Verwaltungsakademie des Bundes) and the High School for Public Administration, a training programme in human resource management has started operation this year and includes the employees of state bodies (ministries) and of their training organisations.

The two-year Slovenian-Swiss project for modernising the public administration, carried out on the basis of the international agreement between the two governments is much larger and more demanding in content. This project has multi-level targets but focus primarily on training 40 civil servants in developing the state administration system - organisation, methods and techniques of work - and in training within public administration. The consequence of this training effort would be a specialised organisational unit taking care of the development of state administration, while the main tasks of the Administrative Academy would be planning, organising and programme management of civil servants'.

Taken together, these projects represent a starting point or a precondition for modernising administrative system, defined as a national priority. Responsibility for implementation was therefore transferred to the National Project Council, composed of various ministers. All other projects in the framework of modernisation of administrative system are included, by their programme, in the work plans of the government.

\section{Teaching Personnel}

The structure of pedagogical staff participating in training processes differs (full-time, part time, on contract basis) according to training degree and form. However, in regular graduate programmes (primary and secondary), full-time employees prevail, in high level education and in professional training the share of part-time employees and collaborators on contract basis is increasing (already more than a quarter); in adult education practically all teachers participate as collaborators on contract basis.

Full and part-time teaching staff by types of institutions (1995):

\begin{tabular}{|l|c|c|c|c|}
\hline & Total & Full-Time & Part-Time & Contract \\
\hline Primary Schools & 15053 & 14490 & 430 & 133 \\
\hline Secondary Schools & 7360 & 6019 & 476 & 865 \\
\hline Colleges, Faculties & 3172 & 2090 & 69 & 1013 \\
\hline Adult Education Institutes & 3575 & 28 & - & 3547 \\
\hline
\end{tabular}

This also means that the structure of pedagogical staff in educational processes is gradually changing. As schools above are all responsible for implementing graduate programmes, their staff comprises mostly regular teachers and professors. This is also characteristic for basic programmes run by ministerial 
education systems, especially of the Interior and of Defence. In the professional perfection programmes, experts from particular fields of work collaborate on a contract basis.

This is not true for programmes of particular ministries and for other programmes. Thus, in the training centre for public administration of the Ministry of the Interior, training is given by various experts and collaborators; the centre itself only organises the work and takes all necessary preparatory steps. This is true in the courses for public administration of the High School for Public Administration where contracted freelance personnel participate to a considerable extent.

Education of teachers and trainers of the programmes depends on their type and level. Thus, for example, in the system of secondary schools, higher (university) education and some pedagogic qualifications is required of teachers. At universities, special criteria such as academic degree and status of university teacher (habilitation) apply where they are less important for trainers in professional perfection courses or other programmes of training where professional knowledge and experience in specific fields of work are of greater importance. Nevertheless, the majority of trainers has gone through higher education. Here, the question arises as to whether they have sufficient pedagogic qualifications . Research studies show that on the whole, they do not. "Training the trainers" is therefore a task for the future. The courses and programmes of training offered by higher education organisations are conducted mainly by university teachers with academic degrees.

The salaries of all regularly employed teachers and professors are defined by the Law on the Rates of Salaries in Public Institutions, State Authorities and Local Community Bodies. By contrast, the salaries of teachers solely by contract. As a rule, fees differ according to the level of particular programmes, teacher's degree of education, and qualification to teach at universities.

\section{Needs Assessment and Content of Training}

The entire national education system is changing in form, duration and content. At the same time, the content of training curricula should be adapted. While the curricula of secondary, tertiary and post-graduate institutions have been changed, the same cannot be said for public administration training.

A comprehensive analysis of training needs in public administration has not been carried out so far, and only particular ministries and their training systems deal with these questions more systematically. As a result, there are elaborate systems for some fields of work, from basic to specialised professional training, while others depend mostly on the programmes available on the market by schools and particular (private) organisations. This also means that, in the first case, programmes are subject to constant evaluation and modernisation, the percentage and level of qualification of the lecturers (practitioners) has been increasing and didactic approaches are being up dated, while in the second case, this depends on the creativity of the bidders.

International involvement in training has introduced certain curricular novelties. The number of training curricula for managers has increased, new human resource management techniques are taught, as are other subjects such as communication, financial management, research methods, public accountancy, etc. Last but not least, comparative studies of foreign systems have been conducted on the basis of which organisational changes will be implemented into the functional education system (National Academy).

Evaluating participant success or failure is obligatory in graduate programmes, run by schools, in proficiency examinations and in basic programmes of professional education, while in other formats evaluation of participants is the exception. Evaluation at schools is carried out in accordance with national 
criteria and standards, which are defined in the rules. The examination of proficiency in administrative procedure, successfully passed proficiency examination or basic programmes of professional education are conditions for employment or for filling a particular post respectively.

Candidates for education at secondary schools and universities are chosen on by the invitation for applications publicly published (a uniform standard for all secondary schools and universities), while the realisation of specialised, special and advanced programmes is planned in annual work plans of organisational units of the ministries. Target groups of professional training are being defined at the same time.

\section{8. $\quad$ Target Groups}

Several criteria are taken into consideration in identifying target groups for professional training (degree of education, post, field of work):

- The participants are included in general programmes for passing the proficiency examinations on the basis of their degree of education;

- Participants in basic professional programmes are selected according to two criteria, regarding the degree of education and the field of work;

- In specialised, professional programmes, candidates are selected with a view on their field of work and their present post;

- Among the programmes for management staff, distinctions are made with regard to respective positions (top, middle, lower management).

For pre-service training, candidates are chosen according to a group-related principle, while in specialist training a problem-specific principle is applied. In the management programmes, both principles are to be respected; for lower management candidates, the position and field of work are important, while the working position is the decisive factor in selecting middle management candidates (group-related principle). Candidates for top civil service training are chosen according to their position in the hierarchy.

\section{Training Formats}

The model of education and training followed and the usage of pedagogical methods and educational technology depend on the variety and purpose of a particular programme.

In graduate programmes run by schools (secondary, high, faculties), the time depends on the degree of education to be acquired. Thus, in secondary schools, 4-year maturity programmes and programmes ending with the final examinations are provided; college and high school education lasts two years, higher professional schools, three or four years, and university programmes four to five years. As a rule, MA programmes last two years. Lectures, group discussions and team exercises are the prevailing pedagogical method.

In some ministries' basic professional knowledge training, the programmes run from six months to one year; lectures and team exercises prevail in the main.

Apart from basic training programmes, the duration and pedagogical methods of professional training programmes for particular fields of work are defined by programme contents and aims. As a rule, they last for a period of one week, similar time is allotted for training abroad. Seminars (ad hoc), courses and 
conventions organised by other educational organisations usually last one day or at most two days. These are the so-called refresher programmes and programmes on novelties in particular legislation or organisational changes. The pedagogical methods vary and they include workshops, case studies, role playing, simulations, etc.

Training of teachers at all educational levels (training the trainers) is the exception. Some training is provided in co-operation with Verwaltungsakademie des Bundes (three modules, each for three days). A further exception is the Slovenian-Swiss Master project (the programme lasts one and a half years) which is organised in a similarly to other MA programmes (MBA). A more detailed survey of the methods is found in Annex 1.

\section{Development of Training Curricula and Evaluation}

The emergence of new training curricula, their development and evaluation are closely related processes. The correlation is reflected in the contents and also in verification procedures. Identification of the training needs and starting points for introducing the contents are common features of these processes.

The formulation of programmes (as to contents) and their verification and evaluation vary. All graduate and specialised programmes are prepared using a uniform methodology for the formation of educational programmes, prescribed by the Institute for Education. Graduate education programmes are prepared by study commissions and approved by their council or senate respectively; they are also discussed by the national authorities, responsible for education. Evaluation follows the same procedure.

As a rule, professional and specialised programmes are prepared by commissions composed of experts for the particular fields and lecturers (including university teachers): However, their verification is not uniform. Some are discussed and approved by school authorities (the council, the senate), the majority by the collegiate bodies of professional services in the ministries. They are finally verified by the signature of the minister responsible for the particular field for work.

Several elements are taken into consideration for programme evaluation: the analysis carried out by schools and professional services by means of questionnaires to be filled out by the participants at the end of the programme. A written questionnaire is also used as an analytical method, as are interviews with the organisers and trainers of professional training courses.

Regarding contents, the evaluation considers the suggestions of experts. Comparative analyses including similar programmes (also their organisation) in foreign countries are not rare in this context. Co-operation with foreign educational organisations and academies (above all on the level of university education) is widespread. Thus, for example, an international conference (High School for Internal Affairs) on Policing in Central and Eastern Europe is being prepared at the moment and representatives of 14 countries in the field of internal affairs are participating in the programme committee (faculty teachers, representatives of various institutes and senior state officials).

The programme evaluation procedure depends on the level of the programme. For large scale programmes (graduate, basic programmes), university professors, experts in particular fields and programme lecturers are invited to participate in the renewal. The standards for approval are in accordance with national standards. Less strict rules are in force for ad-hoc programmes which only try to present, for example, individual system changes. 


\section{Planned Changes and Further Developments in the Training System}

In transforming public administration, Slovenia follows two basic objectives: to increase its effectiveness and to adapt its structure and functions to the needs of the accession to the European Union. Drawing up a long-term plan has commenced, which is trying to define the project activities in the next four year period. The training of civil servants who will be one of the key players in the transformation process must play a special role in the process.

The entire restructuring of public administration includes five basic fields, where project and educational activities are intertwined: state administration; local self-government; public services; protection of the rights of individuals in relation to administration; development of administration, the position of civil servants and their education.

State administration project and educational activities can be divided into two parts: training on the relevant environment for accession to the European Union, and to the necessary changes in administrative structure and function. In this context, the following issues have to be addressed: further development of the mechanisms of democracy; relations in the administrative system; the modernisation of state administration, the building up of the structure and functions of state administration on local and regional levels; informatisation and computerisation of state administration.

The following questions arise for local self-government: what should be the structure and the functions of local self-government; how to finance it; how to divide competencies and responsibilities between the state and local self-government; how to perform individual transferred responsibilities and carry out control; what are the legal means for protecting the rights of local self-government in relation to the state; how to modernise the administration (new public management), etc.

The third segment of structural and functional changes in the administrative system affects a wide area of public services and the public sector. Project activities include defining public sector and public services; the status and situation of public enterprises and public institutions and ownership and administrative relations in them; performing public services on concession basis; public interest; deregulation, liberalisation and privatisation of civil services and the introduction of competitive elements in performing of civil services.

One of the most sensitive areas is undoubtedly the protection of individual rights in relation to administration. Standardisation is relatively well regulated. However, more attention should be paid to its implementation, above all to informal forms of protection of individuals in relation to administration, to special forms of legal protection of individuals in relation to administration and to the role of the Constitutional Court in this context, to the institution of the ombudsman, etc.

The fifth and last area deals with internal relations in administration. This area could also be defined as the preservational subsystem in the framework of administrative system. In this context, very specific project tasks are envisaged: establishing the system of civil servants on central and local levels and institutions for the development of state administration. The latter anticipates the establishment of the organisational unit for the organisation, methods and techniques of administration, and the establishment of the State Administration Academy.

The establishment of the State Administration Academy (institutional and programme-related) probably represents the most difficult of all envisaged projects. The aim is to establish a system of permanent professional training, dedicated to the spread of knowledge and the attainment of new skills. Nowadays, the existent educational institutions do not offer such forms of professional training, but are mostly 
oriented towards acquiring knowledge for particular occupations. The Academy should have a double role:, it should upgrade the knowledge obtained at schools; it should form an educational nucleus (in organisational and programme terms) for the needs of public administration which could attract professional expertise from the administration as well as from other educational organisations. With such an organisation, Slovenia would undoubtedly find it easier to integrate into the international exchange of knowledge.

Last but not least, the role of the State Administration Academy is also closely connected with the system of civil servants, or put differently, it represents one of its constituent parts. Professional training in administration is directly related to other elements within the system, such as the systems of promotion, remuneration and classification. In essence, it represents one of the conditions for establishing a comprehensive system of civil servants.

\section{Identification of Problems in Training and Conclusion}

If the statistical indicators are critically examined, they clearly show that the education and training of civil servants is quite dispersed and complex, that no comprehensive system has been established to define the conditions for education and enable their implementation for the administration as a whole. However, some parts of public administration have developed very high quality training systems (interior, defence) though only for very specific professional areas.

A more detailed analysis of educational programmes shows that:

- The faculties and high professional schools offer mostly graduate programmes (to acquire education) and with few exceptions, do not develop programmes for perfection courses and training of public administration employees;

- Functional training is mainly provided by professional services of particular authorities and only very few (the Ministries of the Interior, Defence, and the planning undertaken by the Ministry of Finance) developed their own organisations, where attention is mainly focused on perfection courses for specific fields of work;

- A comparative analysis also indicates that professional perfection courses are mostly directed towards basic programmes (for work, proficiency examinations) and specialised ones (for particular fields of work). In comparison (in numbers as well as extent), perfection courses for management are more of an exception than the rule;

- The participation of external (private) institutions in professional perfection courses is rather limited, the exception being only the areas of foreign languages and information technology. As a rule, they offer programmes which are mostly designed for management staff and for which special knowledge is required (human resource management, communication, management, etc.). However, there are not very many organisations on the market which offer educational programmes in administration.

The research results as to the form and method of programmes of professional perfection courses also show that the greatest deficiencies or weaknesses are evident in the programme evaluation procedures and in the evaluation of the impact of courses on improving work in practice respectively, and above all in pedagogy. Contemporary pedagogics is developing a series of new methods and techniques for adult education, ranging from those including direct experience in teaching situations to those in which reflection and expression of cognition on the basis of experience prevail. Unfortunately, one-way communication in the form of lectures still prevails. 
The weaknesses or deficiencies in the organisation and conception of the programme can only be overcome by establishing a training system in public administration in a comprehensive and systematic way. A system which fulfils a whole range of functions: analysis of personnel and training needs, preparation of programmes for professional perfection courses, (basic and specialised), research on the organisation system and others. Beside these, other questions arise: which training programmes should be compulsory for all administration employees (employment and promotion), how to implement these organisationally and which training programmes (contents and implementation) to include in the training system of individual organs or independent organisations. This is all connected to the legal regulation of civil servants (civil servant law). Both tasks are top priority and have already begun to be carried out in the framework of the project of modernising public administration. 


\section{ANNEX 1. COURSE SYNOPSES: SLOVENE - SWISS MASTER PROJECT}

\section{Basic Programme Phase}

Topic 1: Comparative Administrative System

Methods: Lectures, case examples, reference materials, O\&A

Topic 2: $\quad$ Organisational Theories \& Methods

Methods: Lectures, case examples, simulations/exercises, reference materials, O\&A

Topic 3: Organisational Development \& Organisational Learning

Methods: Lectures, mini case examples, simulations/exercises, reference materials and group work

Topic 4: Financial Management in the Public Sector

Methods: Lectures, balance sheets, exercises, group discussions, reference materials

Topic 5: $\quad$ Policy Evaluation and Research Methods

Methods: $\quad$ Lectures, exercises, group discussions, case analysis, reference materials

Topic 6: Human Resource Management \& Development

Methods: Lectures, group discussions, case analysis, examples, reference materials

Topic 7: Personal Effectiveness (presentation skills, public speaking, time management

Methods: $\quad$ Lectures, video taping, role playing, feedback and reference materials

Topic 8: $\quad$ Working Methods (decision making methods and project planning)

Methods: Lectures, role playing, team exercises, home assignments and reference materials

Topic 9: $\quad$ Slovene Administrative Systems

Methods: $\quad$ Lectures, group discussions, cases, reference materials

Topic 10: Slovene Public Administrative Law and Legislation

Methods: Lectures, group discussions, cases, and reference materials. 


\section{Specific Programme Phase for Track I}

Topic 1: Advanced Financial Analysis \& Audit

Methods: Lectures, group discussions, team exercises, home assignment and reference materials

Topic 2: $\quad$ Project Management: Managing the Change Processes

Methods: Lectures, role playing, case studies, simulations, home assignment and reference materials

Topic 3: $\quad$ Strategy \& Decision Making in the Public Sector

Methods: Lectures, role playing, team exercises, home assignments and reference materials

Topic 4: $\quad$ Consulting Techniques

Methods: Lectures, role playing, simulations, task assignments and reference materials

\section{Specific Phase for Track II}

Topic 1: $\quad$ Policy Studies and Training Needs Analysis

Methods: Lectures, simulation, team work, group discussions and reference materials

Topic 2: $\quad$ Adult Learning \& Action Learning Methods

Methods: Lectures, role playing, simulations, task assignments and reference materials

Topic 3: $\quad$ Management Theories and Leadership

Methods: Lectures, role playing, simulation, personal feedback and reference materials

Topic 4: $\quad$ Training Management

Methods: Lectures, group discussion, simulations, task assignments and reference materials

Topic 5: $\quad$ Organisational Behaviour

Methods: Lectures, role playing, simulations, task assignments and reference materials

Topic 6: Public Finance and Accountancy

Methods: Lectures, case studies, task assignments and readings

Topic 7: Personal Effectiveness II

Methods: Lectures, role playing, simulations, video feedback, task assignments and reference materials

Topic 8: Instructional Technology

Methods: Lectures, group discussion, individual consultation and reference materials. 